UNIVERSIDADE DE SÃO PAULO

FACULDADE DE FILOSOFIA, LETRAS E CIÊNCIAS HUMANAS

DEPARTAMENTO DE LINGÜÍSTICA

PÓS-GRADUAÇÃO EM SEMIÓTICA E LINGÜÍSTICA GERAL

ÁREA DE PESQUISA: DESCRIÇÃO DAS LÍNGUAS DE SINAIS: DESCRIÇÃO

DA LÍNGUA DE SINAIS BRASILEIRA

\title{
DESCRIÇÃO FONÉTICO-FONOLÓGICA DOS SINAIS DA LÍNGUA DE SINAIS BRASILEIRA (LIBRAS)
}

\author{
Aluno: André Nogueira Xavier (CNPq) \\ Dissertação apresentada ao Programa de Pós-Graduação em \\ Semiótica e Lingüística Geral, do Departamento de \\ Lingüística da Faculdade de Filosofia, Letras e Ciências \\ Humanas da Universidade de São Paulo, para obtenção do \\ título de Mestre em Lingüística
}

Orientadora: $\operatorname{Prof}^{\mathrm{a}} \operatorname{Dr}^{\mathrm{a}}$ Evani de Carvalho Viotti

São Paulo

2006 


\section{UNIVERSIDADE DE SÃO PAULO}

FACULDADE DE FILOSOFIA, LETRAS E CIÊNCIAS HUMANAS

DEPARTAMENTO DE LINGÜÍSTICA

PÓS-GRADUAÇÃO EM SEMIÓTICA E LINGÜÍSTICA GERAL

ÁREA DE PESQUISA: DESCRIÇÃO DAS LÍNGUAS DE SINAIS: DESCRIÇÃO

DA LÍNGUA DE SINAIS BRASILEIRA

\section{DESCRIÇÃO FONÉTICO-FONOLÓGICA DOS SINAIS DA LÍNGUA DE SINAIS BRASILEIRA (LIBRAS)}


A meu pai, José Antônio Xavier (in memoriam), sem quem jamais teria chegado até aqui. 


\section{Resumo}

Este trabalho objetivou dar um primeiro passo em direção a uma descrição das unidades do nível fonético-fonológico da língua de sinais brasileira (libras). Para isso, ele se baseou no modelo de análise sublexical proposto por Liddell (1984) e desenvolvido por Liddell \& Johnson (2000 [1989]), segundo o qual, os sinais das línguas sinalizadas, semelhantemente às palavras das línguas faladas, são consituídos por segmentos.

Além de oferecer uma análise segmental dos sinais, capaz de capturar os contrastes seqüenciais também possíveis nessas línguas, esse modelo apresenta uma descrição bastante detalhada dos traços que caracterizam cada um de seus segmentos. Por conta disso, neste trabalho, foi possível não apenas levantar alguns traços articulatórios que têm valor distintivo na fonologia da libras, mas também esboçar uma análise segmental para alguns de seus itens lexicais.

Palavras-chave: libras, fonologia, segmento, língua de sinais. 


\begin{abstract}
This research aimed at doing a first description of the phonetic-phonological units of Brazilian Sign Language (libras). To do so, I assumed Liddell \& Johnson (2000 [1989])'s proposal, according to which signed languages' lexical items are structured by segments, in the same way as spoken languages' words.

This model not only offers a segmental analysis for the signs, but also makes possible a detailed description of their articulatory features. For that reason, in this research, it was possible to identify some libras's features used to distinguish signs, as well as outline a segmental analysis to some of its lexical items.
\end{abstract}

Key-words: libras, phonology, segment, signed language. 


\section{Agradecimentos}

Agradeço à Prof ${ }^{a}$ Evani Viotti pela competência, seriedade, responsabilidade, dedicação, e, sobretudo, pelo grande amor com que orientou esta pesquisa. Agradeço a ela também pela formação sólida que me proporcionou, pelos ensinamentos sobre como fazer pesquisa e pelas inúmeras discussões que fundamentaram este trabalho.

Agradeço ao Prof. Leland McCleray por acompanhar este trabalho desde o ínicio, alertando-me para os problemas, apontando-me formas de solucioná-los e incentivando-me.

Ao grupo de pesquisa "Estudos da Comunidade Surda: Língua, Cultura e História" (ECS) por me proporcionar momentos de riquíssimas discussões acadêmicas.

Ao surdo Alexandre Melendes, meu primeiro professor de língua de sinais brasileira (libras), e à surda Sylvia Lia, minha eterna professora de libras, por me ensinarem a configurar, localizar, mover e orientar minhas mãos lingüisticamente.

Ao amigo e colega de grupo de pesquisa Tarcísio Leite por me ajudar a ampliar meu contato com a comunidade surda, ao contribuir para a minha inclusão na organização da II CONDICISUR (Conferência dos Direitos e Cidadania dos Surdos do Estado de São Paulo). Graças à minha participação na organização desse evento, pude não apenas exercitar e desenvolver minha língua de sinais, mas também me sensibilizar para a luta da comunidade surda e me envolver nela.

À amiga surda Regiane Agrella, uma das organizadoras da II CONDICISUR, por ter colaborado com este trabalho. Agradeço a ela também pela sua amizade e pela credibilidade que depositou em mim e nesta pesquisa.

À amiga e também colega de grupo de pesquisa Renata Moreira, por todo o apoio e pelo incentivo em fazer trabalho voluntário no Instituto Santa Terezinha, uma das mais antigas escolas de surdos de São Paulo. Graças a isso, pude conviver com crianças surdas e viver algumas das muitas experiências proporcionadas por este trabalho que tiveram não só grande valor acadêmico, mas também pessoal.

Ao Prof. Sherman Wilcox pelas conversas e pelas sugestões de leitura.

Ao Prof. Fernando César Capovilla e ao Prof. Leo Wetzels, membros da banca de qualificação, pelas sugestões que, sem dúvida, contribuíram para uma melhora deste trabalho. 
Ao Prof. Marcos Lopes por me ajudar a construir o banco de dados com base no qual este trabalho foi desenvolvido, por me ensinar a operar com ele e por me orientar durante todo o tempo em que trabalhei com esse banco.

À amiga e colega de grupo de pesquisa Andréa Iguma por fazer todas as fotos contidas neste trabalho.

Ao amigo Maiko Palos por me ajudar, entre tantas outras coisas, a escanear as figuras do dicionário.

À Escola do Futuro pelo apoio à pesquisa do grupo ECS.

$\mathrm{E}$ ao $\mathrm{CNPq}$ por financiar este trabalho.

Aproveito esta oportunidade para agradecer também a todos os professores do DL (Departamento de Lingüística) da FFLCH/USP pela formação que recebi em cursos de graduação e de pós-graduação. Em especial, agradeço à Prof ${ }^{a}$ Diana Luz Pessoa de Barros e à Prof ${ }^{a}$ Cristina Altman que, por terem sido minhas primeiras professoras de lingüística, foram, sem dúvida, as primeiras grandes responsáveis pelo meu interesse e pelo meu enorme amor por essa ciência.

Agradeço também à Prof ${ }^{a}$ Esmeralda Negrão, minha primeira professora de língüística formal, que, com suas aulas cheias de vida e de grande entusiasmo, despertaram em mim questões lingüísticas e um grande desejo de me tornar um estudioso e um pesquisador das línguas humanas.

À Prof ${ }^{a}$ Raquel Santana Santos, ao Prof. Paulo Chagas, ao Prof. Leo Wetzels e ao Prof. Leland McCleary pela formação sólida que me ofereceram em fonética e fonologia, áreas da língüística na qual desenvolvi meu trabalho.

Agradeço também aos funcionário do DL, Érica, Bem Hur e Robson, pelo apoio de sempre e a todos os amigos e colegas com quem convivi durante a graduação e a pósgraduação, dos quais ainda não mencionei Ariadne Olímpio, Cristiane Silva, Flávia Machado, Carolina Lemos, Juliana Nasser, Eneida Góes, Milca Veloso, Eduardo Piris, Renata Leung, Lídia Lima e Marcus Avelar.

Por fim, agradeço à minha mãe Ivone e ao meu irmão Alexander pelo apoio incondicional em todos os momentos. 
Resumo IV

Abstract______ V

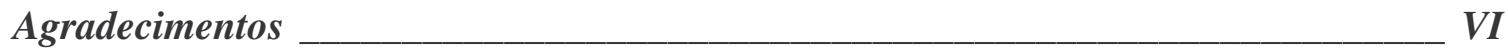

Introdução _______________________________________________ 4

Capítulo 1: A fonologia das línguas sinalizadas ____________________

1.1 O pioneirismo de William Stokoe___ 10

1.2 O modelo de Liddell \& Johnson (1989) __ 14

1.2.1 Observações de Liddell \& Johnson sobre o modelo de Stokoe___ 14

1.2.2 A estrutura segmental dos sinais _ 23

Capítulo 2: Descrição e representação das propriedades articulatórias dos sinais __ 27

2.1 O sistema de representação de Liddell \& Johnson _ 27

2.2 Representação e descrição dos segmentos dos sinais __ 28

2.3 Descrição do feixe segmental__ 30

2.3.1 Segmentos de classe maior __ 32

2.3.2 Contornos de movimento__ 38

2.3.3 Planos de contorno___ 41

2.3.4 Traços de qualidade__ 45

2.3.5 Movimentos locais__ 47

2.4 Descrição do feixe articulatório _ـ 53

2.4.1 Configuração de mão $[\mathrm{CM}] \_53$

2.4.2 Ponto de Contato [PC]__ 64

2.4.3 Face $[\mathrm{FA}]$ e orientação $[\mathrm{OR}] \ldots 73$

2.5 Conclusão _ 74

Capítulo 3: $\mathrm{O}$ banco de dados ______ 76

3.1 Formação e organização do banco de dados ___ 76

3.1.1 A constituição do banco de dados: critérios de seleção dos sinais __ 77

3.1.2 Critérios de organização do banco de dados _ 80

3.1.2.1 [ $\pm 1 \mathrm{mão}] \_81$

3.1.2.2 [ \pm movimento] __ 82

3.1.2.3 [ \pm movimento local $] \_84$ 
3.1.2.4 [ \pm 1 configuração de mão]

3.1.2.5 [ \pm contato $] \quad 87$

3.1.2.6 [ \pm marcação não-manual] __ 88

3.1.2.7 [ \pm reduplicação] _ 89

3.2 Classes e subclasses de sinais ___ 91

3. 3 Conclusão_—_ 95

Capítulo 4: Descrição dos traços segmentais e articulatórios dos sinais da libras___ 96

4.1 Articuladores manuais___ 96

4.2 Feixe segmental _ـ 100

4.2.1 Traços de contorno de movimento___ 100

4.3 Feixe articulatório — 102

4.3.1 Configuração de mão ___ 102

4.3.1.1 Sinais feitos com uma mão ___ 103

4.3.1.2 Sinais articulados com duas mãos paradas ou em movimento __ 110

4.3.1.3 Sinais articulados com uma das mãos parada ___ 112

4.3.2 Ponto de Contato _ـ 115

4.4 Conclusão _ _ 117

Capítulo 5: Análise segmental dos sinais da libras ____ 118

5.1 Movimentos transicionais versus segmentos de movimento 118

5.2 Análise dos sinais da libras em suspensões e movimentos _ 125

5.2.1 Sinais mono-segmentais___ 126

5.2.2 Sinais pluri-segmentais _ 133

5.3 Corolários de uma análise segmental___ 139

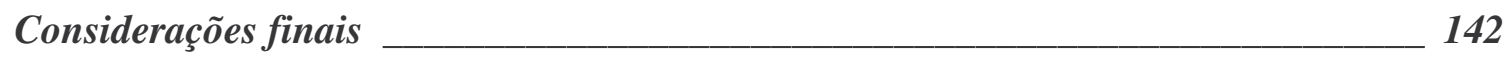

Referências Bibliográficas_________________________

$\mathrm{ANEXO}$

Quadro (1) - Configurações de mão da ASL (Klima \& Bellugi, 1979:44) ___ i

Quadro (2) - Símbolos taxonômicos para da descrição dos dedos indicador, médio, anelar e mínimo

Quadro (3) - Localizações sobre o corpo e seus respectivos símbolos (Liddell \& Johnson, 
2000:286 [1989])

Tabela (1) - Classes mais numerosas de sinais i

Tabela (2) - Classes menos numerosas de sinais iii

Tabela (3) - Buscas que não encontraram sinais $\mathbf{v}$

Tabela (4) - Configurações de mão atestadas entre os sinais feitos com uma mão e sem mudança de configuração vii

Tabela (5) - Configurações de mão atestadas como iniciais em sinais realizados com mudança de configuração ix

Tabela (6) - Configurações de mão atestadas como finais em sinais realizados com mudança de configuração $\mathbf{x}$

Tabela (7) - Outros sinais realizados com uma mão e com mudança de configuração de mão xi

Quadro (4) xiii

Quadro (5) - Símbolos para a representação de localizações sobre a mão passiva e sinais da libras realizados em uma dessas localizações Xv 


\section{Introdução}

Como se sabe, a lingüística é a ciência que busca explicar os mecanismos que regulam o funcionamento das línguas naturais. Diante disso, o valor e a importância de trabalhos de descrição e análise de línguas não precisa ser buscado na aplicabilidade que eles possam ter fora do seio dessa ciência (embora isso também possa reforçá-los), mas sim no próprio esforço investido na tentativa de melhor compreender a natureza do objeto estudado.

Por ser a língua humana, nas palavras de Saussure (1973 [1916]), "heteróclita e multifacetada", ou seja, por seus elementos poderem ser vistos de formas diferentes de acordo com o ponto de vista assumido pelo lingüista, a descrição e a análise das línguas são metodologicamente divididas em níveis que vão das micro às macro-unidades (Benveniste, 1976). Mais especificamente, a descrição e a análise lingüísticas abrangem desde o estudo das unidades mínimas distintivas, nível fonético-fonológico, passando pelo nível das unidades mínimas significativas, nível morfológico, e pelo nível das unidades sintagmáticas, nível sintático, até o nível do texto.

Nessa perspectiva, este trabalho pode ser caracterizado como sendo um primeiro passo rumo a uma investigação de unidades do nível fonético-fonológico da língua de sinais brasileira (libras) que, semelhantemente ao estudo das línguas orais nesse mesmo nível de análise, tem como finalidade (i) fazer um levantamento das unidades que recorrentemente aparecem na constituição de seus itens lexicais, (ii) separar as unidades que têm, no sistema lingüístico investigado, a função de contrastar itens lexicais daquelas que são apenas diferentes realizações de uma mesma unidade, (iii) identificar os traços mínimos (merismas, nos termos de Benveniste) com base nos quais essas unidades contrastam entre si, e (iv) mapear e explicar os processos fonológicos ocorrentes.

O trabalho que examinou, pioneiramente, as unidades distintivas de uma língua de sinais, e que mais impacto teve no desenvolvimento dos estudos lingüísticos das línguas sinalizadas foi o de Stokoe $\left(1960 ; 2000\right.$ [1965]) ${ }^{1}$. O autor investigou, na língua de sinais americana (ASL), quais eram as unidades que, além de recorrentemente constituírem seus itens lexicais (sinais), também cumpriam a função de distingui-los uns dos outros.

\footnotetext{
${ }^{1}$ É importante dizer que, segundo Hulst (1996:5), antes de Stokoe, o holandês Bem Tervoort já tinha observado a comunicação de crianças surdas e notado algumas de suas propriedades que indicavam ser ela baseada em um sistema lingüístico independente.
} 
Com base em seus estudos, Stokoe apontou que as unidades de nível fonéticofonológico da ASL (e, por extensão, das demais línguas sinalizadas) eram de três tipos, a saber, configuração de mão (forma da(s) mão(s) durante a realização de um sinal), localização (lugar no corpo ou em frente a ele em que um sinal é produzido) e movimento (forma em que a(s) mão(s) se move(m)). Tendo isso em mãos, para cada um desses três parâmetros, o autor levantou as possíveis especificações, ou seja, os possíveis valores que cada um deles pode assumir na ASL.

Como se ateve basicamente a sinais que são dotados de uma única especificação para cada um desses três parâmetros, e, conseqüentemente, apresentam-nos articulados ao mesmo tempo, Stokoe defendeu que, diferentemente das línguas orais, as línguas sinalizadas apresentam uma estrutura fonológica que tem como princípio de organização a simultaneidade.

Stokoe sustentou essa hipótese também na existência de pares de sinais que diferem entre si unicamente pela diferente especificação que apresentam para um dos seus parâmetros constitutivos. Em outras palavras, ele acreditava que a estrutura fonológica das línguas sinalizadas não era regida pela sequiencialidade, tal como nas línguas faladas, porque todos os contrastes lexicais que encontrou na ASL se baseavam unicamente na diferença de um dos três aspectos articulatórios dos sinais, a seu ver, sempre realizados simultaneamente.

O trabalho de Stokoe teve continuidade em muitos outros trabalhos, dentre os quais destaco o de Battison (1984 [1978]) e o de Klima \& Bellugi (1979).

A Battison, deve-se o acréscimo de um quarto parâmetro com base no qual os sinais podem contrastar lexicalmente. Trata-se da orientação da palma. Além disso, a esse autor, deve-se também um estudo bastante interessante acerca das propriedades articulatórias dos sinais. Com base em suas investigações, ele observou a existências de restrições (ou princípios), que atuam na forma exibida pelos itens lexicais da ASL (esses princípios serão discutidos no capítulo 4 desta dissertação).

Além de contribuir para um melhor entendimento da forma dos sinais, pode-se dizer que as descobertas de Battison, somadas às de Stokoe, sem dúvida, reforçaram ainda mais o estatuto de língua natural das línguas sinalizadas. Mais especificamente, tornou-se cada vez mais difícil afirmar que as línguas de sinais não passam de sistemas de comunicação incompletos, baseados em uma língua oral e realizados por meio de mímicas e/ou 
pantomimas tendo em vista a demonstração de Stokoe de que os itens lexicais das línguas sinalizadas são constituídos por unidades recorrentes e distintivas, assim como os itens lexicais das línguas orais. O mesmo pode ser dito em relação aos achados de Battison, segundo os quais os itens lexicais das línguas sinalizadas são regidos por princípios de boaformação, semelhantemente ao que acontece nas línguas faladas.

A Klima \& Bellugi, devem-se estudos sobre uma das questões que, certamente, levou a lingüística a ignorar, por muito tempo, as línguas sinalizadas. Refiro-me aqui ao trabalho desenvolvido pelos autores acerca da iconicidade dos sinais.

Como se sabe, para Saussure, a relação entre significante e significado nos itens lexicais das línguas naturais é necessariamente arbitrária. Em outras palavras, para o autor, não existe entre essas duas grandezas lingüísticas nenhuma relação de motivação, de maneira que o significante de um signo espelhe (em maior ou menor grau) o significado que veicula. Porém, esse não parece ser o caso das línguas sinalizadas. É bastante notório o fato de que o significante dos signos dessas línguas mantêm com o significado que veiculam uma certa relação de motivação.

De acordo com Klima \& Bellugi, os sinais são icônicos porque, originalmente, derivam de representações miméticas ou pantomímicas. Entretanto, como os autores tiveram oportunidade de observar, apesar de sua origem, os sinais não são articulados da mesma maneira que uma representação mimética ou uma pantomima do mesmo significado expresso por eles.

Mímicas e pantomimas são produzidas sem uma aparente restrição quanto ao espaço de realização, quanto ao uso do corpo e quanto às formas, localizações e movimentos das mãos. Diferentemente, os sinais são realizados em um espaço mais limitado, produzidos fundamentalmente pelas mãos, e articulados apenas com configurações, localizações e movimentos permitidos pela língua.

Tal fato reforçou achados como os de Battison e, assim, mostrou que a iconicidade presente nas línguas sinalizadas não podia mais ser usada como evidência contrária ao seu estatuto de língua natural.

Apesar de reconhecer o inegável valor dos trabalhos mencionados e de muitos de seus achados, Liddell (1984) apresentou evidências contrárias à análise fonológica proposta por Stokoe e seguida por Battison e Klima \& Bellugi.

De acordo com Liddell, a maior parte dos itens lexicais da ASL não apresenta, do ponto 
de vista articulatório, um comportamento que espelhe a organização sublexical simultânea defendida por Stokoe. Segundo o autor, a grande maioria dos sinais da ASL apresenta mais de uma especificação para pelo menos um de seus aspectos articulatórios (configuração de mão, localização, movimento e orientação da palma) e, conseqüentemente, exibem seqüencialidade em sua realização.

Mais do que isso, Liddell observou que a seqüencialidade também pode ser usada distintivamente, da mesma forma que é nas línguas orais. De acordo com os achados do autor, é possível encontrar nas línguas sinalizadas pares de sinais que contrastem unicamente pela ordem em que as especificações de um mesmo parâmetro é realizado.

Diante dessas evidências, Liddell (1984) propôs, para os sinais das línguas sinalizadas, uma estrutura sublexical que, diferentemente da proposta por Stokoe, é regida pelo princípio da seqüencialidade, à semelhança do que ocorre nas línguas orais.

Além de incorporar a seqüencialidade na realização dos sinais, é importante dizer que, a partir do trabalho de 1984, Liddell \& Johnson (2000 [1989]) desenvolvem um sistema de representação não apenas capaz de capturar a seqüencialidade observada na realização dos sinais, mas capaz também de capturar uma riqueza muito maior de detalhes envolvidos na articulação destes.

Partindo dos três parâmetros articulatórios propostos por Stokoe e incorporando a orientação da palma, proposta por Battison, Liddell \& Johnson apresentaram para cada um deles uma análise e uma descrição mais fina. Mais especificamente, ao contrário do que se fazia até então, configurações de mão, localizações, movimentos e orientações da palma passaram a ser tratados como feixes de traços. Com isso, os autores conseguiram precisar exatamente os traços com base nos quais um determinado sinal pode contrastar em relação ao outro.

Embora, a princípio, esse tratamento possa parecer exageradamente detalhista, deve-se considerar que ele encontra respaldo no valor distintivo que diferentes línguas sinalizadas podem atribuir aos traços propostos pelos autores para descrever mais finamente cada um dos parâmetros dos sinais.

Como exemplo disso, pode-se mencionar o fato de que o modelo de Liddell \& Johnson, ao analisar as configurações de mão, trata o polegar independentemente dos demais dedos. Com isso, os autores são capazes não apenas de precisar o(s) traço(s) que distingue(m) configurações parecidas, mas também de capturar contrastes lexicais em que a oposição se 
estabelece com base em um dos traços da configuração de mão e não com base na configuração inteira.

Levando em conta a capacidade do modelo de Liddell \& Johnson de capturar a seqüencialidade observável nos sinais e o seu grande poder descritivo, este trabalho se baseou nessa proposta para dar início à descrição fonético-fonológica dos sinais da libras ${ }^{2}$.

Essa possibilidade de descrição detalhada que o modelo fornece é particularmente interessante para este trabalho, na medida em que não existem descrições da libras semelhantes à feita aqui. Não dispomos ainda de estudos substanciais e baseados em corpora sobre nenhum dos níveis em que essa língua pode ser descrita. Em outras palavras, não dispomos, até o momento, de trabalhos sobre a fonética, a fonologia, a morfologia, a sintaxe e, muito menos, sobre o discurso da libras.

Entretanto, essa língua já dispõe de uma importante obra lexicográfica que documenta um considerável número de seus itens lexicais. Refiro-me aqui ao Dicionário Enciclopédico Ilustrado Trilíngüe da Língua de Sinais Brasileira de Capovilla \& Raphael (2001). Nessa obra, encontram-se documentados, ilustrados, traduzidos para o português e para o inglês e descritos com base nos aspectos mais salientes de sua produção mais de 2000 sinais da libras.

Graças a essa obra, este trabalho pôde ser realizado. Primeiramente, porque ela, como já dito, apresenta um considerável número de dados da libras. Em segundo lugar, porque ela, além de oferecer ilustrações dos sinais, largamente reproduzidas aqui, também oferece uma descrição dos aspectos articulatórios mais salientes dos sinais, que foi utilizada como ponto de partida para esta pesquisa.

Posso dizer que um dos produtos deste trabalho foi o desenvolvimento de uma ferramenta que não apenas facilitou o uso do dicionário de Capovilla \& Raphael em minha pesquisa, mas que também poderá facilitar o uso dessa mesma obra em pesquisas lingüísticas futuras. Refiro-me aqui ao banco de dados (banco de sinais) criado para fins da

\footnotetext{
${ }^{2}$ Este trabalho foi desenvolvido no âmbito do grupo de pesquisa "Estudos da Comunidade Surda: Língua, Cultura e História" (ECS), cujo objetivo é descrever a língua de sinais brasileira (libras), estudar a cultura da comunidade surda usuária dessa língua e documentar sua história. Pelo caráter interdisciplinar, esse grupo, coordenado pelo Prof. Dr. Leland McCleary do Departamento de Letras Modernas (DLM) e registrado junto ao Conselho Nacional de Desenvolvimento Científico e Tecnológico (CNPq) e à Pró-Reitoria de Pesquisa da USP, abrange um outro departamento e dois outros núcleos da Faculdade de Filosofia, Letras e Ciências Humanas (FFLCH) da USP: o Departamento de Língüística (DL), representado pela Prof ${ }^{\mathrm{a}} \operatorname{Dr}^{\mathrm{a}}$ Evani Viotti, coordenadora do subgrupo de língua, o Núcleo de Antropologia Urbana (NAU), representado pelo Prof. Dr. José Magnani, e o Núcleo de Estudos em História Oral (NEHO), representado pelo Prof. Dr. José Carlos Sebe.
} 
descrição e análise dos sinais da libras aqui desenvolvidas. Esse banco de dados será apresentado e descrito no capítulo 3 desta dissertação.

Este trabalho não objetivou fazer uma descrição fonético-fonológica completa dos sinais da libras. Na verdade, dado o pouco conhecimento que se tem das línguas sinalizadas, este trabalho não objetivou mais do que dar um primeiro passo nessa direção. Sendo assim, há ainda muito a ser feito, não só no que diz respeito à fonética e à fonologia da libras, mas também no que concerne à gramática dessa língua como um todo.

Esta dissertação está dividida em cinco capítulos. No primeiro deles, apresento a proposta pioneira de Stokoe e seus problemas apontados por Liddell. No capítulo 2, descrevo o modelo de análise e descrição dos sinais de Liddell \& Johnson à luz da libras. No capítulo 3, apresento a organização que fiz, em um banco de dados, dos sinais dicionarizados em Capovilla \& Raphael, objetivando descrevê-los e analisá-los com base na proposta de Liddell \& Johnson. No capítulo 4, mostro a descrição dos traços constitutivos dos sinais da libras. Finalmente, no capítulo 5, apresento os resultados de uma primeira análise segmental dos sinais. 


\section{Capítulo 1: A fonologia das línguas sinalizadas}

Neste capítulo, destaco a importância que o trabalho pioneiro de Stokoe (1960) teve para a defesa do estatuto de língua natural das línguas de sinais e apresento a proposta de análise sublexical que o referido autor fez para os sinais da língua de sinais americana (ASL).

Além disso, apresento os desdobramentos da análise sublexical dos sinais. Mais especificamente, menciono os problemas que Liddell (1984) identificou na proposta de Stokoe e a forma como o modelo de análise que este último autor propôs resolve esses problemas.

\subsection{O pioneirismo de William Stokoe}

Contradizendo as idéias equivocadas que sempre povoaram o senso comum, e a visão de muitos intelectuais de sua época, Stokoe (1960), considerado o pai da lingüística das línguas sinalizadas, foi o primeiro lingüista a defender abertamente que essas línguas são línguas naturais e que, como quaisquer outras línguas, também devem ser estudadas pela lingüística.

Stokoe advogava que, apesar das diferenças de modalidade de realização e de percepção ${ }^{3}$, as línguas sinalizadas seguem princípios de organização estrutural semelhantes aos das línguas orais. Para sustentar sua hipótese, Stokoe demonstrou que os sinais, à semelhança do que ocorre com os itens lexicais das línguas faladas, são constituídos de partes.

Dito de outra maneira, Stokoe foi o primeiro a defender e a demonstrar que os sinais não deveriam ser pensados como "figuras desenhadas no ar com as mãos", , mas sim como símbolos complexos e abstratos que podem ser analisados em elementos menores.

Com base em suas observações, Stokoe propôs que os sinais da língua de sinais americana (ASL) são constituídos de três partes ou parâmetros independentes, a saber:

\footnotetext{
${ }^{3}$ Diferentemente das línguas faladas, que são articuladas pelos órgãos do aparelho fonador e percebidas pela audição, as línguas sinalizadas são articuladas fundamentalmente pelas mãos e percebidas pela visão.

${ }^{4}$ Stokoe (1960) citado em Battison (2000 [1978])
} 
(i) localização: lugar no corpo ou no espaço em frente ao corpo em que o sinal é produzido;

(ii) configuração de mão: a forma (ou estado dos dedos) que a mão apresenta quando da realização de um sinal e;

(iii) movimento: maneira como a mão se move ao longo da articulação de um sinal.

A partir disso e de uma análise minuciosa dos sinais dessa língua, Stokoe constatou que, semelhantemente aos parâmetros articulatórios das línguas orais, existe um número finito de valores diferentes que cada uma dessas três categorias pode assumir, e que esses valores, tal como acontece nas línguas faladas, podem se recombinar, ou seja, podem reaparecer na constituição de outros itens lexicais.

Além da finitude e da possibilidade de recombinação dos valores que idenficou para os parâmetros constitutivos dos sinais, Stokoe constatou uma outra característica destes que permitiu a ele reforçar ainda mais sua tese de que as línguas sinalizadas e as línguas orais são estruturalmente semelhantes. Trata-se do caráter contrastivo que os valores assumidos por cada um dos parâmetros que propôs para os sinais podem apresentar.

Essa constatação se deveu à identificação de pares de sinais que diferem em um único valor dos três parâmetros propostos e que apresentam significados diferentes. Em outras palavras, essa constatação se deveu à identificação de pares mínimos na ASL, que, analogamente aos identificados nas línguas faladas, conferem um caráter fonológico ao traço articulatório com base no qual o contraste semântico é estabelecido. Como exemplos de pares mínimos na ASL, Battison (2000 [1978b]) cita os pares CAR/DRIVE (carro/dirigir) x WHICH (qual), CHINESE (chinês) x SOUR (amargo) e NAME (nome) $\mathrm{x}$ SHORT/BRIEF (curto/breve) ${ }^{5}$.

Como indicam as figuras abaixo, no primeiro par, CAR/DRIVE (carro/dirigir) $\mathrm{x}$ WHICH (qual), o contraste entre os sinais é estabelecido unicamente com base nas

\footnotetext{
${ }^{5}$ Neste trabalho, no que diz respeito à notação do nome de sinais, cabe dizer que ela sempre será feita em letras maiúsculas (para uma discussão a respeito do nome dos sinais, ver McCleary \& Viotti (a sair)). Já no que diz respeito à notação do nome de sinais da ASL, é preciso dizer que sigo o padrão adotado por Hulst \& Mills (1996), lingüistas holandeses que estudam a língua de sinais holandesa. No texto a que me refiro, os autores, apesar de o escreverem em inglês, mantêm o nome original dos sinais da língua de sinais holandesa em holandês e apresentam para eles uma tradução em inglês. Além disso, é importante dizer que sigo também a forma de indicação do nome do sinal em legendas de ilustrações deles. Mais especificamente, nesses casos, só apresento o nome original do sinal da ASL em inglês.
} 
diferentes configurações exibidas por cada um deles, dado que a localização e os movimentos realizados pelas mãos são idênticos nos dois sinais.

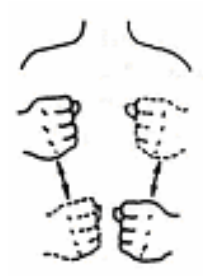

CAR/DRIVE

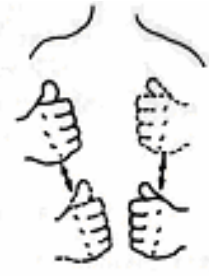

WHICH

Figura (1) Battison (2000:201 [1978b])

Já no segundo par, CHINESE (chinês) x SOUR (amargo), o contraste entre os sinais é estabelecido unicamente com base na localização da mão, já que seus outros dois parâmetros apresentam as mesmas especificações.

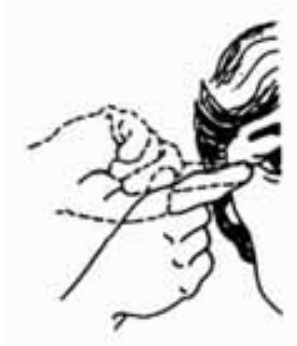

CHINESE

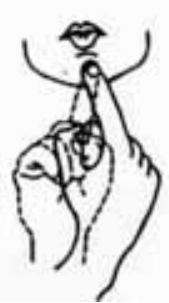

SOUR

Figura (2) Battison (2000:201 [1978b])

Por fim, no terceiro par, NAME (nome) x SHORT/BRIEF (curto/breve), os sinais contrastam apenas na forma de movimento produzido pela mão. Como sugerem as figuras abaixo, enquanto no primeiro sinal a mão ativa realiza um movimento para baixo, que termina quando esta contacta a mão passiva, no segundo sinal a mão ativa realiza movimentos para frente e para trás, mantendo-se em contato com a mão passiva durante toda a articulação do sinal ${ }^{6}$.

\footnotetext{
${ }^{6}$ As expressões mão ativa e mão passiva são empregadas para descrever a forma de participação da mão em certos sinais realizados com duas mãos. A mão ativa é aquela que, nesses sinais, se move, enquanto a mão passiva é aquela que, durante toda a realização desses sinais, fica parada e serve de ponto de contato ou de referência para a mão ativa. Battison (2000a [1978]) menciona que, além dessas expressões, duas outras são necessárias para descrever as mãos. Trata-se das expressões mão dominante e mão não-dominante. De acordo com o autor, a primeira delas se diferencia da segunda por ser a mão preferida para a realização de sinais feitos só com uma mão e por ser a mão preferida para desempenhar o papel de mão ativa em certos sinais
} 


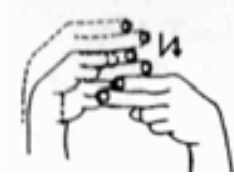

NAME

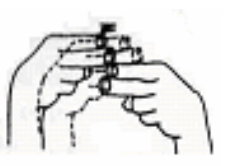

SHORT/BRIEF

Figura (3) Battison (2000:202 [1978b])

A esses três parâmetros, Battison (2000 [1978a]) somou um quarto: a orientação da palma. Esse acréscimo se deveu à identificação de pares mínimos na ASL, como CHILD (criança) (Figura (4a)) x THING (coisa) (Figura (4b)), em que a única diferença que distingue um sinal do outro é justamente a orientação exibida pela mão em cada um deles.

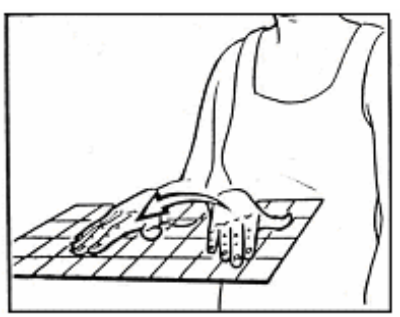

(a)

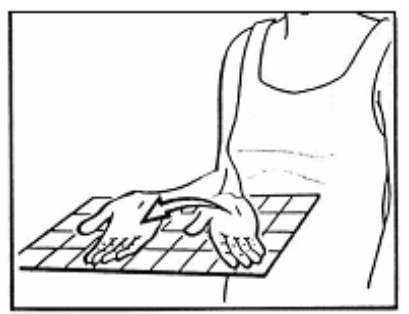

(b)

CHILD

THING

Figura (4) Klima \& Bellugi (1979:48)

Stokoe acreditava que cada um dos três aspectos que propôs como essenciais na articulação de um sinal (configuração de mão, localização e movimento), em decorrência do caráter distintivo que podem assumir, desempenhavam, nas línguas sinalizadas, o mesmo papel que os fonemas desempenham nas línguas orais. Nesse sentido, de acordo com sua hipótese, uma das mais marcantes diferenças entre a organização fonológica das línguas orais e das línguas sinalizadas residiria no fato de que, no caso destas últimas, os fonemas seriam realizados simultaneamente, em contraste com as primeiras, cujos fonemas são produzidos seqüencialmente.

Por ter isso em mente, e por querer salvaguardar as diferenças de modalidade das línguas sinalizadas, Stokoe empregou o termo quirema (do grego, 'quiros', mão), no lugar de fonema, para designar cada um dos aspectos que, nos seus termos, constituíam

articulados com duas mãos. Embora o autor aponte que esse é o caso na maioria das vezes, ele ressalta a importância do uso dessas duas outras expressões por ter em mente que, em situações marcadas, pode não haver essa correspondência entre mão dominante e mão ativa. 
simultaneamente os sinais, e que tinham a função de distingui-los dos outros. Paralelamente, usou o termo quirologia, no lugar de fonologia, para referir-se ao subdomínio da gramática dessas línguas que tem, entre outras, a função de determinar as regras de combinação desses aspectos na formação de morfemas.

Entretanto, esses termos não foram incorporados pelos autores que deram continuidade à descrição e à análise da ASL (Battison, 1978; Klima \& Bellugi, 1979; Liddell, 1984; Liddell \& Johnson, 2000 [1989]), entre outras razões, porque consideraram que o uso de uma mesma terminologia lingüística no tratamento tanto de línguas orais, quanto de línguas sinalizadas, tem a vantagem de iluminar semelhanças entre elas. Além disso, de acordo com Battison, o emprego de termos como fonema e fonologia para as línguas sinalizadas se justifica em razão de eles se referirem, na teoria lingüística, a entidades abstratas, independentes do seu canal de manifestação ${ }^{7}$, ainda que tais termos sejam formados pela raiz gregra 'phone', que significa som.

\subsection{O modelo de Liddell \& Johnson (1989)}

\subsubsection{Observações de Liddell \& Johnson sobre o modelo de Stokoe}

Embora Stokoe tenha sustentado toda a sua argumentação em favor do estatuto de língua natural das línguas sinalizadas no fato de que estas compartilham certas propriedades com as línguas orais, ele não ignorou a existência de diferenças entre elas. Como exemplo disso, ele afirmou, nos termos de sua análise, que uma das diferenças mais marcantes entre as línguas sinalizadas e as línguas orais está ligada à forma de organização sublexical. Para Stokoe, os sinais são constituídos de fonemas estruturados e produzidos simultaneaneamente, fato que os distingue, portanto, dos signos das línguas orais, nos quais a sua estruturação e produção são baseadas na seqüencialidade.

É importante salientar que, ainda que Stokoe e seus seguidores defendessem que os sinais das línguas sinalizadas são constituídos de fonemas produzidos simultaneamente, eles não ignoraram a existência de certos aspectos destes que são realizados

\footnotetext{
${ }^{7}$ A mesma justificativa pode ser estendida aos termos fone e alofone, dado que aquele designa a realização concreta de uma unidade mínima e abstrata do nível fonológico, enquanto este, as suas diferentes possibilidades de produção.
} 
seqüencialmente. Entretanto, para eles, a organização seqüencial nos sinais era fonologicamente irrelevante (Liddell \& Johnson, 2000:268 [1989]).

De fato, como aponta Liddell (1984:373), em um sinal da ASL, como BLACK (preto), representado pela figura abaixo, não faz sentido perguntar se o movimento antecede a configuração da mão ou se ele sucede a localização em que o sinal é produzido. Claramente, todos esses aspectos estão presentes ao longo de toda a realização do sinal.

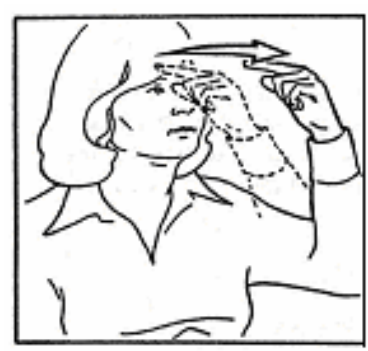

\section{BLACK}

O sinal BLACK (preto) da ASL é realizado com uma mão, configurada em $[\mathrm{G}]^{8}$, com a palma orientada para baixo e com a lateral do polegar em contato com a testa. Durante a realização desse sinal, a mão se move em direção a uma região que fica próxima à lateral do ponto de onde partiu.

Figura (5) Klima \& Bellugi (1979:218)

Entretanto, segundo Liddell, sinais desse tipo constituem uma pequena parcela do léxico da ASL. A seu ver, esse fato torna uma proposta teórica unicamente embasada nesse tipo de sinais incapaz de oferecer explicações adequadas quanto à organização interna de todos os sinais das línguas sinalizadas.

De acordo com Liddell, os sinais da ASL podem ser dois tipos: sinais unitários e sinais seqüenciais. Os sinais unitários têm como principal característica o fato de que seus aspectos formacionais são estáveis (a configuração de mão, a localização e a orientação da palma são as mesmas ao longo de toda a articulação do sinal). Esses sinais, segundo o mesmo autor, podem ser de dois subtipos. Um deles abrange sinais que, como BLACK (preto) (Figura (5)), são realizados com movimento. Já o outro engloba sinais que, assim como o verbo LOOK-AT (olhar para) da ASL (Figura (6)) modulado para expressar

\footnotetext{
${ }^{8}$ Embora este trabalho siga o sistema de representação de configurações de mão desenvolvido por Liddell \& Johnson (2000 [1989]), antes de apresentá-lo, utilizo os símbolos propostos por Stokoe e adotados por seus seguidores. Tais símbolos, bem como figuras de mãos que os ilustram, podem ser vistos no quadro (1) do anexo desta dissertação.
} 
aspecto durativo, são produzidos sem movimento ${ }^{9}$.

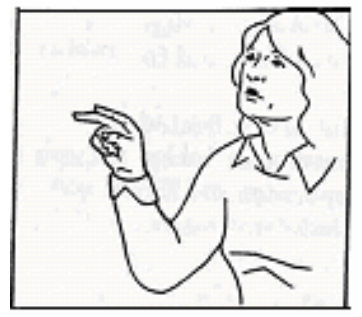

LOOK-AT

O sinal LOOK-AT (olhar para) da ASL, quando modulado para expressar aspecto durativo, é produzido por meio da manutenção da mão, por alguns instantes, em um ponto paralelo e em frente ao ombro ipsilateral. Como sugere a figura acima, nesse sinal, a mão, orientada para frente, aparece com o indicador e com o dedo médio distendidos e os demais fechados.

Figura (6) Klima \& Bellugi (1979:293)

Já o segundo tipo de sinais, os sinais seqüenciais, constitui a maioria, no léxico da ASL. Esses sinais se caracterizam por apresentar alguns de seus aspectos formacionais nitidamente realizados em seqüência.

Como exemplo de sinais desse tipo, Liddell cita CHICAGO e WHEN (quando) da ASL, que apresentam seqüencialidade na realização de alguns de seus aspectos articulatórios, e requerem uma ordem fixa para eles. Para a articulação de CHICAGO, por exemplo, é necessário primeiramente mover a mão, configurada em $[\mathrm{C}]$, para a direita e, somente na seqüência, movê-la para baixo. Já em WHEN (quando), representado pela figura a seguir, o contato que a mão ativa faz com a mão passiva ocorre apenas depois do movimento circular.

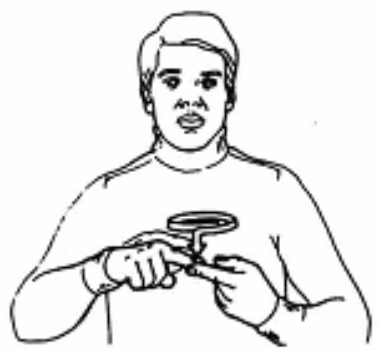

WHEN

Figura (7) Liddell \& Johnson (2000:270 [1989])

\footnotetext{
${ }^{9}$ Em casos como LOOK-AT (olhar para), assume-se que o movimento responsável pelo posicionamento da mão no lugar adequado para a realização do sinal não faz parte de sua estrutura sublexical, sendo, portanto, um movimento meramente transicional. Para uma discussão a respeito desse tipo de movimento, ver capítulo 5 .
} 
Para Liddell (1984) e Liddell \& Johnson (2000 [1989]), evidências de que a seqüencialidade desempenha um papel importante na estrutrura interna dos sinais podem ser encontradas entre seus diversos aspectos formacionais, dado que há sinais na ASL que são realizados com duas configurações de mão, e/ou com dois movimentos, e/ou com duas localizações, que necessariamente são articulados em seqüiência ${ }^{10}$.

Embora, como já dito, Stokoe não tenha ignorado a existência de sinais duplamente especificados para um dos seus aspectos formacionais, ele apresentou, para eles, uma análise que não enfatizava essa característica.

Assim, para dar conta de sinais como UNDERSTAND (entender) (Figura (8)) e RESTRAIN-FEELINGS (reprimir sentimentos) (Figura (9)), em que há duas configurações, por exemplo, Stokoe propôs a existência de um movimento de abrir (opening movement), que explicaria a mudança da configuração de mão de [S] para [G] no primeiro sinal, e outro de fechar (closing movement), que caracterizaria, no segundo sinal, a passagem da configuração de mão de [5] para [S].

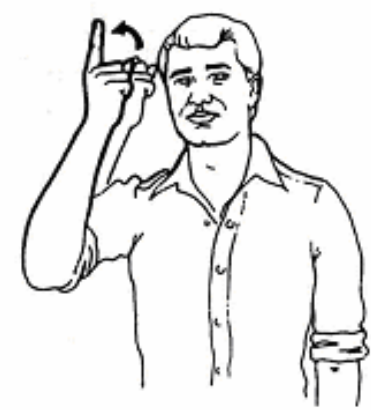

\section{UNDERSTAND}

A realização do sinal UNDERSTAND (entender) da ASL consiste em mover a mão, configurada em [S], orientada para dentro e localizada em frente à lateral ipsilateral da testa, para um ponto alguns centímetros à frente dessa posição inicial. Além disso, a articulação desse sinal, como sugere a figura acima, também requer que se altere, durante esse movimento, a configuração da mão de [S] para [G].

Figura (8) Liddell \& Johnson (2000:268 [1989])

\footnotetext{
${ }^{10}$ Liddell \& Johnson (2000:269 [1989]) mencionam que existem, embora em número reduzido, sinais simples da ASL que são constituídos de três configurações de mão (cf. SHOCKED (chocado) (Figura (10)). Entretanto, não fazem qualquer observação nesse sentido em relação aos outros aspectos.
} 


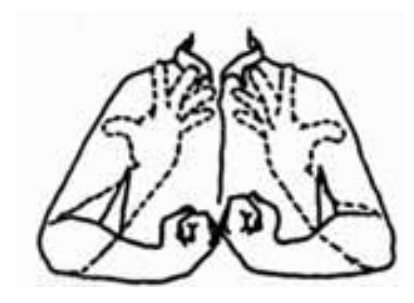

\section{RESTRAIN-FEELINGS}

O sinal RESTRAIN-FEELINGS (reprimir sentimentos) da ASL é realizado com duas mãos, movendo-se simultaneamente. Nesse sinal, as mãos, configuradas em [5], orientadas para cima e localizadas em uma região à frente do torso e um pouco acima do peito, deslocam-se para baixo, mudando sua configuração para $[\mathrm{S}]$.

Figura (9) Battison (1978:214)

No sistema notacional de Stokoe et al (1965), esses sinais eram representados como mostra a representação em (1).

$$
\mathrm{A}^{\square[\mathrm{G}]}
$$

UNDERSTAND

$$
\varnothing 5^{\#\left[{ }^{[A]}\right]}
$$

\section{RESTRAIN-FEELINGS}

Notação segundo o sistema de Stokoe (1)

Mais especificamente, o sinal UNDERSTAND (entender) é representado por meio dos símbolos [, , para indicar a localização; [A], para indicar a configuração de mão inicial; [ם], para indicar o movimento de abrir e [G] para indicar a configuração de mão final do sinal. Já o sinal RESTRAIN-FEELINGS (reprimir sentimentos) da ASL é representado pelos símbolos [Ø], para indicar que o sinal é articulado no espaço em frente ao corpo do sinalizador; [5], para indicar a configuração de mão que aparece no início do sinal; [\#], para indicar o movimento de fechar e, por fim, [A], para a configuração de mão que aparece com o fechamento da configuração inicial.

Como se pode ver nas representações acima, além de símbolos para representar o movimento de abrir ou de fechar, fazia-se necessário especificar também a configuração de mão final. A razão disso se deve ao fato de que uma dada configuração pode "se abrir" ou "se fechar" em configurações diferentes: embora, em UNDERSTAND (entender) (Figura (8)), a configuração resultante do movimento de abrir seja [G], a configuração resultante do movimento de abrir em um sinal como SHOCKED (chocado) (Figura (10)) é diferente. 
Como ilustra a figura abaixo, nesse sinal a configuração [S] "se abre" em [C].

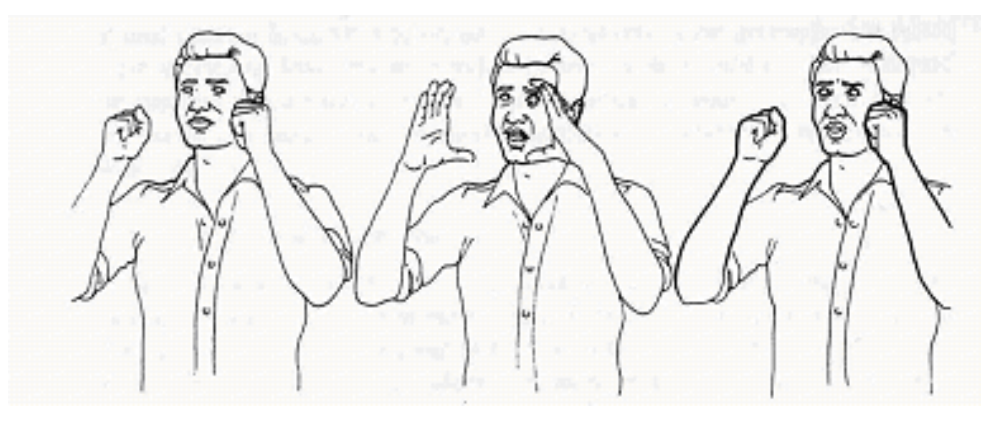

SHOCKED

Figura (10) Liddell (1990:52)

Já em relação a sinais especificados para um movimento de fechar, a necessidade de se determinar para esse movimento a configuração final da mão se torna visível na comparação entre sinais como RESTRAIN-FEELINGS (reprimir sentimentos) (Figura (9)) e WHITE (branco) (Figura (11)) da ASL. Embora eles sejam constituídos da mesma configuração de mão inicial, [5], "fecham-se" em configurações diferentes: [S], no caso do primeiro sinal, e [Ô], no caso do segundo.

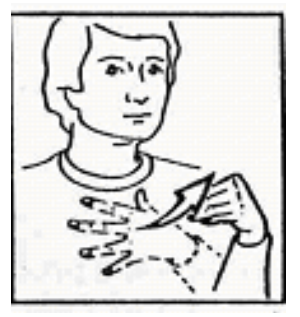

WHITE

Como sugere a figura acima, para realizar o sinal WHITE (branco) da ASL, deve-se mover a mão, orientada para dentro e em contato com a região central do peito, horizontalmente para a frente, mudando, durante esse movimento, a sua configuração de [5] para [Ô].

Figura (11) Klima \& Bellugi (1979:139)

No que diz respeito ao tratamento de sinais constituídos de dois movimentos produzidos ordenadamente, é interessante observar que o sistema notacional de Stokoe capturava a seqüencialidade desse aspecto, apesar de ter sido desenvolvido à luz de uma análise calcada na simultaneidade dos elementos formacionais dos sinais.

Sendo assim, sinais como CHICAGO, além de apresentarem especificações para o 
lugar de articulação (espaço neutro [Ø]) e para a configuração de mão [C], apresentavam também, na sua representação estrutural, especificações para os dois movimentos de que é constituído -- movimento para a direita [>] e movimento para baixo [ $\mathrm{\vee}]$--, tal como indica a representação a seguir.

\section{$\varnothing C^{>\vee}$}

CHICAGO

Notação segundo o sistema de Stokoe (2)

Por fim, para dar conta de sinais especificados com duas localizações, Stokoe estendeu a eles a mesma análise desenvolvida para sinais dotados de mais de um movimento. Tendo em vista que Stokoe, diferentemente de Liddell (1984), considerava o contato realizado pela mão com alguma parte do corpo como uma forma de movimento, sinais da ASL como INDIAN (índio) (Figura (12)) e PICTURE (quadro, desenho) (Figura (13)), por exemplo, eram descritos e representados por ele como sendo formados por uma seqüência de movimentos.

Em INDIAN (índio), como sugere a figura a seguir e como mostra a representação abaixo dela, o "movimento de contato" $[\mathrm{x}]$ realizado no nariz $[\Delta]$ é seguido por um movimento que leva a mão à região lateral da testa $[\mathrm{T}]$, onde outro "movimento de contato" é produzido.

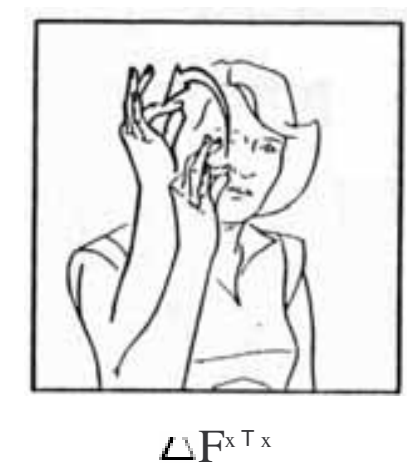

INDIAN

Figura (12) Klima \& Bellugi (1979:59)

Algo semelhante pode ser observado na figura e na representação de PICTURE (quadro, desenho), em que, após o primeiro contato realizado na região da bochecha ipsilateral [3], 
há um movimento em direção à palma da mão passiva, representado por $[\perp]$, onde também ocorre outro "movimento de contato".

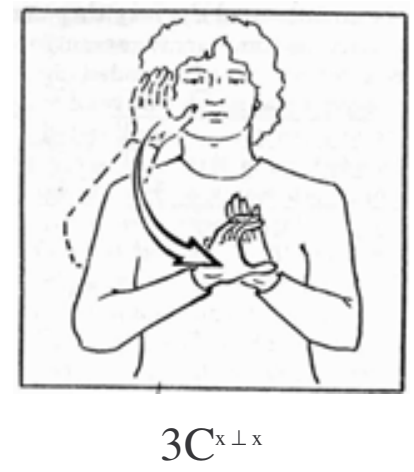

PICTURE

Figura (13) Klima \& Bellugi (1979:74)

Liddell \& Johnson apontam alguns problemas no tratamento que Stokoe dá a sinais que apresentam mais de uma especificação para um (ou mais de um) de seus parâmetros articulatórios. No que diz respeito aos sinais que apresentam mais de uma especificação para o parâmetro configuração de mão, os autores ressaltam a insuficiência da proposta de movimentos de abrir e fechar para descrevê-los. A razão disso se vincula ao fato de que ela, por si só, não determina a especificação da configuração de mão final que sinais dotados de um desses movimentos apresentam, como sinaliza a própria representação que Stokoe propôs.

Já no que diz respeito a sinais dotados de duas especificações para o parâmetro localização, Liddell \& Johnson apontam que, além de ser um problema considerar o contato como uma forma de movimento ${ }^{11}$, o modelo de Stokoe, por ser calcado na simultaneidade dos parâmetros articulatórios, só prevê a existência de um único ponto de articulação para cada sinal. Tal fato se reflete na representação proposta para sinais como INDIAN (índio) e PICTURE (quadro, desenho) no fato de que apenas a localização do primeiro contato é

\footnotetext{
${ }^{11}$ A argumentação de Liddell (1984) contra o tratamento do contato como um tipo de movimento se baseia na possibilidade de alguns sinais dotados desse traço poderem ser realizados sem ele. Um exemplo disso, segundo o autor, é o sinal THINK (pensar) da ASL. Na realização das duas versões desse sinal (com e sem contato), observa-se que, igualmente, a mão se move em direção à lateral ipsilateral da testa. Tal fato contraria as expectativas da análise do contato como um tipo de movimento, na medida em que o movimento realizado pela mão em direção à região de contato é observável mesmo na versão em que o contato não é produzido.
} 
especificada (cf. $\left[\Delta \mathrm{F}^{\mathrm{x}} \mathrm{x}\right]$ e $\left.\left[3 \mathrm{C}^{\mathrm{x} \perp \mathrm{x}}\right]\right)$.

Liddell (1984) e Liddell \& Johnson (2000 [1989]) observaram, em aspectos formacionais dos itens lexicais da ASL, diferentes daqueles previstos no modelo de Stokoe, outras evidências que favorecem uma análise seqüencial dos sinais. Dentre esses outros aspectos, pode-se mencionar as marcações não-manuais.

Segundo as observações de Liddell (1984), embora existam na ASL sinais como NOON (meio-dia) (Figura (14)) em que uma mesma marcação não-manual é produzida durante toda a articulação do sinal (observe-se na figura abaixo que as bochechas da sinalizadora ficam comprimidas do começo ao fim do sinal), há também sinais como GIVE-IN (desistir) (Figura (15)) no qual ocorrem duas marcações não-manuais em seqüência ${ }^{12}$.

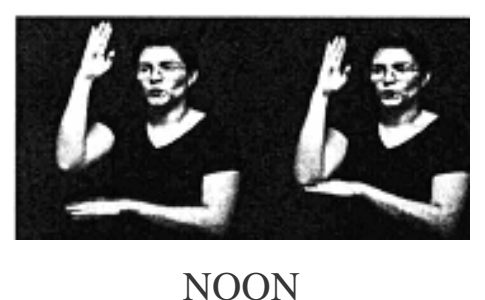

Figura (14) Liddell (2003: 41)

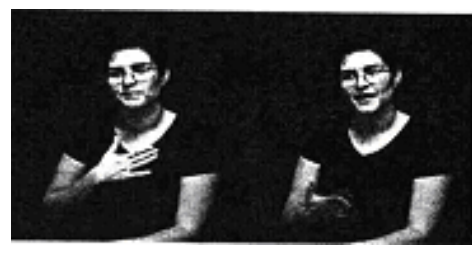

GIVE-IN

Figura (15) Liddell (2003:13)

Como se pode ver na figura (15), o sinal GIVE-IN (desistir) começa com a palma da mão tocando a região do esterno e, simultaneamente, com os lábios pressionados um contra o outro. Logo depois, a mão se move alguns centímetros à frente de sua posição inicial, enquanto a boca se abre pouco a pouco. Por fim, a mão pára e fica em suspensão por alguns instantes, durante os quais os lábios são mantidos separados.

De acordo com Liddell, é interessante notar que, em sinais como GIVE-IN (desistir),

\footnotetext{
${ }^{12}$ Para efeitos de sua argumentação, Liddell concentra-se nas marcações não-manuais que fazem parte do sinal, desconsiderando as que ocorrem no nível sintático, para indicar pergunta, topicalização etc.
} 
da ASL, as marcações não-manuais, além de serem realizadas em uma ordem fixa, também são produzidas em estrita correspondência com as atividades feitas pelas mãos. Segundo o autor, em GIVE-IN (desistir), os lábios só se mantêm pressionados um contra o outro durante o tempo em que a mão fica em contato com a região do esterno.

Em suma, a análise de Stokoe, baseada na simultaneidade dos aspectos formacionais dos sinais, não parece dar conta, adequadamente, da seqüencialidade visivelmente presente na organização de vários aspectos constitutivos destes. Por essa razão, um modelo como o proposto por Liddell \& Johnson, assentado sobre a hipótese de que organização da estrutura sublexical dos sinais é regida pela seqüencialidade, apresenta vantagens sobre o de Stokoe, no que diz respeito não só à descrição fonética dos sinais, como também no que diz respeito à possibilidade de explicitar vários processos fonológicos observados na ASL.

\subsubsection{A estrutura segmental dos sinais}

Liddell (1984), a partir da observação de gravações, verificou a existência de dois tipos de atividade durante a produção dos sinais. De acordo com ele, há momentos em que a(s) mão(s) está(ão) em movimento contínuo e há outros em que ela(s) fica(m) estacionada(s).

Ao mensurar os intervalos de tempo em que a(s) mão(s) realiza(m) esses dois tipos de atividade, Liddell constatou um fato que contraria o que normalmente se pensa acerca da sinalização corrente: a(s) mão(s) passa(m) mais tempo parada(s) do que em movimento. Além disso, o autor observou não apenas que existem sinais em que a dinamicidade e a estaticidade se alternam seqüencialmente em sua produção, mas sobretudo que essa alternância se dá em uma ordem fixa.

Como evidência disso, tomemos o sinal AGREE (concordar) (Figura (16)) da ASL. Nesse sinal, é possível notar três momentos de sua articulação:

(i) primeiramente, a mão, configurada em [G], mantém-se estática e em contato com a lateral da testa por alguns instantes;

(ii) na sequiência, essa mão move-se em direção à frente do torso, onde já está a outra mão, estacionada e igualmente configurada;

(iii) por fim, a mão que se moveu da testa pára ao lado da outra mão, voltando a ficar estática por mais alguns instantes. 


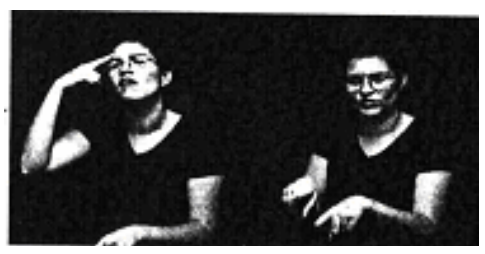

AGREE

Figura (16) Liddell (2003:15)

As observações a respeito da seqüencialidade de realização de diferentes especificações para um mesmo aspecto formacional e as observações referentes à seqüencialidade dos tipos de atividade realizada pela(s) mão(s) na produção dos sinais levaram Liddell à seguinte correlação: a estaticidade da(s) mão(s) corresponde à estabilidade dos aspectos constitutivos dos sinais, enquanto que a sua dinamicidade corresponde à alteração de pelo menos um desses aspectos ${ }^{13}$.

Em um sinal como AGREE (concordar) (Figura (16)), por exemplo, nos dois momentos em que as mãos estão paradas, (i) e (iii), a configuração de mão, a orientação da palma, a localização, entre outros aspectos, apresentam-se estáveis. É somente durante o movimento que a mão faz, de sua posição inicial (lateral da testa) à sua posição final (ao lado da outra mão, em frente ao torso), que alguns desses aspectos variam.

A hipótese de Liddell (1984) e Liddell \& Johnson (2000 [1989]) é a de que esses dois tipos de atividade presentes na articulação dos sinais constituem os dois tipos de segmentos a partir dos quais se estruturam os itens lexicais das línguas sinalizadas. Os autores denominam os segmentos definidos pela ausência de movimento e estabilidade de seus aspectos formacionais de suspensões (holds). Já os segmentos caracterizados pela presença de movimento e pela alteração de pelo menos um dos aspectos que os descrevem são designados como movimentos (movements) ${ }^{14}$.

Aqui cabe ressaltar uma das mais significativas diferenças entre o modelo de Stokoe e seus seguidores, e o modelo de Liddell \& Johnson. Para os primeiros, configuração de mão, localização, orientação da palma e movimento equivalem, em função, aos fonemas das

\footnotetext{
${ }^{13}$ Alguns autores (cf. Hulst, 1993) se baseiam justamente em observações como essa para assumir que movimentos não são elementos fonologicamente relevantes. Entretanto, como se verá mais adiante e como se pode ver em Sandler (1996), há traços que são específicos dos movimentos e que podem ser usados distintivamente pelas línguas sinalizadas, fato que corrobora o seu estatuto fonológico nessas línguas.

${ }^{14}$ Adoto neste trabalho a tradução proposta por Amaral, Coutinho \& Delgado-Martins (1994) para os termos movement e hold.
} 
línguas orais, diferenciando-se destes por serem estruturados e realizados simultaneamente. Para Liddell \& Johnson, os três primeiros aspectos equivalem aos traços articulatórios que constituem conjunta e simultaneamente cada um dos fonemas das línguas sinalizadas (que podem ser do tipo movimento ou suspensão), enquanto que o último deles representa um dos dois tipos de segmentos existentes nessas línguas.

Sendo assim, nos termos da análise de Liddell \& Johnson, tal como na estrutura sublexical das palavras das línguas orais, a simultaneidade e a seqüencialidade estão presentes e desempenham, cada uma, seu papel na fonologia das línguas sinalizadas. Enquanto a simultaneidade é o princípio organizador da estrutura de cada segmento, a seqüencialidade é o princípio organizador da estrutura interna de cada sinal, uma vez que este pode ser constituído de mais de um segmento.

Com base no estatuto fonológico que Liddell \& Johnson dão à sequiêncialidade, é possível levantar a possibilidade de haver nas línguas sinalizadas contrastes lexicais baseados na ordem em que os segmentos são encadeados, assim como se verficam nas línguas faladas (cf. [kæt] 'cat' x [tæk] 'tack'). Nesse sentido, seria possível, por exemplo, encontrar sinais que se distinguissem um do outro unicamente pela ordem do(s) movimento(s) e da(s) suspensão(ões) de que são constituídos.

Embora Liddell \& Johnson não citem casos desse tipo na ASL, identifiquei na língua de sinais brasileira (libras) pares de sinais como o representado pelas figuras em (17).

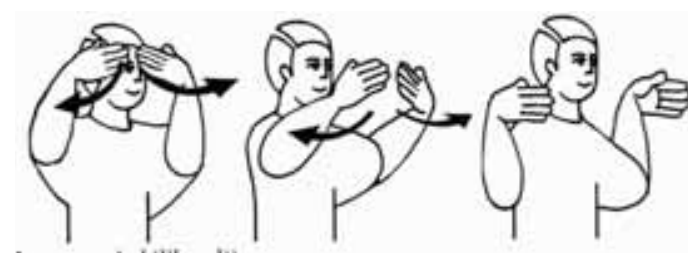

MENTE-ABERTA (p.890)

(a)

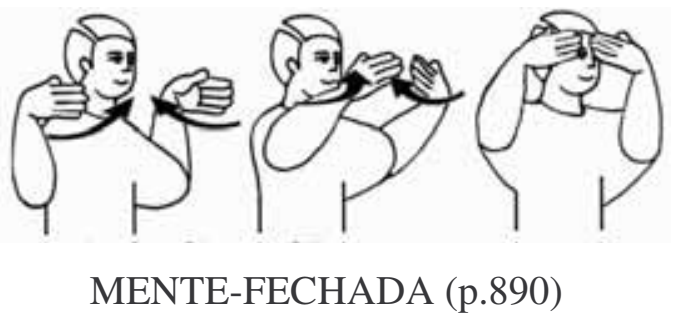

(b)

Figura (17) Capovilla \& Raphael (2001)

Como sugerem as figuras acima, tanto em MENTE-ABERTA quanto em MENTEFECHADA, os traços que descrevem as mãos articulatoriamente são idênticos, ou seja, a configuração, a orientação e a localização das mãos são as mesmas. Porém, a ordem das atividades das mãos (correspondentes ao tipo de segmento que elas realizam) é diferente. 
No primeiro sinal, as mãos, paradas e em contato com a testa, ou seja, em suspensão (S), são giradas pelos pulsos para frente (M). Já no segundo, observa-se exatamente o contrário: as mãos, uma de frente para a outra, movem-se em direção à testa, ou seja, realizam um segmento de movimento $(\mathrm{M})$, onde param e fazem contato, realizando uma suspensão $(\mathrm{S})^{15}$.

Em síntese, nesse par de sinais, o contraste lexical é estabelecido unicamente com base nas diferentes ordens dos segmentos que eles possuem: enquanto em MENTE-ABERTA se tem a seqüência $S$ M, em MENTE-FECHADA observa-se a seqüência M S.

A ocorrência de contraste desse tipo é, sem dúvida, mais uma evidência favorável ao papel da sequiencialidade na fonologia das línguas sinalizadas e contrária a modelos de estrutura fonológica dos sinais que, como o de Stokoe, relegam-na a um segundo plano.

\footnotetext{
${ }^{15}$ Outro par de sinais cujo contraste se estabelece com base na seqüencialidade das atividades da mão é CLARO (p.416) x ESCURO (p.605), dicionarizados em Capovilla \& Raphael (2001) nas páginas indicadas entre parênteses. Nessa mesma obra, foram encontrados também pares de sinais como FUNDAR (p.693) x SUMIR (1) (p.1218) e EMERGIR (p.582) x MERGULHAR (2) (p.893) em que o contraste lexical é estabelecido com base na ordem da especificação de um de seus traços articulatórios, nesses casos, localização.
} 


\section{Capítulo 2: Descrição e representação das propriedades articulatórias dos sinais}

Neste capítulo, apresento a proposta de Liddell \& Johnson (1989) para a descrição e representação de cada uma das propriedades articulatórias dos sinais. Em outras palavras, apresento como os referidos autores tratam cada um dos aspectos dos sinais (configuração de mão, localização, orientação, movimento e marcação não-manual) mencionados no capítulo anterior.

\subsection{O sistema de representação de Liddell \& Johnson}

De acordo com Liddell \& Johnson (1989), para capturar adequadamente os fatos de uma língua, um sistema de representação precisa atender concomitantemente a dois requisitos:

(i) ele deve ser capaz de representar de maneira acurada toda a riqueza dos detalhes envolvidos na produção lingüística e;

(ii) deve ser capaz de expressar a organização desses detalhes.

Embora o sistema de representação proposto para os sinais das línguas sinalizadas pelos referidos autores tente alcançar esses dois objetivos, oferecendo uma conexão entre os aspectos concretos e os aspectos abstratos da organização fonológica dessas línguas, ele o faz, em um primeiro momento, de forma ainda não inteiramente comprometida com qualquer um deles.

Mais precisamente, ele não se compromete totalmente com a representação dos aspectos concretos da realização dos sinais, na medida em que exclui dessa representação diferenças lingüisticamente não-distintivas. Ele tampouco se compromete totalmente com os aspectos abstratos da estrutura dos sinais, uma vez que representa muitas informações redundantes, que análises fonológicas mais refinadas poderão eliminar (cf. Liddell, 1990). 


\subsection{Representação e descrição dos segmentos dos sinais}

Por defenderem que o segmento é a unidade básica sobre a qual se estruturam internamente os sinais das línguas sinalizadas, Liddell \& Johnson (2000 [1989]) desenvolveram, para os itens lexicais dessas línguas, um modelo de representação e descrição segmentais análogo ao desenvolvido para as línguas orais pela Fonogia Gerativa Padrão (Chomsky \& Halle, 1968) e compatível com o seu desdobramento, conhecido como Fonologia Auto-segmental (Goldsmith, 1976).

Como já dito, de acordo com o modelo de Liddell \& Johnson, os sinais das línguas sinalizadas podem ser constituídos por um único segmento, do tipo suspensão ou do tipo movimento, ou por uma sequiência de segmentos desses dois tipos. Tais segmentos, por sua vez, são dotados de uma organização interna que consiste, basicamente, de dois conjuntos ou feixes de traços. Um deles, denominado de feixe segmental, tem a função de especificar a atividade da mão durante a produção de um segmento, mais precisamente, de determinar se a mão está parada ou se movendo. No caso de ela estar se movendo, o feixe determina a forma do movimento. Já o outro feixe, designado de feixe articulatório, é responsável por descrever a postura da mão, ou seja, a sua configuração, localização e orientação.

Em princípio, todos os segmentos das línguas sinalizadas deveriam exibir uma organização interna semelhante, constituída pelos dois tipos de feixes (segmental e articulatório) e representada, nos moldes da Fonologia Gerativa Padrão, por uma matriz de traços. Entretanto, a natureza diferente de suspensões de um lado, e de movimentos de

outro, faz com que as matrizes que os representam sejam distintas. As suspensões se caracterizam pela estaticidade da mão e pela estabilidade dos traços que descrevem a sua postura quando de sua articulação. Por isso, são representadas por meio de uma matriz simples de traços constituída de um único feixe segmental, que determina a ausência de movimento, e de um único feixe articulatório, que determina como a mão está configurada, onde ela está localizada e para que lado está orientada.

Diferentemente, segmentos do tipo movimento são caracterizados pela dinamicidade da mão e pela alteração de algum(s) dos traços que descrevem a sua postura. Por isso, embora segmentos de tal tipo só precisem de um único feixe segmental que os defina como movimentos e que descreva de que forma ocorrem, eles requerem dois feixes articulatórios (um inicial e outro final), nos quais são especificadas as mudanças articulatórias ocorridas 
durante a sua produção.

Segmentos de suspensão são representados como em (1a), enquanto a representação de segmentos de movimento é feita como em (1b).

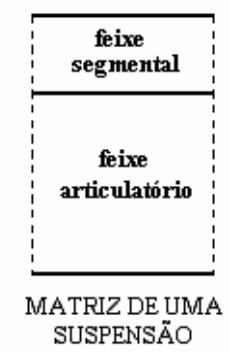

(a)

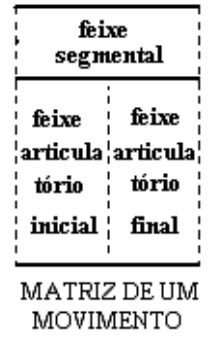

(b)

Representações (1) adaptadas de Liddell \& Johnson (2000:276 [1989])

Liddell \& Johnson observam que segmentos de movimento realizados entre duas suspensões têm suas características articulatórias iniciais e finais idênticas às especificadas nas suspensões que os antecedem e os sucedem, respectivamente. Por esse motivo, em vez de representarem tais seqüências redundantemente (como fariam se utilizassem uma representação como a em (2)), lançam mão de princípios da fonologia auto-segmental, segundo os quais é possível expressar a semelhança entre os feixes articulatórios de um movimento e os das suspensões adjacentes, por meio de linhas de associação, como mostra a representação (3).

\begin{tabular}{|c|c|c|c|}
\hline $\mathbf{S}$ & & & $S$ \\
\hline a & a & b & b \\
\hline
\end{tabular}

Representação (2) adaptada de Liddell \& Johnson (2000:277 [1989]) 


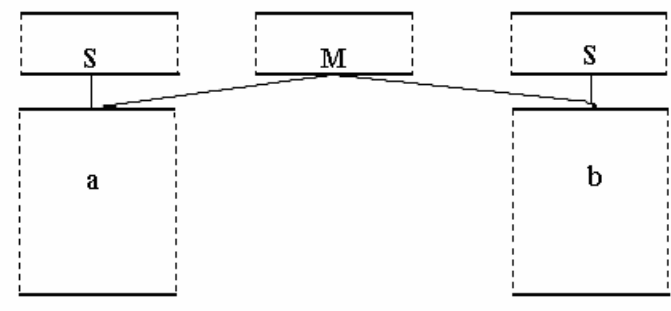

Representação (3) adaptada de Liddell \& Johnson (2000:278 [1989])

É importante frisar que, além de reduzir as redundâncias que uma representação nãoauto-segmental traria, a representação em (3) expressa também a autonomia que as duas diferentes classes de traços apresentam, uma vez que feixes segmentais de diferentes tipos podem se associar a um mesmo feixe articulatório.

O sistema desenvolvido por Liddell \& Johnson prevê ainda uma matriz de traços exclusiva para a representação das marcações não-manuais (expressões faciais e movimentos da cabeça e do torso). Dado o pouco conhecimento que se tem a respeito desse aspecto articulatório e dado o fato que, até onde eu saiba, os autores não desenvolveram um sistema de notação para tal aspecto, neste trabalho não tratarei dele. Como mostrarei no capítulo 3, classifico os sinais que apresentam essa propriedade, mas com vistas a facilitar trabalhos futuros.

Resta dizer que, no caso de sinais produzidos com duas mãos, a(s) atividade(s) de cada uma delas é (são) representada(s) independentemente, ou seja, por meio de uma seqüência de segmentos para cada uma delas. Liddell \& Johnson convencionam representar o segmento ou a sequiência de segmentos que refletem a(s) atividade(s) da mão dominante acima da do segmento ou da seqüência de segmentos que descrevem a(s) atividade(s) da mão não-dominante, como se verá no capítulo 5 .

\subsection{Descrição do feixe segmental}

Os traços que constituem o feixe segmental (traços segmentais) descrevem a atividade da mão. Em outras palavras, eles especificam se ela está ou não se movendo e, se sim, de que maneira. A principal função desses traços é distinguir os dois tipos de segmentos existentes nas línguas sinalizadas, movimentos e suspensões, e, conseqüentemente, 
segmentar o continuиm sinalizado em termos dessas unidades.

De acordo com Liddell \& Johnson, essa hipótese não é completamente distinta da que se faz para as línguas faladas, uma vez que os traços de classe maior, postulados pela teoria fonológica dessas línguas, ao especificarem propriedades fonéticas, como vozeamento espontâneo, interrupção da corrente de ar e silabicidade, distinguem segmentos vocálicos de consonantais e, ao mesmo tempo, permitem a divisão do fluxo da fala com base nesses elementos.

Além de determinarem se um segmento é um movimento ou uma suspensão, os traços do feixe segmental também descrevem detalhes envolvidos em sua produção. O modelo de Liddell \& Johnson prevê cinco diferentes informações (e, conseqüentemente, cinco diferentes subclasses de traços segmentais) que devem ser especificadas no feixe segmental de cada segmento. Essas informações ou traços são denominados:

(i) traços de classe maior;

(ii) traços de contorno de movimento;

(iii) traços de plano de contorno;

(iv) traços de qualidade;

(v) traços de movimentos locais

e representados como em (6):

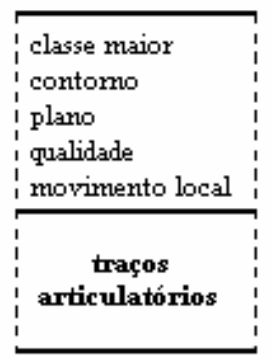

Representação (4) adaptada de Liddell \& Johnson (2000:282 [1989]) 


\subsubsection{Segmentos de classe maior}

Os traços de classe maior caracterizam os segmentos das línguas sinalizadas como movimentos ou suspensões. Segmentos definidos como movimento são caracterizados pela dinamicidade da mão e pela alteração de pelo menos um dos traços articulatórios que a caracteriza. Segmentos definidos como suspensão, por sua vez, são caracterizados pela estaticidade da mão e pela estabilidade de todos os traços que a definem articulatoriamente.

A ocorrência de segmentos desses dois tipos em um mesmo item lexical pode ser ilustrada por um sinal como FILHO da libras, representado pela figura abaixo:

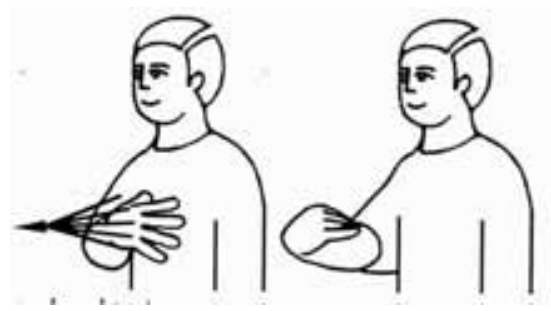

FILHO

Figura (18) Capovilla \& Raphael (2001:668)

Como a ilustração sugere, a realização de tal sinal depende da coordenação de três atividades da mão:

(i) Primeiramente, a mão, aberta e com os dedos espalmados, fica parada e em contato com a região central do peito, por um brevíssimo intervalo de tempo.

(ii) Na seqüência, a mão se move horizontalmente para a frente. Durante esse movimento, além da alteração da sua localização, a configuração da mão também muda, pois os dedos, inicialmente disdendidos e separados uns dos outros, começam a se fechar.

(iii) Finalmente, a mão, com todos os dedos dobrados nas juntas proximais e contactando a almofada do polegar, pára em um ponto alguns centímetros à frente de sua posição inicial e se mantém aí por um breve intervalo de tempo.

Com base nessa observação e nos tipos de segmentos propostos por Liddell \& Johnson, pode-se entender a primeira e a última atividade da mão na produção do sinal FILHO como 
correspondentes à realização de segmentos de suspensão. Já a atividade intermediária pode ser vista como a realização de um segmento de movimento.

Tomando por base um segmento de movimento como o presente no sinal FILHO, descrito acima, poder-se-ia pensar que segmentos desse tipo são necessariamente realizados por meio de um deslocamento da mão entre dois pontos no espaço de sinalização. Entretanto, há movimentos, também caracterizados pelo dinamismo da mão e pela alteração de algum(s) de seus traços articulatórios, que não se realizam através de um deslocamento.

Liddell \& Johnson designaram movimentos desse último tipo de movimentos sem trajetória (non-path movements), em contraste com movimentos do tipo identificado no sinal FILHO, que denominaram movimentos com trajetória (path movement). De acordo com os autores, movimentos do primeiro tipo se caracterizam pela ocorrência de mudança de configuração de mão e/ou de orientação da palma, enquanto os movimentos do último tipo se caracterizam necessariamente pela mudança na localização da(s) mão(s).

Os sinais LEITE e BRANCO (1) ${ }^{16}$, representados pelas figuras (19) e (20), respectivamente, ilustram casos de sinais constituídos de movimento com e sem trajetória, respectivamente.

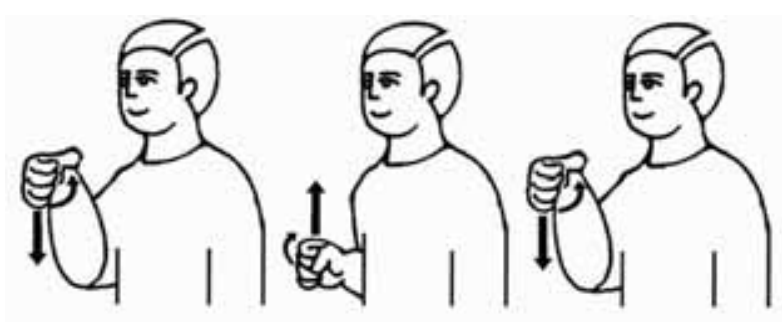

\section{LEITE}

A realização do sinal LEITE da libras consiste em mover a mão, por duas vezes, de uma posição alguns centímetros à frente do peito ipsilateral do sinalizador para uma posição paralela a esta, mas à altura do abdômen. Como sugere a figura acima, ao longo desse movimento, a mão muda sua configuração, passando de $[\mathrm{C}]$ a $[\mathrm{S}]$.

Figura (19) Capovilla \& Raphael (2001:806)

\footnotetext{
${ }^{16} \mathrm{O}$ número (1) pode ser considerado como parte do nome do sinal, uma vez que, no dicionário de Capovilla \& Raphael (2003), numeram-se as entradas sempre que existe mais de um sinal com a mesma tradução em português.
} 

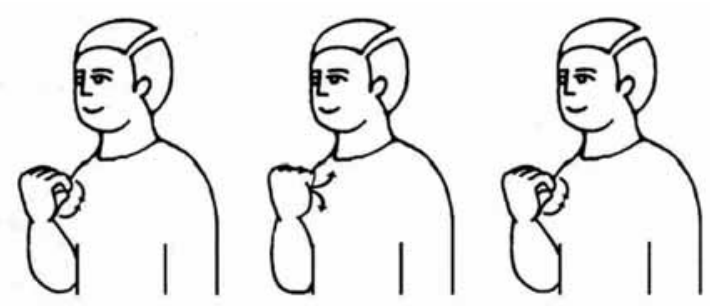

BRANCO (1)

O sinal BRANCO (1) da libras é produzido por meio de um movimento que, repetido por duas vezes, fecha completamente a mão, semi-fechada e orientada para dentro, de maneira a configurá-la em [S].

Figura (20) Capovilla \& Raphael (2001:314)

Embora, aparentemente, a oposição movimento com trajetória x movimento sem trajetória seja a principal responsável pela diferença de significados entre os sinais LEITE e BRANCO (1) ${ }^{17}$, o modelo de Liddell \& Johnson sugere uma outra interpretação desses dados.

Assumindo uma mesma estrutura para esses sinais, a saber, M S M S ${ }^{18}$, a diferença entre eles pode ser explicada em termos das suas especificações para o traço articulatório localização. No sinal LEITE, como indica a representação a seguir, pode-se dizer que os segmentos de movimento e os de suspensão são diferentemente especificados para a localização: os movimentos são iniciados na altura do peito ipsilateral e as suspensões são produzidas na altura do abdômen.

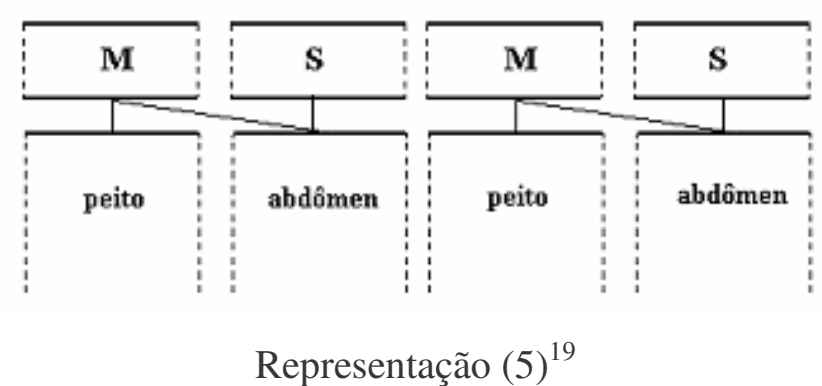

\footnotetext{
${ }^{17}$ Como mostram as figuras (19) e (20), os sinais LEITE e BRANCO (1) também diferem na orientação da mão, uma vez que, no primeiro sinal, a palma está voltada para o lado contralateral do sinalizador, enquanto, no segundo, ela está voltada para dentro. Entretanto, essa diferença foi deixada de lado por não ser relevante para a discussão.

${ }^{18}$ Estou ignorando o movimento que leva a mão à posição inicial para a repetição do movimento e da suspensão, por considerá-lo transicional, ou seja, por não atribuir a ele estatuto de segmento integrante do sinal. Para uma discussão sobre os movimentos transicionais, ver capítulo 5.

${ }^{19}$ Os traços do feixe articulatório serão notados informalmente até que sejam apresentados e explicados um a um.
} 
Já o sinal BRANCO (1), conforme expressa a representação em (8), apresenta tanto os segmentos de movimento quanto os de suspensão igualmente especificados no que diz respeito ao traço que descreve sua localização: [peito].

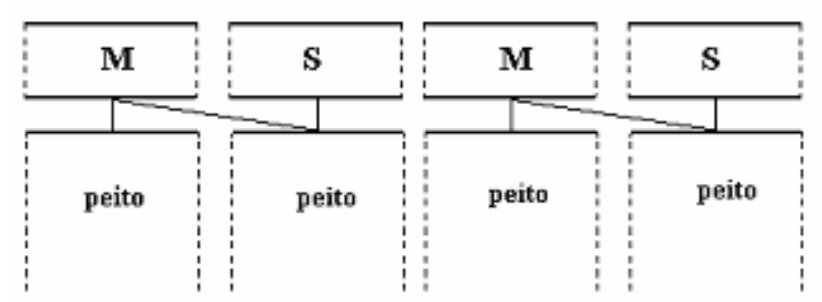

Representação (6)

Nessa perspectiva, a diferença entre movimentos com e sem trajetória é, na verdade, uma decorrência das especificações dos traços que caracterizam o lugar (ou os lugares, no caso dos movimentos) em que um determinado segmento é articulado, não havendo, portanto, necessidade de qualquer tipo de traço exclusivamente concebido para distinguir esses dois tipos de movimento encontrados nos sinais.

A mesma análise pode ser usada para explicar o contraste entre o tipo de movimento presente em sinais como OUTRO e OUTRA-VEZ, representados pelas figuras a seguir.

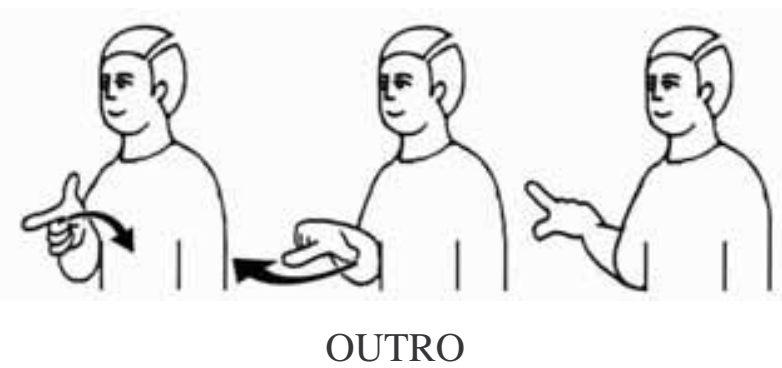

O sinal OUTRO da libras é realizado com uma só mão, configurada de forma que o indicador e o polegar apareçam distendidos, posicionada em frente ao peito ipsilateral e com a palma orientada para o lado. Nesse sinal, a mão se move em direção ao lado do ombro ipsilateral, voltando a sua palma para baixo.

Figura (21) Capovilla \& Raphael (2001:987) 


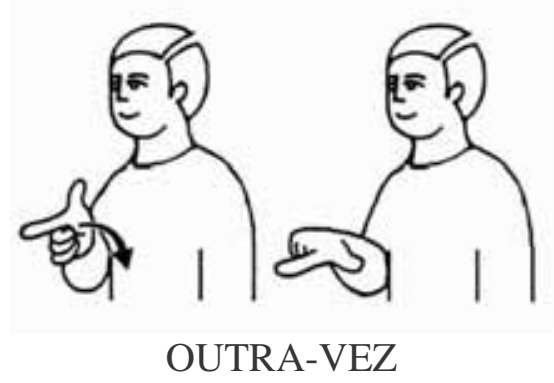

O sinal OUTRA-VEZ da libras é articulado com uma só mão, com o indicador e o polegar distendidos, posicionada em frente ao peito ipsilateral e com a palma orientada para o lado. O pulso gira, voltando a palma da mão para baixo.

Figura (22) Capovilla \& Raphael (2001:987)

Com base nas figuras e nas descrições acima, pode-se atribuir aos sinais OUTRO e OUTRA VEZ as representações em (9) e (10), respectivamente. Essas representações capturaram, tal como no par LEITE x BRANCO, a diferença no tipo de movimento que cada um dos sinais apresenta: com trajetória, no caso de OUTRO, e sem trajetória, no caso de OUTRA-VEZ.

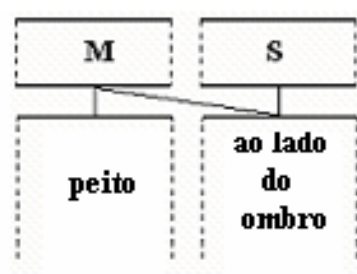

Representação (7)

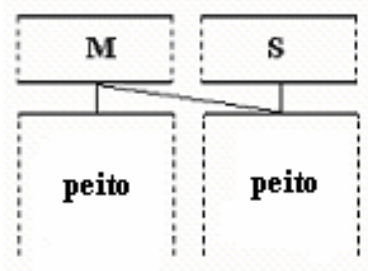

Representação (8)

É interessante notar que, além de movimentos com e sem trajetória, as especificações de localização também derivam o movimento alternado das mãos em certos sinais. Em outras palavras, para Liddell \& Johnson, não há necessidade de existir um traço que 
determine um ou outro tipo de movimento ${ }^{20}$, dado que eles podem ser derivados das especificações inicial e final do segmento de movimento.

A título de ilustração, cito os sinais DESCONFIAR (Figura (23)) e PSICOLOGIA (1) (Figura (24)) da libras (realizados com duas mãos e representados no modelo de Liddell \& Johnson por meio de duas seqüências paralelas de segmentos, uma para cada mão) que constrastam basicamente por ser o primeiro realizado com movimento simultâneo, enquanto o segundo é articulado com movimento alternado ${ }^{21}$.

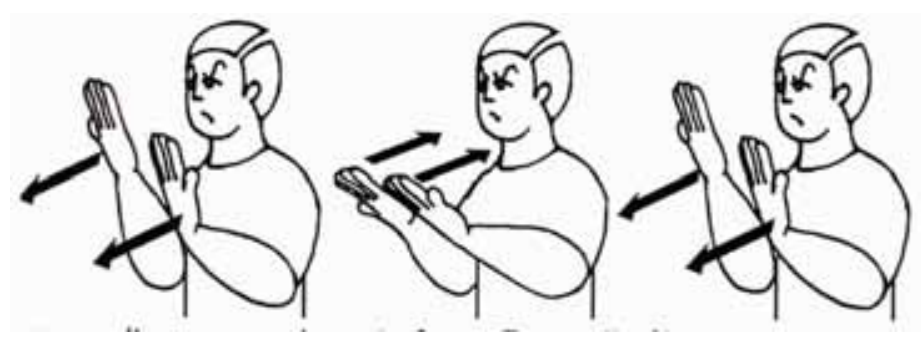

DESCONFIAR

Figura (23) Capovilla \& Raphael (2001: 522)

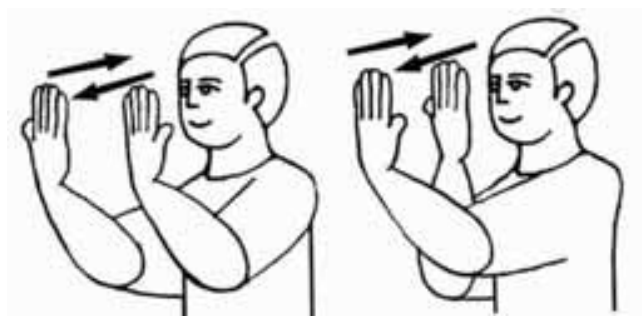

PSICOLOGIA (1)

Figura (24) Capovilla \& Raphael (2001:1093)

Para diferenciar esses sinais, Liddell \& Johnson procedem da seguinte forma. Eles representam sinais semelhantes a DESCONFIAR com suas especificações para localizações inicial e final idênticas e pareadas, tal como mostra a representação a seguir.

\footnotetext{
${ }^{20}$ Para uma crítica à inexistência de um traço que caracteriza movimentos alternados ver Padden \& Perlmutter (1987). Agradeço a sugestão dessa leitura ao Prof. Dr. Sherman Wilcox.

${ }^{21}$ Por não ser relevante para a discussão, estou ignorando a marcação não-manual que o sinal DESCONFIAR apresenta, de acordo com a descrição do dicionário.
} 


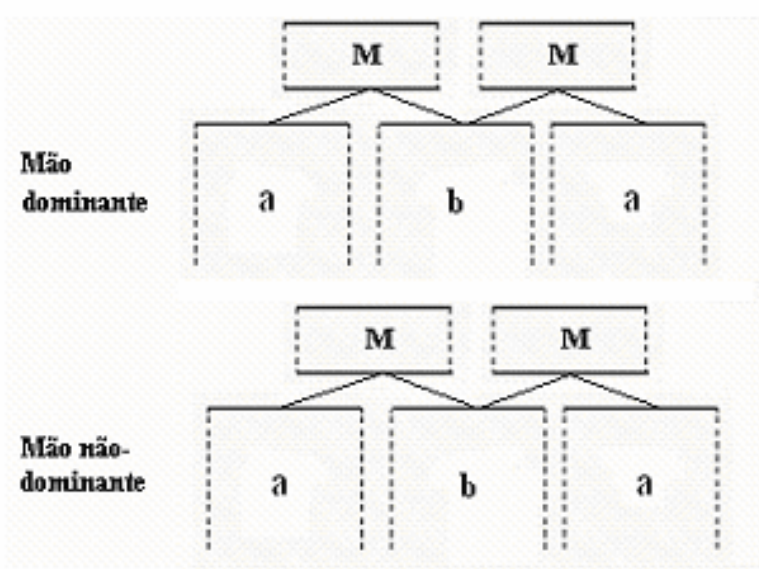

Representação (9) inspirada em Liddell \& Johnson (2000:282 [1989])

Em contraste, representam sinais como PSICOLOGIA (1) com suas especificações para localização inicial e final idênticas, mas invertidas, como se pode ver na representação a seguir $^{22}$.

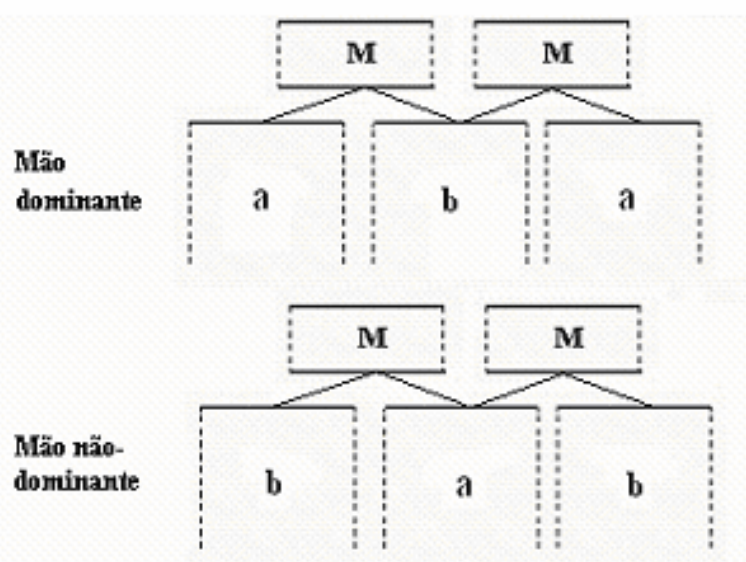

Representação (10) adaptada de Liddell \& Johnson (2000:282 [1989])

\subsubsection{Contornos de movimento}

Por observarem que movimentos com trajetória podem ser realizados por meio de diferentes contornos, e que essas diferenças podem ser usadas distintivamente pelas línguas

\footnotetext{
${ }^{22}$ Tanto o sinal DESCONFIAR quanto o sinal PSICOLOGIA (1) são reduplicados, ou seja, têm seus movimentos realizados duas vezes. Como isso não é relevante para a discussão, a representação só mostra a primeira parte de cada sinal.
} 
sinalizadas $^{23}$, Liddell \& Johnson incluem, entre os traços segmentais, traços que descrevem o deslocamento da mão de um ponto a outro no espaço de sinalização. Esses traços, designados pelos autores como traços de contorno de movimento, podem ser de dois tipos: reto [str] (straight) ou circular [rnd] (round).

Movimentos especificados com o traço de contorno reto [str] são realizados através de um deslocamento retilíneo da mão. Um exemplo de sinal constituído por um movimento descrito por tal traço é o sinal PRESIDENTE da libras, ilustrado pela figura abaixo.

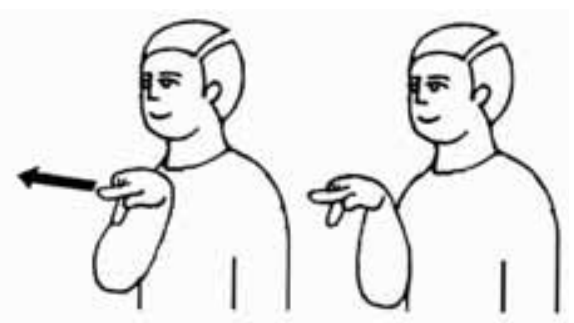

PRESIDENTE

Figura (25) Capovilla \& Raphael (2001:1078)

Como se pode observar na figura (25), nesse sinal, a mão se move retilineamente de um ponto alguns centímetros à frente da região central do peito, a outro na mesma altura, mas localizado à direita e ao lado do ombro ipsilateral.

Já os movimentos especificados com o traço de contorno circular [rnd] podem ser realizados de duas maneiras diferentes: circular propriamente dita, caso em que a mão delineia um círculo completo; ou arqueada, situação em que a mão se desloca formando um arco. Liddell \& Johnson afirmam que essas duas formas são realizações do mesmo traço de contorno, pois assumem que as formas 'circular propriamente dita' e 'arqueada' são decorrentes das especificações dos traços articulatórios de localização que caracterizam o início e o fim do movimento. Movimentos cujos traços de localização inicial e final coincidem produzem contornos no formato de um círculo completo, ao passo que movimentos cujos traços de localização inicial e final são diferentes realizam-se de uma forma arqueada.

\footnotetext{
${ }^{23}$ Sandler (1996:202) cita os sinais YOU (você), GO (ir) e INSULT (insultar) da ASL como evidência de que o contorno do movimento é usado contrastivamente nessa língua. Segundo a autora, os três sinais são realizados com a mão configurada em [G] e orientada para a esquerda e com um movimento para frente. Entretanto, no caso do sinal YOU (você), o movimento é reto; no caso do sinal GO (ir), arqueado-côncavo e, por fim, no caso do sinal INSULT (insultar), arqueado-convexo.
} 
Sendo assim, tanto sinais como SHOPPING-CENTER (Figura (26)) quanto sinais como PROFESSOR (Figura (27)) têm seu movimento especificado pelo mesmo traço de contorno [rnd].

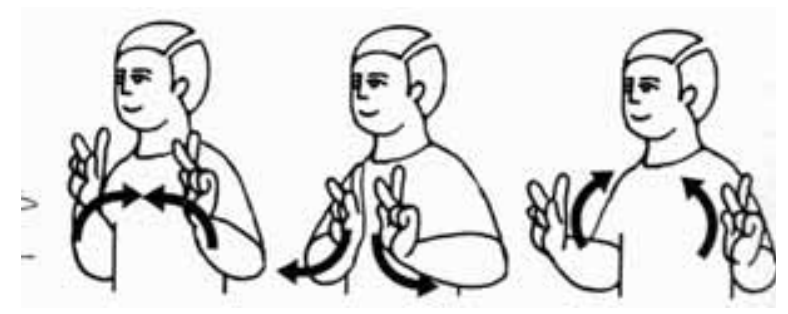

SHOPPING-CENTER

Figura (26) Capovilla \& Raphael (2001:1196)

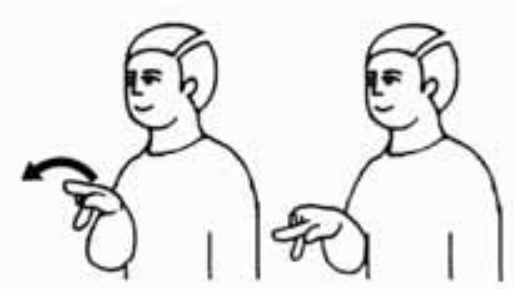

PROFESSOR

Figura (27) (Capovilla \& Raphael, 2001:1084) ${ }^{24}$

É interessante observar que, mais uma vez, o traço de localização deriva a realização de um determinado tipo de movimento, pois, no caso de SHOPPING-CENTER, o que determina que a forma do movimento delineia um círculo completo é o fato de tal movimento começar e terminar no mesmo ponto, ou seja, de apresentar a mesma especificação para o traço de localização tanto na sua fase inicial quanto na sua fase final.

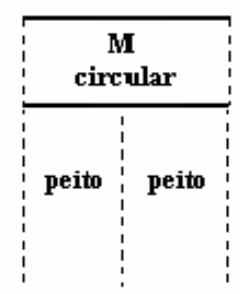

Representação (11)

\footnotetext{
${ }^{24}$ Observa-se que, neste sinal, o movimento circular é repetido por duas vezes.
} 
Diferentemente, no caso do sinal PROFESSOR, o que determina a forma arqueada do movimento são as diferentes especificações para os traços de localização que descrevem as fases inicial e final desse segmento. Como indicam a figura (27) e a representação a seguir, nesse sinal, a mão começa seu deslocamento em um ponto alguns centímetros à frente do esterno e o finaliza em um ponto localizado na mesma altura, mas à direita e ao lado do ombro ipsilateral.

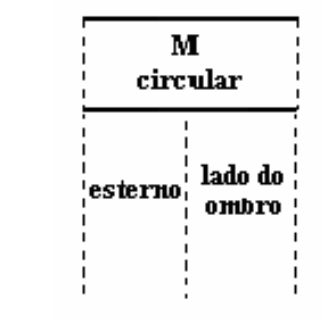

Representação $(12)^{25}$

\subsubsection{Planos de contorno}

De acordo com o modelo de Klima \& Bellugi (1979), sinais como TELEVISÃO (Figura (28)) e TRABALHAR (Figura (29)) da libras podem ser analisados como um exemplo de par mínimo no qual o contraste semântico se estabelece basicamente por meio do plano em que o movimento é realizado: vertical no caso do primeiro sinal e horizontal no caso do segundo, como se pode ver nas figuras abaixo.

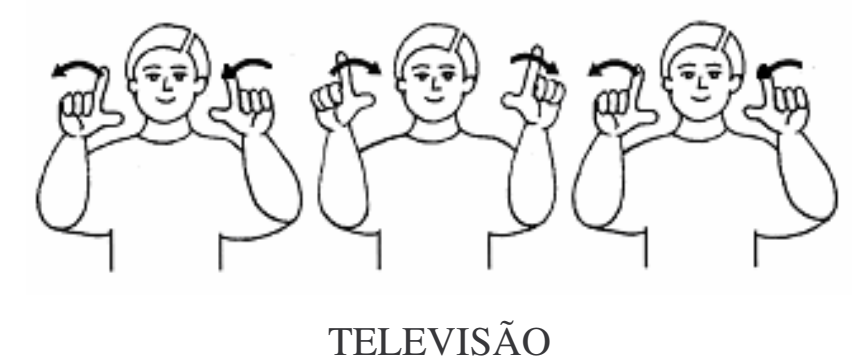

Figura (28) Capovilla \& Raphael (2001:1238)

\footnotetext{
${ }^{25}$ No caso do sinal PROFESSOR, estou ignorando a estrutura segmental completa do sinal e considerando apenas o segmento de movimento constitutivo desse sinal, dada a sua relevância para a discussão neste momento.
} 


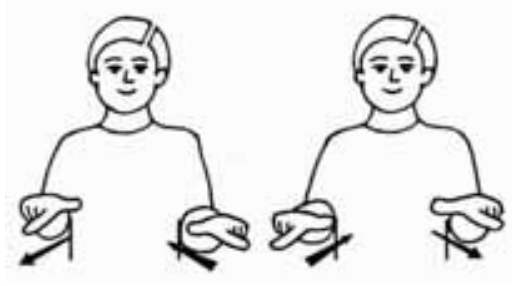

TRABALHAR

Figura (29) Capovilla \& Raphael (2001:1263)

Entretanto, a análise de Liddell \& Johnson trata sinais como esses de forma diferente. Os autores defendem que sinais que apresentam contorno do movimento reto [str] (straight) têm seu plano derivado de suas localizações inicial e final. Por isso, atribuem a elas -- e não ao plano em que o movimento é produzido, como fazem Klima \& Bellugi -- a responsabilidade pelo contraste lexical.

Essa explicação funciona bem para movimentos descritos pelo traço de contorno reto [str]. Porém, como reconhecem os próprios autores, ela não é satisfatória para a descrição de movimentos especificados com o traço circular [rnd] (round). Tendo em vista que um movimento arqueado, por exemplo, que leva a mão de um ponto a outro, pode fazê-lo, pelo menos teoricamente, tanto por meio de um movimento no plano vertical quanto por meio de um movimento no plano horizontal, Liddell \& Johnson afirmam que é necessário especificar o plano em que a mão se desloca sempre que o movimento não for descrito pelo traço de contorno reto [str].

De acordo com Liddell \& Johnson, os movimentos caracterizados pelo traço de contorno circular [rnd] podem ser realizados em cinco planos diferentes, como sumariza e exemplifica o quadro a seguir.

\section{Quadro (1)}

\begin{tabular}{|c|c|c|}
\hline \multicolumn{3}{|c|}{ Planos de contorno de movimento na libras } \\
\hline plano & descrição & exemplos de sinais \\
\hline $\begin{array}{c}\text { [HP] (horizontal } \\
\text { plane): plano } \\
\text { horizontal }\end{array}$ & paralelo ao chão \\
\hline
\end{tabular}




\begin{tabular}{|c|c|c|}
\hline $\begin{array}{l}{[\mathrm{VP}](\text { vertical }} \\
\text { plane }) \text { : plano } \\
\quad \text { vertical }\end{array}$ & $\begin{array}{l}\text { paralelo à frente do } \\
\text { torso }\end{array}$ & $\begin{array}{c}\text { COMPUTADOR } \\
\text { Figura (31) (Capovilla \& Raphael, } 2001: 440)\end{array}$ \\
\hline $\begin{array}{l}\text { [SP] (superficial } \\
\text { plane): plano de } \\
\text { superfície }\end{array}$ & $\begin{array}{l}\text { paralelo à superfície } \\
\text { de uma localização } \\
\text { sobre o corpo ou } \\
\text { sobre a mão }\end{array}$ & Figura (33) (Capovilla \& Raphael, 2001:975) \\
\hline $\begin{array}{l}\text { [PO] (oblique } \\
\text { plane): plano } \\
\text { oblíquo }\end{array}$ & $\begin{array}{l}\text { plano horizontal, mas } \\
\text { inclinado para cima e } \\
\text { para fora do corpo }\end{array}$ & $\underset{\text { FUTURO }}{\text { Figura (34) }} \underset{\text { (Capovilla \& Raphael, 2001:697) }}{ }$ \\
\hline $\begin{array}{l}\text { [MP }] \text { (midline } \\
\text { plane): } \\
\text { plano da linha } \\
\text { medial }\end{array}$ & $\begin{array}{l}\text { Plano que inteseccio- } \\
\text { na o plano superficial } \\
\text { ao longo da linha } \\
\text { meso-sagital do corpo } \\
\text { ou o plano ao longo } \\
\text { da linha medial dos } \\
\text { ossos do braço ou da } \\
\text { mão }\end{array}$ & Figura (35) (Capovilla \& Raphael, 2001:) \\
\hline
\end{tabular}


Uma outra proposta de descrição dos planos em que o movimento pode ser realizado é oferecida por Capovilla \& Sutton (2001:84-98) ${ }^{26}$. Os autores recorrem aos conceitos de eixos $\mathrm{X}, \mathrm{Y}$ e Z e, a partir deles, definem planos em que as mãos podem se deslocar.

De acordo com Capovilla \& Sutton, o eixo X representa a lateralidade do espaço de sinalização e seus pontos permitem descrever a localização inicial e a final de sinais em que a(s) mão(s) se move(m) da direita para esquerda ou vice-versa. O eixo Y, por sua vez, representa a altura do espaço de sinalização e, com base nele, se pode precisar os pontos inicial e final de movimentos que se realizam de cima para baixo ou de baixo para cima. Por fim, o eixo $\mathrm{Z}$ representa a profunididade do espaço de sinalização e os seus pontos permitem descrever as localizações inicial e final de movimentos para frente ou para trás.

Nessa perspectiva, o plano em que movimentos podem ser produzidos é derivado da composição de dois eixos e, segundo os autores, podem ser XY (lateralidade - altura), XZ (lateralidade - profundidade) e YZ (altura - profundidade), como indica a figura a seguir.

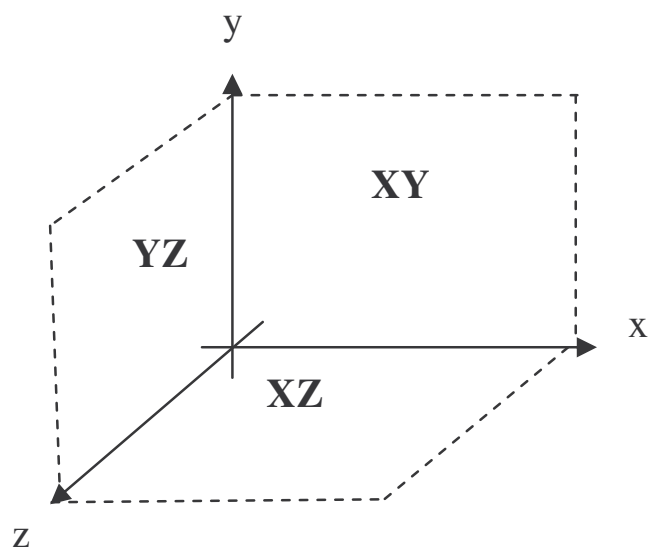

Figura (36)

Há também a possibilidade de as mãos se deslocarem em um plano tridimensional, ou seja, definido pela composição dos três eixos: XYZ.

Essa proposta é bastante interessante porque ela, assim como a de Liddell \& Johnson, é capaz de representar todos os planos em que os sinais podem ser produzidos. Além disso, ela parece ser mais elegante e mais econômica por descrever todos esses planos através de quatro combinações dos eixos X, Y e Z, a saber XY, XZ, YZ e XYZ, prescindindo do plano

\footnotetext{
${ }^{26}$ Agradeço ao Prof. Dr. Fernando César Capovilla, membro da banca de qualificação, por me sugerir a leitura deste artigo.
} 
de superfície $[\mathrm{SP}]^{27}$.

\subsubsection{Traços de qualidade}

Traços de qualidade são aqueles que capturaram aspectos relacionados à duração e à extensão dos movimentos, bem como à possibilidade de ocorrer contato com alguma parte do corpo durante a sua produção. Segundo Liddell \& Johnson, essa categoria se divide em três subclasses: traços de qualidade temporal, traços de qualidade não-temporal e contato.

Os traços de qualidade temporal determinam o tempo de realização de um sinal. Esse tempo pode ser descrito pelos traços prolongado [long] (prolonged), acelerado [acc] (accelerating) ou reduzido [short] (short). Embora em Capovilla \& Raphael (2001) não tenham sido encontrados sinais cuja descrição incluísse (ou, pelo menos, sugerisse) o traço reduzido [short], a descrição de alguns itens lexicais da libras sugere a presença dos traços prolongado [long] e acelerado [ace] como propriedades definidoras da forma de seu movimento. Como ilustração disso, pode-se citar o sinal DEMORAR (Figura (37)), em que o movimento é descrito como sendo produzido de forma prolongada, e o sinal RÁPIDO (Figura (38)), descrito como tendo um movimento realizado de maneira acelerada.

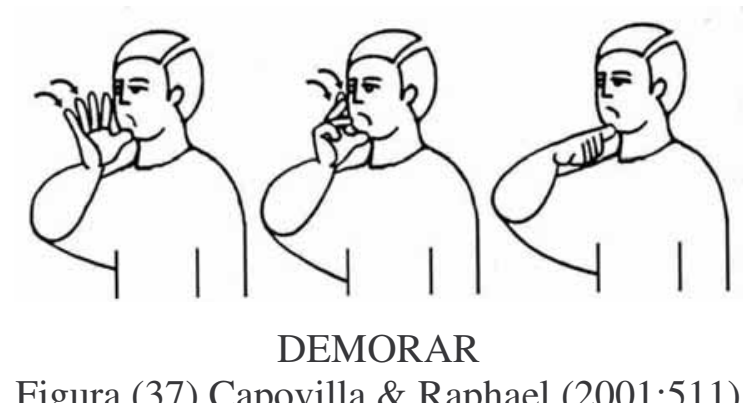

${ }^{27}$ Agradeço a Alexander Nogueira Xavier pela discussão a respeito desta questão. 


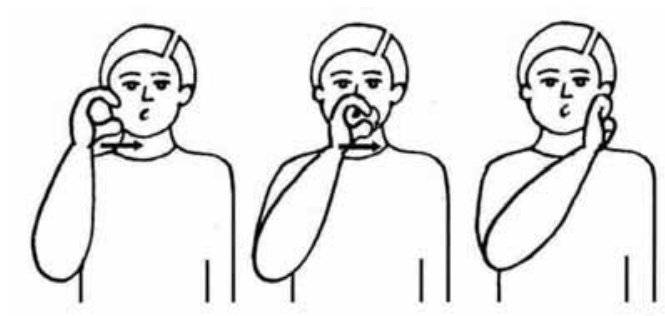

RÁPIDO

Figura (38) Capovilla \& Raphael (2001:1115)

Os traços de qualidade não-temporal, por sua vez, referem-se à extensão (longa ou curta) do movimento e à tensão [tns] (tense) que a mão apresenta quando da articulação de um sinal. De forma geral, o dicionário de Capovilla \& Raphael não faz menção explícita à extensão do movimento. Entretanto, quando parece ser relevante, a tensão da mão é incluída.

Como exemplo disso, pode-se citar o sinal OBRIGAÇÃo (1) (Figura (39a)), que não apenas indica a necessidade do traço tenso [tns] para descrever precisamente o movimento realizado pela mão, mas também sugere, se comparado ao sinal PAGAR, ilustrado em (Figura (39b)), a possibilidade de a libras fazer uso fonológico desse traço. O sinal OBRIGAÇÃO (1) só difere de PAGAR por apresentar tensão na mão durante a realização do movimento e expressão facial "negativa", ao longo de toda a articulação do sinal, como ilustram as figuras a seguir.

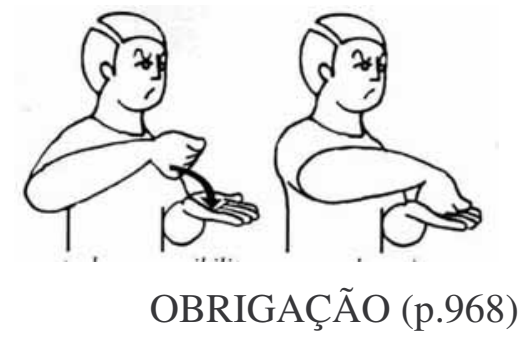

(a)

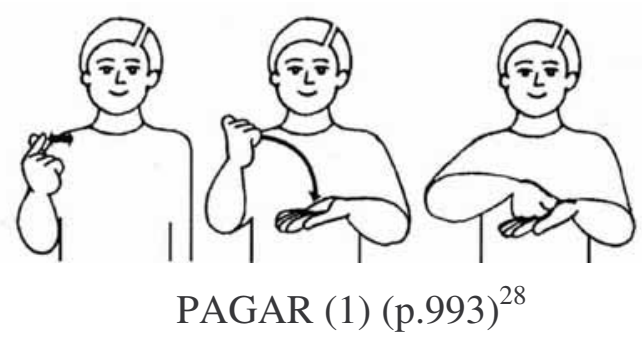

(b)

Figura (39) Capovilla \& Raphael (2001)

Por fim, o traço contato [contact] tem a função de indicar se a mão toca a outra mão ou alguma parte do corpo durante o movimento. Mais especificamente, esse traço descreve os

\footnotetext{
${ }^{28}$ Embora o sinal PAGAR seja dicionarizado como um composto (DINHEIRO + sinal não dicionarizado isoladamente), considero aqui a forma simples (constituída apenas da segunda parte, ou seja, sem o sinal DINHEIRO) que é o que é relevante para a presente discussão.
} 
chamados movimentos de roçar ${ }^{29}$ (brushing movements), nos quais a mão faz um contato com alguma região localizada entre os dois pontos em que ela se desloca.

O sinal PROIBIR, ilustrado pela figura (40), exemplifica um caso de movimento de roçar na libras. Como sugere a ilustração abaixo, a mão ativa, posicionada acima da mão passiva, descreve um movimento arqueado para baixo e para a direita, durante o qual ela toca rapidamente a ponta do indicador da mão passiva.

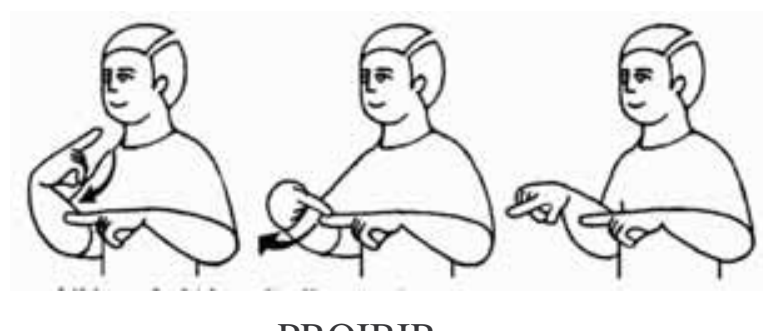

PROIBIR

Figura (40) Capovilla \& Raphael (2001:1086)

\subsubsection{Movimentos locais}

Como se viu na seção 2.3.1, a distinção entre suspensões e movimentos se faz a partir da estaticidade e da dinamicidade da mão. Nesse momento, a mão é tomada como um todo. Entretanto, é muito comum encontrarem-se sinais que apresentam movimentos realizados pelos dedos ou pelo pulso.

Por observarem que esses movimentos ocorrem simultaneamente à atividade principal da mão, ou seja, à realização de suspensões e de movimentos, e por observarem que todos eles se caracterizam como movimentos rápidos, repetidos e, em geral, incontáveis, Liddell \& Johnson os reuniram em uma classe de traços segmentais que denominaram movimentos locais.

Para evidenciar que os movimentos locais constituem uma classe separada de traços, e que sua inclusão entre os traços que descrevem os segmentos das línguas sinalizadas é necessária por conta do papel distintivo que eles podem assumir, pode-se citar o par ANUNCIAR x ELETRICIDADE ${ }^{30}$, ilustrado pelas figuras em (41).

\footnotetext{
${ }^{29}$ Tradução sugerida pelo Prof. Capovilla durante sua arguição deste trabalho.

${ }^{30} \mathrm{O}$ sinal ELETRICIDADE, embora representado pela figura como um sinal realizado com apenas uma mão, também pode ser realizado com as duas, igualmente especificadas para todos os traços segmentais e
} 


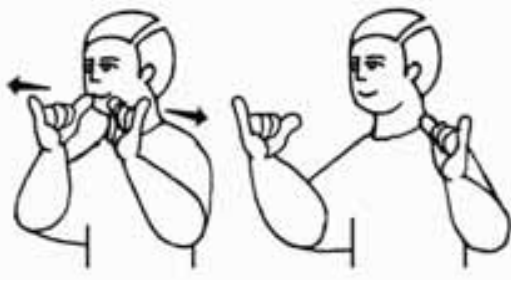

ANUNCIAR (p.204)

(a)

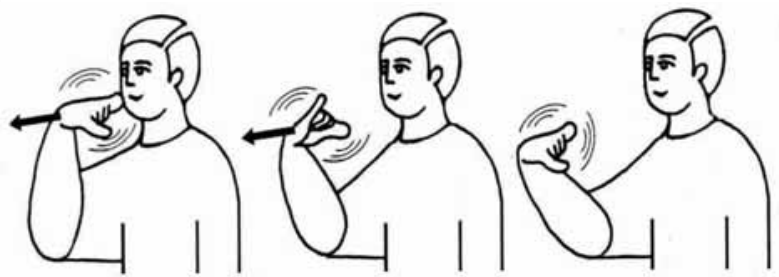

ELETRICIDADE (p.575)

(b)

Figura (41) Capovilla \& Raphael (2001)

Com base nas figuras acima, pode-se dizer que os movimentos locais são independentes do movimento principal de cada mão (correspondente à realização de um segmento de movimento), em razão de esse movimento poder ser realizado com (cf. ELETRICIDADE) ou sem eles (cf. ANUNCIAR). Já em relação ao caráter distintivo que movimentos locais podem assumir em uma língua sinalizada, pode-se evidenciá-lo por meio do mesmo par de sinais em (41), uma vez que o contraste entre eles se estabelece com base na presença, em ELETRICIDADE, versus na ausência, em ANUNCIAR, de movimentos desse tipo.

É importante dizer que movimentos locais não são traços segmentais que caracterizam apenas segmentos de movimento. Há também suspensões dotadas desse traço. Como exemplo disso, pode-se citar o sinal Ç (Figura (42). Nesse sinal, observa-se que à atividade principal da mão (correspondente à realização de uma suspensão, dado que a mão está parada), sobrepõem-se rotações rápidas, repetidas e incontáveis do pulso.

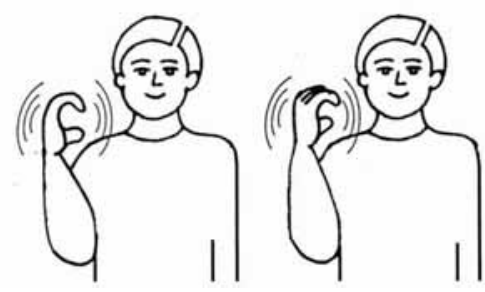

Ç

Figura (42) Capovilla \& Raphael (2001:327)

É interessante dizer ainda em relação a esse sinal que ele forma com o sinal C (figura (42)) um par mínimo perfeito, fato que reforça ainda mais o uso fonológico que a libras faz do traço em questão.

articulatórios. É nessa versão que ele forma um par mínimo perfeito com o sinal ANUNCIAR, dado que só se distingue deste último por apresentar movimento local concomitantemente ao seu movimento com trajetória. 


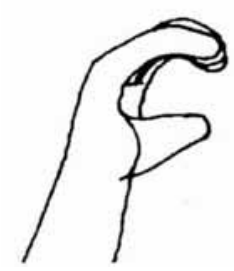

Figura (43) Capovilla \& Raphael (2001:327)

De acordo com Liddell \& Johnson, a classe dos movimentos locais se constitui de oito tipos diferentes. A descrição e a exemplificação de ocorrência desses movimentos em segmentos de suspensão e de movimento de sinais da libras são apresentadas no quadro a seguir.

Quadro (2)

\section{Tipologia dos movimentos locais}

[wg] (wiggling): tamborilar - descreve retrações rápidas e seqüencialmente alternadas da junta proximal dos dedos distendidos.

[circ] (circling): circular - define movimentos circulares repetidos e incontáveis.




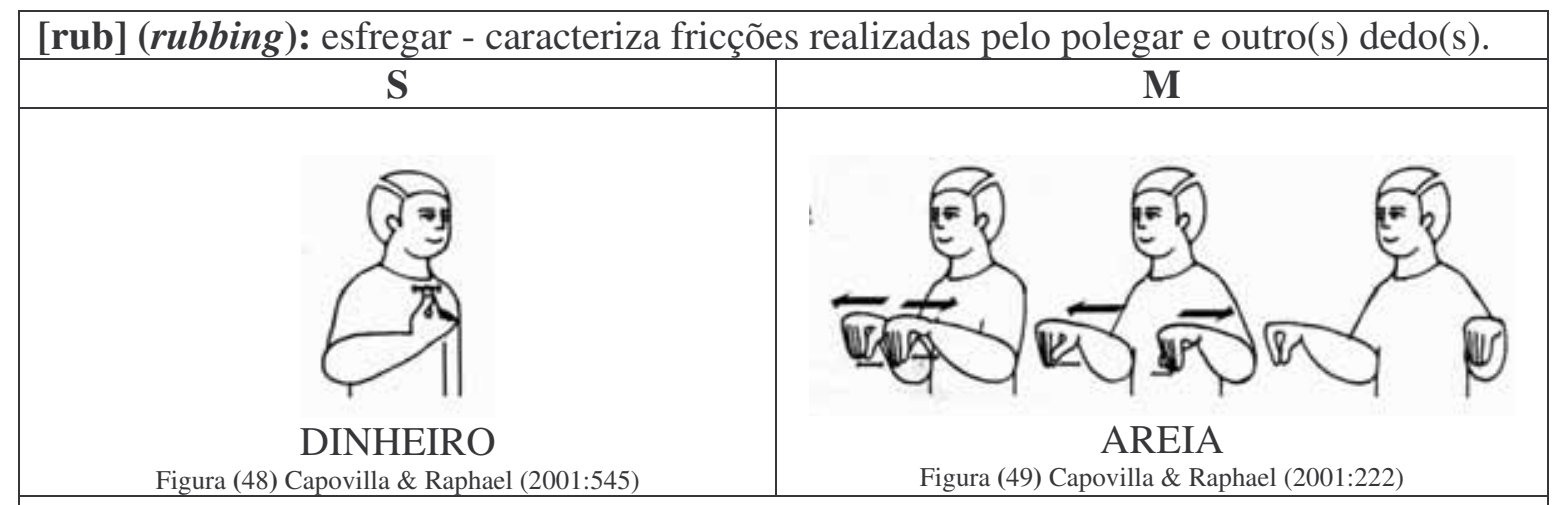

[hk] (hooking): dobrar junta(s) distal(is) - descreve retrações repetidas da(s) junta(s) distal(is) do(s) dedo(s) distendido(s) na(s) junta(s) proximal(is).

(2001:726)

[fl] (flattening): achatar - define retrações rápidas, simultâneas e repetidas da junta proximal de todos os dedos estendidos nas juntas medial e distal.

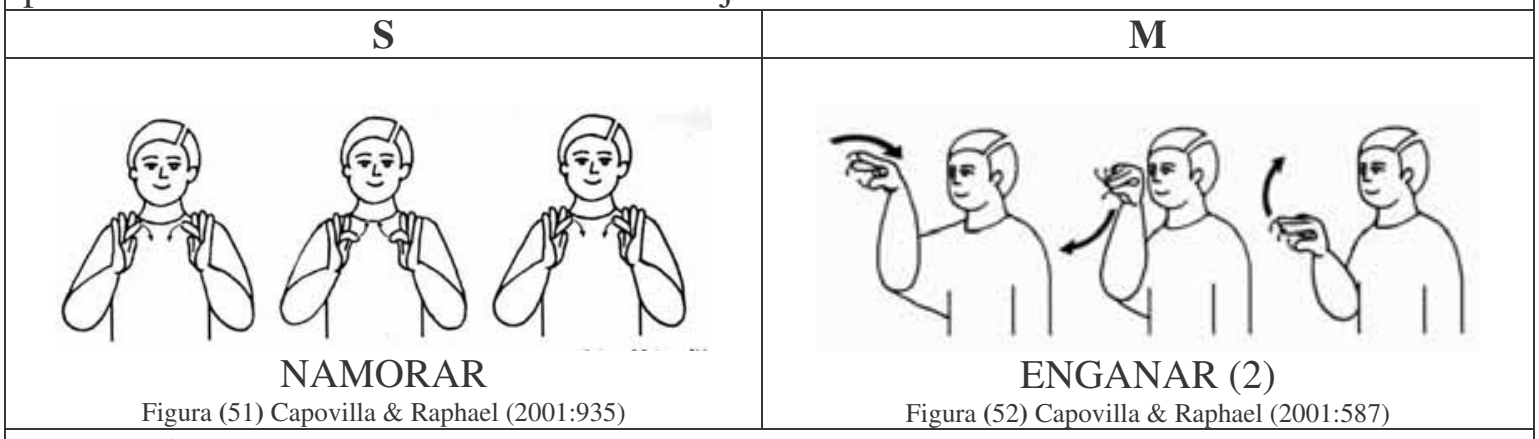

[rel] (releasing): soltar - caracteriza aberturas rápidas e repetidas dos dedos presos pelo polegar.

S




[nod] (nodding): dobrar - descreve retrações e extensões repetidas da junta do pulso

Observando mais detidamente os oito tipos de movimentos locais propostos em Liddell \& Johnson (2000 [1989]), Liddell (1990) percebeu uma particularidade em sinais dotados de movimentos locais do tipo tamborilar [wg] ou circular [circ] que os opõe a sinais descritos como sendo articulados com movimentos locais de outros tipos.

Quando os dedos tamborilam [wg] ou quando o pulso (ou o todo o ante-braço) realiza movimentos circulares rápidos, repetidos (e incontáveis) [circ], a configuração de mão e a orientação da palma de sinais articulatoriamente descritos com essas propriedades não sofrem alteração. Diferentemente, quando o movimento local do sinal é caracterizado como sendo esfregar [rub], dobrar a(s) junta(s) distal(is) [hk], achatar [fl], soltar [rel], dobrar [nod] e torcer [tw], observa-se, no caso dos quatro primeiros, uma oscilação entre duas configurações de mão e, no caso dos dois últimos, uma oscilação entre duas orientações da palma.

Tal fato conduziu Liddell a uma análise diferenciada dos movimentos locais, de acordo com a qual os traços que descrevem os diferentes tipos de movimentos dos dedos ou do pulso deixam de ser oito e passam a ser quatro: tamborilar [wg], circular [circ], oscilação

\footnotetext{
${ }^{31}$ O sinal BIBLIOTECA, tal como dicionarizado em Capovilla \& Raphael, é um composto constituído pelo sinal LIVRO e um outro sinal não dicionarizado isoladamente. Para a presente discussão, somente a segunda parte desse sinal é relevante.
} 
de configuração de mão [osc-h] (oscillating handshape) e oscilação de orientação [osc-o] (oscillating orientation).

Essa nova análise trouxe consigo restrições quanto à ocorrência de certos tipos de movimentos locais em segmentos de suspensão. Segundo Liddell, embora movimentos locais do tipo tamborilar e circular possam ocorrer tanto em suspensões quanto em movimentos, movimentos locais do tipo oscilação de configuração de mão [osc-h] e oscilação de orientação [osc-o] só podem ocorrer em segmentos de movimento (não importando se esse movimento é com ou sem trajetória).

Tal restrição decorre do fato de que somente segmentos de movimento podem apresentar especificações diferentes (uma para cada uma de suas fases) para qualquer um dos traços articulatórios que os descreve. Sendo assim, a reformulação da análise dos movimentos locais levou Liddell a reanalisar sinais como DINHEIRO (Figura (48)), NAMORAR (Figura (51)), MOTO (Figura (54)) e MOTOR (Figura (55)). Para que os dois primeiros sinais exibam um movimento local do tipo oscilação de configuração de mão [osc-h] e os dois últimos um movimento local do tipo oscilação de orientação [osc-o] é necessário que eles sejam constituídos de um segmento de movimento e não de suspensão, como mostram as representações de NAMORAR e de MOTO, a seguir.

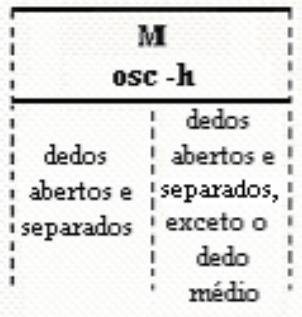

NAMORAR

(a)

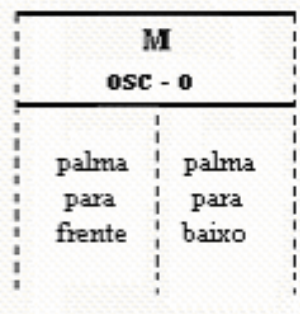

MOTO

(b)

Representação (13)

Além desses quatro traços que descrevem movimentos locais, Liddell (1990) propõe um outro para descrever sinais em que há oscilações rápidas de localização, como a que se pode observar em sinais como CARONA (Figura (57)). ${ }^{32}$ Esse traço é designado pelo autor

\footnotetext{
${ }^{32}$ Nem sempre é clara a distinção entre movimentos locais e movimentos segmentais (M). Sem dúvida essa é
} 
como oscilação de localização [osc-1] (oscillating location).

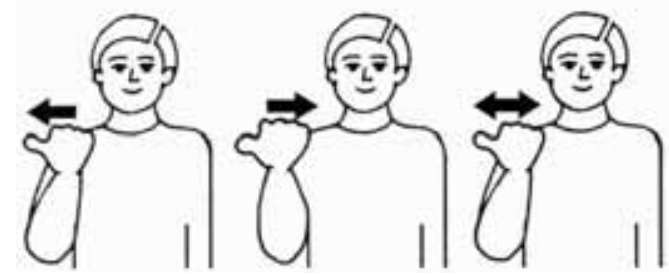

CARONA

Figura (57) Capovilla \& Raphael (2001:365)

\subsection{Descrição do feixe articulatório}

De acordo com a proposta de Liddell \& Johnson (2000 [1989]), o feixe articulatório, responsável pela descrição da postura da mão, se constitui de quatro subconjuntos de traços:

(i) configuração de mão [CM]

(ii) ponto de contato [PC]

(iii) face $[\mathrm{FA}]$

(iv) orientação [OR]

Cada um desses subconjuntos também se subdivide em subclasses de traços. A organização interna de cada um dos quatro subconjuntos de que é formado um feixe articulatório será descrita nas seções subseqüentes.

\subsubsection{Configuração de mão [CM]}

Os traços que descrevem a forma da mão (ou seja, a disposição dos dedos) são reunidos no subfeixe articulatório denominado configuração de mão. Esse subfeixe, por sua vez, se constitui de três subconjuntos de traços, organizados e representados como mostra o esquema a seguir.

uma questão que precisa ser mais bem estudada. 


\section{(f) [Configdedos] [Dedo $2^{\circ}$ [Relax] [Rotação do polegar] [Polegar $2^{\circ}$ ] [Contato]}
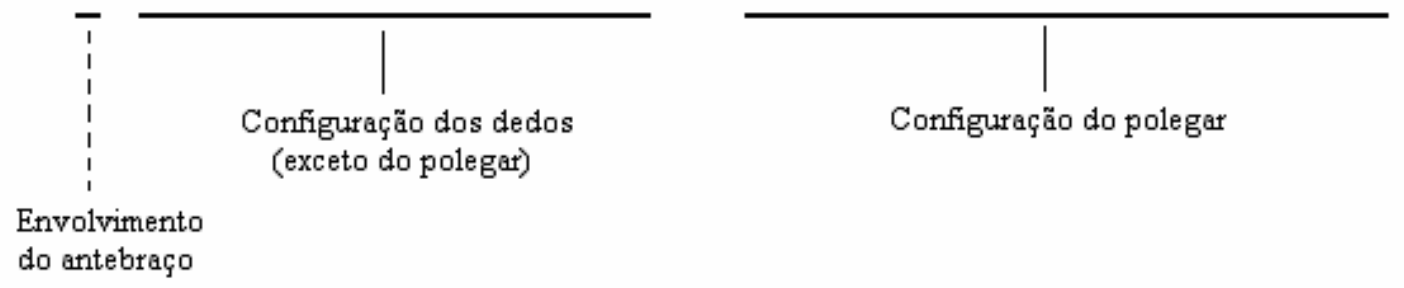

Representação (14) traduzida de Liddell \& Johnson (2000:283 [1989])

O primeiro traço, representado no esquema acima, determina se a mão e o antebraço atuam conjuntamente na realização de uma dada configuração de mão. Nesse sentido, configurações de mão dotadas do traço (/) são especificadas positivamente para o envolvimento do antebraço em sua articulação, ao passo que configurações desprovidas de tal traço são produzidas apenas pela mão.

A necessidade de se especificar a participação ou não do antebraço na realização de uma configuração de mão pode ser exemplificada pelo par de sinais DEPENDER x PÉ (2) da libras (Figura (58)), em que essa oposição parece ser fonologicamente distintiva.

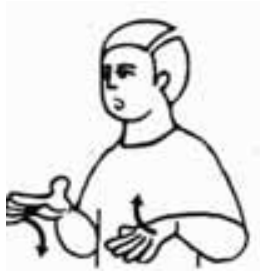

DEPENDER (p.513)

(a)

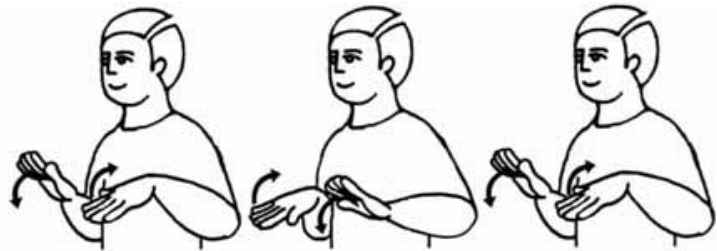

PÉ (2) (p.1020)

(b)

Figura (58) Capovilla \& Raphael (2001)

Como indicam as ilustrações acima, a única diferença entre os sinais DEPENDER e PÉ (2) é a articulação do corpo que faz a flexão necessária para a produção do movimento que reiteradamente leva a mão para cima e para baixo. No caso de DEPENDER, a flexão se dá nos cotovelos, sugerindo que o antebraço atua em conjunto com a mão na articulação desse sinal. Diferentemente, no caso de PÉ (2), a flexão ocorre nos pulsos, indicando participação exclusiva das mãos, pelo que se pode depreender do dicionário.

Na seqüência, no esquema em (14), aparece um subconjunto de traços que se constitui de três especificações: [Configdedos], [Dedo $2^{\circ}$ ] e [Relax]. Tais especificações têm a 
função de descrever, conjuntamente, a disposição dos dedos indicador, médio, anelar e mínimo.

As especificações [Configdedos] e [Dedo $2^{\circ}$ ] codificam as diferentes formas em que os dedos indicador, médio, anelar e mínimo podem ser configurados. A primeira delas, [Confdedo], determina os dedos que estão abertos e os que estão fechados. Dedos abertos são aqueles que apresentam uma distensão tanto na junta proximal - JP - (junta que une o dedo à palma da mão) quanto na junta distal - JD - (junta localizada entre a falange medial e a distal) (Figura (59a)). Já dedos fechados são aqueles que apresentam essas duas juntas flexionadas (Figura (59b)) ${ }^{33}$.

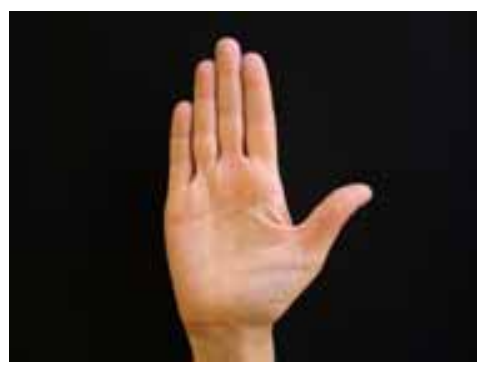

(a)

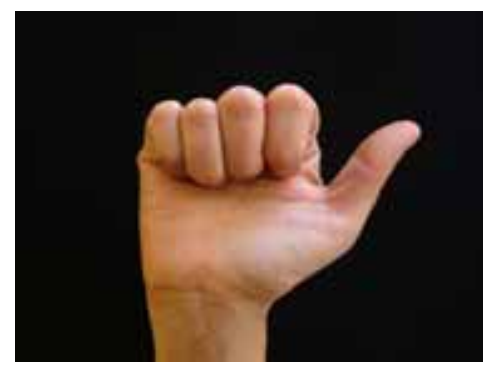

(b)

Figura (59)

A especificação [Dedo $2^{\circ}$, por sua vez, tem a função de determinar se os dedos abertos estão "achatados", ou seja, flexionados na junta proximal; ou se estão em gancho, isto é, flexionados nas juntas distais, como mostram as imagens na figura (60a) e na figura (60b), respectivamente.

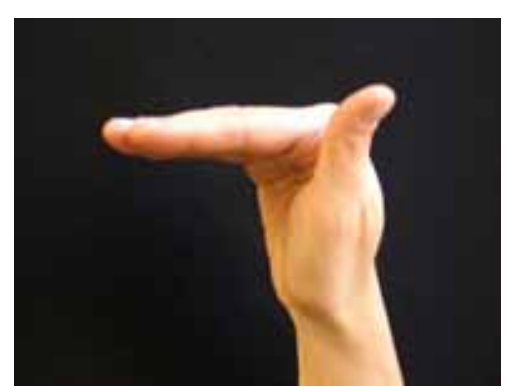

(a)

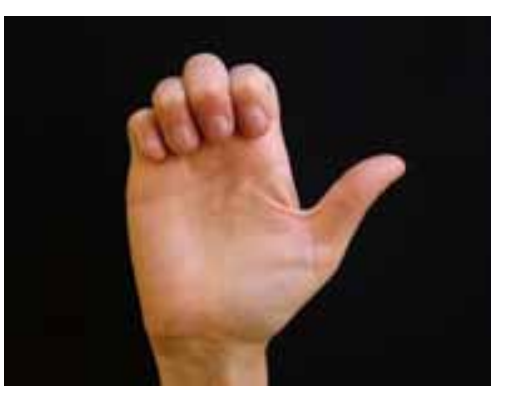

(b)

Figura (60)

\footnotetext{
${ }^{33}$ Para esta discussão, a configuração do polegar está sendo ignorada.
} 
Para indicar simultaneamente os dedos abertos e os dedos fechados de uma determinada configuração, ou seja, a [Confded], Liddell \& Johnson lançam mão de 25 símbolos, listados no quadro (2) do anexo desta dissertação. De acordo com essa lista, as configurações dos dedos indicador, médio, anelar e mínimo, apresentadas em (59), por exemplo, são simbolizadas, respectivamente, por [B] e [S]. [B] indica que todos os dedos mencionados estão distendidos nas juntas proximais e distais, e [S], que, além de todos esses mesmos dedos estarem flexionados nessas duas juntas, eles estão posicionados de forma que suas pontas tocam a palma da mão.

Já para especificar se os dedos abertos, determinados pelo traço [Configdedos] estão achatados ou em gancho, os autores utilizam os símbolos [^] e ["], respectivamente.

Nos termos da análise em questão, uma configuração de mão do tipo ilustrado na figura (61a) abaixo é representada unicamente pelo símbolo [1], uma vez que o dedo aberto não apresenta flexão nem na junta proximal nem na junta distal. Já configurações do tipo apresentado na figura (61b) e na figura (61c), além do símbolo [1], precisarão ser descritas quanto à flexão das juntas. Sendo assim, a forma achatada do dedo em (61b) é representada como [1^], enquanto a forma em gancho, apresentada em (61c), é notada como [1"].

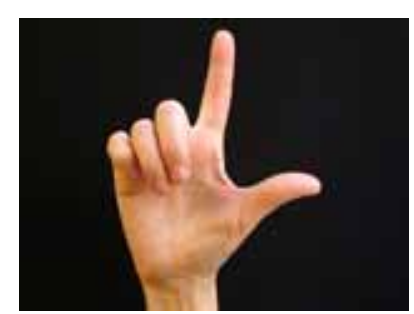

[1]

(a)

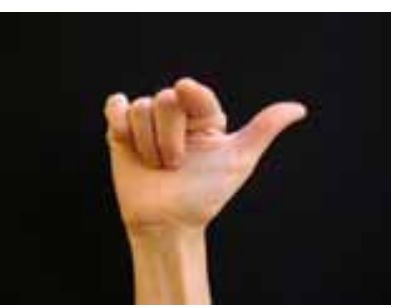

$\left[1^{\wedge}\right]$

(b)

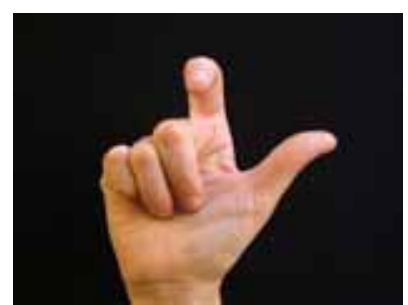

[1"]

(c)

Figura (61)

Em suma, por serem os dedos indicador, médio, anelar e mínimo igualmente capazes de flexionar-se e distender-se na juntas proximal (JP) e distal (JD), cada um deles pode ser posicionado de quatro formas diferentes: aberto, fechado, "achatado" ou em gancho. Como mostra o quadro a seguir, essas diferentes disposições dos dedos são resultantes da combinação dos diferentes estados (flexionado e distendido) que as juntas proximais e distais podem apresentar. 
Quadro (3) 34

\begin{tabular}{|c|c|c|}
\hline JP flexionada & JD flexionada & $\begin{array}{c}\text { Disposição do(s) } \\
\text { dedo(s) }\end{array}$ \\
\hline+ & + & fechado \\
\hline- & - & aberto \\
\hline- & + & em gancho \\
\hline+ & - & achatado \\
\hline
\end{tabular}

É interessante observar que a riqueza de detalhes do sistema de notação permite a ele capturar com precisão o(s) traço(s) com base nos quais as configurações de mão diferem. Isso é de grande importância quando se observa que esse(s) traço(s) pode(m) ser distintivos. Na libras, por exemplo, a oposição [dedos unidos] x [dedos espalmados], capturada pelos 25 símbolos taxonômicos apresentados no quadro (2) do anexo desta dissertação, é fonologicamente relevante em algumas configurações de mão, pois é com base nela que os sinais U (Figura (62a)) e V (Figura (62b)) contrastam $^{35}$.

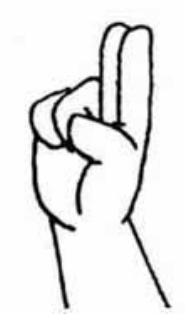

$\mathrm{U}$ (p.1281)

(a)

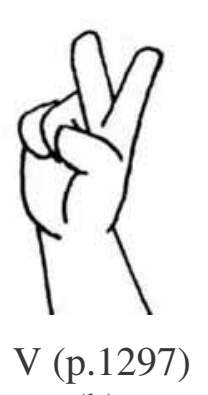

(b)

Figura (62) Capovilla \& Raphael (2001)

Nessa mesma língua, a oposição [dedos abertos] x dedos "em gancho" ["] também é fonologicamente relevante, uma vez que é com base nela que se estabelece o contraste entre o sinal V (Figura (62b)) supracitado e o sinal NÚMERO-CINCO, ilustrado na figura (63).

\footnotetext{
${ }^{34}$ Agradeço ao Prof. Dr. Leo Wetzels pela sugestão deste quadro binário dos traços que descrevem o estado dos dedos.

${ }^{35}$ A maior parte dos pares mínimos desta seção advirão de sinais para letras. Tal fato se deve à dificuldade de encontrar pares mínimos perfeitos.
} 


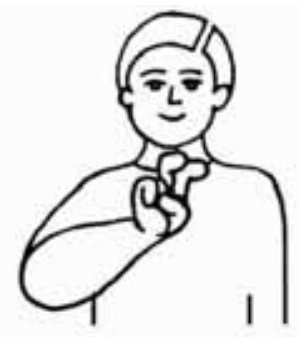

NÚMERO-CINCO

Figura (63) Capovilla \& Raphael (2001:958)

A última especificação do subconjunto configuração de dedos, [Relax], diz respeito a uma mudança tênue que a configuração dos dedos indicador, médio, anelar e mínimo pode sofrer por efeito do relaxamento de seus músculos. Embora esse relaxamento, indicado pelo símbolo [ ], não provoque uma alteração nos traços das especificações [Configdedos] e [Dedo $2^{\circ}$, ele os torna menos rígidos.

Por meio desse traço, é possível distinguir, por exemplo, a configuração dos dedos indicador, médio, anelar e mínimo, tal como eles aparecem em sinais como E (Figura (64a)), da configuração que esses mesmos dedos exibem em sinais como C (Figura (64b)).

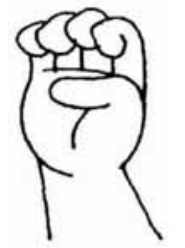

E (p.569)

(a)

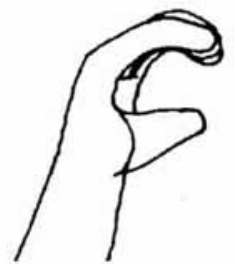

C (p.327)

(b)

Figura (64) Capovilla \& Raphael (2001)

A representação tanto da configuração do primeiro sinal, quanto da do segundo, envolvem os símbolos [B"], dado que, em ambos os sinais, os dedos encontram-se distendidos nas juntas proximais e flexionados nas juntas distais. Mas, para capturar, na representação da configuração do sinal C (Figura (64a)), o fato de que as juntas distais não aparecem tão flexionadas quanto aparecem no sinal E (Figura (64b)), Liddell \& Johnson lançam mão do traço [Relax], simbolizado por [ ], e representam a configuração desse sinal como $\left[\mathrm{B}^{\prime \prime} \sim\right]$. 
Por fim, a terceira e última sublcasse de traços do subfeixe configuração de mão tem como função descrever a disposição do polegar. De acordo com Liddell \& Johnson, a caracterização de tal dedo depende da especificação de três traços: [Rotação do polegar], [Polegar $2^{\circ}$ ] e [Contato].

O primeiro deles, [Rotação do polegar], define se o polegar está posicionado adjacente ou paralelamente ao plano criado pela palma da mão. No primeiro caso, designado pelos autores de não-oposto [u] (unopposed), o polegar se localiza ao lado dos demais dedos, de tal forma que é capaz de tocar a lateral radial do indicador distendido (Figura (65a)) ou a lateral radial da junta medial de qualquer dedo achatado (Figura (65b)), como ilustram as imagens abaixo.

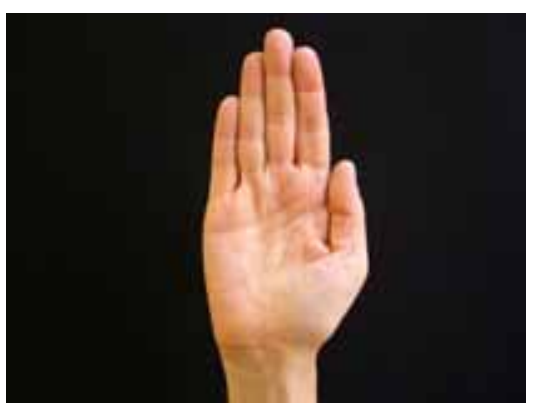

(a)

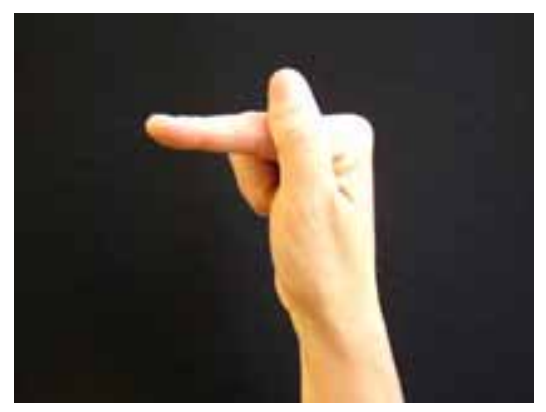

(b)

Figura (65)

Já no segundo caso, denominado pelos autores de oposto [o] (opposed), a almofada do polegar, voltada para a palma da mão, posiciona-se paralelamente ao plano criado por esta, como mostra a figura (66a). O polegar, nessa posição, é capaz de tocar a palma dos outros dedos, como mostra a imagem em (66b) a seguir.

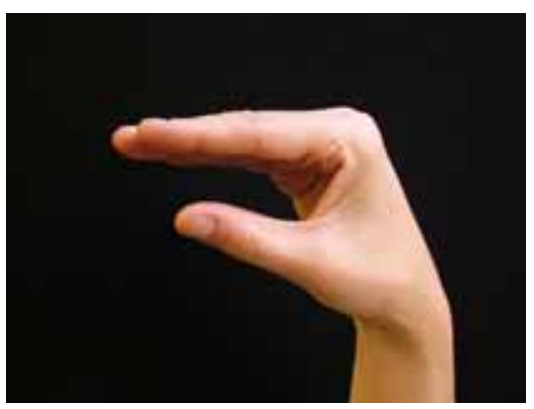

(a)

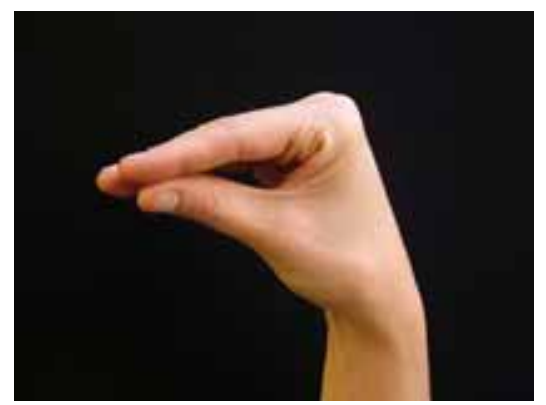

(b)

Figura (66) 
Assim como no caso dos demais dedos, o polegar, independentemente de estar nãooposto [u] ou oposto [o], também é capaz de flexionar-se nas juntas proximal e distal. Dessa maneira, pode se configurar em qualquer uma das quatro formas citadas para os demais dedos: aberta, fechada, achatada e em gancho. Por essa razão, para determinar em qual(is) (das) junta(s) ocorre(m) flexão, Liddell \& Johnson incluíram, entre os traços que descrevem o polegar, a especificação [Polegar $2^{\circ}$, análoga à que propuseram para caracterizar a flexão e a extensão dos outros dedos.

Nesse sentido, um polegar será descrito como aberto, quando as suas duas juntas (proximal e distal) estiverem distendidas; será descrito como fechado, quando essas duas juntas estiverem flexionadas; e será descrito como achatado ou em gancho, quando apenas uma das juntas estiver flexionada (a proximal no primeiro caso e distal no segundo). $\mathrm{O}$ quadro abaixo ilustra configurações em que tanto o polegar não-oposto quanto o oposto aparecem configurados em uma dessas quatro formas.

\section{Quadro (4)}

\begin{tabular}{|c|c|}
\hline \multicolumn{2}{|c|}{ Disposições do polegar não-oposto e oposto } \\
\hline$[\mathrm{u}]$ - aberto & {$[\mathrm{o}]-$ aberto } \\
\hline$\left[\mathrm{u}^{\prime \prime}\right]-$ em gancho & {$\left[\mathrm{o}^{\prime \prime}\right]-$ em gancho } \\
\hline & \\
\hline $\left.\mathrm{u}^{\wedge}\right]$ - achatado & \\
\hline
\end{tabular}




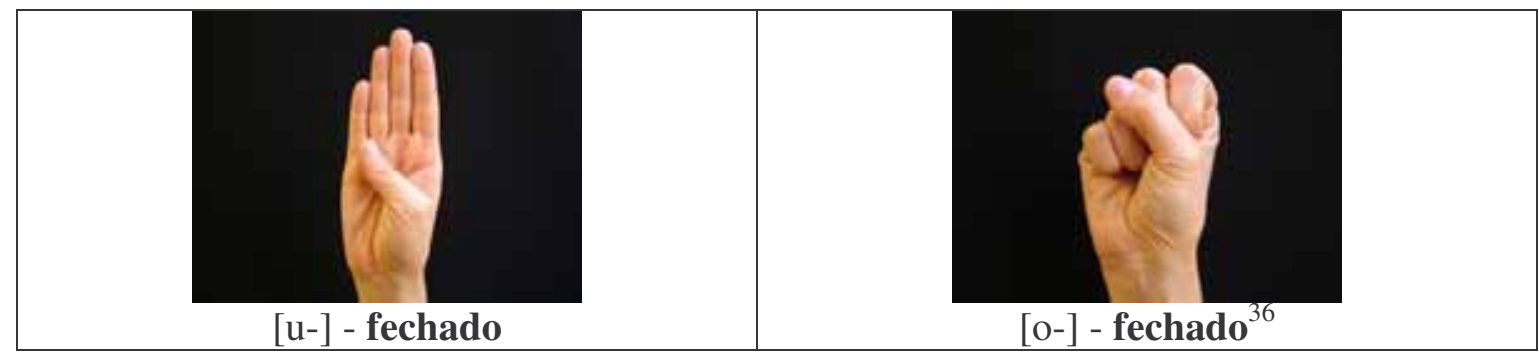

É importante observar que os símbolos usados para descrever a característica achatada [^] ou em gancho ["] do polegar são os mesmos usados para a descrição dessa característica nos outros dedos. Também como no caso dos demais dedos, a especificação [aberto] do polegar não recebe nenhum símbolo especial. Entretando, no que diz respeito à especificação [fechado] do polegar, usa-se o símbolo [-], tanto para um polegar oposto quanto para um polegar não-oposto.

Embora, à primeira vista, pareça não motivado o tratamento individualizado que Liddell \& Johnson dão ao polegar, pares de sinais como os apresentados a seguir desfazem essa impressão. Como se pode depreender das figuras que representam os sinais PROMETER (Figura (67a)) e B (Figura (67b)) da libras, a configuração do polegar pode ser fonologicamente relevante, dado que, nesses sinais, essa é a única diferença com base na qual eles contrastam: no primeiro, o polegar aparece não-oposto e achatado, $\left[\mathrm{u}^{\wedge}\right]$, enquanto no segundo ele aparece não-oposto, mas fechado, [u-].

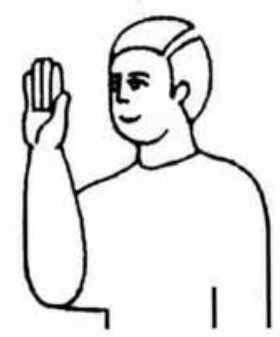

PROMETER (p.1087)

(a)

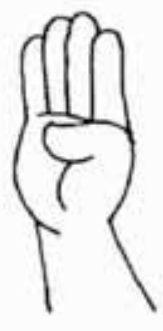

B (p.255)

(b)

Figura (67) Capovilla \& Raphael (2001)

\footnotetext{
${ }^{36}$ De acordo com a descrição de Liddell \& Johnson (2000:285 [1989]), o polegar oposto e fechado se caracteriza por tocar o dorso do(s) dedo(s) flexionado(s) nas duas juntas (proximal e distal). Por essa razão, o exemplo de polegar caracterizado por esses traços foi dado aqui com uma configuração diferente da dos demais dedos, na medida em que é articulatoriamente impossível o polegar tocar o dorso de dedos abertos.
} 
Um outro par de sinais em que a configuração do polegar é relevante não só para a distinção de duas configurações, mas também para o estabelecimento de contraste lexical na libras, é formado pelos sinais L e G, representados pelas figuras em (68).

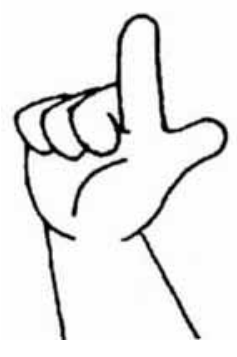

$\mathrm{L}(\mathrm{p} .795)$

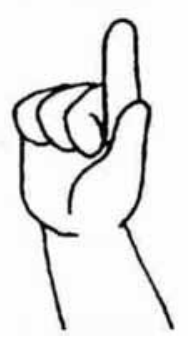

$\mathrm{G}(\mathrm{p} .699)$

(b)

Figura (68) Capovilla \& Raphael (2001)

Como se pode ver nas figuras acima, em ambos os sinais, o polegar está não-oposto [u] e aberto. A única diferença entre eles é que, no sinal $\mathrm{G}$, o polegar se encontra achatado $\left[{ }^{\wedge}\right.$, ou seja, dobrado na junta proximal, diferentemente do polegar no sinal L, que não apresenta flexão nenhuma nessa junta.

O último traço que compõe o subconjunto de traços que descrevem o polegar -- contato -- tem a função de determinar se ocorre contato entre o polegar e outro(s) dedo(s) e que região do polegar contacta os outros dedos. Liddell \& Johnson propuseram quatro diferentes traços para essa especificação, que são descritos a seguir e ilustrados pelas imagens em (69).

(a) [c]: contato realizado pela ponta do polegar;

(b) [p]: contato realizado pela almofada do polegar;

(c) [f]: contato realizado pela almofada do polegar na unha de outro(s) dedo(s);

(d) [t]: contato realizado pela unha do polegar na almofada de outro(s) dedo(s). 


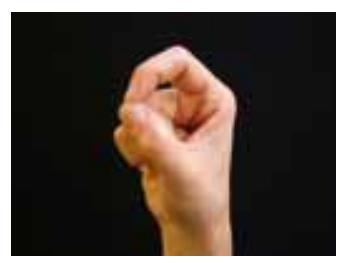

(a)

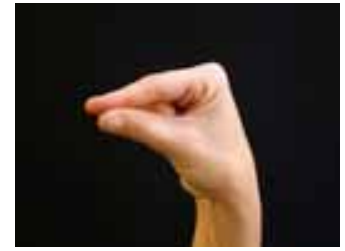

(b)

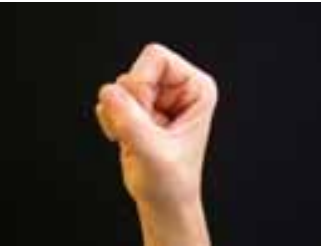

(c)

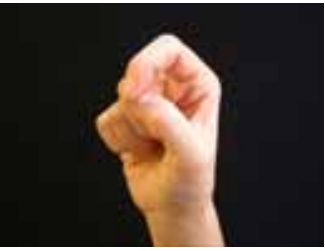

(d)

Figura (69)

Por meio desses traços é possível capturar diferenças entre configurações de mão que podem ser usadas distintivamente por uma língua sinalizada. Na libras, por exemplo, podese observar o uso fonológico que essa língua faz do traço [c] (contato), ao se compararem os sinais C (Figura (70a)) e O (Figura (70b)).

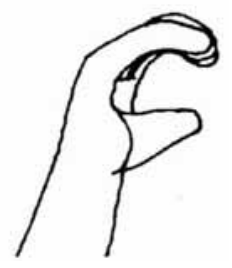

C (p.327)

(a)

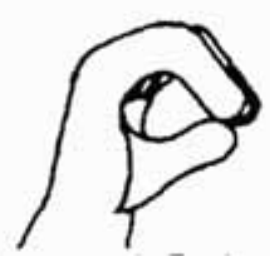

$\mathrm{O}(\mathrm{p} .967)$

(b)

Figura (70) Capovilla \& Raphael (2001)

Como sugerem as figuras, a característica com base na qual esses dois itens lexicais contrastam consiste na ausência de contato do polegar com outros dedos versus a sua presença.

A parte do polegar que contacta o(s) dedos(s) também pode ter valor distintivo. Um evidência disso, na libras, são os sinais F (Figura (71a)) e T (Figura (71b)) em que o contraste lexical é estabelecido com base nesse traço: enquanto no primeiro a parte do polegar que toca o dedo indicador é a sua almofada [p], no segundo o contato é feito pela unha $[\mathrm{t}]$. 


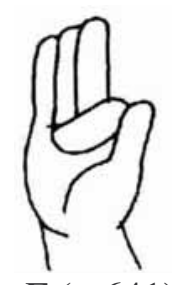

F (p.641)

(a)

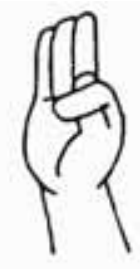

$\mathrm{T}(\mathrm{p} .1229)$

(b)

Figura (71) Capovilla \& Raphael (2001)

\subsubsection{Ponto de Contato [PC]}

$\mathrm{O}$ subfeixe articulatório ponto de contato [PC] é formado por quatro subconjuntos de traços, a saber:

(i) localização;

(ii) parte da mão;

(iii) proximidade;

(iv) relação espacial.

O primeiro deles, localização, tem sido assemelhado ao que se chama de ponto de articulação na fonologia das línguas orais, visto que ele também tem a função de especificar um ponto no articulador passivo, que é tocado pelo articulador ativo ou que serve de ponto de referência para ele.

Entretanto, uma diferença marcante entre esse traço nas línguas orais e seu correlato nas línguas sinalizadas é a de que, no caso dessas últimas, a gama de "articuladores passivos" é maior, dado que os sinais podem ser produzidos em três regiões diferentes:

(a) sobre o corpo;

(b) sobre alguma região da mão passiva e;

(c) no espaço de sinalização, ou seja, na região em frente à cabeça e ao torso do sinalizador.

Cada uma dessas três diferentes localizações é caracterizada de forma específica no 
modelo de Liddell \& Johnson. Sinais produzidos sobre alguma região do corpo (excluindose a mão passiva), por exemplo, têm a sua localização descrita por meio de quatro traços, organizados e representados como no esquema a seguir .

(\%) (i) localização (t ou b)

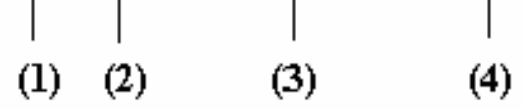

Representação (15) adaptada de Liddell \& Johnson (2000:286 [1989])

A especificação (1) do esquema acima, [\%], tem a função de expressar em que lado do corpo está localizado o ponto de articulação de um sinal. Mais precisamente, ela indica se uma determinada localização é contralateral (lado da mão não-dominante), caso no qual a sua descrição inclui o símbolo [\%], ou se é ipsilateral (lado da mão dominante), situação na qual não há qualquer tipo de marcação. Já a especificação (3), [localização], é responsável por indicar a área do corpo sobre a qual um determinado sinal é articulado. Por fim, a especificação (2), (i), determina que o ponto de contato não corresponde exatamente à região especificada por (3), mas sim a um ponto em sua periferia.

Segundo Liddell \& Johnson, na ASL, a especificação (3) abrange 20 áreas fonologicamente distintivas, listadas no quadro a seguir.

Quadro (5)

\begin{tabular}{|l|l|}
\hline \multicolumn{2}{|c|}{ Localizações sobre o corpo possíveis na ASL } \\
\hline $\begin{array}{l}\text { BH (back of head): região posterior da } \\
\text { cabeça }\end{array}$ & CN (chin): queixo \\
\hline TH (top of head): topo da cabeça & NK (neck): pescoço \\
\hline FH (forehead): testa & SH (shoulder): ombro \\
\hline SF (side of forehead): lado da testa & ST(sternum): esterno \\
\hline NS (nose): nariz & CH (chest): peito \\
\hline CK(cheek): bochecha & TR (trunk): tronco \\
\hline ER (ear): orelha & UA (upper arm): parte superior do braço \\
\hline MO (mouth): boca & FA (forearm): antebraço \\
\hline LP (lip): lábio & AB (abdomen): abdômen \\
\hline JW (jaw): mandíbula & LG (leg): perna \\
\hline
\end{tabular}


Para ver exemplos de sinais da libras articulados em cada uma dessas regiões, consulte o quadro (4) no anexo deste trabalho.

Com base no par de sinais abaixo, pode-se observar o valor distintivo de pelo menos duas dessas áreas listadas no quadro acima, na libras.

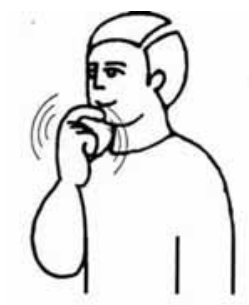

CAMPINAS (p. 348)

(a)
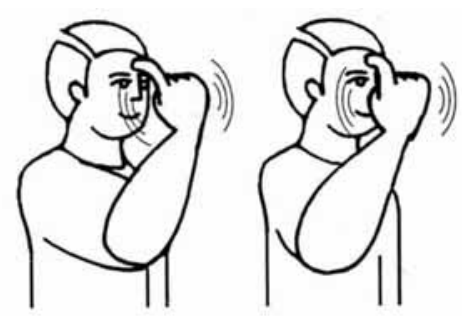

ÍNDIA (p.752)

(b)

Figura (72) Capovilla \& Raphael (2001)

Como sugerem as figuras acima, o único traço que distingue um sinal do outro é justamente o ponto de contato: enquanto em CAMPINAS o sinal é realizado no queixo [CN] (chin), o sinal ÍNDIA é articulado na testa [FH] (forehead).

Por observarem a existência de sinais que não são articulados exatamente na região central de cada uma das localizações listadas no quadro (5), Liddell \& Johnson incluíram entre os traços que descrevem o ponto de articulação de um sinal as especificações (2) e (4). A função de tais especificações é determinar pontos adjacentes a uma dada localização principal como, por exemplo, regiões ao lado, acima ou abaixo desta. Nos termos do modelo em questão, uma região situada ao lado de uma localização principal é indicada pelo traço [i] (ipsilateral) e áreas situadas na porção superior e inferior desta são descritas pelos traços [t] (top) e [b] (botton), respectivamente.

Graças a esse recurso, é possível diferenciar a localização de sinais da libras como AINDA-NÃO (Figura (73)), PINGA (Figura (74)) e NÃO-ADIANTA (Figura (75)). Embora, grosso modo, o ponto de articulação de tais sinais possa ser igualmente descrito pelo traço queixo $[\mathrm{CN}]$, eles não são produzidos exatamente nas mesmas áreas deste. Como indicam as figuras a seguir, o sinal AINDA-NÃO é articulado na região central do queixo [CN]; o sinal PINGA, na porção superior (logo abaixo do lábio inferior) [CNt] e, por fim, o sinal NÃO-ADIANTA, na região inferior deste, ou seja, no submaxilar [CNb]. 


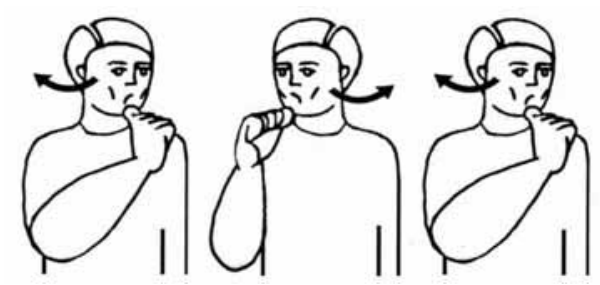

AINDA-NÃO

Figura (73) Capovilla \& Raphael (2001:169)

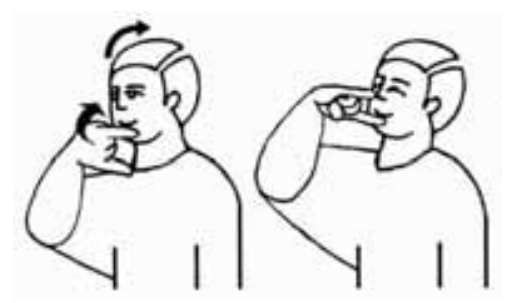

PINGA

Figura (74) Capovilla \& Raphael (2001:1046)

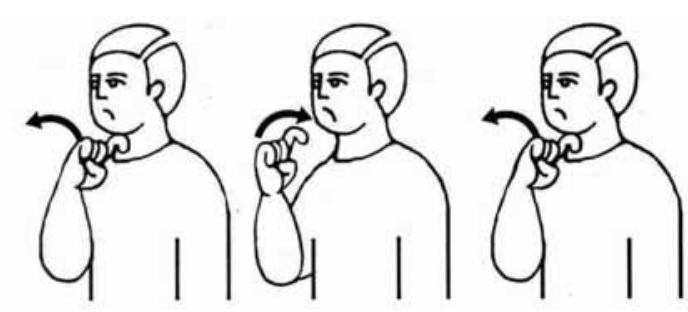

NÃO-ADIANTA

Figura (75) Capovilla \& Raphael (2001:935)

A combinação dos quatro tipos de especificações presentes no subfeixe localização produz pontos de articulação que podem ser usados fonológica ou foneticamente pelas línguas sinalizadas. Esses pontos encontram-se representados em figuras retiradas de Liddell \& Johnson (2000 [1989]) no quadro (3) do anexo deste trabalho.

Quando o sinal é articulado sobre alguma região da mão passiva, o modelo de Liddell \& Johnson utiliza outro esquema de descrição e outro conjunto de traços para descrever tal ponto de articulação. O esquema, nesse caso, é constituído de duas especificações: uma indica uma localização principal na mão (a mão, os dedos, o polegar, etc); a outra especifica uma região nessa localização principal (dentro, no dorso, na extremidade radial, etc). Os símbolos utilizados são os representados no quadro (6). 


\section{Quadro (6)}

\begin{tabular}{|c|c|c|c|c|c|c|c|}
\hline & $\begin{array}{l}\text { HAND: } \\
\text { mão }\end{array}$ & $\begin{array}{c}\text { FI (fingers): } \\
\text { dedos } \\
\text { (exceto } \\
\text { polegar) }\end{array}$ & $\begin{array}{c}\text { TH }(\text { thumb): } \\
\text { polegar }\end{array}$ & $\begin{array}{c}\text { XF (index } \\
\text { finger): dedo } \\
\text { indicador }\end{array}$ & $\begin{array}{l}\text { MF (middle } \\
\text { finger): } \\
\text { dedo médio }\end{array}$ & $\begin{array}{c}\text { RF (ring } \\
\text { finger): dedo } \\
\text { anelar }\end{array}$ & $\begin{array}{l}\text { LF (little } \\
\text { finger): } \\
\text { dedo } \\
\text { mínimo }\end{array}$ \\
\hline $\begin{array}{l}\text { IN: parte } \\
\text { interna }\end{array}$ & $\begin{array}{c}\text { PA } \\
\text { (palma) }\end{array}$ & INFI & INTH & INXF & INMF & INRF & INLF \\
\hline $\begin{array}{l}\text { PD (pad): } \\
\text { almofada }\end{array}$ & & PDFI & PDTH & PDXF & PDMF & PDRF & PDLF \\
\hline $\begin{array}{l}\text { BK }(\text { back }): \\
\quad \text { dorso }\end{array}$ & $\mathrm{BK}$ & BKFI & BKTH & BKXF & BKMF & BKRF & BKLF \\
\hline RA: radial & RA & RAFI & RATH & RAXF & RAMF & RARF & RALF \\
\hline UL: ulnar & UL & ULFI & ULTH & ULXF & ULMF & ULRF & ULLF \\
\hline $\begin{array}{c}\text { TI (tip): } \\
\text { ponta }\end{array}$ & & TIFI & TITH & TIXF & TIMF & TIRF & TILF \\
\hline $\begin{array}{c}\text { KW } \\
(\text { knuckle }): \\
\text { nó dos } \\
\text { dedos }\end{array}$ & KW & & & & & & \\
\hline BA: base & $\mathrm{BA}$ & & & & & & \\
\hline $\begin{array}{l}\text { HL (heel): } \\
\text { "calcanhar" }\end{array}$ & $\mathrm{HL}$ & & & & & & \\
\hline $\begin{array}{l}\text { WB }(\boldsymbol{w e b}): \\
\text { região } \\
\text { interdigital }\end{array}$ & & WBFI & WBTH & WBXF & WBMF & WBRF & WBLF \\
\hline
\end{tabular}

Nos termos desse esquema, um sinal como REMÉDIO (Figura (76)) teria sua localização descrita pelo traço palma [PA], que representa a palma da mão passiva; um sinal como CONVERSAR (1) (Figura (77)) teria sua localização descrita pelo traço [BK] (back), que representa o dorso da mão passiva, e um sinal como FEIJÃO (1) (Figura (78)) teria sua localização descrita pelo traço [TIXF] (tip + index finger), que representa a ponta do dedo indicador.

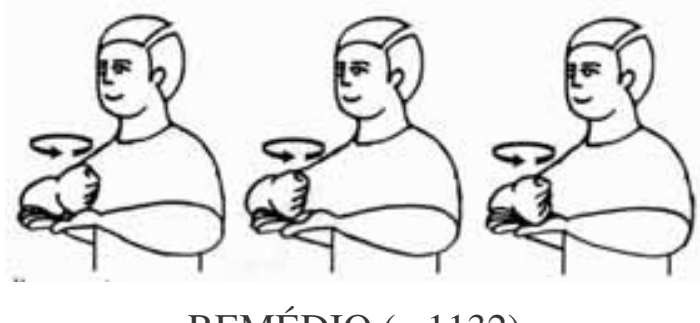

REMÉDIO (p.1132)

Figura (76) Capovilla \& Raphael (2001:935) 


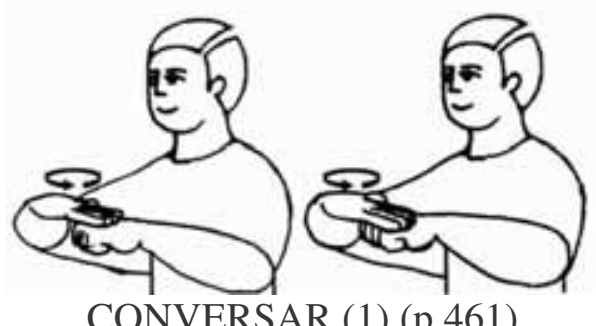

Figura (77) Capovilla \& Raphael (2001:935)

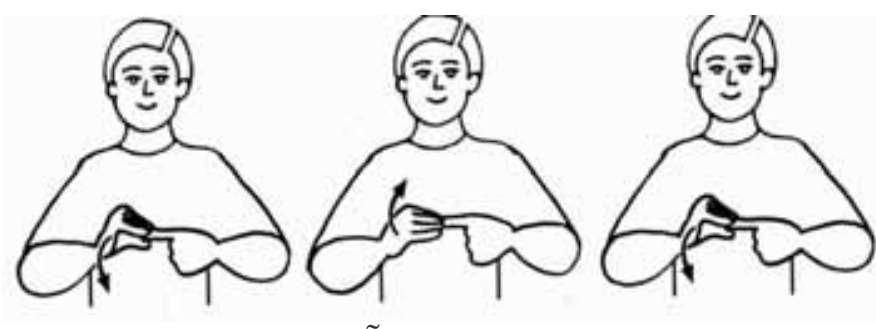

FEIJÃO (1) (p.658)

Figura (78) Capovilla \& Raphael (2001:935)

Finalmente, quando um sinal é produzido no espaço de sinalização, a descrição de sua localização inclui traços que expressam: (i) a que distância perpendicular a mão está localizada em relação ao corpo; (ii) qual o grau de afastamento da mão em relação à linha medial do corpo; e (iii) em que altura a mão se situa em relação às localizações principais que se encontram ao longo da região central do corpo. Liddell \& Johnson representam esses traços seguindo o esquema abaixo.

\section{Proximidade - Deslocamento Ipsilateral - Localização Central}

Representação (16) traduzida de Liddell \& Johnson (2000:287 [1989])

Para a especificação proximidade, há quatro possíveis traços, a saber:

(i) proximal [p]: indica uma localização a poucos centímetros de uma região sobre o corpo (cf. ADVOGADO (Figura (46)));

(ii) medial [m]: indica uma localização em frente ao corpo cuja distância é aproximadamente equivalente à de um cotovelo horizontalmente posicionado (cf. BRANCO (1) (Figura (20)));

(iii) distal [d]: indica uma localização em frente ao corpo cuja distância é 
aproximadamente equivalente à de um braço semi-estendido e horizontalmente posicionado (cf. a posição final da mão no sinal VIAJAR (2) (Figura (53)));

(iv) estendido [e]: indica uma localização em frente ao corpo cuja distância é equivalente à de um braço totalmente estendido e horizontalmente posicionado (cf. a posição final da mão no sinal FUNDO (Capovilla \& Raphael, 2001:694) $)^{37}$.

Já para a segunda especificação, deslocamento ipsilateral, o modelo de Liddell \& Johnson registra dois graus de afastamento da linha medial que intesecciona o corpo: o primeiro deles é paralelo ao peito, notado pelos autores como [1] (cf. DEPENDER (Figura (58a))), e o segundo, paralelo à extremidade do ombro, notado como [2] (cf. PROMETER (Figura (67a))). Nos casos em que um sinal é realizado em uma localização paralela à linha medial, ou seja, sem deslocamento ipsilateral, esse traço tem a especificação [0] (cf. BRASIL (Figura (79))).

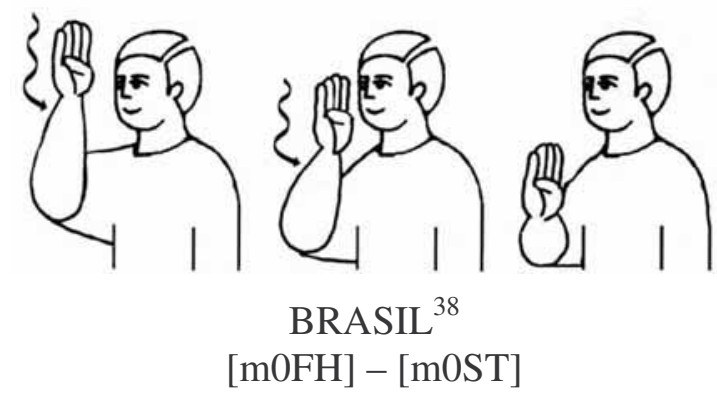

Figura (79) (Capovilla \& Raphael (2001: 315))

Como se pode ver na representação tanto do ponto de contato incial [m0FH] quando do ponto de contato final [m0ST], no sinal BRASIL, a mão, localizada à uma distância média do corpo $[\mathrm{m}]$, move-se de um ponto à altura da testa $[\mathrm{FH}]$ em direção a outro à altura do esterno [ST]. Por estar a mão, nesse sinal, localizada em um plano paralelo à linha medial

\footnotetext{
${ }^{37}$ Embora Capovilla \& Raphael (2001) descrevam sinais do tipo de ADVOGADO (Figura (46)) como sendo realizados em uma região próxima ao corpo, eles não fazem menção aos outros graus de proximidade previstos no modelo de Liddell \& Johnson. Por essa razão, cabe dizer que os exemplos dados para as especificações [medial], [distal] e [estendido] do subfeixe [proximidade] são baseados na representação pictórica desses sinais no dicionário, bem como nas minhas observações. Somente com estudos mais aprofundados a respeito da fonética da libras é que se poderá descrever com maior precisão o grau de proximidade da(s) mão(s) em relação ao corpo do sinalizador durante a articulação de um sinal.

${ }^{38}$ Por ser realizado com mudança de [PC], o sinal em questão apresenta a descrição de dois pontos de contato: o inicial e o final.
} 
do corpo, diz-se que seu deslocamento ipsilateral é [0].

Por fim, para a última especificação do esquema acima, localização central, utilizam-se os símbolos $\mathrm{TH}, \mathrm{FH}, \mathrm{NS}, \mathrm{MO}, \mathrm{CH}, \mathrm{NK}, \mathrm{ST}, \mathrm{CH}$, TR e AB, também utilizados para determinar pontos de articulação sobre o corpo (ver quadro (5)).

A figura abaixo apresenta possíveis pontos de articulação no espaço de sinalização, especificados de acordo com os três tipos de traços previstos pela proposta de Liddell \& Johnson.

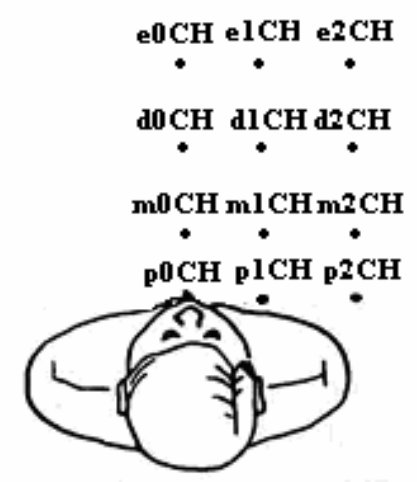

Figura (80) adaptada de Liddell \& Johnson (2000:287 [1989])

Conforme dito no início desta seção, o feixe ponto de contato [PC], além do subfeixe localização, constitui-se de três outros subfeixes de traços: parte da mão, proximidade e relação espacial. O primeiro deles, parte da mão, tem a função de determinar que parte desta está voltada para o ponto de articulação especificado pela localização ou que parte desta contacta essa localização.

A importância dessa especificação pode ser observada em sinais como COMPASSO, representado pela figura a seguir.

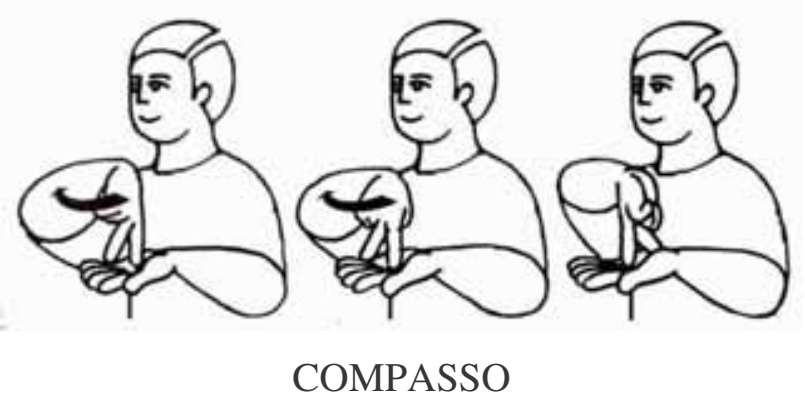

Figura (81) Capovilla \& Raphael (2001:437) 
Como sugere a Figura (81), embora nesse sinal os dois dedos distendidos da mão dominante estejam voltados para a mão não dominante, somente um deles, o dedo indicador (e não o médio), contacta a palma da mão passiva durante a realização do sinal.

Já o segundo subfeixe, proximidade, é responsável por indicar se a parte da mão, especificada pelo subfeixe mencionado acima, está ou não em contato com uma determinada localização. Em caso afirmativo, tal subfeixe é especificado pelo traço [c] (como em COMPASSO), mas em caso negativo, ele pode receber três especificações diferentes conforme a distância entre a parte da mão e a localização para qual ela está voltada. De acordo com Liddell \& Johnson, essa distância pode ser determinada pelos traços proximal [p] (cf. LER (Capovilla \& Raphael, 2001:809)), medial [m] (cf. segmento inicial de OFICIAL (Capovilla \& Raphael, 2001:973)) e distal [d] (segmento final de GRANDE (Capovilla \& Raphael, 2001:718)) ${ }^{39}$.

Por fim, o terceiro subfeixe, relação espacial, especifica a direção na qual a parte da mão está deslocada de uma localização. Essa especificação é necessária para sinais que, assim como PROIBIR (Figura (40)) e MENTIR (Figura (82)), apresentam movimento de roçar. Como sugerem suas respectivas figuras, nesses casos, a mão, antes e depois de contactar a localização descrita pelo ponto de contato, é posicionada em pontos próximos a ela.

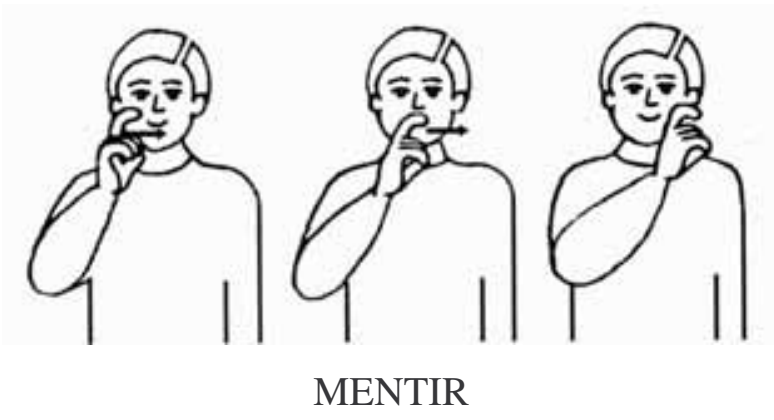

Figura (82) Capovilla \& Raphael (2001:891)

No sinal MENTIR, por exemplo, a mão parte de uma região próxima à parte ipsilateral do nariz em direção a uma região próxima à parte contralateral deste.

\footnotetext{
${ }^{39}$ Valem aqui as mesmas observações feitas na nota 34.
} 


\subsubsection{Face [FA] e orientação [OR]}

De acordo com Liddell \& Johnson, os sinais fazem uso de duas especificações diferentes que determinam conjuntamente a orientação da mão. Uma delas, denominada por eles de face [FA], é responsável por indicar a parte da mão que é alocada no ponto em que um determinado sinal é produzido e/ou a direção para a qual os dedos apontam. Já a outra, designada de orientação [OR], tem a função de determinar que parte da mão está situada paralelamente ao plano do chão [HP].

Pares de sinais como DOIS x V (Figura (83)) e TRÊS x W (Figura (84)) são evidências de que a libras faz uso fonológico do subfeixe face [FA].

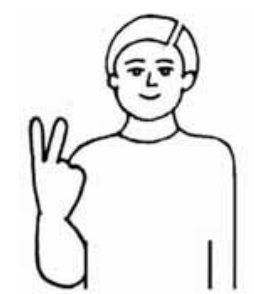

DOIS (p.560)

(a)

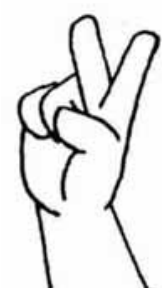

$\mathrm{V}(\mathrm{p} .1296)$

(b)

Figura (83) Capovilla \& Raphael (2001)

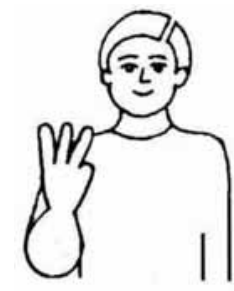

TRÊS (p.1272)

(a)

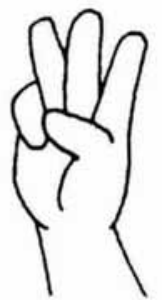

W (p.1331)

(b)

Figura (84) Capovilla \& Raphael (2001)

Embora o contraste nesses sinais pareça ser estabelecido pela orientação, o modelo de Liddell \& Johnson trata esses sinais como casos de contraste da face. Tal como concebida por Liddell \& Johnson, a orientação determina a parte da mão que está paralela ao plano do chão que, tanto o sinal TRÊS quanto o sinal W é a mesma: a base da mão. Sendo assim, o que distingue um sinal do outro é a parte da mão alocada no ponto de contato (ponto de 
articulação de cada um desses sinais), ou seja, a sua face. Enquanto no sinal TRÊS o subfeixe face é especificado pelo traço dorso [BK] (back), ele é especificado no sinal W pelo traço palma [PA].

Já pares de sinais como PESAR x DEPENDER (Figura (85)) e JUSTIÇA x MARIONETE (Figura (86)) evidenciam o caráter distintivo, nessa mesma língua, do subfeixe orientação [OR].

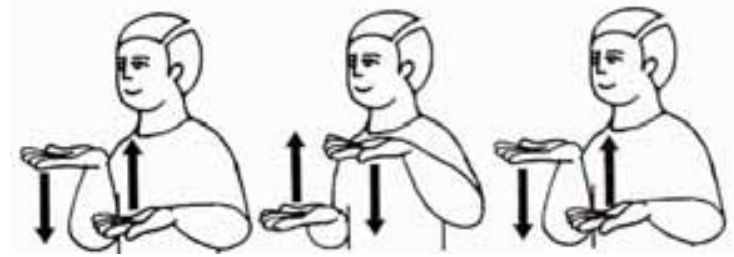

PESAR (p.1039)

(a)

Figura (85) Capovilla \& Raphael (2001)
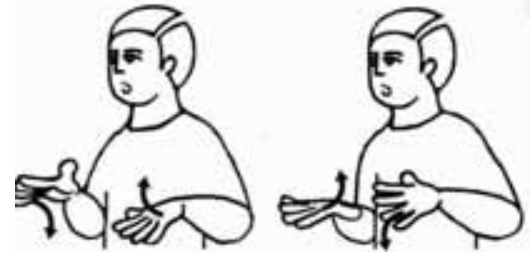

DEPENDER (p.513)

(b)

)

\author{
(1)
}

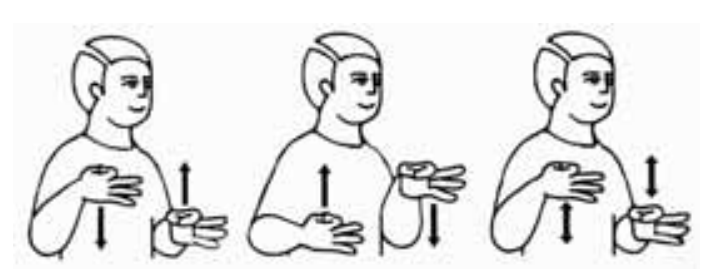

JUSTIÇA (p.791)

(a)

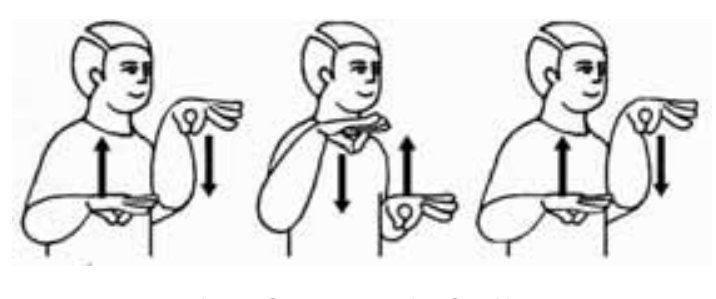

MARIONETE (p.871)

(b)

Figura (86) Capovilla \& Raphael (2001)

Como sugerem as figuras, nesses casos,o que está em jogo é a parte da mão que está paralela ao plano do chão. No sinal PESAR, é o dorso e no sinal DEPENDER, a palma. Já no sinal JUSTIÇA, é a parte radial de cada mão que está paralela ao plano do chão, enquanto no sinal MARIONETE é a palma.

\title{
2.5 Conclusão
}

Neste capítulo, apresentei e exemplifiquei, com dados da libras, o modelo fonéticofonológico com base no qual os sinais da referida língua foram descritos e analisados neste trabalho. Entre as razões que me levaram a assumir esse modelo, destaco, em primeiro lugar, o seu alto poder descritivo. Diferentemente de propostas anteriores, Liddell \& 
Johnson apresentam uma descrição mais refinada dos aspectos articulatórios envolvidos na produção dos sinais, a saber, configuração de mão, localização, movimento e orientação. Mais especificamente, eles não tratam cada um deles como todos inanalisáveis, mas sim como aspectos dotados de subaspectos com base nos quais contrastes lexicais podem ser estabelecidos.

Em segundo lugar, destaco a capacidade do modelo de Liddell \& Johnson de capturar a seqüencialidade de certos aspectos articulatórios observável durante a produção dos sinais. Ao contrário de Stokoe (1960) que propunha uma organização interna do sinal pautada na simultaneidade, Liddell \& Johnson propõem uma estrutura interna para os sinais definida em termos de segmentos que são realizados seqüencialmente, à semelhança do que ocorre nas línguas orais.

Em terceiro lugar, destaco a enorme preocupação dos autores em respeitar o pouco conhecimento que se tem a respeito das línguas sinalizadas em comparação às línguas orais e, conseqüentemente, em não assumir análises apressadas. É nesse sentido que, apesar de ser compatível com a fonologia auto-segmental, Liddell \& Johnson ainda não propõem uma geometria para os traços que utilizam na descrição dos segmentos dos sinais.

No próximo capítulo, discuto como o modelo de Liddell \& Johnson norteou a formação do banco de dados sem o qual este trabalho não poderia ter começado. No capítulo 4, apresento resultados da descrição dos traços constitutivos de segmentos dos sinais da libras. Finalmente, no capítulo 5, apresento os resultados de uma primeira análise segmental dos sinais da libras. 


\section{Capítulo 3: O banco de dados}

Conforme dito anteriormente, o objetivo deste trabalho é descrever a estrutura interna dos sinais da língua de sinais brasileira (libras) de acordo com o modelo fonéticofonológico desenvolvido por Liddell \& Johnson (2000 [1989]). Para a realização dessa descrição, utilizei o dicionário de Capovilla \& Raphael (2001) como minha principal fonte de dados.

A escolha dessa importante obra lexicográfica como fonte de dados se deve ao fato de que, até o presente momento, ela representa a mais extensa documentação lexical que se tem da libras. Além disso, o dicionário contém uma descrição dos aspectos articulatórios mais críticos envolvidos na realização dos sinais, o que representou, para este trabalho, um primeiro passo rumo a uma descrição mais refinada que se prestará a análises lingüísticas dos sinais da libras.

\subsection{Formação e organização do banco de dados}

Os sinais da libras dicionarizados em Capovilla \& Raphael (2001) estão organizados, até o momento, apenas com base na ordem alfabética de suas respectivas traduções para o português. Portanto, nele, não é possível o acesso aos sinais a partir de suas propriedades articulatórias.

Como uma tentativa pioneira de permitir esse tipo de acesso, Capovilla et al (2001) criaram um sistema computadorizado de busca de sinais a partir de suas propriedades sublexicais. Porém, esse sistema, denominado BuscaSigno, ainda não está disponível.

Sendo assim, para descrever os sinais nos termos propostos por este trabalho, foi preciso, de início, formar e organizar um banco de dados que permitisse o acesso aos sinais a partir de algumas de suas propriedades articulatórias.

A organização do banco de dados a partir das propriedades articulatórias dos sinais se deve, também, a razões metodológicas: em vez de descrever e analisar os sinais isoladamente, optei por reuni-los, primeiramente, em classes definidas por algumas de suas propriedades articulatórias, para, posteriormente, proceder à sua análise e descrição nos termos do modelo de Liddell \& Johnson (2000 [1989]). 
A descrição que aqui se apresenta toma por base esse banco de dados, que conta com 2274 sinais, escolhidos a partir de 4335 entradas do dicionário de Capovilla \& Raphael.

\subsubsection{A constituição do banco de dados: critérios de seleção dos sinais}

O dicionário de Capovilla \& Raphael (2001) se constitui de 4335 entradas lexicais, das quais 2274 são sinais simples e 861 são formas complexas da libras. As demais entradas (1205) representam, na verdade, traduções diferentes para um desses sinais simples ou para uma dessas formas complexas.

As formas identificadas como complexas no dicionário foram excluídas do banco de dados ${ }^{40}$. Como ilustram as figuras abaixo, essas formas podem ser dos seguintes tipos:

a) complexo constituído por sinais que apresentam entradas independentes no dicionário (cf. IGREJA e ANALFABETO);
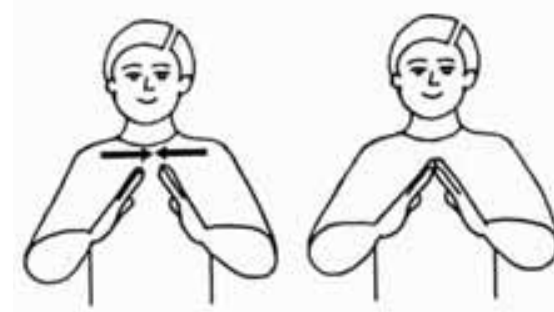

CASA

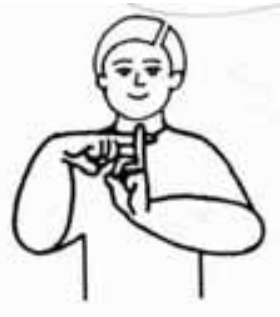

$+\quad$ CRUZ

IGREJA

Figura (87) Capovilla \& Raphael (2001:743)

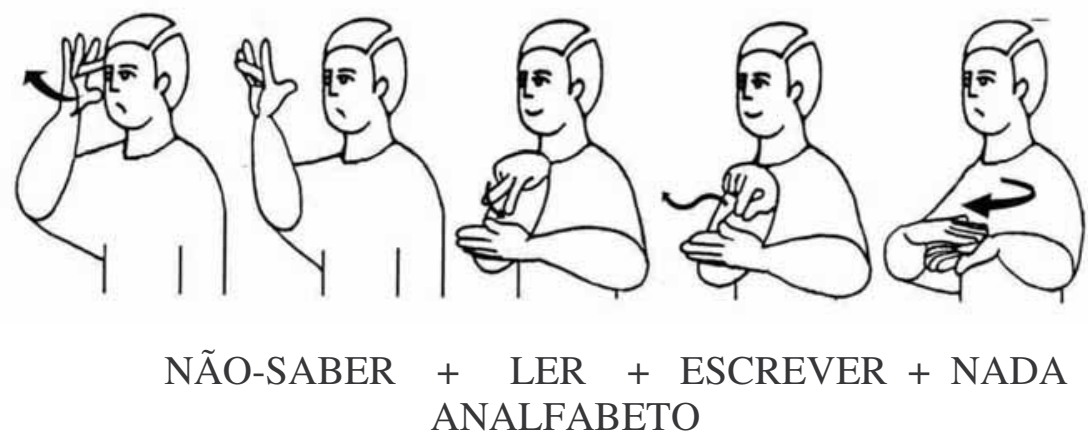

Figura (88) Capovilla \& Raphael (2001:192)

\footnotetext{
${ }^{40}$ Criei um banco de dados exclusivo para essas formas. Tal banco pode ser acessado no mesmo CD-ROM que acompanha esta dissertação.
} 
b) complexo constituído por formas que, no dicionário, não apresentam entrada própria (cf. BASQUETE);

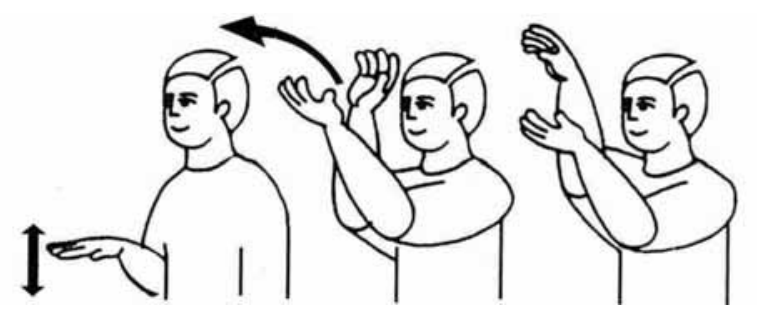

forma não-dic. isoladamente + forma não-dic. isoladamente BASQUETE

Figura (89) Capovilla \& Raphael (2001:278)

c) complexo misto, ou seja, constituído por sinais que apresentam entrada própria no dicionário e por formas não-dicionarizadas isoladamente (cf. ALÇAPÃO) e;

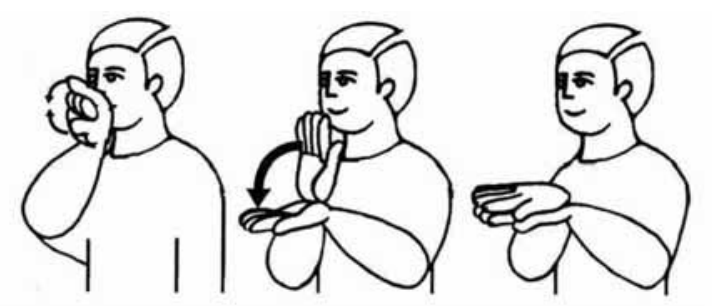

$$
\begin{aligned}
& \text { BICO (ave) + forma não-dic. isoladamente } \\
& \text { ALÇAPÃO }
\end{aligned}
$$

Figura (90) Capovilla \& Raphael (2001:172)

d) complexo formado por sinal(is) que apresenta(m) entrada própria no dicionário (ou por forma(s) não-dicionarizada(s) isoladamente) e a digitalização de uma palavra do português (cf. CLÍNICA).

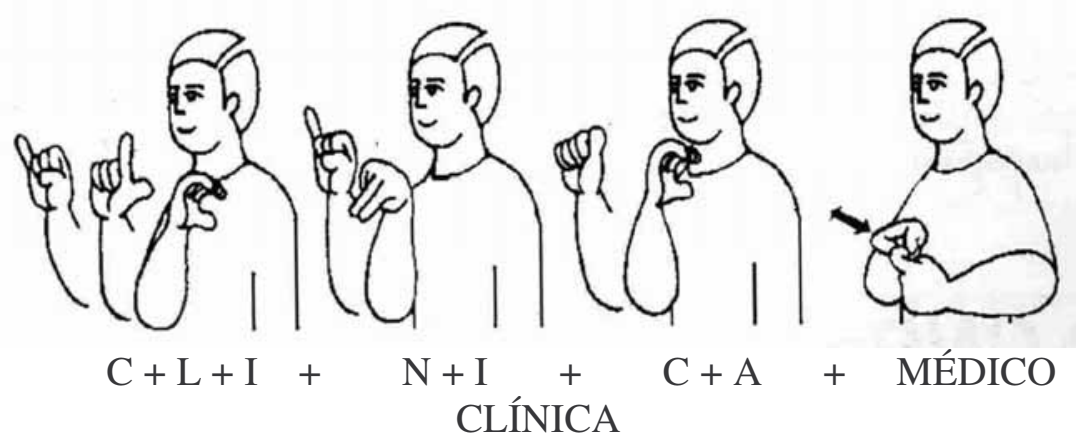

Figura (91) Capovilla \& Raphael (2001:417)

Essas formas não foram incluídas entre os sinais que compõem o banco de dados pelo 
fato de seu estatuto de item lexical composto não ser claro. A descrição apresentada pelo dicionário não permite afirmar se elas são itens lexicais derivados de um processo de composição morfológica ou se são sintagmas ou sentenças, como parece ser o caso de ANALFABETO (Figura (88)). Como o dicionário descreve formas como IGREJA e, em parte, ALÇAPÃO, simplesmente por meio da remissão aos sinais de que elas são constituídas, não é possível estabelecer se houve algum tipo de alteração em pelo menos um dos elementos do complexo. Mais especificamente, não é possível, com base no dicionário, comparar o sinal isolado e o sinal realizado enquanto parte do complexo e, dessa maneira, identificar evidências que poderiam sugerir seu caráter de sinal composto ${ }^{41}$.

Em casos como BASQUETE e, novamente em parte, como ALÇAPÃO, mesmo havendo a descrição das formas não-dicionarizadas isoladamente, também não é possível estabelecer o seu estatuto de item lexical composto. Dessa vez, essa impossibilidade decorre da inexistência de uma entrada em que a forma integrante do complexo ocorra separadamente e com a qual esta poderia ser comparada.

Por fim, casos como CLÍNICA foram excluídos não apenas pelas razões mencionadas acima, mas também por serem constituídos por uma datilologia (soletração digital). Outros sinais desse tipo encontrados no dicionário foram igualmente excluídos do escopo deste trabalho (cf. DEPARTAMENTO (Figura (92)) por não apresentarem qualquer tipo de alteração (simplificação ou adaptação), pelo menos de acordo com a descrição do dicionário $^{42}$.

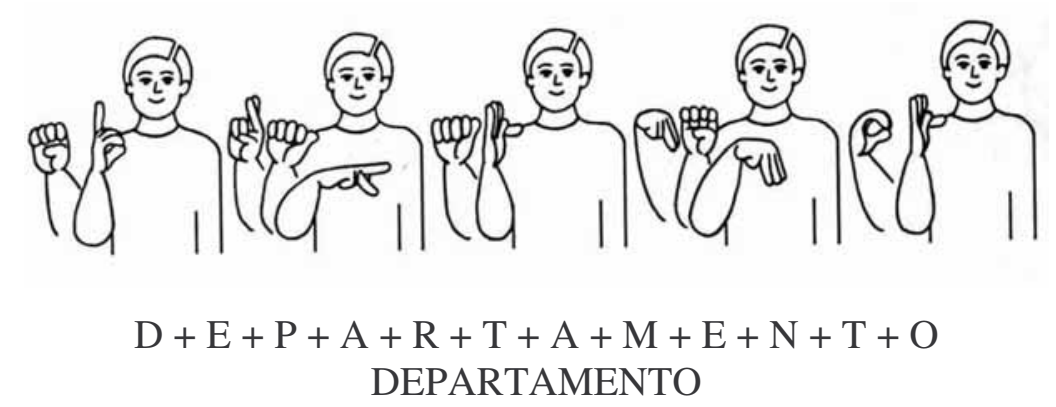

Figura (92) Capovilla \& Raphael (2001:513)

\footnotetext{
${ }^{41}$ A hipótese, aqui assumida, de que processos de composição morfológica são evidenciados por alterações na forma original de uma das partes do composto se baseia nos achados de Klima \& Bellugi (1979).

${ }^{42}$ É importante mencionar que sinais como AZUL (Capovilla \& Raphael, 2001:254), derivado da soletração da palavra 'azul' do português, assim como os sinais para as letras, são parte do banco de sinais. A inclusão de sinais como AZUL no banco de sinais se deve ao fato de que já se pode observar na forma dicionarizada a ocorrência de processos de simplificação / adaptação que tornaram esse sinal parecido a outros sinais da libras. Mais especificamente, ao invés de o sinal AZUL consistir de uma seqüência de configurações de mão, ele se transformou em um sinal com apenas duas configurações de mão.
} 
Excluí também as 1205 entradas que representam traduções diferentes para alguns dos sinais simples ou para algumas das formas complexas mencionadas acima pelo fato de não apresentarem nenhuma diferença articulatória em relação a eles, pelo menos de acordo com o tratamento que lhes é dado no dicionário ${ }^{43}$.

Dessa forma, o banco de dados que reúne os sinais a serem analisados e descritos neste trabalho é formado por 2274 itens lexicais simples da libras, o que, como indica a tabela (1) a seguir, representa $52 \%$ de todas as entradas lexicais existentes no dicionário.

Tabela (1)

\begin{tabular}{|l|c|c|}
\hline Tipo de sinal & quantidade & $\%$ \\
\hline Sinais simples & $2274^{44}$ & $52 \%$ \\
\hline Formas complexas (sinal + sinal) & 283 & $7 \%$ \\
\hline Formas complexas (formas não dic. isoladamente) & 99 & $2 \%$ \\
\hline Formas complexas (sinal(is) + forma(s) não dic. isoladamente ) & 326 & $8 \%$ \\
\hline Formas complexas (sinal + digitalização) & 73 & $2 \%$ \\
\hline Soletração digital (datilologia) & 75 & $2 \%$ \\
\hline Entradas que remetem a sinais/formas de um dos tipos acima & 1205 & $28 \%$ \\
\hline Total de verbetes & 4335 & $100 \%$ \\
\hline
\end{tabular}

\subsubsection{Critérios de organização do banco de dados ${ }^{45}$}

Uma vez selecionados os sinais a serem analisados e descritos neste trabalho, estabeleci alguns critérios para a sua organização, baseando-me em algumas de suas propriedades articulatórias, consideradas na proposta de Liddell \& Johnson.

Os sinais foram classificados por meio dos seguintes critérios:

\footnotetext{
${ }^{43}$ Assim como no caso das formas complexas constituídas por sinais que apresentam entrada própria no dicionário, a descrição dos verbetes que representam outras traduções em português para um dos sinais simples ou para parte(s) de uma dessas formas complexas é puramente remissiva. Como exemplo, pode-se citar o sinal ACABAR (p.142), que pode ser encontrado no dicionário de Capovilla \& Raphael por meio de seis outras entradas, a saber, BASTA (p.278), CHEGA (1) (p.397), CONCLUIR (p.442), ENCERRAR (p.584), FINDAR (p.671) e TERMINAR (p.1245).

${ }^{44}$ Estão incluídos aqui cinco sinais realizados unicamente por meio de expressões não-manuas, listados na nota 46.

${ }^{45}$ Agradeço ao Prof. Dr. Marcos Lopes por construir o banco de dados que viabilizou este trabalho, por me ensinar a operar com o programa Access, utilizado para construir o banco de sinais, e por me orientar diversas vezes ao longo de todo o tempo em que trabalhei com esse banco.
} 

a) [ \pm 1mão]
b) $[ \pm$ movimento]
c) $[ \pm$ movimento local $]$
d) [ \pm 1 configuração de mão]
e) $[ \pm$ contato $]$
f) [ \pm marcação não-manual]
g) $[ \pm \text { reduplicação }]^{46}$

\subsubsection{1 [}

Este primeiro critério foi utilizado para distinguir sinais articulados só com uma mão, como IDADE (Figura (93)), de sinais que, semelhantemente a ANIVERSÁRIO (2) (Figura (94)), são produzido com as duas.

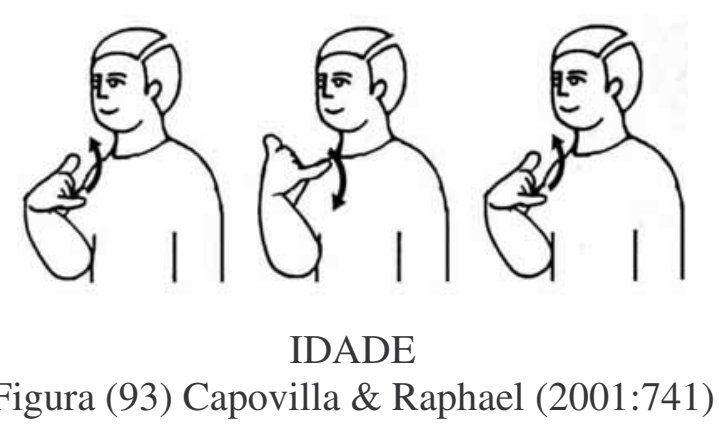

\footnotetext{
${ }^{46}$ Como visto no capítulo anterior, os critérios selecionados para a organização do banco de dados, em sua maioria, dizem respeito a traços distintivos que, de acordo com o modelo de Liddell \& Johnson, fazem parte dos segmentos que constituem os sinais. Mais especificamente, os critérios $[ \pm$ movimento] e $[ \pm$ movimento local] foram estabelecidos com base em dois dos traços que compõem o feixe segmental, enquanto os critérios [ \pm 1 configuração de mão] e [ \pm contato] foram estabelecidos com base em dois dos traços que constituem o feixe articulatório. Já o critério [ \pm marcação não-manual] representa o feixe de traços à parte no modelo em questão. Já os critérios [ \pm 1 mão] e [ \pm reduplicação], apesar de não serem baseados em traços, foram incluídos entre os critérios classificatórios pelo fato de que também tenho interesse em analisar a estrutura segmental dos sinais. Como mencionei no capítulo 2, sinais feitos com duas mãos requerem duas representações segmentais, uma para cada mão e, como tratarei mais adiante, sinais classificados como reduplicados são aqueles que apresentam o seu movimento realizado duas vezes, fato diretamente relacionado com a sua estrutura segmental.
} 


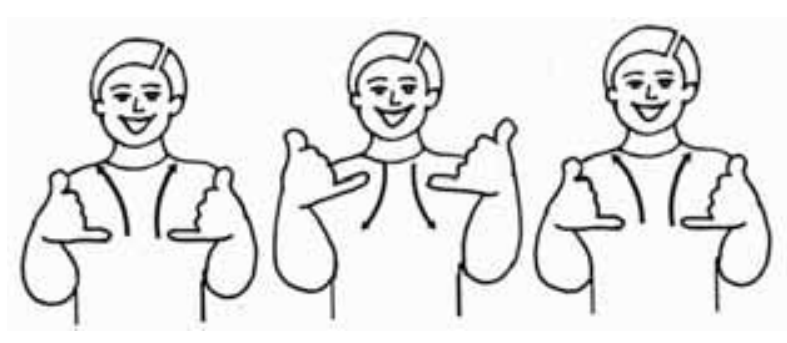

ANIVERSÁRIO

Figura (94) Capovilla \& Raphael (2001:199)

\subsubsection{2 [ \pm movimento]}

Já com base no segundo critério, $[ \pm$ movimento], pude diferenciar sinais articulados sem movimento, tais como o sinal NÚMERO-OITO (Figura (95)), de sinais produzidos com movimento, semelhantemente a SOGRO (Figura (96)).

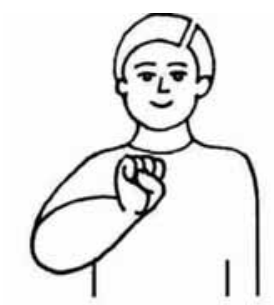

NÚMERO-OITO

Figura (95) Capovilla \& Raphael (2001:958)

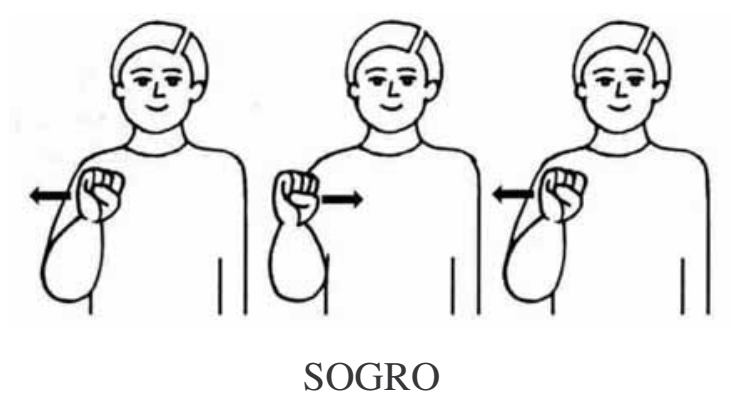

Figura (96) Capovilla \& Raphael (2001:1206)

Embora a especificação negativa e a positiva de tal propriedade articulatória sejam suficientes para dar conta dos tipos de sinais produzidos com uma mão, o mesmo não ocorre com os sinais realizados com as duas mãos. Como mostram as ilustrações a seguir, além de sinais como AMÉRICA (Figura (97)) e FESTEJAR (Figura (98)), em que as duas 
mãos ficam, respectivamente, ou estáticas, ou em movimento, há sinais como REMÉDIO (Figura (99)), em que apenas uma das mãos se move, enquanto a outra fica estacionada.

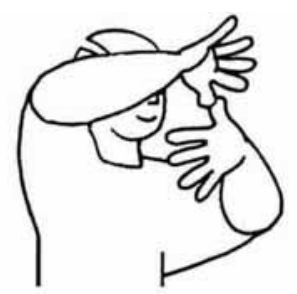

AMÉRICA

Figura (97) Capovilla \& Raphael (2001:187)
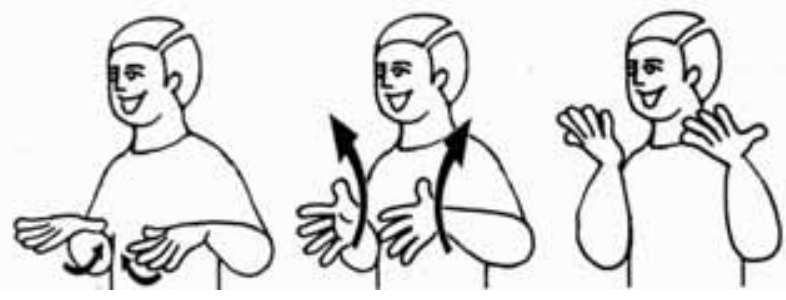

FESTEJAR

Figura (98) Capovilla \& Raphael (2001:603)

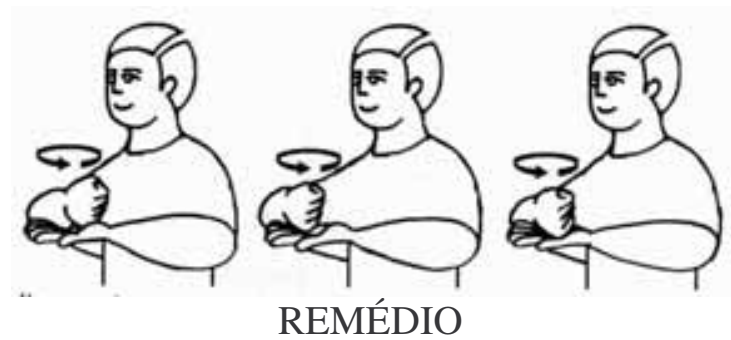

Figura (99) Capovilla \& Raphael (2001:1132)

Para capturar essa terceira possibilidade, acrescentei o critério $[ \pm 1 \text { mão parada }]^{47}$ como

47 A especificação positiva desse critério descreve sinais em que a mão não-dominante, passiva, funciona
como ponto de articulação do sinal (não apenas de contato, mas também de referência). Apesar disso, atribuí
o valor positivo desse critério ao sinal JESUS-CRISTO (p.778), único sinal, dentre os selecionados de
Capovilla \& Raphael, em que, curiosamente, as mãos alternam seus papéis, ativo e passivo, ao longo da sua
articulação. Sinais como esse são reportados na literatura sobre ASL (ver Padden \& Perlmutter (1987) citado
em Hulst (1996)). Entre os sinais feitos com uma das mãos parada, encontrei um outro caso bastante
interessante. Trata-se do sinal NOIVAR (p. 949) que, curiosamente, representa um contra-exemplo à
afirmação de Battison (2000 [1978]) de que a oposição esquerdo versus direito não é funcional nas línguas
sinalizadas. Tal sinal contrasta com o sinal CASAR (p. 372) unicamente no que diz respeito à mão que 
um subcritério do critério [ \pm movimento]. Também acrescentei a este um outro subcritério, [ \pm movimento alternado], dado que há sinais como BICICLETA (Figura (100)) em que as mãos, diferentemente do que acontece em sinais como FESTEJAR (Figura (98)), não se movem simultaneamente, mas sim alternadamente ${ }^{48}$.

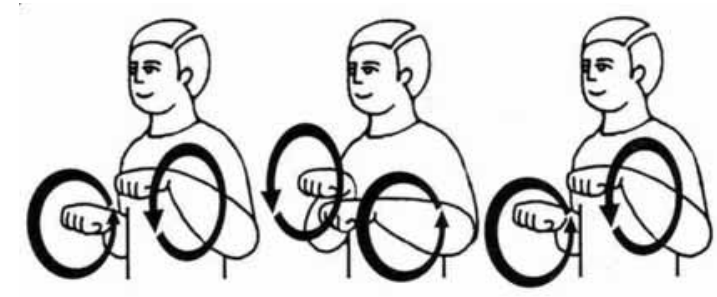

BICICLETA

Figura (100) Capovilla \& Raphael (2001:291)

\subsubsection{3 [ \pm movimento local]}

O terceiro critério classificatório, [ \pm movimento local] permitiu a distinção de sinais levando em conta a ausência (cf. CABRA (Figura (101)) ou a presença (cf. BARATA (Figura (102)) de movimentos locais, ou seja, a ausência ou presença de movimentos rápidos, repetidos e, em geral, incontáveis dos dedos ou do pulso.

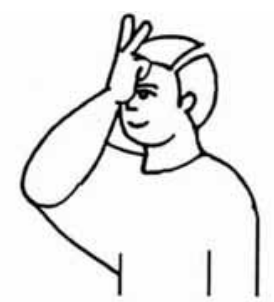

CABRA

Figura (101) Capovilla \& Raphael (2001:332)

desempenha os papéis ativo e passivo: enquanto em CASAR a mão ativa é a direita e a mão passiva é a esquerda, em NOIVAR, a situação é contrária, ou seja, a mão ativa é a esquerda e a mão passiva é a direita.

${ }^{48}$ Encontrei no dicionário cinco sinais (ALMA (p.180), AMARRAR (p.185), MACARRÃO (p.851), NÓ (p.948) e PRESENTE (p.1077)) que apresentam movimento alternado seguido de movimento simultâneo. Dado o pequeno número de sinais como esses, não acrescentei nenhum outro subcritério aos critérios já mencionados e tratei tais sinais indistintamente dos outros sinais realizados apenas com movimento alternado. É interessante notar que esses sinais também podem ser considerados evidências em favor do papel da seqüencialidade na realização dos itens lexicais das línguas sinalizadas, uma vez que, além de não ser possível produzir movimentos alternados e simultâneos ao mesmo tempo, eles não são produzidos em qualquer ordem: primeiramente as mãos descrevem círculos alternados e, somente depois, se movem retilínea e simultaneamente em direções opostas. 


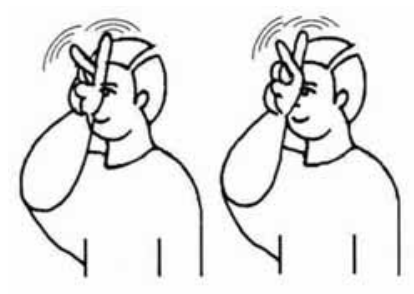

BARATA

Figura (102) Capovilla \& Raphael (2001:275)

\subsubsection{4 $[ \pm 1$ configuração de mão]}

O quarto critério se vincula à configuração de mão, ou seja, à(s) forma(s) como a(s) mão(s) é(são) disposta(s) quando da realização de um sinal. Convencionei classificar, por meio da especificação positiva desse critério, sinais em que a configuração de mão se mantém a mesma do início ao fim da produção do sinal, como no sinal TER (Figura (103), e, através da especificação negativa, sinais em que há mudança de configuração de mão, como no sinal AMANHÃ (Figura (104)).

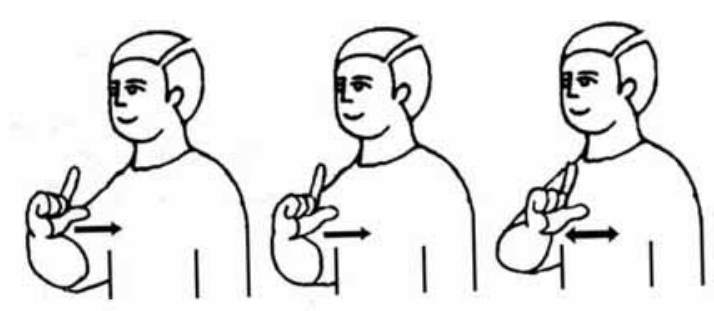

TER

Figura (103) Capovilla \& Raphael (2001:1242)

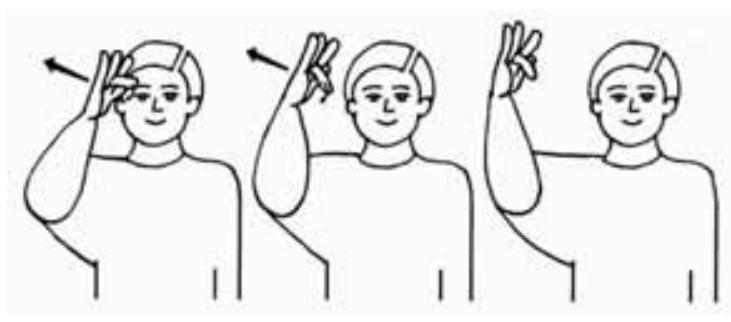

AMANHÃ

Figura (104) Capovilla \& Raphael (2001:183)

Mais uma vez, os dois diferentes valores desse critério foram suficientes para capturar os tipos de sinais feitos com uma mão. Entretanto, o mesmo não se pode dizer em relação 
aos sinais articulados com as duas mãos. Nesses casos, a especificação negativa do critério [ \pm 1 configuração de mão] não foi capaz de diferenciar, de um lado, sinais produzidos com as duas mãos em movimento, sem mudança de configuração, mas exibindo formas diferentes em cada uma delas (cf. PÁRA-QUEDAS (Figura (105))); e, de outro, sinais articulados também com duas mãos em movimento, mas com ambas as mãos mudando sua configuração (cf. JOVEM (Figura (106))).

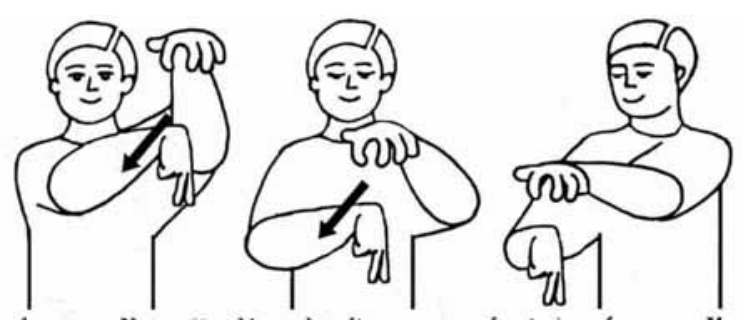

PÁRA-QUEDAS

Figura (105) Capovilla \& Raphael (2001:1010)

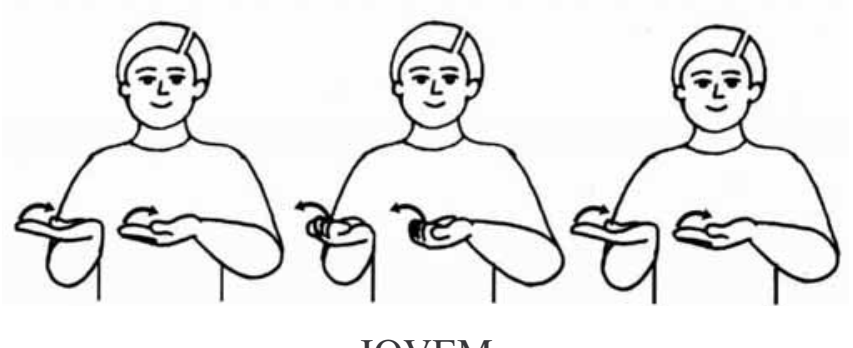

JOVEM

Figura (106) Capovilla \& Raphael (2001:787)

A especificação negativa do critério [ \pm 1 configuração de mão] também não foi capaz de diferenciar, de um lado, sinais realizados com uma mão parada e outra em movimento, sem mudança de configuração, mas exibindo formas diferentes em cada uma delas (cf. COMBINAR (1) (Figura (107)); e, de outro, sinais também produzidos com uma mão parada e outra em movimento, configuradas diferentemente e com mudança de configuração na mão dominante (cf. ALUGAR (Figura (108)) ${ }^{49}$.

\footnotetext{
${ }^{49}$ Encontrei no dicionário sete sinais (DERRAMAR (p.516), ESTRELA-DO-MAR (p.630), FUNIL (p.694), GRAVATA (p.719), GRAVIOLA (p.720), PIMENTÃO (p.1045) e PORCO-ESPINHO (p.1063)) em que há mudança de configuração na mão dominante, mas em que a configuração incial de tal mão é igual à da mão não-dominante. Por tais sinais representarem uma parcela muito pequena dos sinais feitos com uma mão parada e com mudança de configuração na mão dominante, não os tratei distintamente daqueles em que a configuração inicial da mão dominante é diferente da configuração da mão não-dominante.
} 


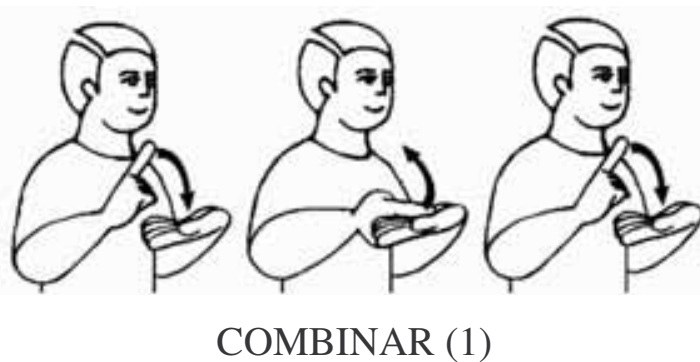

Figura (107) Capovilla \& Raphael (2001:432)

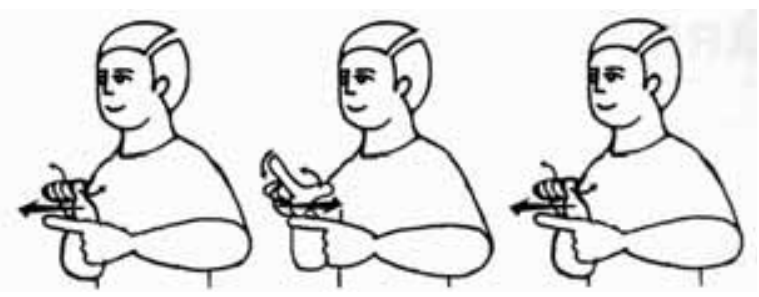

ALUGAR

Figura (108) Capovilla \& Raphael (2001:182)

Porém, mesmo ciente disso, optei por não sobrecarregar o banco de dados com mais critérios de classificação e deixar distinções mais refinadas como as apontadas acima para um momento posterior.

\subsubsection{5 $[ \pm$ contato $]$}

Com base na quinto critério, [ \pm contato], distingui sinais cuja realização não prevê qualquer tipo de contato da(s) mão(s) com alguma parte do corpo, de sinais cuja articulação prevê esse contato. Os sinais MADRUGADA (Figura (109)) e HOMEM (Figura (110)) exemplificam, respectivamente, casos como esses.

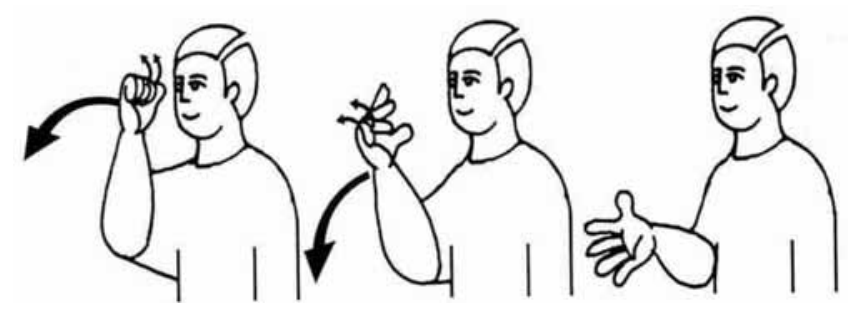

MADRUGADA

Figura (109) Capovilla \& Raphael (2001:855) 


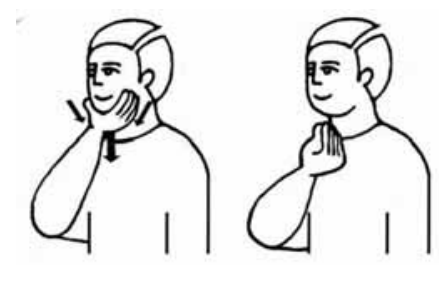

HOMEM

Figura (110) Capovilla \& Raphael (2001:736)

\subsubsection{6 [ \pm marcação não-manual $]$}

O sexto critério utilizado diz respeito às marcações não-manuais, ou seja, expressões faciais e movimentos da cabeça e do torso que estão previstos entre os traços articulatórios que constituem um sinal ${ }^{50}$. Com base nesse critério, foi possível distinguir sinais que não apresentam, entre os traços que o descrevem articulatoriamente, uma marcação não-manual (cf.CIDADE (figura (111)), de sinais que, como MAGRO (Figura (112)), são dotados dessa propriedade articulatória.

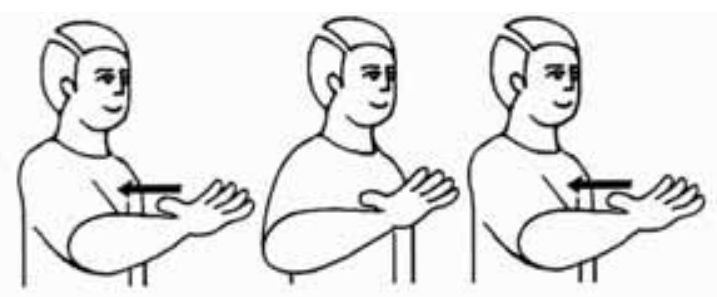

CIDADE

Figura (111) Capovilla \& Raphael (2001:408)

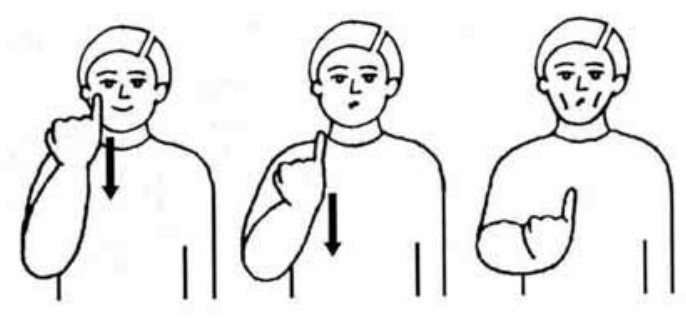

MAGRO

Figura (112) Capovilla \& Raphael (2001:856)

\footnotetext{
${ }^{50}$ Identifiquei no dicionário apenas cinco sinais da libras que são articulados unicamente por meio de expressões não-manuais, a saber, ASSOBIAR (p.235), BUFAR (p.324), MASTIGAR (p.875), ROUBAR (2) (p.1154) e SEXO (ato sexual) (p.1194). Desses cinco, os dois últimos podem, respectivamente, ocorrer como marcação não-manual de ROUBAR (1) (dicionarizado sem essa marcação) e MOTEL (p.923).
} 
É importante ressaltar que, pelo fato de essas marcações estarem previstas entre os traços articulatórios que descrevem o sinal, elas se diferenciam de outras marcas nãomanuais existentes na libras que são empregadas por razões sintáticas ou pragmáticodiscrusivas.

\subsubsection{7 [ \pm reduplicação]}

Por fim, o sétimo critério com base no qual classifiquei os sinais do banco de dados refere-se à característica reduplicada ou não do movimento. Assim, pude distinguir sinais cuja realização consiste em repetir o mesmo movimento duas vezes, tais como NÚMERO (Figura (113)); de outros em que o movimento não se repete ou em que o número de vezes não é especificado pelo dicionário. Exemplos desses dois últimos casos são, respectivamente, os sinais ROSTO (Figura (114)) e AÇÚCAR (Figura (115)).

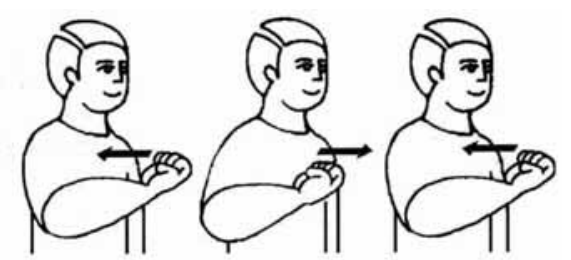

NÚMERO

Figura (113) Capovilla \& Raphael (2001:956)

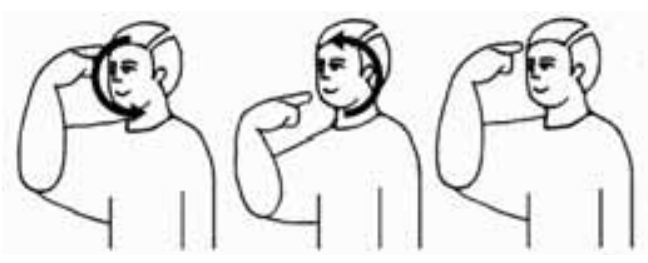

ROSTO

Figura (114) Capovilla \& Raphael (2001:1152)

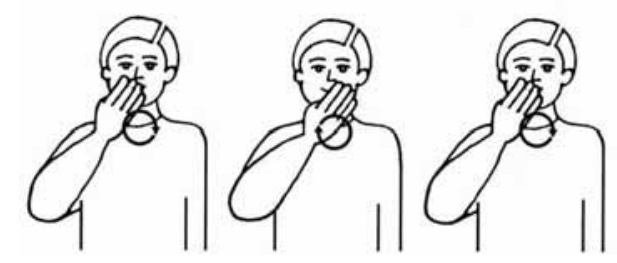

AÇÚCAR

Figura (115) Capovilla \& Raphael (2001:153) 
Com isso, foi possível reunir os sinais em classes definidas a partir da especificação positiva e negativa dos critérios considerados e, assim, identificar as propriedades que são mais ou menos recorrentes no conjunto de itens lexicais selecionados e, provavelmente, no léxico da libras. Além de facilitar o trabalho de descrição e análise apresentados nos capítulos subseqüentes, dispor de um recurso como esse facilitará também trabalhos futuros que venham a explorar um, alguns ou todos os aspectos articulatórios com base nos quais os sinais foram classificados no banco de dados. A tabela (2) a seguir mostra a quantidade de sinais que exibem as propriedades relevantes e a porcentagem.

Tabela (2)

\begin{tabular}{|l|l|c|c|}
\hline Propriedade articulatória & valor & quantidade & $\begin{array}{c}\text { \% no banco } \\
\text { de sinais }\end{array}$ \\
\hline Número de mãos & uma mão & 1002 & $44 \%$ \\
\cline { 2 - 4 } & duas mãos & 1267 & $56 \%$ \\
\hline \multirow{2}{*}{ Uma mão / movimento } & - & 119 & $5 \%$ \\
\cline { 2 - 4 } & + & 883 & $39 \%$ \\
\hline Duas mãos / movimento & - & 94 & $4 \%$ \\
\cline { 2 - 4 } & $\begin{array}{l}\text { movimento } \\
\text { simultâneo }\end{array}$ & 549 & $24 \%$ \\
\cline { 2 - 4 } & $\begin{array}{l}\text { movimento } \\
\text { alternado }\end{array}$ & 114 & $5 \%$ \\
\cline { 2 - 4 } & $\begin{array}{l}\text { uma } \\
\text { mãos parada }\end{array}$ & 510 & $22 \%$ \\
\hline Configuração de mão & uma & 1334 & $59 \%$ \\
\cline { 2 - 4 } & mais de uma & 935 & $41 \%$ \\
\hline Contato & - & 1070 & $47 \%$ \\
\cline { 2 - 5 } & + & 1199 & $53 \%$ \\
\hline Reduplicação & - & 1897 & $84 \%$ \\
\hline Marcação não-manual & + & 372 & $16 \%$ \\
\hline & + & 1885 & $83 \%$ \\
\hline & + & 384 & $17 \%$ \\
\hline
\end{tabular}




\begin{tabular}{|l|c|c|c|}
\hline Movimento local & - & 2097 & $92 \%$ \\
\cline { 2 - 4 } & + & 172 & $8 \%$ \\
\hline
\end{tabular}

\subsection{Classes e subclasses de sinais}

Como dito na seção anterior, depois de classificar os sinais do banco de dados de acordo com os critérios selecionados, tornou-se possível acessá-los por meio de alguns de seus aspectos articulatórios. Mais precisamente, tornou-se possível buscar no banco de dados tanto sinais especificados positivamente quanto aqueles especificados negativamente para cada uma das propriedades articulatórias consideradas, como a tabela (2) acima já mostrou.

Porém, esse não foi o único tipo de buscas que o banco de dados permitiu. Também pude acessar os sinais levando em conta mais de um critério ao mesmo tempo e, assim, observar correlações entre eles.

Com base na conjugação de mais de um critério, foi possível elaborar buscas que me permitiram observar as combinações que reúnem mais ou menos sinais, bem como as combinações que não são atestadas em nenhum sinal do banco. Embora, para este trabalho, a realização dessas buscas tenha objetivado basicamente mostrar as potencialidades do banco de sinais, ela também objetivou estimular e facilitar pesquisas futuras que venham a comparar esses resultados com os relativos a outras línguas sinalizadas e que venham a investigar por que certas combinações de traços são mais raras ou não são possíveis.

Como ilustração de buscas baseadas na combinação de mais de um critério classificatório, apresento aqui, passo a passo, a formulação das buscas envolvendo sinais feitos com uma mão.

Primeiramente, correlacionei sinais feitos com uma mão à ausência ou presença de movimento. Para isso, conjuguei o valor positivo do critério [ \pm 1 mão] com os dois possíveis valores do critério [ \pm movimento]. A partir disso, derivei as duas buscas que fiz no banco, a saber: [+ 1 mão, - movimento] e [+ 1 mão, + movimento]. Por meio dessas buscas, foi possível reunir em grupos diferentes sinais como NÚMERO-OITO (Figura (95)) e sinais como SOGRO (Figura (96)), bem como observar qual deles apresenta mais ou menos sinais. Conforme já mostrou a tabela (2) acima, sinais semelhantes a S totalizam 119 
no banco de dados e sinais semelhantes a SOGRO, 883.

Dado o considerável número de critérios e, conseqüentemente, de combinações possíveis de seus valores, utilizei esquemas arbóreos para a elaboração dessas buscas, o que é ilustrado pelas buscas subseqüentes ${ }^{51}$.

Acrescentei o critério [ \pm movimento local] às buscas que correlacionavam número de mãos e ausência ou presença de movimento, mencionadas anteriormente. A conjugação dos diferentes valores desse critério com as buscas já estabelecidas, gerou quatro novas buscas que revelaram que, pelo menos entre os sinais do banco de dados, predominam sinais articulados com uma mão em movimento e sem movimento local.

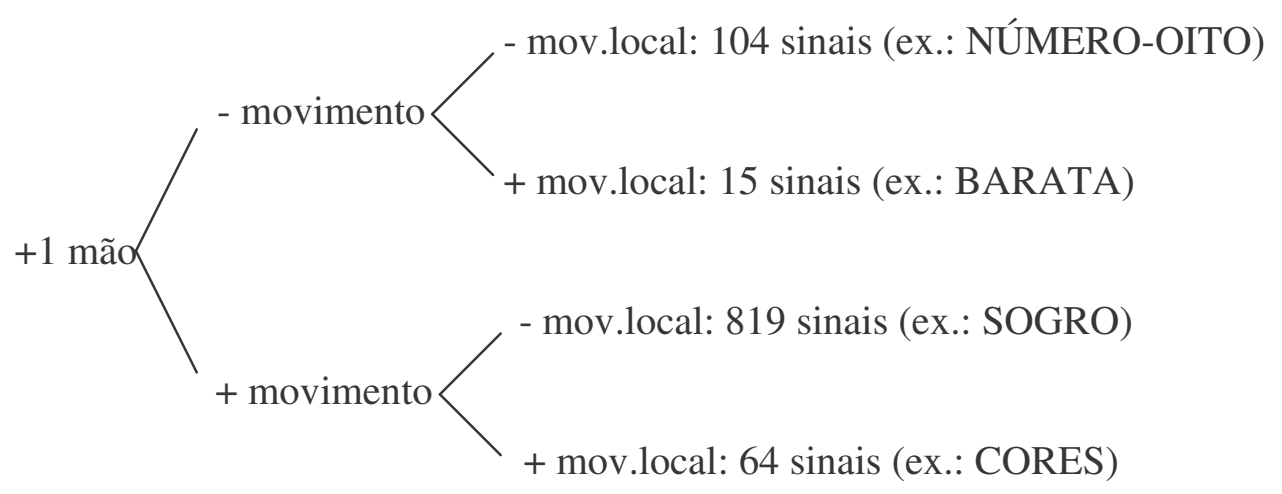

Seguindo o mesmo procedimento, incluí dessa vez o critério [ \pm 1 configuração de mão] que, combinado com as quatro buscas já realizadas, gerou oito novas buscas. Essas buscas, ilustradas pelo esquema arbóreo a seguir, revelaram que predominam no banco de dados sinais articulados com uma mão em movimento, sem movimento local e com apenas uma configuração de mão.

Tais buscas também revelaram, além dos tipos menos numerosos de sinais, tipos não atestados entre os sinais que compõem o banco de sinais. Não foram encontrados, por exemplo, sinais realizados com uma mão, sem movimento, com ou sem movimento local e com mudança de configuração.

\footnotetext{
${ }^{51}$ Agradeço ao Prof. Dr. Leland E. McCleary por me orientar na elaboração das buscas que fiz no banco de dados.
} 


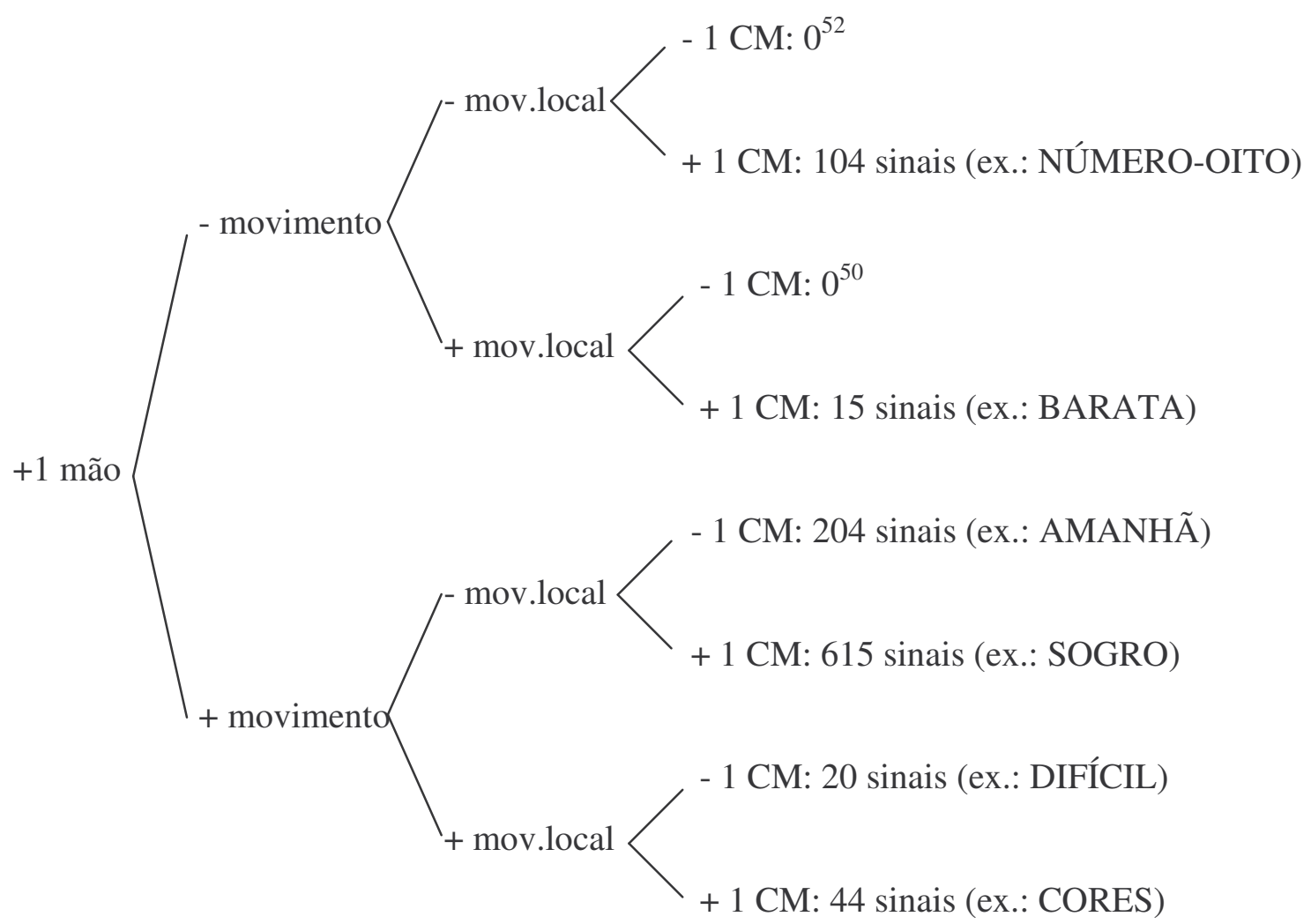

A seguir, acrescentei o critério [ \pm contato]. A combinação dos dois valores desse critério com as buscas anteriores derivou outras doze buscas, como representa o esquema a seguir.

\footnotetext{
${ }^{52}$ Considerando que, de acordo com a análise de Liddell \& Johnson, a existência de mais de uma configuração de mão em um mesmo sinal só se dá quando este é realizado com movimento, a não-ocorrência de sinais destes tipos é esperada, dado que, como se pode ver pelo esquema arbóreo, o valor do critério [ \pm movimento] é negativo. Porém, como se pode ver na tabela (3) do anexo desta dissertação, houve outras buscas que, sem nenhuma razão, não encontraram sinais no banco de dados.
} 


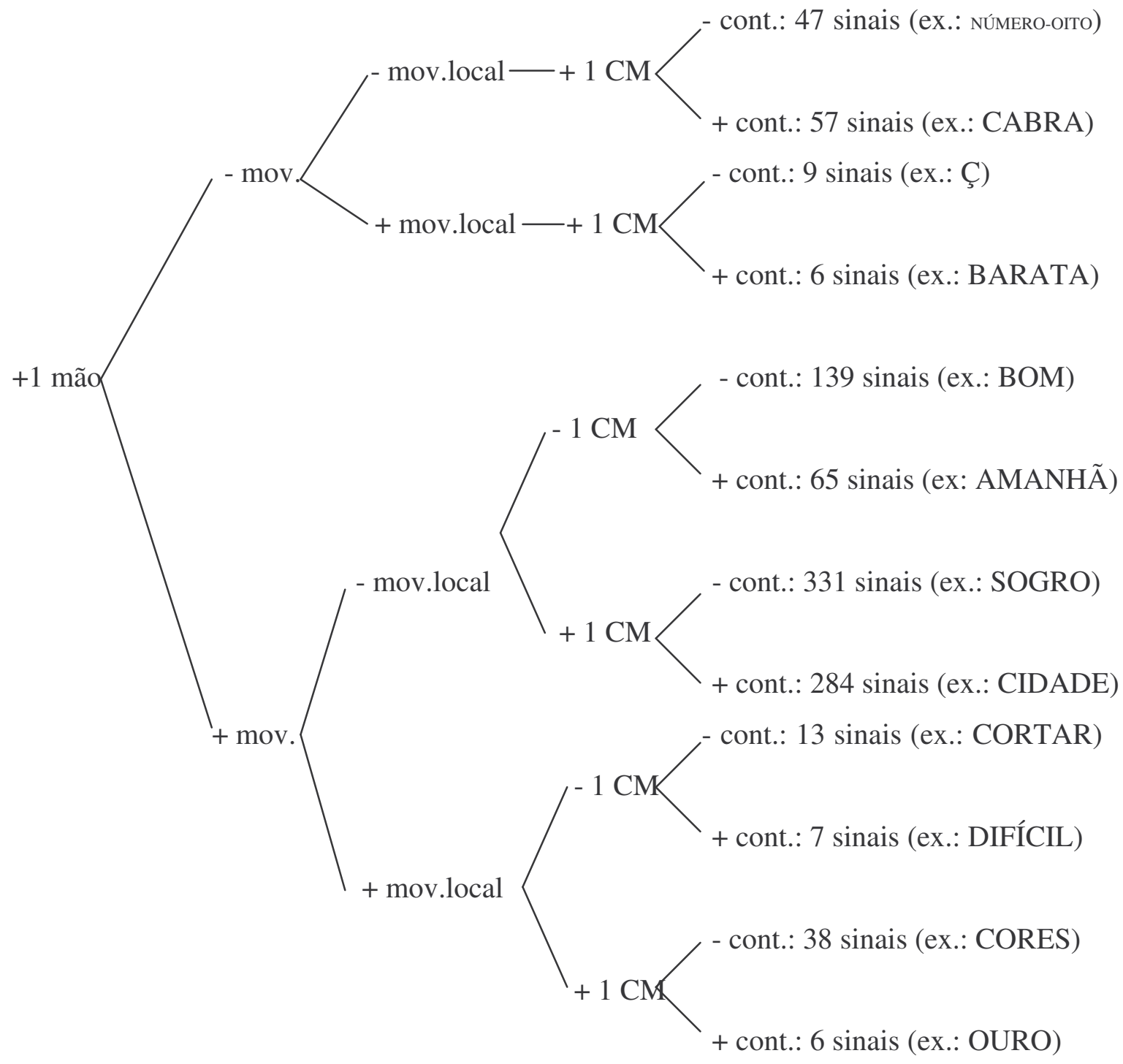

Por fim, criei novas buscas considerando os critérios [ \pm marcação não-manual] e [ \pm reduplicação]. Dado que este último critério é compatível somente com sinais articulados com movimento, não realizei as buscas em que a especificação do critério [ \pm movimento] era negativa.

Com isso, cheguei a todas as combinações possíveis e, consequientemente, a grupos de sinais definidos por um dos valores de todos os critérios considerados. Depois de proceder da mesma forma com os sinais realizados com duas mãos, pude observar, como mostram as tabelas (1) e (2) do anexo desta dissertação, quais são os grupos mais e menos numerosos de sinais, bem como quais combinações de valores dos critérios não encontram sinais no 
banco (cf. tabela (3) no anexo deste trabalho) ${ }^{53}$.

\section{3 Conclusão}

Neste capítulo, apresentei (i) o que me levou a formar um banco de dados para este trabalho, (ii) como esse banco está organizado e (iii) quais são suas potencialidades.

Em relação às razões pelas quais formei o banco, devo destacar a necessidade metodológica de acessar os sinais por meio de suas propriedades articulatórias. Entretanto, é importante ressaltar que esse banco não visa a ser mais eficiente do que o dicionário ou mesmo do que o BuscaSigno. Na verdade, ele foi criado com o objetivo de facilitar este trabalho e, eventualmente, trabalhos futuros. Mais especificamente, ele visa a pesquisas lingüísticas e não ao uso leigo, tal como o dicionário e, futuramente, o BuscaSigno.

Já em relação à organização do banco de sinais, é importante dizer que ela está totalmente calcada no modelo assumido neste trabalho para a descrição e análise dos sinais. Como se verá nos capítulos que seguem, além de os critérios terem sido selecionados com base nas propriedades articulatórias relevantes na proposta de Liddell \& Johnson, há também uma tentativa de classificar os sinais levando em conta a seqüencialidade que estes apresentam. Sendo assim, é possível acessar sinais que apresentam mais de uma configuração de mão, mais de uma localização, mais de um contato, etc.

Por fim, em relação às potencialidades do banco de sinais, é importante dizer que elas poderão ser exploradas por outras pesquisas. Como exemplo disso, pode-se mencionar o fato de que há correlações de critérios que, embora não tenham sido feitas por não serem necessárias para este trabalho, podem vir a ser para outros.

\footnotetext{
${ }^{53}$ A elaboração das buscas para sinais articulados com duas mãos seguiu o mesmo esquema. A única diferença é que para esses sinais os esquemas arbóreos contaram com critérios como [ \pm 1 mão parada] e [ \pm movimento alternado], não aplicáveis a sinais feitos apenas com uma mão.
} 


\section{Capítulo 4: Descrição dos traços segmentais e articulatórios dos sinais da libras}

Como dito no capítulo anterior, a organização dos sinais selecionados de Capovilla \& Raphael (2001) no banco de dados tornou possível acessá-los a partir da presença ou ausência de algumas propriedades articulatórias. Esse acesso, como mostro a seguir, facilitou a descrição dessas propriedades estabelecidas a partir do modelo de Liddell \& Johnson (2000 [1989]).

\subsection{Articuladores manuais}

Ao separar, através do critério [ \pm 1 mão], os sinais da libras que são produzidos com as duas mãos daqueles que são articulados só com uma delas, identifiquei alguns casos interessantes que reporto aqui.

O primeiro deles diz respeito a pares de sinais como AVISAR x ANUNCIAR (Figura (116)) e IDADE x ANIVERSÁRIO (2) (Figura (117)).

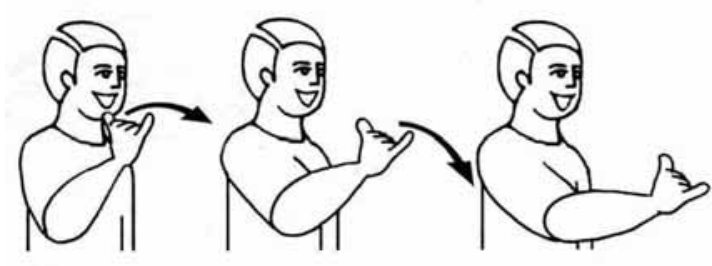

AVISAR (p.252)

(a)

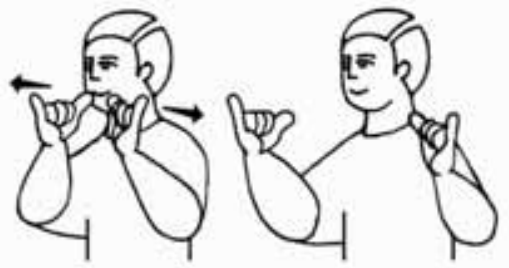

ANUNCIAR (p.555)

(b)

Figura (116) Capovilla \& Raphael (2001)

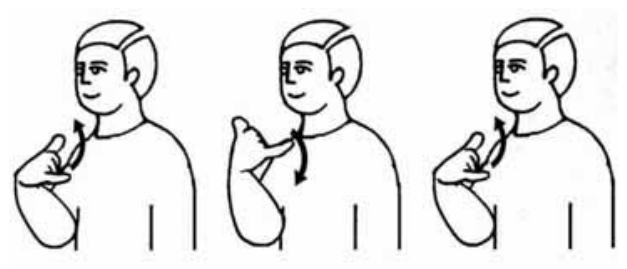

IDADE (p.741)

(a)

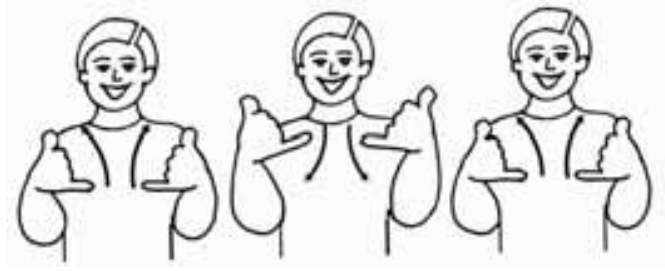

ANIVERSÁRIO (p.199)

Figura (117) Capovilla \& Raphael (2001) 
Ao que parece, nesses sinais, o número de mãos envolvidas em sua articulação é, se não o único, pelo menos um dos aspectos com base nos quais eles contrastam. Embora, na literatura a respeito das línguas sinalizadas, encontrem-se menções a casos como esses (ver Klima \& Bellugi, 1979; Hulst, 1996), reporta-se também que eles são pouco numerosos.

De qualquer forma, a existência de pares como AVISAR x ANUNCIAR e IDADE $\mathrm{x}$ ANIVERSÁRIO é particularmente interessante para um trabalho que se apóia no modelo teórico de Liddell \& Johnson, pois levanta a possibilidade de haver, além dos vários traços distintivos propostos pelos autores, outros traços com base nos quais contrastes lexicais podem ser estabelecidos.

Além de encontrar, no dicionário de Capovilla \& Raphael, sinais que sugerem o valor contrastivo do número de mãos empregadas na realização de um sinal, identifiquei outros sinais que sugerem uma outra função, na libras, para esse aspecto articulatório. Como se pode ver nas figuras em (b) e em suas respectivas traduções para o português, o número de mãos empregadas na produção de um sinal pode estar associado a um processo gramatical de "intensificação" do significado.

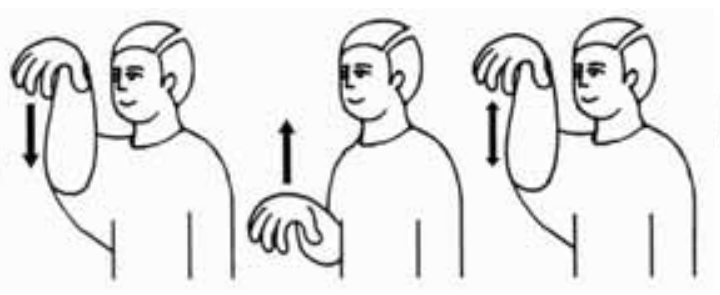

(a)

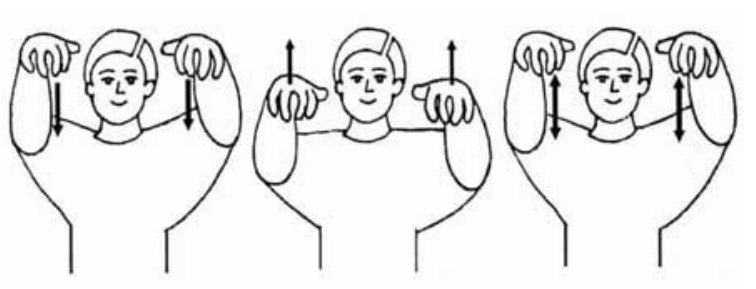

(b)

CHUVA (1) (p.407) CHUVA (2) (alta intensidade) (p.407) Figura (118) Capovilla \& Raphael (2001)

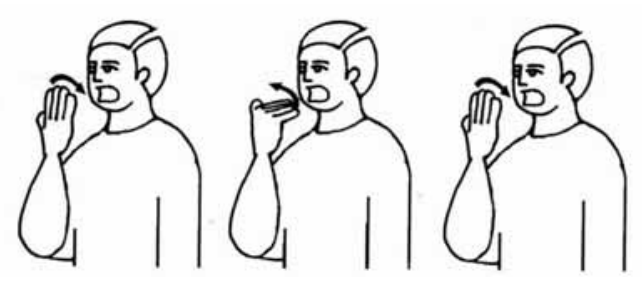

(a)

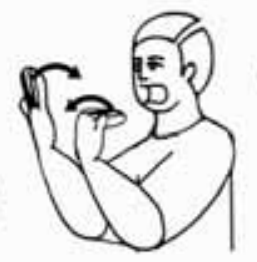

COMER (p.434)

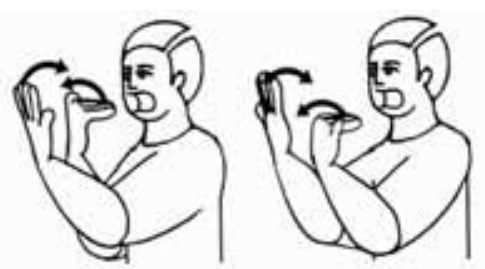

(b)

Figura (119) Capovilla \& Raphael (2001) 


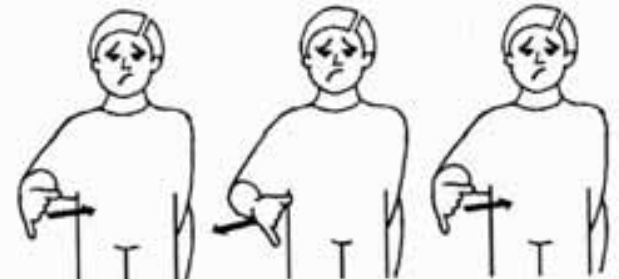

(a)

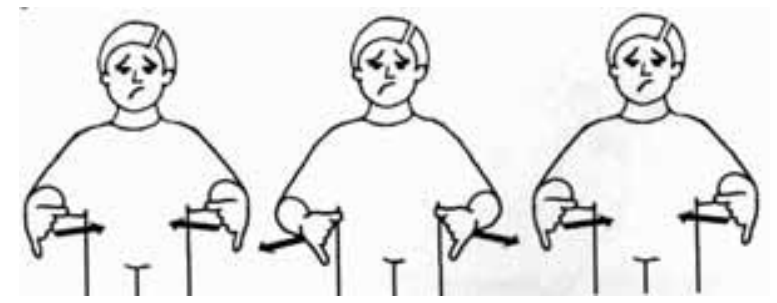

(b)

SOFRER (1) (p.1205)

SOFRER (2) (intensamente) (p.1205)

Figura (120) Capovilla \& Raphael (2001)

Porém, essa é uma questão que requer uma investigação mais aprofundada, dado o pouco conhecimento que se tem a respeito dos processos gramaticais que atuam nas línguas sinalizadas e, em especial, na libras.

Uma terceira situação observada quando separei os sinais da libras em dois grupos, levando em conta o número de articuladores manuais, vincula-se a alguns sinais que podem tanto ser produzidos com duas mãos quanto com uma só, sem que isso acarrete qualquer alteração no seu significado (cf. ABANAR-SE, ACEITAR, OBRIGADO, PESCAR e BEGE).

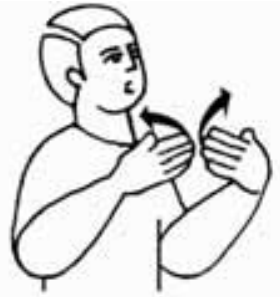

ABANAR-SE (1) (p.134)

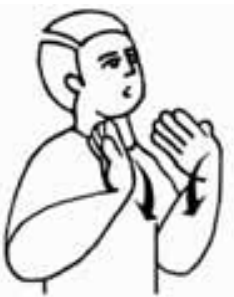

Figura (121) Capovilla \& Raphael (2001)
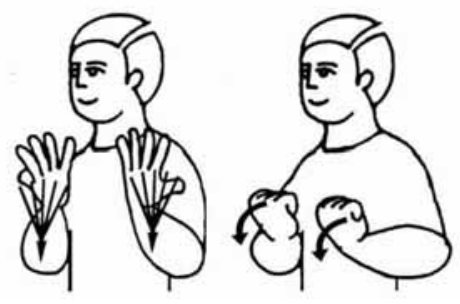

ACEITAR (1) (p.145)
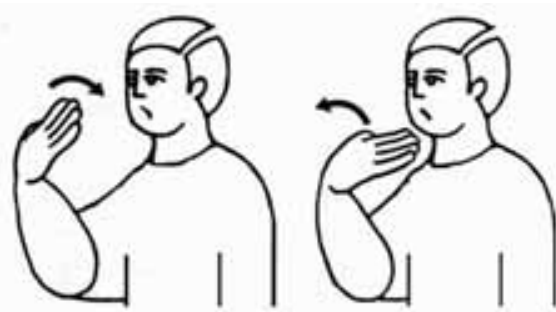

ABANAR-SE (2) (p.134)

Figura (122) Capovilla \& Raphael (2001)

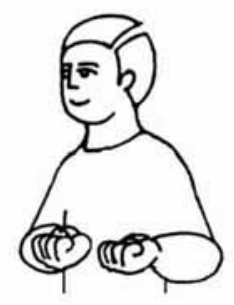

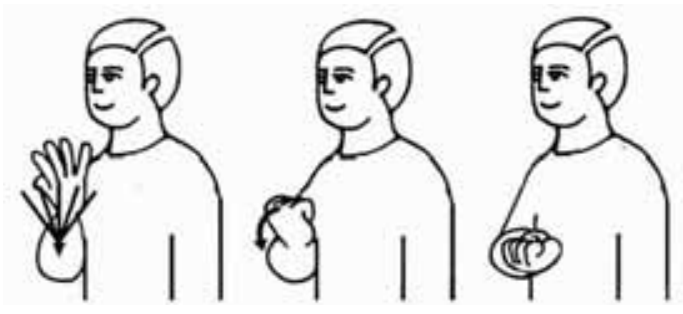

ACEITAR (2) (p.145) 


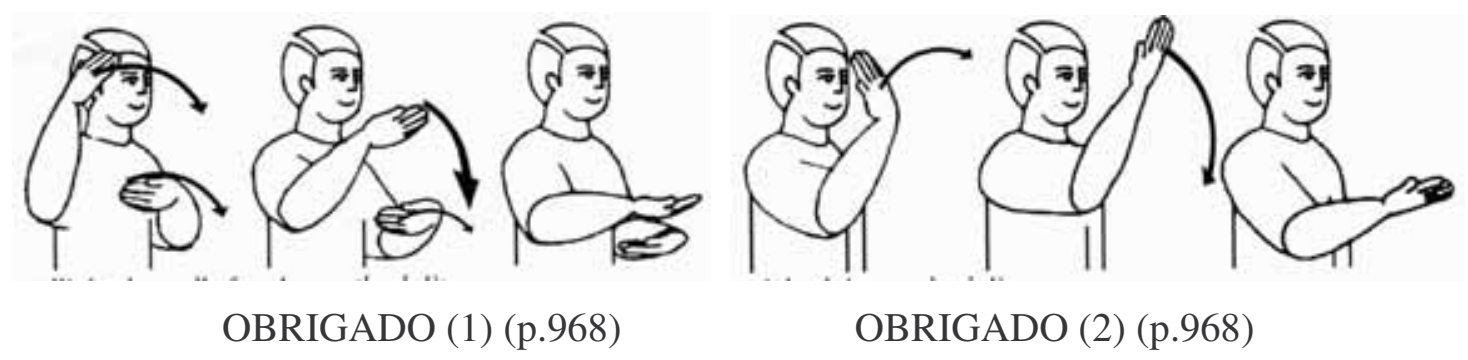

Figura (123) Capovilla \& Raphael (2001)

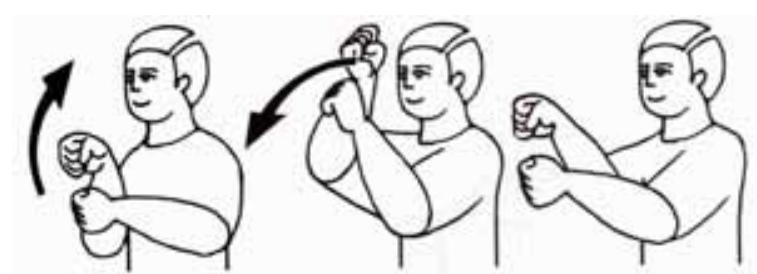

PESCAR (1) (p.1039)

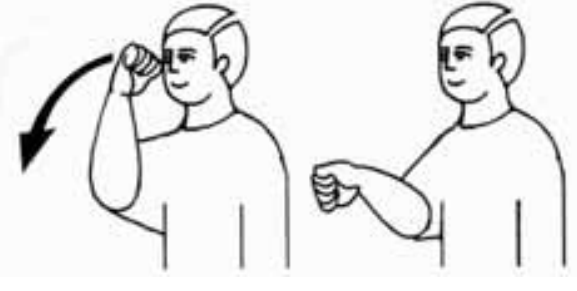

PESCAR (2) (p.1040)

Figura (124) Capovilla \& Raphael (2001)

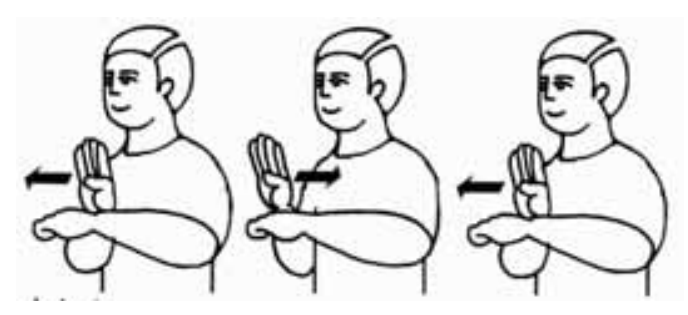

BEGE (1) (p.284)
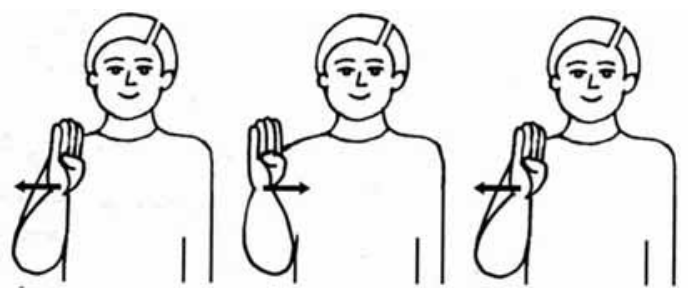

BEGE (2) (p.284)

Figura (125) Capovilla \& Raphael (2001)

Esse fenômeno é muito comum de ser observado na sinalização espontânea. Evani Viotti sugere (c.p.) que é possível que isso esteja associado a fatores extra-lingüísticos, como, por exemplo, o fato de uma das duas mãos do sinalizador estar ocupada no momento da sinalização. Porém, essa é mais uma questão que requer maiores investigações. Antes de mais nada é preciso averiguar se quaisquer sinais produzidos com duas mãos (inclusive aqueles em que as mãos se mantêm em contato ao longo de toda a sua articulação (cf. CAMPEONATO (Capovilla \& Raphael, 2001:348)) podem apresentar esse tipo de alternância, sem que isso acarrete problemas de comunicação.

Nesse sentido, a meu ver, somente com base em um estudo desse tipo é que se poderia decidir, por exemplo, se as versões realizadas com apenas uma mão de sinais usualmente produzidos com duas devem ser incluídas em um dicionário. Mais especificamente, 
somente assim se poderia justificar um tratamento diferenciado, tal como o que Capovilla \& Raphael (2001) dão aos sinais mencionados acima, quando documentam somente para estes as suas duas possíveis realizações no que diz respeito ao número de articuladores manuais.

\subsection{Feixe segmental}

Como visto no capítulo 2, o feixe segmental de que se constituem os segmentos das línguas sinalizadas é formado por cinco especificações: classe maior, contorno de movimento, plano de contorno, qualidade e movimento local.

A especificação classe maior é responsável por determinar o tipo de segmento a ser produzido (movimento ou suspensão). As especificações contorno de movimento e plano de contorno (específicas para segmentos de movimento) descrevem a forma do movimento (reto ou circular) e o plano em que esse movimento é realizado (horizontal, vertical, etc), respectivamente. Já a especificação qualidade diz respeito, basicamente, ao tempo, à tensão e à relação de contato entre articuladores, durante a realização de suspensões e movimentos. E, finalmente, a especificação movimento local refere-se à ocorrência de movimentos rápidos, repetidos e, em geral, incontáveis dos dedos ou do pulso simultaneamente à produção de um segmento.

Neste trabalho, por razões de tempo, restringi-me às duas primeiras especificações do feixe segmental: classe maior e contorno de movimento. A primeira delas será tratada no próximo capítulo, e a segunda, na seção subseqüente.

\subsubsection{Traços de contorno de movimento}

Embora Liddell \& Johnson tenham proposto apenas os traços reto [str] e circular [rnd] para descrever o contorno dos movimentos, dados da libras sugerem a necessidade de um outro, a saber, o traço de contorno ondulado [ond].

A inclusão desse traço se baseia em pelo menos duas razões. Uma primeira se vincula à existência de sinais como FELIZ (Figura (126)) em que o tipo de movimento descrito pela mão não se assemelha ao caracterizado pelos traços reto [str] e circular [rnd]. Como se pode 
ver na figura abaixo, nesse sinal, a mão se desloca ondulatoriamente.

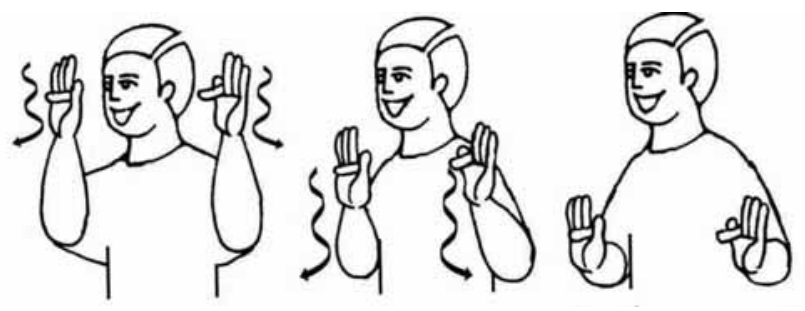

FELIZ

Figura (126) Capovilla \& Raphael (2001:660)

Uma segunda razão para tal proposta, talvez a mais forte das duas, se fundamenta na existência de pares mínimos na libras em que o único elemento responsável pela diferenciação dos dois sinais envolvidos é o contorno do movimento. Um exemplo de par mínimo que sugere o caráter distintivo do traço ondulado [ond] na libras são os sinais METADE e DIVIDIR, representados em (127).

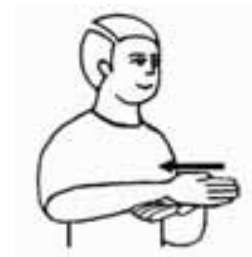

METADE (p.895)

(a)

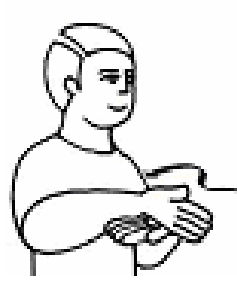

DIVIDIR (p.554)

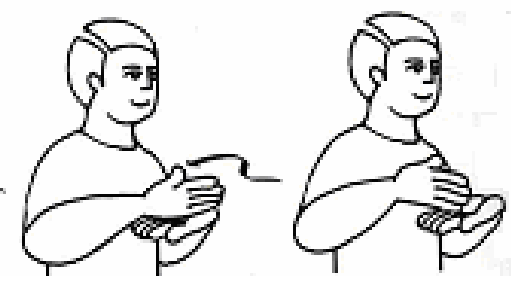

(b)

Figura (127) Capovilla \& Raphael (2001)

Como mostram as figuras acima, com exceção do contorno de movimento -- [str] em METADE e [ond] em DIVIDIR -- todos os outros traços que descrevem as mãos articulatoriamente são exatamente os mesmos.

A descrição de alguns sinais do dicionário sugere um outro traço de contorno: o traço [ziguezague], utilizado para descrever movimentos do tipo observado em sinais como PAZ (1) (Figura (128)). 


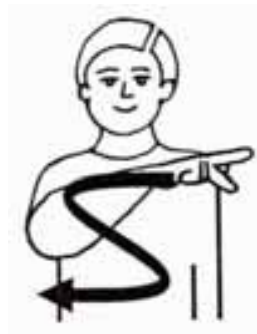

PAZ (1)

Figura (128) Capovilla \& Raphael (2001:1019)

Entretanto, movimentos desse tipo podem ser reanalisados, à luz do modelo de Liddell \& Johnson (2000 [1989]), como sendo constituídos de outros movimentos cujo contorno é reto [str], não havendo, portanto, a necessidade de se propor um outro traço.

\subsection{Feixe articulatório}

De acordo com o que foi dito no capítulo 2, o feixe articulatório de que são formados os segmentos das línguas sinalizadas se contitui de três subfeixes de traços: configuração de mão $[\mathrm{CM}]$, ponto de contato $[\mathrm{PC}]$, e orientação [OR]. O primeiro deles é responsável por descrever a forma como a(s) mão(s) se apresenta(m) durante a realização de um sinal. Já o segundo tem a função de descrever o lugar (no corpo, na mão não-dominante ou no espaço de sinalização) em que um sinal é produzido. Por fim, o último subfeixe é aquele através do qual é descrita a parte da mão que está posicionada na localização (ou voltada para ela) determinada pelo ponto de contato.

Por razões de tempo, neste trabalho, restringi-me a dois desses subfeixes: configuração de mão e ponto de contato, que serão discutidos nas seções subseqüentes.

\subsubsection{Configuração de mão}

No capítulo anterior, através do critério [ \pm 1 configuração de mão], mostrei como diferenciei sinais cuja realização envolve uma única forma de mão de sinais cuja produção exibe mais de uma dessas formas. Mostrei também que, apesar de os valores desse critério serem suficientes para diferenciar os dois tipos possíveis de sinais feitos com uma única 
mão no que diz respeito ao número de configurações, eles ainda deixavam indiferenciados sinais articulados com duas mãos e com mais de uma configuração.

Nesta seção, apresento como essa organização dos sinais no banco de dados facilitou a descrição das configurações de mão presentes nos sinais selecionados de Capovilla \& Raphael, bem como os meios que utilizei para diferenciar os subtipos (definidos pelo número de configurações) de sinais feitos com duas mãos.

\subsubsection{Sinais feitos com uma mão}

Ao buscar, no banco de dados, sinais especificados positivamente tanto para o critério [ \pm 1 mão] quanto para o critério [ \pm 1 configuração de mão], pude acessar todos os sinais que, de acordo com a descrição do dicionário, são produzidos com uma mão e sem mudança de configuração. Esse acesso facilitou a descrição da configuração de todos os sinais desse tipo e a identificação e quantificação de todas as configurações mais e menos recorrentes no conjunto de sinais considerados.

As duas configurações mais recorrentes são: $\left[\mathrm{Bu}^{\wedge}\right]$ e [10-]. A primeira delas é aquela em que os dedos indicador, médio, anelar e mínimo se apresentam abertos (distendidos nas juntas proximais e distais) e unidos [B], e o polegar se encontra não-oposto [u] e achatado [^]. Já a segunda configuração é aquela em que os dedos, com exceção do indicador, estão fechados (dobrados nas juntas proximais e distais) [1], e o polegar está oposto [o] e fechado [-]. Como exemplos de sinais que exibem, respectivamente, essas configurações, podem ser citados os sinais CRIANÇA e CHINA, representados pelas figuras abaixo ${ }^{54}$.

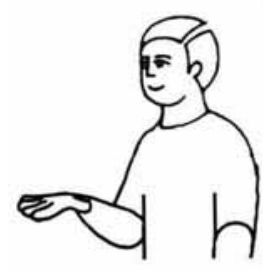

\section{CRIANÇA}

Figura (129) Capovilla \& Raphael (2001:481)

\footnotetext{
${ }^{54}$ Para ver o levantamento completo das configurações de mão ocorrentes em sinais do tipo em questão, ver a tabela (4) do anexo desta dissertação.
} 


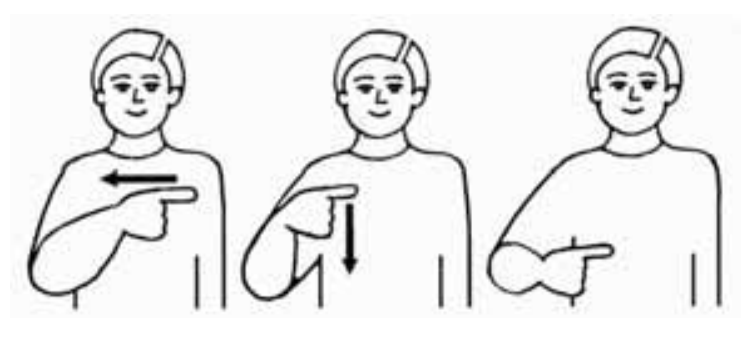

CHINA

Figura (130) Capovilla \& Raphael (2001:402)

Já ao buscar os sinais realizados com uma mão e com mais de uma configuração, pude fazer um levantamento de todas as configurações iniciais, bem como de todas as configurações finais desses sinais ${ }^{55}$.

A principal razão que me levou a fazer esse levantamento se relaciona a uma das críticas de Sandler (1990) ao modelo de Liddell \& Johnson (2000 [1989]). Segundo ela, ao representar as configurações iniciais e finais de forma independente, os autores assumem que qualquer configuração de mão pode iniciar ou finalizar um sinal. Dessa maneira, eles assumem que não existe nenhuma relação de previsibilidade (ou de implicação mútua) entre elas. Diferentemente, para Sandler, dada uma configuração inicial, é possível preverse a configuração final.

Ao observar casos como os retratados na tabela (3) a seguir, constatei, assim como Liddell (1990), a impossibilidade de haver uma relação de previsibilidade entre a configuração inicial e a final de um sinal. Como se pode ver na tabela a seguir, por exemplo, na mudança de configurações "abertas" para configurações "fechadas", há casos em que uma mesma configuração pode se "fechar" de formas diferentes. A configuração [4u], por exemplo, "se fecha" de quatro formas diferentes. Ela "se fecha" em [So-] em CHEIRAR (1), em $\left[\mathrm{Au}^{\wedge}\right]$ em BONITO, em [B^op] em FILHO e em e [Au] em MATO-GROSSO.

Contrariamente, há casos em que configurações diferentes se "fecham" de maneira a configurar-se igualmente. Como exemplos da tabela, tem-se [B"o"], em APRENDER, [B" o"], em TIRADENTES, e [4" o"], em MORDER, “fechando-se" em [So-]).

\footnotetext{
${ }^{55}$ Para ver o levantamento completo das configurações iniciais e finais atestadas em sinais do tipo em questão, ver as tabela (5) e (6), respectivamente, no anexo desta dissertação.
} 
Tabela (3)

\begin{tabular}{|c|c|c|c|}
\hline $\begin{array}{l}\text { Configuração } \\
\text { inicial ("aberta") }\end{array}$ & $\begin{array}{c}\text { Configuração final } \\
\text { ("fechada") }\end{array}$ & Exemplo & $\begin{array}{l}\mathrm{n}^{\mathbf{0}} \mathrm{de} \\
\text { sinais }\end{array}$ \\
\hline \multirow{4}{*}{$4 u$} & So- & CHEIRAR (1) (p.399) & 16 \\
\hline & $\mathrm{Au}^{\wedge}$ & BONITO (p.310) & 3 \\
\hline & $\mathrm{B}^{\wedge} \mathrm{op}$ & FILHO (p.668) & 3 \\
\hline & $\mathrm{Au}$ & MATO-GROSSO & 3 \\
\hline B"o" & \multirow{3}{*}{ So- } & APRENDER (p.215) & 5 \\
\hline B" O" & & TIRADENTES (p.1253) & 3 \\
\hline 4" 0" & & MORDER (1) (p.921) & 1 \\
\hline \multicolumn{3}{|l|}{ TOTAL } & 34 \\
\hline
\end{tabular}

O mesmo pode ser dito em relação a configurações "fechadas" que passam a "abertas", retratadas na tabela (4). Para que a partir de uma configuração se pudesse prever a que segue (ou vice-versa), não deveria ser possível que uma mesma configuração "fechada" se "abrisse" de três maneiras diferentes, como se observa em BALEIA, ESTRANHO e SE que, incialmente configuradas em [So-], "abrem-se" em [4u], [1o-] e [lo-], respectivamente. Da mesma forma, não deveria ser possível que configurações "fechadas" diferentes se "abrissem" de maneira a configurar-se igualmente, tal como acontece, por exemplo, em LUZ, GALO e NOVO que são iniciados com as configurações fechadas $\left[\mathrm{B}^{\wedge} \mathrm{op}\right],\left[\mathrm{Au}^{\wedge}\right]$ e $[B " \sim 0 " c]$ e terminam o sinal configuradas em $[4 \mathrm{u}]^{56}$.

Tabela (4)

\begin{tabular}{|c|c|c|c|}
\hline $\begin{array}{c}\text { Configuração } \\
\text { inicial ("fechada") }\end{array}$ & $\begin{array}{l}\text { Configuração final } \\
\text { ("aberta") }\end{array}$ & Exemplo & $\begin{array}{l}\mathrm{n}^{0} \mathrm{de} \\
\text { sinais }\end{array}$ \\
\hline \multirow{3}{*}{ So- } & $4 \mathrm{u}$ & BALEIA (p.267) & 9 \\
\hline & $10-$ & ESTRANHO (2) (p.629) & 4 \\
\hline & Io- & SE (p.1171) & 2 \\
\hline $\mathrm{B}^{\wedge} \mathrm{op}$ & \multirow{3}{*}{$4 u$} & LUZ (p.832) & 7 \\
\hline $\mathrm{Au}^{\wedge}$ & & GALO (p.700) & 4 \\
\hline B" O"c & & NOVO (p.955) & 3 \\
\hline \multicolumn{3}{|l|}{ TOTAL } & 29 \\
\hline
\end{tabular}

Apesar disso, observei casos que, embora não confirmem a hipótese de Sandler, sugerem que talvez a mudança de configuração de mão apresenta uma certa tendência.

\footnotetext{
${ }^{56}$ Para outros casos, ver tabela (7) no anexo deste trabalho.
} 
Segundo Sandler, a previsibilidade na mudança de configuração se explica por questões articulatórias. Para ela, uma dada configuração só pode mudar para uma outra que apresente o mesmo grupo de dedos envolvidos. Assim, seria excepcional a passagem, de uma configuração em que apenas os dedos indicador, médio e anelar estivessem distendidos, para uma outra em que o dedo mínimo e o polegar estivessem destacados.

É nesse sentido que, a meu ver, casos como ÁGUA e COMER evidenciariam que a mudança de configuração de mão parece seguir uma certa tendência. Como sugerem as representações pictográficas desses sinais na figura (131), a mudança de configuração que se observa neles consiste na variação de um único traço: o traço achatado [^]. Mais especificamente, passa-se, tanto em ÁGUA, quanto em COMER, de uma configuração em que o(s) dedo(s) relevante(s) está(ão) distendido(s) na(s) junta(s) proximal(is) para uma outra em que ele(s) está(ão) dobrado(s) nessa(s) mesma(s) junta(s).

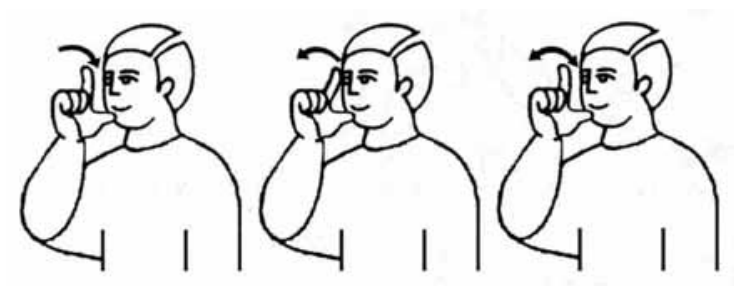

ÁGUA (p.167)

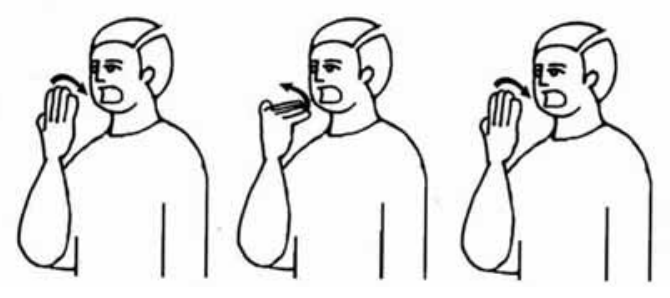

COMER (p.434)

Figura (131) Capovilla \& Raphael (2001)

Outros exemplos de sinais que exibem o mesmo tipo de mudança de configuração de mão podem ser encontrados na tabela (5).

Tabela (5)

\begin{tabular}{|c|c|c|c|c|}
\hline & $\begin{array}{c}\text { Configuração } \\
\text { inicial }\end{array}$ & $\begin{array}{c}\text { Configuração } \\
\text { final }\end{array}$ & Exemplo & $\begin{array}{c}\mathbf{n}^{\mathbf{0}} \text { de } \\
\text { sinais }\end{array}$ \\
\hline $\mathbf{1}$ & $1 \mathrm{u}$ & $1^{\wedge} \mathrm{u}$ & ÁGUA (p.167) & 2 \\
\hline $\mathbf{2}$ & $1 \mathrm{u}^{\wedge}$ & $1^{\wedge} \mathrm{u}^{\wedge}$ & BAIRRO-ACLIMAÇÃO (p. 258) & 2 \\
\hline $\mathbf{3}$ & $\mathrm{Au}$ & $\mathrm{Au}^{\wedge}$ & CANETA (p.352) & 2 \\
\hline $\mathbf{4}$ & $\mathrm{Bu}$ & $\mathrm{B}^{\wedge} \mathrm{u}^{\wedge}$ & COMER (p.434) & 2 \\
\hline $\mathbf{5}$ & $\mathrm{Ho}-$ & $\mathrm{H}^{\wedge} \mathrm{o}-$ & NUNCA (2) (p.964) & 2 \\
\hline $\mathbf{6}$ & $\mathrm{Hu}$ & $\mathrm{Au}$ & CAVALO (p.379) & 1 \\
\hline \multicolumn{2}{l}{ TOTAL } & \multicolumn{3}{l}{} \\
\hline
\end{tabular}


O mesmo pode ser dito em relação a sinais como ÚNICO e CEGO, representados na figura (132).

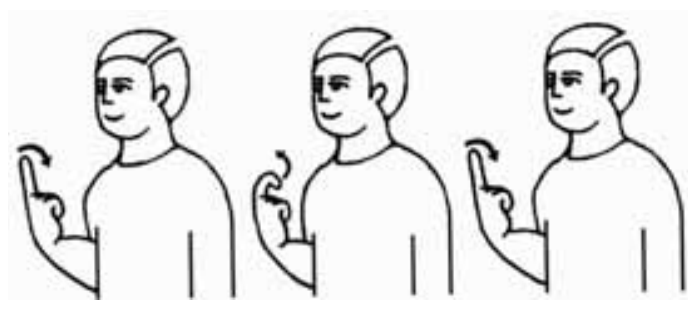

ÚNICO (p.1283)

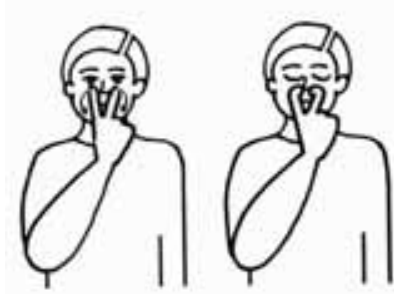

CEGO (1) (p.383)

Figura (132) Capovilla \& Raphael (2001)

Nesses sinais, nota-se que a mudança de configuração também consiste, comparando-se a configuração inicial à final, na variação de um único traço: o traço "em gancho" ["]. Em outras palavras, passa-se de uma configuração em que o(s) dedo(s) relevante(s) não está(ão) dobrado(s) na(s) junta(s) distal(is) para uma outra em que ele(s) está(ão) flexionado(s) nessa(s) mesma(s) junta(s).

Outros exemplos de sinais que exibem o mesmo tipo de mudança de configuração de mão podem ser encontrados na tabela (6).

Tabela (6)

\begin{tabular}{|c|c|c|c|c|}
\hline & $\begin{array}{c}\text { Configuração } \\
\text { inicial }\end{array}$ & $\begin{array}{c}\text { Configuração } \\
\text { final }\end{array}$ & Exemplo & $\begin{array}{c}\mathbf{n}^{\mathbf{0}} \mathbf{d e} \\
\text { sinais }\end{array}$ \\
\hline $\mathbf{1}$ & $10-$ & 1 "o- & ÚNICO (p.1283) & 10 \\
\hline $\mathbf{2}$ & 1 " o- & 1 "o- & REVÓLVER (p.1145) & 1 \\
\hline $\mathbf{3}$ & Doc & D"oc & CAVALO-MARINHO (p.379) & 1 \\
\hline $\mathbf{4}$ & Vo- & V"o- & CEGO (1) (p.383) & 1 \\
\hline TOTAL & \multicolumn{3}{|r}{} \\
\hline
\end{tabular}

Uma outra regularidade observada entre os sinais que mudam sua configuração ao longo de sua articulação está na passagem de uma configuração em que o polegar não está em contato com um determinado dedo (ou dedos) relevante(s) em uma configuração para outra em que ele está, tal como se pode observar no sinal CRACHÁ abaixo e nos exemplos listados na tabela (7). 


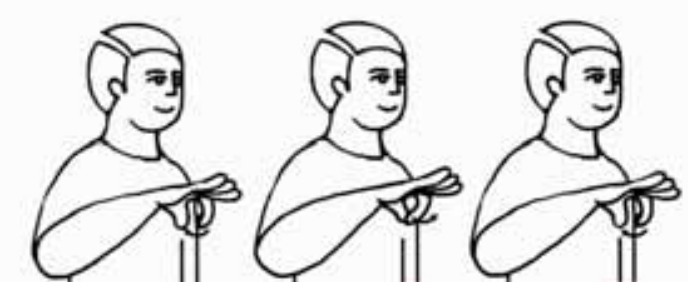

CRACHÁ (p.479)

Figura (133) Capovilla \& Raphael (2001)

Tabela (7)

\begin{tabular}{|c|c|c|c|c|}
\hline & $\begin{array}{c}\text { Configuração } \\
\text { inicial }\end{array}$ & $\begin{array}{c}\text { Configuração } \\
\text { final }\end{array}$ & Exemplo & $\begin{array}{l}\mathrm{n}^{\mathbf{0}} \mathrm{de} \\
\text { sinais }\end{array}$ \\
\hline 1 & $11^{\wedge} \mathrm{O}$ & $1^{\wedge}$ op & PREFERIR (p.1073) & 14 \\
\hline 2 & $\mathrm{~B}^{\wedge} \mathrm{O}$ & $\mathrm{B}^{\wedge} \mathrm{op}$ & HOMEM (p.736) & 5 \\
\hline 3 & 10 & $1^{\wedge} \mathrm{op}$ & ALIVIAR (1) (p.179) & 4 \\
\hline 4 & $/ 4^{\wedge} \sim 0$ & $/ \mathrm{B}^{\wedge} \mathrm{op}$ & ESPIRITISMO (p.614) & 2 \\
\hline 5 & 40 & Bop & CONVENCER (1) (p.459) & 2 \\
\hline 6 & $\mathrm{H}^{\wedge} \mathrm{O}$ & $\mathrm{H}^{\wedge} \mathrm{op}$ & PATO (p.1018) & 2 \\
\hline 7 & 1"o" & $1 " \mathrm{o} " \mathrm{c}$ & PERIQUITO (p.1034) & 1 \\
\hline 8 & $1 " \mathrm{u}$ & $1 " \mathrm{u}^{\wedge}$ & ALICATE-DE-UNHA (p.178) & 1 \\
\hline 9 & $1^{\wedge} \mathrm{op}$ & $1 \wedge^{\wedge}$ & CONTA-GOTAS & 1 \\
\hline 10 & $4 \sim \mathrm{u}$ & $\mathrm{B}^{\wedge} \mathrm{op}$ & LULA (p.830) & 1 \\
\hline 11 & 80 & 8 op & COLA (p.426) & 1 \\
\hline 12 & 90 & 9op & CRACHÁ (p.479) & 1 \\
\hline 13 & V"o" & V"o"c & CASTOR (1) (p.374) & 1 \\
\hline 14 & $\mathrm{~V}^{\wedge} \mathrm{O}$ & $\mathrm{H}^{\wedge} \mathrm{op}$ & INJETAR (p.757) & 1 \\
\hline \multicolumn{4}{|c|}{ TOTAL } & 37 \\
\hline
\end{tabular}

O contrário também é possível. Como se pode ver em MEDO a seguir e nos sinais listados na tabela (8), há sinais em que a configuração de mão muda de uma em que o polegar está em contato com um determinado dedo para outra em que ele deixa de estar.
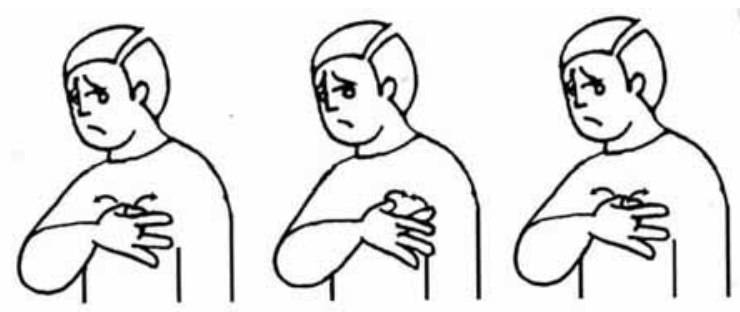

MEDO

Figura (134) Capovilla \& Raphael (2001:882) 
Tabela (8)

\begin{tabular}{|c|c|c|c|c|}
\hline & $\begin{array}{c}\text { Configuração } \\
\text { inicial }\end{array}$ & $\begin{array}{l}\text { Configuração } \\
\text { final }\end{array}$ & Exemplo & $\begin{array}{l}\mathbf{n}^{\mathbf{o}} \text { de } \\
\text { sinais }\end{array}$ \\
\hline \multirow[t]{2}{*}{1} & \multirow[t]{2}{*}{$1^{\wedge} \mathrm{op}$} & $1 \mathrm{u}$ & GATO (p.704) & 3 \\
\hline & & 10 & DARDO (p.496) & 3 \\
\hline \multirow[t]{2}{*}{2} & \multirow[t]{2}{*}{$80 f$} & $4 u$ & SÓ (2) (p.1201) & 3 \\
\hline & & 40 & MEDO (p.882) & 1 \\
\hline 3 & Ao & $1 \mathrm{u}$ & OFENDER (2) (p.972) & 2 \\
\hline 4 & B" o"c & B" o" & VIAJAR (2) (p.1315) & 3 \\
\hline 5 & So- & 10 & PÍLULA (p.1044) & 1 \\
\hline \multicolumn{4}{|c|}{ TOTAL } & 16 \\
\hline
\end{tabular}

Estudos mais aprofundados sobre as propriedades articulatórias das mãos e descrições mais cuidadosas das possibilidades de mudança de configuração de mão atestadas em diferentes línguas de sinais devem corroborar a existência de certas tendências de movimento, e até mesmo de movimentos prototípicos.

Por fim, cabe mencionar que foram encontrados entre os sinais do dicionário alguns casos em que a realização do sinal envolve três configurações. Como mostra a tabela (9), além de tais sinais serem em sua maioria soletrações digitais de palavras ou de siglas do português, eles são numericamente inexpressivos em relação a todos os sinais realizados com uma mão e com mudança de configuração.

Tabela (9)

\begin{tabular}{|c|c|c|c|c|}
\hline $\begin{array}{c}\text { Configuração } \\
\text { inicial }\end{array}$ & $\begin{array}{l}\text { Configuração } \\
\text { intermediária }\end{array}$ & $\begin{array}{l}\text { Configuração } \\
\text { final }\end{array}$ & Exemplo & $\begin{array}{l}\mathrm{n}^{\mathbf{0}} \text { de } \\
\text { sinais }\end{array}$ \\
\hline $1^{\wedge} \mathrm{op}$ & $1^{\wedge} \mathrm{O}$ & $1^{\wedge} \mathrm{op}$ & LUA (p.829) & 2 \\
\hline $9 \mathrm{u}^{\wedge} \mathrm{t}$ & Doc & Doc & TDD (p.1233) & 1 \\
\hline $\mathrm{Au}^{\wedge}$ & $1^{\wedge} \mathrm{O}$ & $1^{\wedge} \mathrm{op}$ & ÁFRICA (p.162) & 1 \\
\hline B" O" & $1 \mathrm{u}$ & 9ut & CLT (p.418) & 1 \\
\hline B" $0 "$ & $\mathrm{~B} " \mathrm{u}^{\wedge}$ & $\mathrm{Ku}^{\wedge}$ & CEP (p.386) & 1 \\
\hline B" O" & $\mathrm{Ku}^{\wedge}$ & 9up & CPF (p.478) & 1 \\
\hline $\mathrm{B}^{\prime \prime} \sim \mathrm{O}$ & lo- & B" O" & CIC (p.408) & 1 \\
\hline Ho- & Vo- & Ho- & $\begin{array}{l}\text { CALCINHA (2) } \\
\text { (p.342) }\end{array}$ & 1 \\
\hline lo-p & Ho-p & $A u^{\wedge} p$ & JAÚ (p. 778) & 1 \\
\hline $\mathrm{V}^{\prime \prime} \sim \mathrm{OC}$ & Vo & $\mathrm{V}^{\prime \prime} \sim \mathrm{oc}$ & $\begin{array}{l}\text { PREFEITURA (2) } \\
\text { (p.1073) }\end{array}$ & 1 \\
\hline \multicolumn{4}{|l|}{ TOTAL } & 11 \\
\hline
\end{tabular}




\subsubsection{Sinais articulados com duas mãos paradas ou em movimento}

No capítulo anterior, foi dito que os valores do critério [ \pm 1 configuração de mão], apesar de distinguirem sinais articulados com duas mãos e com a mesma configuração, não eram capazes de diferenciar os subtipos de sinais feitos com duas mãos e com mais de uma configuração.

Para fazer esse tipo de diferenciação, acrescentei aos critérios, com base nos quais sinais deste último tipo já haviam sido classificados, os subcritérios [ \pm 1 configuração: mão dominante] e [ \pm 1 configuração: mão não-dominante]. Assim como para o critério $[ \pm 1$ configuração], convencionei classificar, por meio do valor positivo dos subcritérios acrescentados, os casos em que não há mudança de configuração de mão e, através do valor negativo, os casos em que a mão sofre mudança em sua forma.

Depois de classificar os sinais com base nesses subcritérios, combinei-os a fim de elaborar buscas que me permitissem identificar e quantificar os diferentes subtipos de sinais que são articulados com duas mãos, paradas ou em movimento, e que apresentam mais de uma configuração ao longo de sua produção. É isso o que mostra a tabela a seguir.

Tabela (10)

\begin{tabular}{|c|c|c|c|c|}
\hline $\begin{array}{l}\text { [ } 1 \text { configuração: } \\
\text { mão dominante] }\end{array}$ & $\begin{array}{c}\text { [ } 1 \text { configuração: mão } \\
\text { não-dominante] }\end{array}$ & exemplo & $\begin{array}{l}\mathrm{n}^{\circ} \mathrm{de} \\
\text { sinais }\end{array}$ & $\%$ \\
\hline- & - & $\begin{array}{l}\text { ACEITAR(1) } \\
\text { (p.145) }\end{array}$ & 125 & $63 \%$ \\
\hline+ & + & JORNAL (p.785) & 67 & $33 \%$ \\
\hline- & + & POLVO (p.1056) & 6 & $3 \%$ \\
\hline+ & - & $\begin{array}{c}\text { CACHORRO- } \\
\text { QUENTE (p.334) }\end{array}$ & 2 & $1 \%$ \\
\hline \multicolumn{3}{|l|}{ TOTAL } & 200 & $100 \%$ \\
\hline
\end{tabular}

Com base nesses resultados e nos obtidos com a busca de sinais feitos com duas mãos igualmente configuradas, foi possível observar como os sinais da libras, feitos com duas mãos em movimento, se comportam em relação a um dos princípios de boa-formação que, de acordo com Battison (2000 [1978a]), rege os sinais do mesmo tipo, na ASL. Trata-se do Princípio de Simetria, segundo o qual sinais articulados com duas mãos ativas devem 
apresentar a mesma configuração nas duas mãos, a mesma localização, o mesmo movimento (não importando se simultâneo ou alternado) e orientações das palmas simétricas ou idênticas.

Dos $663^{57}$ sinais feitos com as duas mãos se movendo; 494 exibem as duas mãos igualmente configuradas (cf. ANUNCIAR (Figura (116b))); 125 (mostrados na tabela (10)) apresentam mudança de configuração nas duas mãos (cf. ACEITAR (1) (Figura (122a)); 36 (que corresponde à parte do que é mostrado na tabela (10), mais precisamente aos sinais que apresentam movimento), embora não exibam mudança de configuração em nenhuma das mãos, são articulados com as mãos configuradas diferentemente (cf. JORNAL (Figura (135)); 6 são produzidos com configurações diferentes em cada mão e com mudança de configuração apenas na mão dominante (cf. POLVO (Figura (136); e, finalmente, 2 são articulados com as mãos diferentemente configuradas, exibindo mudança de configuração apenas na mão não-dominante (CACHORRO-QUENTE (Figura (137)).
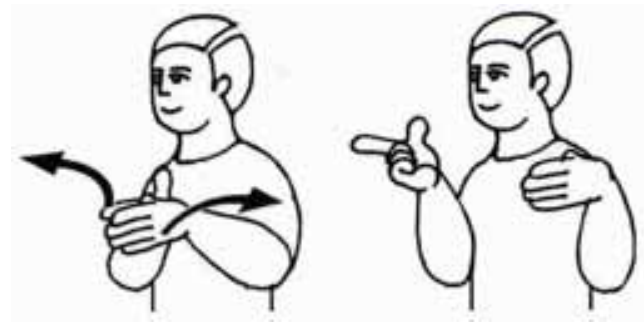

JORNAL

Figura (135) Capovilla \& Raphael (2001:785)

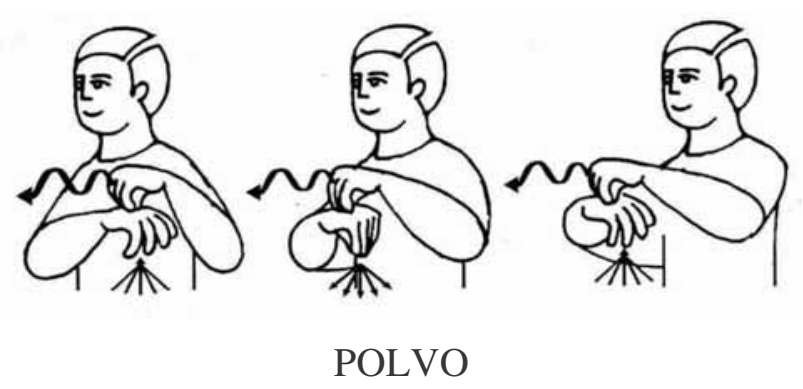

Figura (136) Capovilla \& Raphael (2001:1056)

\footnotetext{
${ }^{57}$ Esse número corresponde à soma do número de sinais feitos com movimento simultâneo ao número de sinais feitos com movimento alternado, apresentados na tabela (2).
} 


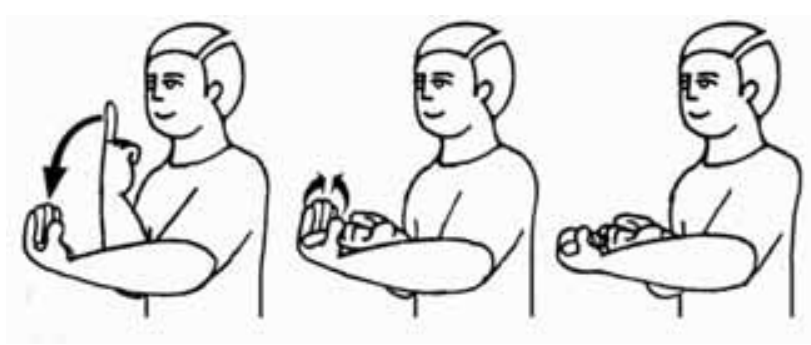

CACHORRO-QUENTE

Figura (137) Capovilla \& Raphael (2001:334)

No que concerne ao princípio de simetria, pode-se dizer que ele é respeitado pela maioria dos sinais da libras. Como dito acima, 494 sinais, ou seja, 74\%, de todos os sinais feitos com duas mãos em movimento, são articulados com a mesma configuração, com o mesmo tipo de movimento e com localizações e orientações idênticas ou simétricas.

Pode-se acrescentar, a esses casos, os 125 sinais (18\%) que, assim como ACEITAR (1) (Figura (122a), apresentam mudança de configuração. A meu ver, esses sinais também respeitam o princípio de simetria, porque, em todos os casos, a mudança de configuração é sempre idêntica. Em outras palavras, as configurações iniciais de cada mão, idênticas, mudam para uma mesma configuração.

Por fim, em relação aos casos que violam o princípio de simetria, observa-se que eles correspondem a uma parcela muito pequena dos sinais da libras, $8 \%$ do total.

\subsubsection{Sinais articulados com uma das mãos parada}

Como também dito no capítulo anterior, o critério [ \pm 1 configuração de mão] pôde distinguir, entre os sinais feitos com duas mãos, mas com uma delas parada, aqueles em que as duas mãos são igualmente configuradas (cf. PROIBIR (Figura (40))). Entretanto, ele não foi capaz de diferenciar casos em que as mãos são configuradas diferentemente (cf. COMBINAR (1) (Figura (107))), de casos em que, além de as mãos exibirem configurações distintas, a mão dominante ainda sofre mudança de configuração (cf. ALUGAR (Figura (108))).

Para fazer essa diferenciação e permitir buscar no banco de dados apenas sinais do tipo de COMBINAR ou do tipo de ALUGAR, também classifiquei esses sinais com base no subcritério [ \pm 1 configuração: mão dominante], mencionado na seção anterior. Sendo assim, 
por meio do valor positivo de tal subcritério, pude acessar sinais que, como COMBINAR, são feitos com uma das mãos parada, com configurações diferentes e sem mudança de configuração na mão dominante, e, por meio do valor negativo, sinais que, como ALUGAR, só se diferenciam do tipo anterior por apresentarem mudança de configuração na mão dominante.

A tabela abaixo mostra como os sinais articulados com uma das mãos parada se distribuem nas subclasses definidas pelo critério $[ \pm 1$ configuração] e pelo subcritério $[ \pm 1$ configuração: mão dominante].

Tabela (11)

\begin{tabular}{|l|c|c|c|}
\hline \multicolumn{1}{|c|}{ Sinais feitos com uma das mãos parada } & exemplo & $\begin{array}{c}\mathbf{n}^{\mathbf{0}} \mathbf{d e} \\
\text { sinais }\end{array}$ & \% \\
\hline Mesma configuração & PROIBIR (p.1086) & 154 & $30 \%$ \\
\hline Configurações diferentes & COMBINAR (p.432) & 287 & $56 \%$ \\
\hline $\begin{array}{l}\text { Configurações diferentes e mudança de } \\
\text { configuração na mão dominante }\end{array}$ & ALUGAR (p.432) & 69 & $14 \%$ \\
\hline TOTAL & & 510 & $100 \%$ \\
\hline
\end{tabular}

Com base nesses resultados, foi possível observar como os sinais da libras se comportam em relação a um segundo princípio de boa-formação, também formulado por Battison, mas, dessa vez, para os sinais da ASL que são realizados com uma das mãos parada. Trata-se do Princípio de Dominância, de acordo com o qual sinais articulados com uma mão ativa e a outra passiva, se não apresentarem a mesma configuração nas duas mãos, necessariamente devem apresentar na mão passiva uma das sete configurações, mostradas a seguir, que o autor assume serem as não-marcadas na ASL. 


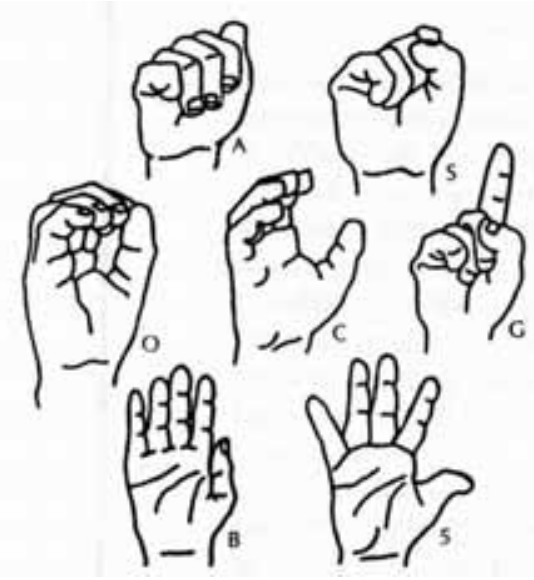

Figura (138) Battison (2000:207 [1987a] $)^{58}$

Na tabela (12) abaixo, as configurações não-marcadas de Battison correspondem aos itens 1 a 5, 7 e 11. Somando-se o número de ocorrências das configurações listadas nesses itens da tabela, observa-se que $293(82 \%)$ dos sinais feitos com uma das mãos parada e com configurações diferentes em cada mão respeitam o princípio de dominância tal como proposto para a ASL. Porém, é importante mencionar que $18 \%$ dos sinais dessa categoria violam esse princípio.

Tabela (12)

\begin{tabular}{|c|c|c|c|}
\hline & $\begin{array}{l}\text { Configuração da mão } \\
\text { não-dominante }\end{array}$ & Exemplo & $n^{\circ}$ de sinais \\
\hline 1 & $\mathrm{Bu}^{\wedge}(\mathbf{B})$ & DETESTAR (p.534) & 152 \\
\hline 2 & So- $(\mathbf{S})$ & CURSO (p. 489) & 54 \\
\hline 3 & B" O" (C) & CHÁ (p.391) & 24 \\
\hline 4 & 10- (G) & OUTONO (p.987) & 17 \\
\hline 5 & $4 \mathrm{u}(5)$ & CALENDÁRIO (p.343) & 15 \\
\hline 6 & Doc & MÊS (p.893) & 14 \\
\hline 7 & B" o"c (O) & GASOLINA (p.703) & 14 \\
\hline 8 & /So- & PEDAGOGIA (p.1022) & 12 \\
\hline 9 & $/ \mathrm{Bu}^{\wedge}$ & PONTE (p.1057) & 8 \\
\hline 10 & Vo- & CHINELO (1) (p.402) & 5 \\
\hline 11 & $\mathrm{Au}^{\wedge}(\mathbf{A})$ & EDUCAÇÃO (p.571) & 5 \\
\hline 12 & $4 " \sim 0 "$ & ÁRVORE (p.229) & 5 \\
\hline
\end{tabular}

\footnotetext{
${ }^{58}$ No modelo de proposto por Liddell \& Johnson, os símbolos que aparecem ao lado de cada configuração são

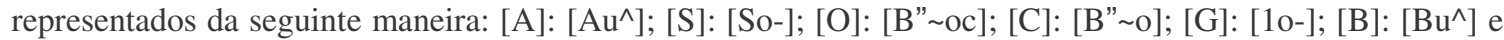
[5]: [4u].
} 


\begin{tabular}{|c|c|c|c|}
\hline & $\begin{array}{l}\text { Configuração da mão } \\
\text { não-dominante }\end{array}$ & Exemplo & $\mathrm{n}^{\circ}$ de sinais \\
\hline 13 & $9 \mathrm{oc}$ & MARTELAR (p.873) & 5 \\
\hline 14 & $1 \mathrm{u}$ & PROBLEMA (p.1083) & 3 \\
\hline 15 & $\mathrm{~B}^{\wedge} \mathrm{O}$ & E-MAIL (p.576) & 2 \\
\hline 16 & Ho- & CADEIRA (p.335) & 2 \\
\hline 17 & Bo & CONSELHO (p.450) & 2 \\
\hline 18 & $\mathrm{~B}^{\wedge} \mathrm{u}^{\wedge}$ & CINZEIRO (p.413) & 2 \\
\hline 19 & $\mathrm{~B}^{\wedge} \mathrm{op}$ & AO-REDOR (p.205) & 2 \\
\hline 20 & $1^{\wedge} \mathrm{op}$ & FOTOGRAFAR (p.686) & 2 \\
\hline 21 & $1^{\wedge} \mathrm{O}$ & FUNIL (p.694) & 2 \\
\hline 22 & lo- & FEIJÃO (2) (p.658) & 1 \\
\hline 23 & 9op & SEXO-ORAL (2) (p. 1195) & 1 \\
\hline 24 & $\mathrm{Bu}-$ & GRÁFICA (p.717) & 1 \\
\hline 25 & $\mathrm{Bu}$ & TÁXI (p.1233) & 1 \\
\hline 26 & $\mathrm{Au}$ & PRIMEIRO (1) (p.1081) & 1 \\
\hline 27 & $4 \mathrm{u}-$ & JOGAR-CARTAS (p.781) & 1 \\
\hline 28 & 4" O"c & VOLKSWAGEN (p.1327) & 1 \\
\hline 29 & 1 "o- & BRÓCOLOS (p.321) & 1 \\
\hline 30 & $1 " \sim 0 "$ & CAULE (p.378) & 1 \\
\hline \multicolumn{3}{|c|}{ TOTAL } & 356 \\
\hline
\end{tabular}

\subsubsection{Ponto de Contato}

O exame dos itens lexicais da libras me perimitiu verificar que, como na ASL, a realização dos sinais se dá em uma das 20 áreas principais propostas por Liddell \& Johnson para os sinais da $\mathrm{ASL}^{59}$. Entretanto, existem algumas diferenças articulatórias entres essas duas línguas. Como indicam as figuras abaixo, os sinais COSTAS (Figura (139)), FOME (Figura (140)), e CAUDA-DE-ANIMAL (Figura (141)) são realizados em partes do corpo que diferem das observadas pelos autores para a ASL: COSTAS, na parte superior e contralateral das costas; FOME, na extremidade ipsilateral da cintura; e CAUDA-DEANIMAL, na parte superior da região glútea.

\footnotetext{
${ }^{59}$ Para exemplos de sinais da libras feitos em uma das 20 áreas propostas por Liddell \& Jonhson para a ASL, ver o quadro (4) do anexo desta dissertação.
} 


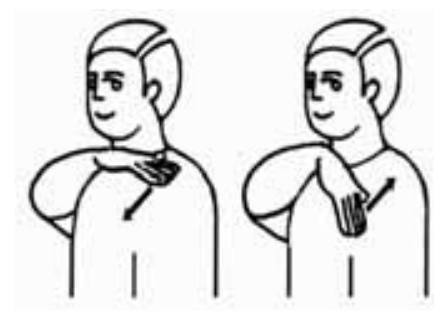

COSTAS

Figura (139) Capovilla \& Raphael (2001:474)

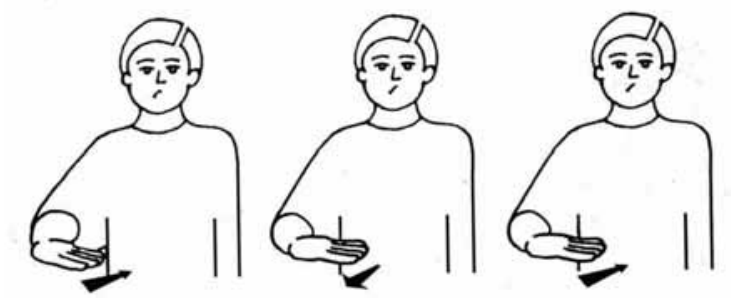

FOME

Figura (140) Capovilla \& Raphael (2001:681)

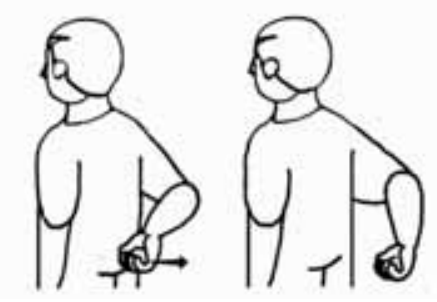

CAUDA-DE-ANIMAL

Figura (141) Capovilla \& Raphael (2001:378)

Uma outra particularidade articulatória da libras se relaciona ao ponto de contato de alguns sinais realizados com uma das mãos parada. $\mathrm{O}$ exame de sinais desse tipo mostrou que, assim como na ASL, as regiões utilizadas como ponto de contato na mão passiva correspondem a uma daquelas descritíveis por meio dos símbolos propostos por Liddell \& Johnson, 2000 [1989]) ${ }^{60}$.

Porém, identifiquei, na libras, 34 sinais que não apresentam como ponto de contato para a mão dominante uma das regiões sobre a palma ou sobre o dorso da mão não-dominante, mas sim uma região no antebraço, como retrata a figura do sinal OBESO abaixo.

\footnotetext{
${ }^{60}$ Para um levantamento de todos as localizações sobre a mão passiva identificadas entre os sinais da libras que foram selecionados para este trabalho, ver quadro (5) no anexo.
} 


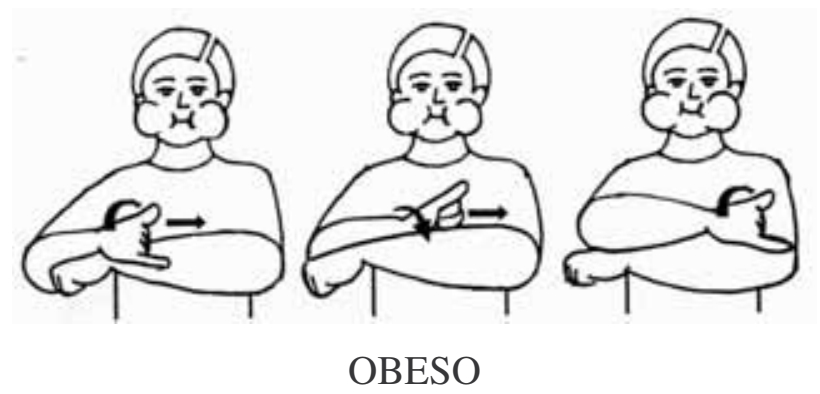

Figura (142) Capovilla \& Raphael (2001:967)

Além disso, nesses sinais, nota-se que o antebraço tem uma configuração particular, podendo aparecer paralelo ao plano do chão e com a mão não-dominante apontando para o lado ipsilateral, tal como em OBESO; paralelo ao plano do chão, mas com a mão nãodominante apontando para frente (cf. NERVOSO (1) e (2) (Capovilla \& Raphael, 2001:946)); ou paralelo ao plano frontal e com a mão não-dominante apontando para cima (cf. JABOTICABA (Capovilla \& Raphael, 2001:774)).

\subsection{Conclusão}

O objetivo deste capítulo foi, em primeiro lugar, mostrar os resultados de um primeiro estudo de alguns dos traços segmentais e de alguns dos traços articulatórios que constituem segmentos da libras. Paralelamente, neste capítulo, foi mostrado como o banco de sinais facilitou esse estudo. 


\section{Capítulo 5: Análise segmental dos sinais da libras}

Com base no que foi dito no capítulo 2, pode-se dizer que o modelo de análise e descrição sublexicais desenvolvido por Liddell \& Johnson (2000 [1989]) se diferencia da proposta pioneira de Stokoe (1960; 2000 [1965]) por incorporar a essa análise e descrição a seqüencialidade observável na realização de aspectos articulatórios envolvidos na produção dos sinais, e, principalmente, por dar a ela o estatuto de princípio de organização interna dos itens lexicais das línguas sinalizadas.

Neste capítulo, faço um exercício de análise segmental para alguns dos sinais da libras, e levanto algumas questões a respeito de sua implementação.

\subsection{Movimentos transicionais versus segmentos de movimento}

Uma das primeiras e, talvez, uma das mais complexas questões que surgem quando se tenta estabelecer a estrutura segmental de um sinal diz respeito à sua delimitação no continuum sinalizado, ou seja, à determinação do momento em que ele começa a ser articulado, e do momento em que sua articulação é finalizada. Essa delimitação é decisiva para estabelecer quantos e quais segmentos constituem um sinal.

A questão se torna ainda mais complexa no que concerne à delimitação dos movimentos. Com base em Liddell (1984), pode-se dizer que nem todo movimento observável na articulação de um sinal faz parte de sua estrutura segmental. Mais especificamente, há movimentos produzidos durante a sinalização que têm como única função posicionar a(s) mão(s) no ponto em que um determinado sinal deve ser iniciado ou totalmente realizado.

$\mathrm{O}$ autor chama esse tipo de movimento de movimento transicional e mostra que somente através de uma análise mais cuidadosa é que se pode diferenciá-lo daqueles movimentos que têm estatuto de segmento.

A argumentação de Liddell se baseou nos sinais THINK (pensar) e BELIEVE (acreditar) da ASL, representados pelas imagens abaixo em todas as suas fases de produção, ou seja, desde o momento em que a(s) mão(s) parte(m) do repouso até o momento em que a articulação do sinal é finalizada. 

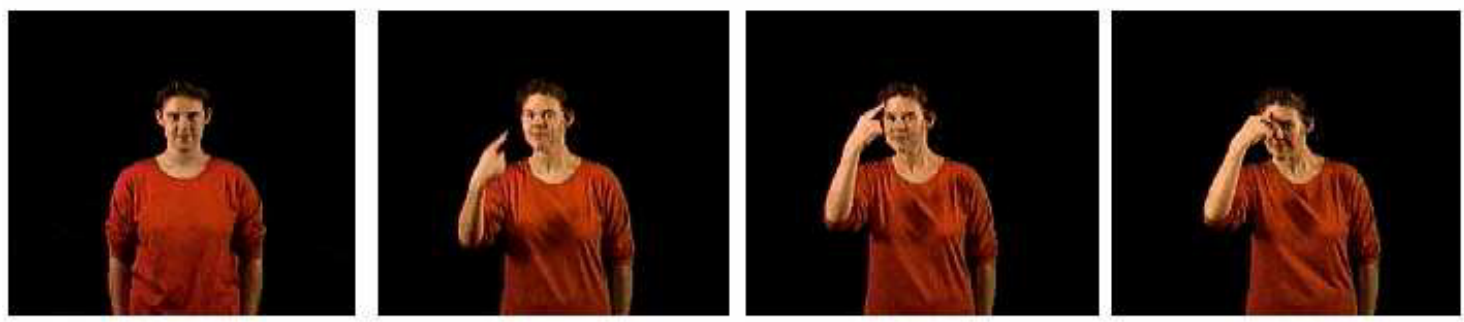

THINK

Figura (143) adaptada de American Sign Language Browser
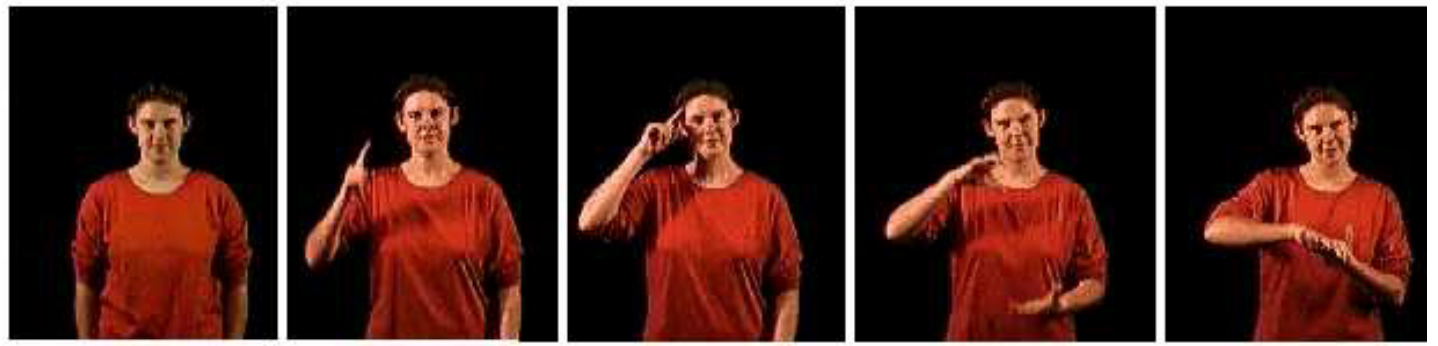

BELIEVE

Figura (144) adaptada de American Sign Language Browser

Pela observação tanto de (143) quanto de (144), seria possível pensar-se que o início da realização de ambos os sinais é o movimento da mão dominante do sinalizador, que parte de uma posição de repouso em direção à lateral ipsilateral da testa, onde, ao realizar contato, fica parada por algum tempo.

Sendo assim e assumindo-se que a estrutura segmental de um sinal consiste numa tradução simples, em termos de movimentos e suspensões, de todas as atividades produzidas pelas mãos durante a articulação de um sinal, também se poderia pensar que ambos os sinais são iniciados por um segmento de movimento seguido de uma segmento de suspensão. Entretanto, ao observar mais atentamente o comportamento desses sinais, Liddell verificou uma diferença entre eles no que diz respeito ao movimento inicial que leva a mão para a lateral ipsilateral da testa.

Segundo Liddell, embora esse movimento seja obrigatoriamente feito quando da realização do sinal THINK (pensar), ele nem sempre é observado na articulação de BELIEVE (acreditar). Conforme observações do autor, quando a mão já está posicionada, antes da realização de BELIEVE (acreditar), na região da testa ou em suas proximidades, por ocasião da articulação de um outro sinal, não se produz um movimento que leve a mão 
até esse ponto de articulação. Tal fato pode ser observado, quando se diz, em ASL, FATHER THINK e FATHER BELIEVE, dado que o sinal FATHER (pai) tem como ponto de articulação a região central da testa $[\mathrm{FH}]$ (forehead), como mostra a imagem abaixo.

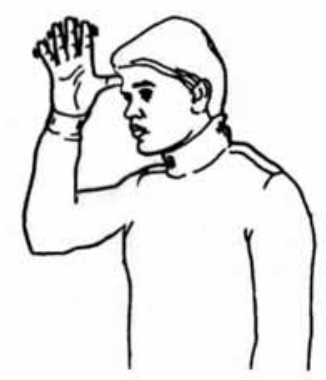

Figura (145) adaptada de Liddell \& Johnson (2000:291 [1989])

Liddell afirma que quando se diz, em ASL, FATHER THINK, observa-se que a mão, depois de articular o sinal FATHER (pai), move-se em direção à lateral da testa [SF] (side of forehead), onde é produzido o sinal THINK (pensar). Mais especificamente, observa-se que a mão se dirige a um ponto a alguns centímetros de distância da lateral da testa e, na seqüência, que ela se move em sua direção, contactando-a e permanecendo aí parada por alguns instantes.

Diferentemente, Liddell afirma que quando se diz, em ASL, FATHER BELIEVE, a mão, posicionada na região central da testa por ocasião da articulação de FATHER (pai), não realiza um movimento semelhante ao observado no caso anterior. Mais precisamente, não se observa a mão, depois de realizar o primeiro sinal, movendo-se para um ponto à frente da testa e, na seqüência, em direção a ela, contactando-a e permanecendo aí parada por alguns instantes. Na verdade, o que se vê nesse caso é a mão, depois de articular o sinal FATHER (pai), movendo-se em direção à mão passiva, contatactando-a e ficando, por alguns intantes, parada e sobre ela.

Diante dessas observações, Liddell concluiu que o movimento que se vê no início da realização do sinal THINK (pensar) faz parte de sua estrutura segmental, ou seja, não tem um caráter meramente transicional, uma vez que é, necessariamente, produzido. Diferentemente, o movimento que leva a mão para a região central da testa para a realização do sinal BELIEVE (acreditar) é transicional, dado o seu caráter opcional.

Neste trabalho, não foi possível realizar um estudo como o de Liddell (1984). Porém, o 
exercício de análise segmental que fiz para alguns sinais da libras, e a observação das sugestões feitas no dicionário para o momento inicial e final de cada sinal, levaram-me a ver o quanto ele é necessário.

Como evidência dessa necessidade, cito os sinais que, tal como dicionarizados em Capovilla \& Raphael (2001), parecem ser constituídos de apenas um segmento de suspensão, por apresentar(em) a(s) mão(s) parada(s) quando de sua realização. Exemplos de sinais desse tipo são os sinais AMÉRICA (Figura (146)), AMÉRICA-DO-NORTE (Figura (147)), AMÉRICA-DO-SUL (Figura (148)) e AMÉRICA-CENTRAL (Figura (149)).

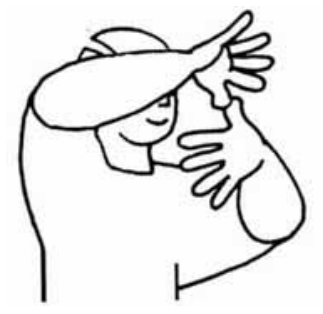

AMÉRICA

Figura (146) Capovilla \& Raphael (2001:187)

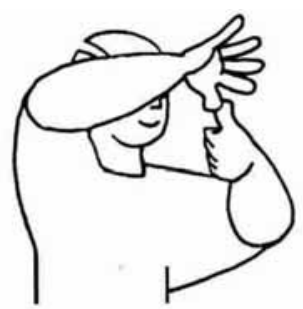

AMÉRICA-DO-NORTE

Figura (147) Capovilla \& Raphael (2001:188)

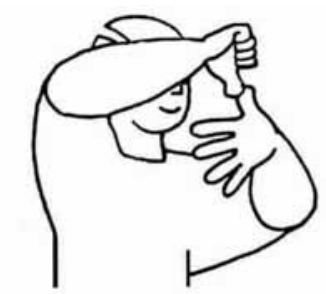

AMÉRICA-DO-SUL

Figura (148) Capovilla \& Raphael (2001:188) 


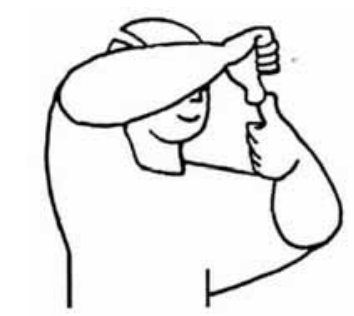

AMÉRICA-CENTRAL

Figura (149) Capovilla \& Raphael (2001:188)

A representação pictórica desses sinais e a sua descrição no dicionário sugerem que o movimento que leva as mãos para a posição em que cada um deles é articulado não está previsto em sua estrutura segmental, e que, conseqüentemente, esse movimento é puramente transicional. Minhas observações desses sinais em uso real vão nesse mesmo sentido. Notei, em uma aula de língua de sinais na qual a professora ensinava sinais para continentes, que ela articulava os sinais supra-citados em seqüência sem repetir o movimento de posicionar as mãos no ponto em que eles são produzidos. Mais precisamente, ela passava de um sinal para o outro apenas mudando a configuração da(s) mão(s) ${ }^{61}$.

Entretanto, encontrei sinais do dicionário cuja observação de seu uso real sugere uma situação diferente. O sinal APOSENTAR (1) (Figura (150)), por exemplo, é descrito e pictorialmente representado no dicionário da mesma forma que os sinais AMÉRICA, AMÉRICA-DO-NORTE, AMÉRICA-DO-SUL e AMÉRICA-CENTRAL. Mais especificamente, o sinal APOSENTAR (1) é dicionarizado em Capovilla \& Raphael como sendo um sinal realizado com as duas mãos paradas. Conseqüentemente, o tratamento que os referidos autores dão a tal sinal sugere que o movimento que posiciona as mãos em frente ao peito é transicional.

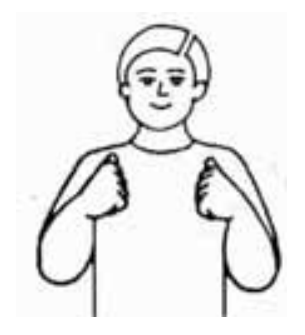

APOSENTAR (1)

Figura (150) Capovilla \& Raphael (2001:214)

\footnotetext{
${ }^{61}$ Nesse caso, o movimento transicional é aquele responsável pela mudança de uma configuração para outra.
} 
Observando a colaboradora desta pesquisa realizar esse sinal em um contexto em que ele significava algo do tipo 'não tenho nada a ver com isso', notei que ela produziu, antes do contato das mãos com o peito, um movimento arqueado [circ]. Baseando-me na argumentação de Sandler (1996) em defesa do estatuto segmental de movimentos por conta da existência de traços que especificamente os descrevem, levanto a possibilidade de que o sinal APOSENTAR (1) seja dotado não apenas de um segmento de suspensão, mas também de um segmento de movimento, realizado em seu início ${ }^{62}$.

Uma outra referência a movimentos transicionais pode ser encontrada em Perlmutter (1990). O autor faz menção a esses movimentos quando contrasta, na ASL, sinais semelhantes a PINTAR (Figura (151)) e a AMANSAR (Figura (152)) da libras.

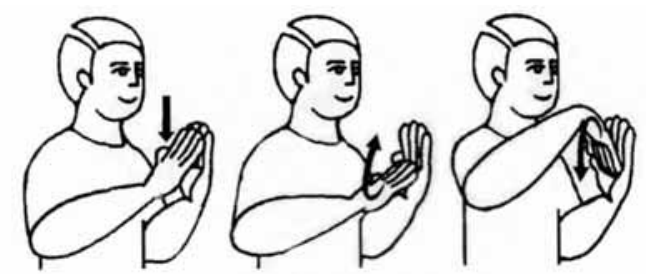

PINTAR

Figura (151) Capovilla \& Raphael (2001:1047)

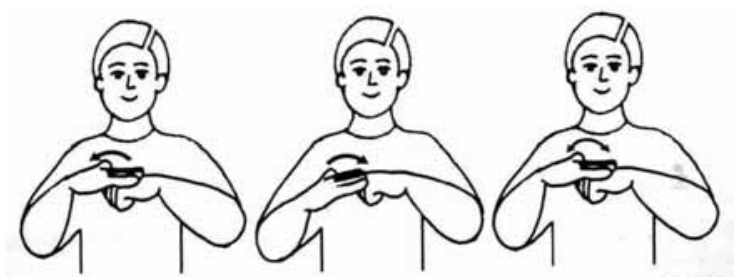

AMANSAR

Figura (152) Capovilla \& Raphael (2001:186)

Como sugere a representação pictográfica de PINTAR, a realização desse sinal consiste em mover a mão ativa, em contato com a ponta dos dedos da mão passiva, em direção à base desta e, na seqüência, em direção ao lugar de onde originalmente saiu. Ao chegar na ponta dos dedos da mão passiva, a mão ativa repete exatamente os mesmos movimentos, de maneira que, ao final da articulação desse sinal, ela passa pela palma da outra mão quatro vezes.

\footnotetext{
${ }^{62}$ Apesar de toda essa discussão estar apoiada nas intuições da colaborada deste trabalho, Evani Viotti (c.p.) levanta a hipótese de o sinal dicionarizado e de o sinal que vi em uso real serem sinais diferentes.
} 
Já o sinal AMANSAR é articulado com um movimento que leva a mão ativa, em contato com a mão passiva, para a frente desta. Ao chegar nessa localização, a mão retorna ao seu ponto inicial, estabelece novamente contato com o dorso da mão passiva e repete o primeiro movimento. Nesse sinal, a mão ativa toca o dorso da mão passiva duas vezes.

Perlmutter designou movimentos do tipo observado em sinais como PINTAR de movimentos bidirecionais e denominou movimentos do tipo observado em sinais como AMANSAR de movimentos unidirecionais.

A relação dessa distinção com os movimentos transicionais pode ser vista no seguinte fato. Segundo Perlmutter, em sinais semelhantes a PINTAR, tanto o movimento que leva a mão ativa da ponta dos dedos da mão passiva à base desta, quanto o movimento contrário, ou seja, o movimento que retorna a mão ativa da base da mão passiva à ponta de seus dedos para a reiteração de ambos os movimentos fazem parte do sinal. $\mathrm{O}$ autor sustenta sua afirmação no fato de que os dois movimentos são caracterizados pela presença de contato, no modelo de Liddell \& Johnson, descrito pelo traço [contact].

Diferentemente, Perlmutter trata o movimento que leva a mão ativa de volta ao ponto em que ela realizou o primeiro movimento no sinal AMANSAR, como movimento transicional. Segundo o autor, esse tratamento se justifica pelo fato de que tal movimento não compartilha o traço contato [contact] com o movimento que leva a mão do dorso da mão passiva a uma região que fica à sua frente.

Nesse sentido, as investigações relacionadas à distinção entre movimentos segmentais e movimentos transicionais não se restringem apenas aos movimentos observados no ínicio ou no fim dos sinais, mas também a movimentos produzidos no meio deles. Em sinais como AMANSAR (Figura (152)), a distinção entre os movimentos segmentais e o movimento transicional intermediário, à luz das idéias de Perlmutter, parece bastante clara. Entretanto o mesmo não pode ser dito em relação ao movimento que considerei como transicional em sinais como LEITE (Figura (19)) e que se pode considerar da mesma forma em sinais como CANCELAR (1) (Figura (153). 


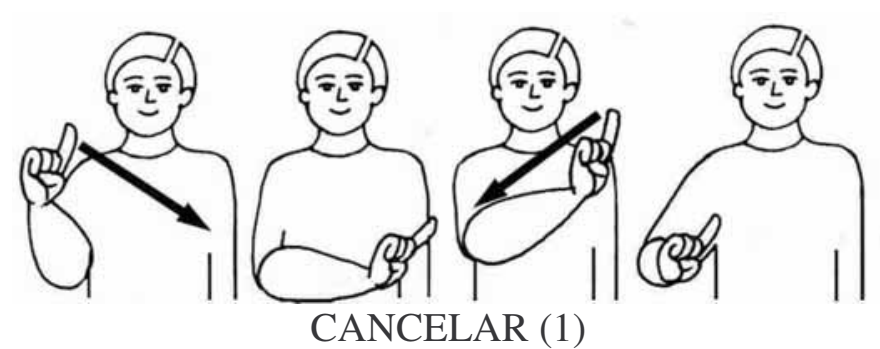

Figura (153) Capovilla \& Raphael (2001:351)

Como sugere a figura acima, o sinal CANCELAR (1) consiste em descrever dois movimentos retos, porém inclinados, de maneira que se produza um ' $x$ '. Para que se realize o segundo movimento do sinal, é preciso levar a mão, posicionada a uma altura próxima do abdômen, a um ponto acima. Esse movimento parece ser transicional, porém, diferentemente de AMANSAR, não se pode contrastá-lo a um movimento segmental. A principal razão disso se deve à ausência do traço [contact], dado que esse sinal não o apresenta.

\subsection{Análise dos sinais da libras em suspensões e movimentos}

Como já dito no capítulo 1, levando em conta a seqüencialidade na realização de aspectos articulatórios dos sinais da ASL, Liddell (1984) separou os itens lexicais dessa língua em dois grupos. Em um deles, ele reuniu sinais que não exibem realização seqüencial em nenhum dos aspectos que os descrevem articulatoriamente, ou seja, apresentam-se inalterados do início ao fim de sua realização. No outro, ele agrupou sinais que exibem seqüencialidade em sua produção, por apresentarem mais de uma especificação para pelo menos um dos aspectos que os caracterizam.

Com essa separação, Liddell mostrou que a seqüencialidade articulatória é recorrente no léxico da ASL, uma vez que os sinais do segundo grupo, designados por ele de sinais seqüenciais, são mais numerosos do que os do primeiro, denominados sinais unitários. Sinais do primeiro grupo são tratados pelos autores como sinais mono-segmentais, enquanto sinais do segundo são considerados pluri-segmentais.

Nas seções subseqüentes, trato desses dois tipos de sinais na libras. Mais especificamente, mostro como esses sinais são representados de acordo com o modelo de 
Liddell \& Johnson e apresento como eles podem ser acessados no banco de dados.

\subsubsection{Sinais mono-segmentais}

De acordo com o que foi dito na seção anterior, sinais mono-segmentais (sinais unitários) são aqueles que se diferenciam dos sinais pluri-segmentais (sinais seqüenciais) por não apresentarem uma seqüência de atividades da mão, tratadas por Liddell \& Johnson como suspensões e movimentos, em sua produção. Um exemplo de sinal desse tipo na libras é o sinal SILÊNCIO, representado pela figura a seguir.

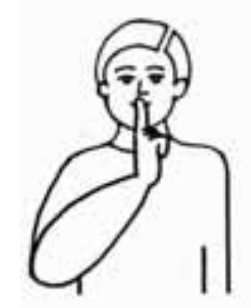

SILÊNCIO

Figura (154) Capovilla \& Raphael (2001:1197)

Como sugere a figura acima, nesse sinal, os traços articulatórios que caracterizam a mão se apresentam estáveis, ou seja, a configuração de mão, o ponto de contato e a orientação da palma são os mesmos do início ao fim da sua realização. Somando-se ao fato de que tal sinal é formado por um único segmento, é importante mencionar que esse segmento é do tipo suspensão, dado que durante a sua articulação a mão fica parada.

Seguindo a proposta de Liddell \& Johnson, um sinal como SILÊNCIO (Figura (154)) pode ser representado como em (17). 


\begin{tabular}{ll|c|} 
Classe Maior: & & \multicolumn{1}{c}{ S } \\
& & \multicolumn{1}{c}{} \\
CM: & & $10-$ \\
PC: & Localização & MO \\
& Parte da mão & RA \\
& Proximidade & C \\
& Relação Espacial & \\
FA: & Parte da mão & \\
& Localização & \\
OR: & Parte da mão & BA \\
& Plano & HP \\
& & \\
& &
\end{tabular}

Representação (17) $)^{63}$

Nessa representação, nota-se, entre os traços segmentais (representados no primeiro retângulo), a única especificação relevante: o tipo de segmento, no caso, suspensão [S]. Já entre os traços articulatórios (representados no segundo retângulo), observam-se os traços que descrevem a postura da mão, ou seja, os traços articulatórios. O primeiro deles diz respeito à configuração de mão $[\mathrm{CM}]$ que, nesse sinal, consiste em indicador aberto e os demais dedos fechados, inclusive o polegar. Como mostra a representação acima, essa configuração é simbolizada por [10-].

$\mathrm{Na}$ seqüência, têm-se os traços que descrevem o ponto de contato [PC]. O primeiro traço desse subfeixe diz respeito à localização, ou seja, ao lugar em que esse sinal é articulado. Como já sugeriu a figura (154), esse sinal tem como ponto de articulação a boca, que, de acordo com o sistema de Liddell \& Johnson, é representado pelo símbolo [MO] (mouth). O segundo traço do subfeixe [PC] se refere à parte da mão que toca ou que está voltada para a localização especificada pelo traço anterior. Como também sugere a figura do sinal em análise, a parte da mão é a radial, representada por [RA]. O terceiro traço desse subfeixe descreve a relação de proximidade entre a localização e a parte da mão, especificadas pelos dois traços anteriores. No caso do sinal SILÊNCIO, observa-se que essa relação se define pelo traço contato [c], uma vez que a mão contacta a localização [MO]. Por fim, cabe dizer que o quarto traço do subfeixe [PC], relação espacial, não apresenta nenhuma especificação na representação acima, por ser tal traço reservado para sinais

\footnotetext{
${ }^{63}$ Em Liddell \& Johnson (2000 [1989]), a representação segmental dos sinais da ASL não traz, como nesta representação e nas seguintes, uma legenda para os traços segmentais e articulatórios. Optei por apresentar essas legendas, por objetivar facilitar a leitura deste trabalho.
} 
realizados com movimentos de roçar (ver seção 2.4.2), que não é o caso.

Por fim, aparece na representação do sinal SILÊNCIO os traços que compõem o subfeixe articulatório orientação [OR] e os traços que compõem o subfeixe face [FA]. Como dito na seção 2.4.3, o primeiro deles é responsável por descrever a parte da mão que está paralela ao plano horizontal [HP] (horizontal plane). No caso em questão, como mostra a representação acima, a parte da mão é a base [BA]. Já o segundo tem a função de determinar a parte da mão que está posicionada (ou apontando) para a localização especificada pelo ponto de contato. Esse subfeixe foi ignorado na representação desse sinal e dos demais sinais deste capítulo por não parecer ser relevante. A importância dele é patente em sinais indicadores, tradicionalmente denominados direcionais. Para uma discussão a respeito deles, ver Moreira (em preparação).

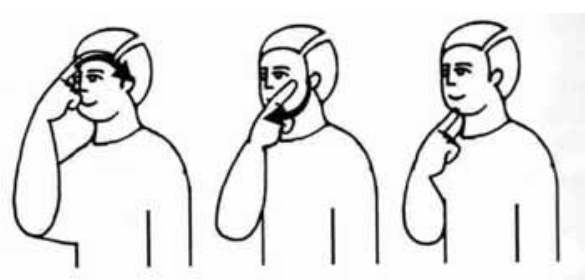

MEIA-HORA

Figura (155) Capovilla \& Raphael (2001:884)

Além de sinais mono-segmentais formados por um único segmento de suspensão, é possível também encontrar sinais como MEIO-DIA que se constituem unicamente por um segmento de movimento. A representação de sinais como esse, segundo o modelo de Liddell \& Johnson, é feita tal como em (18).

Classe Maior:
Contorno:
Plano:

Representação (18)

\begin{tabular}{|c|c|}
\hline \multicolumn{2}{|c|}{ M } \\
rnd \\
SP \\
\hline $10-$ & $10-$ \\
FH & CN \\
TIXF & TIXF \\
p & $p$ \\
& \\
& \\
PA & PA \\
HP & HP \\
\hline
\end{tabular}


Como já discutido na seção 2.2, em termos representacionais, a diferença mais significativa entre segmentos de suspensão e de movimento diz respeito ao uso de duas matrizes de traços articulatórios na representação destes últimos, enquanto, para os segmentos do primeiro tipo, apenas uma é empregada. Como também já discutido, tal fato decorre da necessidade de capturar aquilo que caracteriza os movimentos: a alteração de pelo menos um de seus traços articulatórios. Nos termos do modelo em questão, captura-se essa alteração por meio da representação da fase inicial e da fase final de um segmento de movimento.

$\mathrm{Na}$ representação acima, descrevem-se os traços articulatórios tal como eles aparecem no início e no final do sinal. Nesse caso, os traços de configuração de mão [10-] e de orientação (parte da mão: palma [PA]; e plano: plano horizontal [HP]) são os mesmos nas duas fases do movimento. Porém, entre os traços de ponto de contato, nota-se que, apesar de aquele que descreve a parte da mão (ponta do dedo indicador [TIXF] (tip + index finger)) e o que caracteriza a proximidade (próximo [p]) não variarem, há duas especificações para o traço de localização. Na primeira fase do movimento, ele é descrito pelo traço testa [FH] (forehead), enquanto na segunda ele é caracterizado pelo traço queixo [CN] (chin).

Em relação aos traços segmentais, representados acima dos traços articulatórios, é importante dizer que eles diferem dos mencionados na representação em (19) não apenas por ser o traço de classe maior de outro tipo, a saber, movimento [M], mas também por incluir traços relativos ao contorno do movimento, circular [rnd], e ao plano em que esse contorno é realizado, plano superficial [SP] (superficial plane).

Embora no banco de dados sinais semelhantes a SILÊNCIO possam ser facilmente acessados por meio de uma busca que conjugue o valor positivo do critério [ \pm 1 mão] ao valor negativo do critério $[ \pm$ movimento], o mesmo não pode ser feito com sinais semelhantes a MEIA-HORA. Dentre os sinais feitos com movimento, não é possível diferenciar aqueles que são mono-segmentais, ou seja, constituídos apenas por um segmento de movimento, daqueles que são pluri-segmentais, ou seja, que podem incluir, em sua estrutura segmental, um ou mais de um segmento de suspensão e/ou de movimento.

A principal razão disso se vincula aos limites que um estudo como este apresenta por não ser baseado em um corpus formado por gravações de sinalizações espontâneas e em uma análise fonética, semelhante à que Liddell (1984) fez para os sinais da ASL. Como 
dito na seção 1.2.2, Liddell chegou à estrutura segmental dos sinais da ASL, entre outras coisas, por meio da mensuração do tempo das atividades da(s) mão(s) durante a realização de sinais gravados em vídeo.

Sendo assim, faz-se necessário que trabalhos futuros investiguem mais aprofundadamente essa questão, de maneira a poder diferenciar sinais da libras que são formados por apenas um segmento de movimento, daqueles que apresentam uma estrutura segmental mais complexa.

A meu ver, podem ser incluídos, entre os sinais mono-segmentais, sinais articulados com duas mãos como ALCE (Figura (156)).

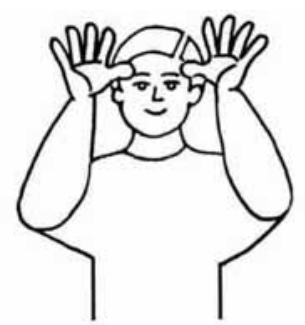

ALCE

Figura (156) Capovilla \& Raphael (2001:172)

À primeira vista, pode não parecer apropriado fazer essa inclusão, dado que as mãos, por serem articulatoriamente independentes, realizam suas próprias estruturas segmentais (no caso de ALCE, cada mão realiza um segmento de suspensão, o que significa que tal sinal se constitui de mais de um segmento). Entretanto, acredito que se possa dar a sinais como esse o mesmo tratamento que Liddell (1984) dá a sinais como SILÊNCIO e MEIAHORA, se assumirmos que a mono-segmentalidade de itens lexicais desse tipo reside no fato de que cada mão produz apenas um segmento.

A independência articulatória das mãos mencionada acima é capturada pelo modelo de Liddell \& Johnson por meio de uma representação, como a do sinal ALCE a seguir, que apresenta uma estrutura segmental para cada mão. 


\begin{tabular}{|c|c|c|c|}
\hline \multirow[t]{10}{*}{ Mão dominante } & \multicolumn{2}{|l|}{ Classe Maior: } & $\mathbf{S}$ \\
\hline & \multicolumn{2}{|l|}{ CM: } & $4 u$ \\
\hline & \multirow{4}{*}{ PC: } & Localização & SF \\
\hline & & Parte da mão & TITH \\
\hline & & Proximidade & c \\
\hline & & Relação Espacial & \\
\hline & \multirow[t]{2}{*}{ FA: } & Parte da mão & \\
\hline & & Localização & \\
\hline & \multirow[t]{2}{*}{ OR: } & Parte da mão & BA \\
\hline & & Plano & $\mathrm{HP}$ \\
\hline \multirow[t]{10}{*}{ Mão não-dominante } & \multicolumn{2}{|l|}{ Classe Maior: } & $\overline{\mathrm{S}}$ \\
\hline & \multicolumn{2}{|l|}{ CM: } & $4 u$ \\
\hline & \multirow[t]{4}{*}{ PC: } & Localização & $\% S F$ \\
\hline & & Parte da mão & TITH \\
\hline & & Proximidade & c \\
\hline & & Relação Espacial & \\
\hline & FA: & Parte da mão & \\
\hline & & Localização & \\
\hline & \multirow[t]{2}{*}{ OR: } & Parte da mão & BA \\
\hline & & Plano & HP \\
\hline
\end{tabular}

Representação (19)

Para casos como o apresentado em (19), os autores convencionaram representar a mão dominante acima da mão não-dominante.

Em relação aos feixes segmental e articulatório do único segmento que cada uma das mãos realiza no sinal ALCE, pode-se observar que, além de as duas mãos serem descritas pelo mesmo traço de classe maior, suspensão [S], elas também se caracterizam pelos mesmos traços de configuração de mão, [4u]; de parte da mão, ponta do polegar, representada por [TITH] (tip of thumb); e de proximidade, contato, representado por [c]. O único traço que as difere (e ainda assim não totalmente) é o traço de localização, dado que o ponto de contato da mão dominante é a lateral ipsilateral da testa [SF] (side of forehead), enquanto o da mão não-dominante é a lateral contralateral da testa [\% SF].

Embora, nesse caso, as mãos estejam paradas, é possível ver nesse sinal a atuação do princípio de simetria, proposto por Battison (2000 [1978a]) e apresentado na seção 4.3.1.2: em ALCE, além de configurações idênticas, o sinal apresenta localizações e orientações simétricas.

Tendo em vista princípios como esse, Liddell \& Johnson reconhecem a redundância da 
representação que propõem para sinais desse tipo. Porém, por não perderem de vista o fato de que os estudos sobre a fonologia das línguas sinalizadas ainda é muito incipiente, eles preferem continuar utilizando representações com informações redundantes a propor representações mais elegantes, mas com grandes chances de estarem incorretas.

A meu ver, também é possível incluir, entre os sinais mono-segmentais, aqueles que são produzidos com duas mãos realizando, cada uma, um segmento de movimento. Um exemplo de sinal desse tipo é o sinal RICO, representado a seguir.

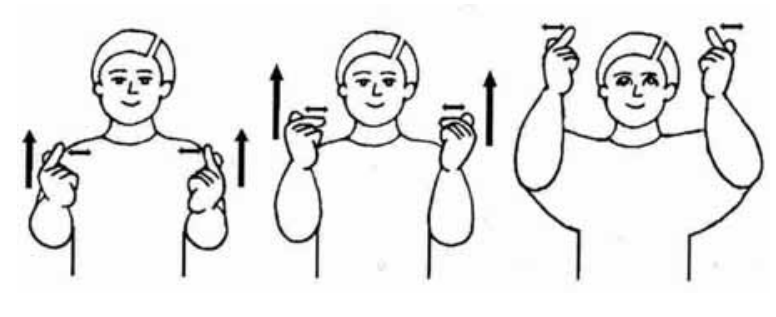

RICO

Figura (157) Capovilla \& Raphael (2001:1146)

Nesse sinal, como sugere a figura acima, as duas mãos se movem [M] simultanea e retilineamente [str] (straight). Durante esse movimento, elas realizam um movimento local denominado por Liddell (1990) de oscilação de configuração de mão [osc-h]. Como sugere a figura, durante todo o movimento realizado por cada mão, elas oscilam sua configuração de $\left[1^{\wedge} \mathrm{O}-\right]$ para $[\mathrm{Au}]$. Como também sugere a figura acima, no que diz respeito ao ponto de contato inicial e ao final, pode-se dizer que as mãos, a cada lado do corpo, partem de uma posição em frente aos ombros [p2ST] em direção a uma outra na altura da cabeça [p2TH]. Por fim, cabe dizer que apresentam a mesma orientação, uma vez que a parte da mão paralela ao plano horizontal [HP] é a base [BA].

Sendo assim, a representação de um sinal como RICO é feita como em (20). 


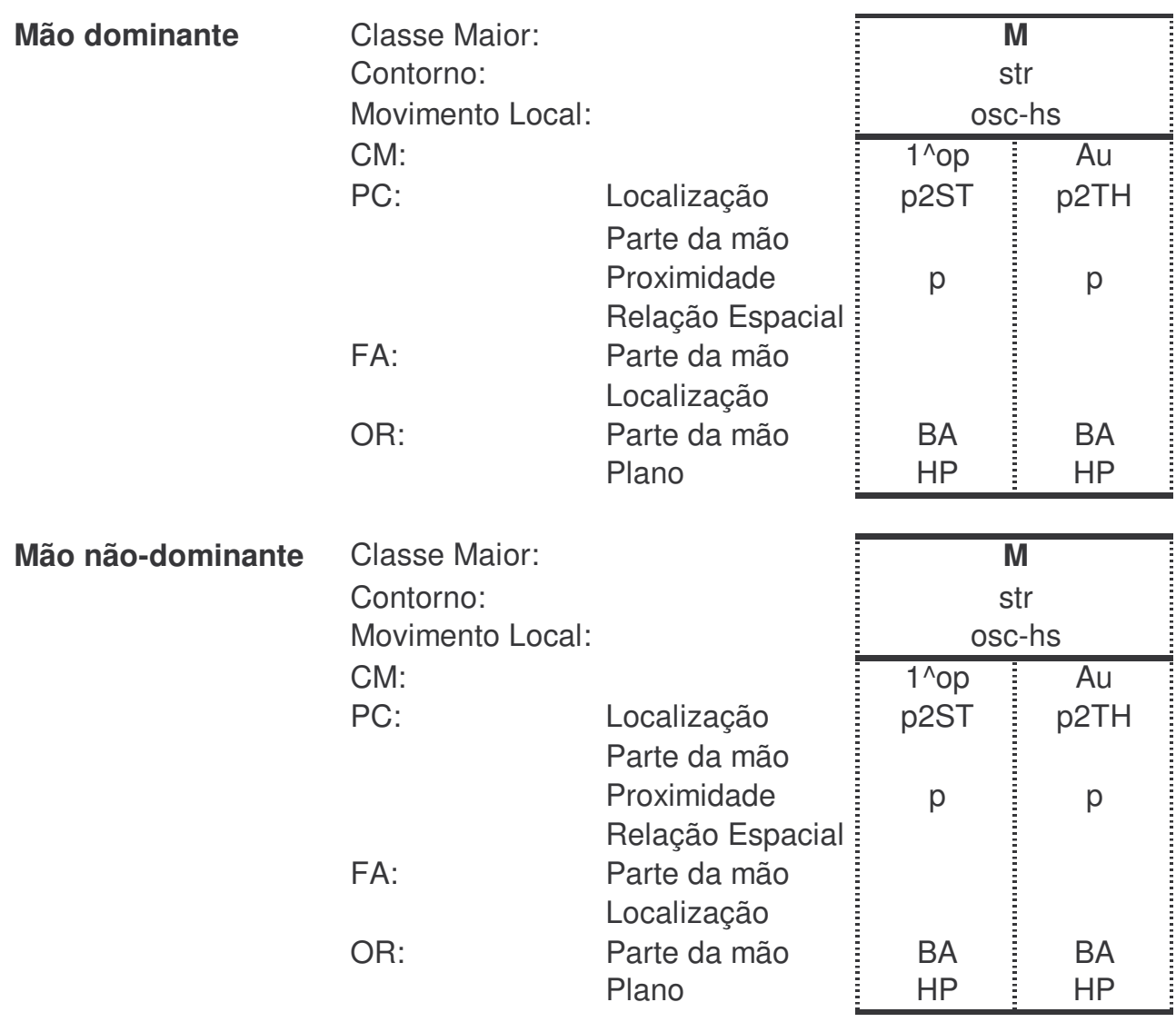

Representação (20)

Embora sinais como ALCE possam ser acessados no banco de dados por meio de uma busca que conjugue o valor negativo do critério [ \pm 1 mão] ao valor negativo do critério [ \pm movimento], o mesmo não se dá com sinais como RICO (Figura (157)), semelhantemente ao que acontece com sinais como MEIA-HORA (Figura (155)). Por não ter evidências de que ambos os sinais são constituídos unicamente por um segmento de movimento, mantiveos, indistintamente, entre os sinais realizados com mais de um segmento de movimento e/ou com um ou mais segmentos de suspensão.

\subsubsection{Sinais pluri-segmentais}

Como mencionado na seção anterior, no banco de dados, não diferenciei, entre os sinais feitos com uma ou duas mãos se movendo, aqueles em que a(s) mão(s) só realiza(m) um segmento de movimento, daqueles em que ela(s) produz(em) mais de um segmento de 
movimento e/ou um ou mais de um segmento de suspensão. Como também mencionado na seção anterior, essa indiferenciação resultou dos limites que este trabalho apresenta por não ser baseado em análises de sinalização real.

Entretanto, ao considerar que o traço contato [c], codificado entre os traços do subfeixe ponto de contato [PC], está, pelo menos até onde eu saiba, sempre associado à realização de uma suspensão, tomei-o como uma pista para dar início a uma primeira tentativa de mapear a estrutura segmental de sinais dotados desse traço.

Para isso, tive que fazer distinções mais finas no conjunto de sinais especificados com o valor positivo do critério [ \pm contato], com dois objetivos: (i) precisar em que momento da articulação do sinal o traço [c] é produzido (no início, no fim ou no início e no fim) e assim determinar a posição do segmento de suspensão; e separar sinais especificados com esse traço, daqueles dotados do traço [contact], codificado entre os traços de qualidade nãotemporal e responsável por descrever os movimentos de roçar.

Sendo assim, acrescentei, a tal critério, cinco subcritérios, a saber:
a) $[ \pm$ contato inicial $]$
b) $[ \pm$ contato medial $]$
c) $[ \pm$ contato final $]$
d) $[ \pm$ contatos inicial e final $]$
e) $[ \pm \text { contato permanente }]^{64}$

Por meio da especificação positiva dos subcritérios $[ \pm$ contato medial $]$ e $[ \pm$ contato permanente], isolei sinais realizados com movimento de roçar. Esses sinais foram desconsiderados dessa tentativa de mapeamento da estrutura segmental dos sinais pela seguinte razão. O traço [contact] que os descreve é um traço próprio de segmentos de movimento. Conseqüentemente, esse traço parece ser uma evidência da existência de um segmento desse tipo na estrutura segmental do sinal. Porém, a meu ver, só por meio dele

\footnotetext{
${ }^{64}$ Entre os sinais classificados com o valor positivo do subcritério [ \pm contato permanente] estão não apenas aqueles que, assim como os classificados com o valor postivo do subcritério [ \pm contato medial], são descritos pelo traço [contact], mas também sinais que, como BARCO (Capovilla \& Raphael, 2001:276), são articulados com as mãos em contato do começo ao fim. Por esse tipo de contato também não ser relevante para o mapeamento da estrutura segmental dos sinais, não fiz distinções mais finas de modo a permitir o levantamento de casos como esse.
} 
não é possível identificar mais do que o segmento de movimento desses sinais. Em outras palavras, não é possível determinar se, além do movimento dotado desse traço, existem segmentos de suspensão.

Diante disso, restringi-me aos sinais especificados pelo valor positivo dos subcritérios $[ \pm$ contato inicial $],[ \pm$ contato final $]$ e $[ \pm$ contatos inicial e final $]$. Embora também não tenha sido possível, a partir dessas subclassificações, determinar, para todos os casos, a estrutura segmental completa dos sinais considerados, foi possível, pelo menos, reunir sinais que apresentam padrões seqüenciais parecidos e mapear parte de seus segmentos.

Um exemplo de sinal dotado de contato inicial é o sinal SOM (Figura (158)).

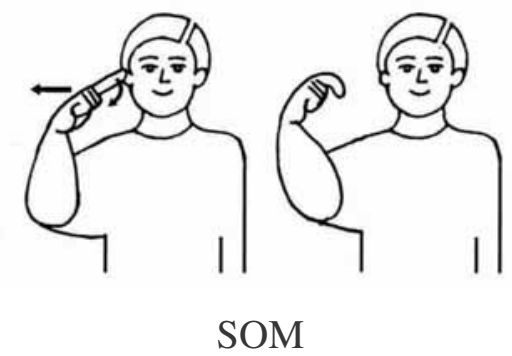

Figura (158) Capovilla \& Raphael (2001:1208)

Como sugere a figura acima, nesse sinal, a mão configurada em [1o-], com a base [BA] orientada para o plano horizontal $[\mathrm{HP}]$, parada $[\mathrm{S}]$ e em contato [c] com a orelha ipsilateral [ER], move-se [M] retilineamente [str] para um ponto localizado a uma distância média do ponto de partida, paralelo ao ombro e na altura do nariz [m2NS]. Mais especificamente, nesse sinal, a mão realiza um segmento de suspensão seguido de um segmento de movimento, tal como representado em (23). 


\begin{tabular}{|c|c|c|c|}
\hline \multicolumn{2}{|c|}{$\begin{array}{l}\text { Classe Maior: } \\
\text { Contorno: }\end{array}$} & $\mathbf{S}$ & $\begin{array}{l}\text { M } \\
\text { str }\end{array}$ \\
\hline \multicolumn{2}{|l|}{ CM: } & 10- & 1"o- \\
\hline \multirow[t]{4}{*}{ PC: } & Localização & ER & m2NS \\
\hline & Parte da mão & TIXF & TIXF \\
\hline & Proximidade & c & $\mathrm{m}$ \\
\hline & Relação Espacial & & \\
\hline \multirow[t]{4}{*}{ FA } & Parte da mão & & \\
\hline & Localização & & \\
\hline & Parte da mão & BA & BA \\
\hline & Plano & HP & HP \\
\hline
\end{tabular}

Representação (21) ${ }^{65}$

Entretanto, é importante dizer que não estou assumindo que a estrutura acima mapeie totalmente os segmentos do sinal em questão. A razão disso se vincula ao fato de nada impedir que, depois do segmento de movimento desse sinal, exista um segmento de suspensão que, diante da maneira utilizada neste trabalho para seu estabelecimento, não pode ser mapeado, dado que não apresenta o traço [c].

Já como exemplo de sinais realizados com contato final, pode-se citar o sinal AMAR, representado pela figura abaixo.

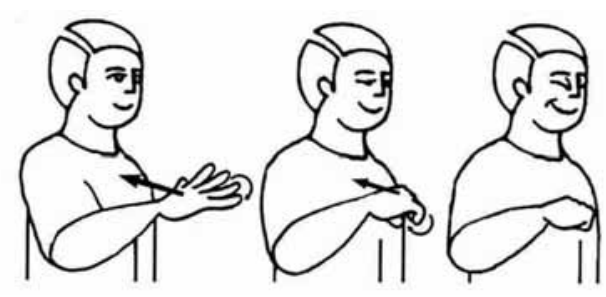

AMAR

Figura (159) Capovilla \& Raphael (2001:184)

Nesse caso, a mão, com a palma [PA] orientada para o plano horizontal $[\mathrm{HP}] \mathrm{e}$ localizada em frente ao peito contralateral, a uma distância média dele e na altura do esterno [m1ST], move-se $[\mathrm{M}]$ retilineamente [str] em direção ao peito contralateral $[\% \mathrm{CH}]$, onde pára $[\mathrm{S}]$ e faz contato [c] pela região radial [RA]. Como sugere a figura e como

\footnotetext{
${ }^{65}$ Como já dito, a linha que está ligando o segmento de movimento ao de suspensão é chamada de linha de associação.
} 
mostra a representação abaixo, além disso tudo, a mão muda sua configuração inicial de [4u] para [So-].

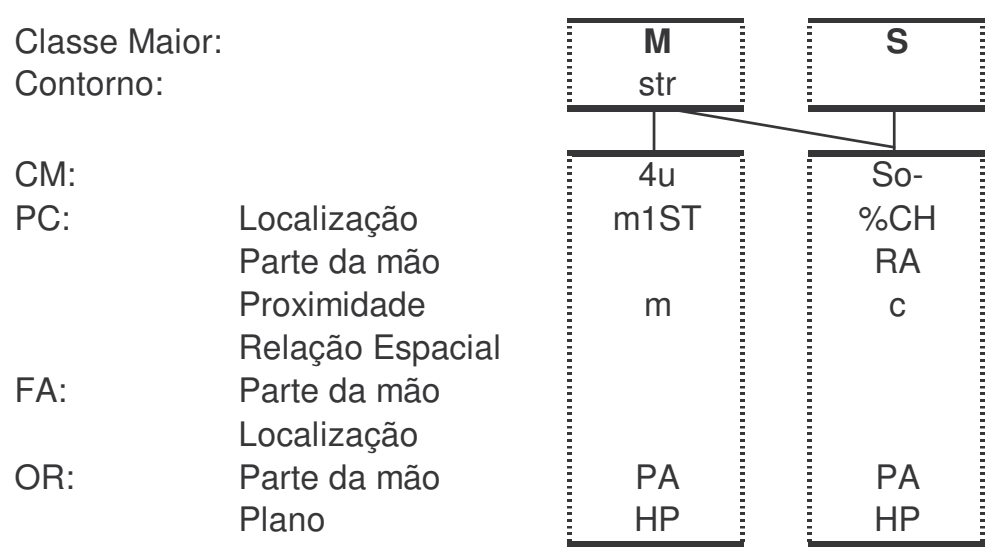

Representação (22)

Mais uma vez, é importante dizer que a estrutura segmental proposta não tem a pretensão de corresponder ao mapeamento total dos segmentos do sinal em discussão. Nada impede, por exemplo, que exista um segmento de suspensão antecedendo o movimento de sinais semelhantes a AMAR. Porém, em decorrência da falta de pistas nesse sentido, prefiro não propor uma estrutura para esse sinal que inclua uma suspensão inicial.

Por fim, pode-se citar como exemplo de sinal constituído de contato em seu início e em seu final, o sinal EGOÍSMO (Figura (160)).

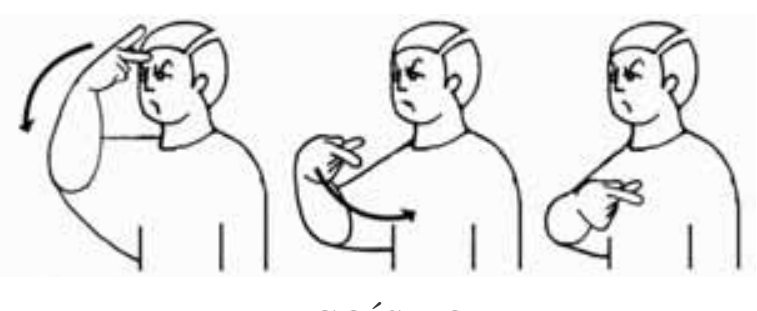

EGOÍSMO

Figura (160) Capovilla \& Raphael (2001:572)

De acordo com a figura acima, a mão, configurada em [Ku], com a parte ulnar [UL] orientada para o plano horizontal [HP], parada [S] e em contato [c] com a testa $[\mathrm{FH}]$ pela ponta do dedo médio [TIMF] (tip + middle finger), move-se [M] arqueadamente [rnd] em direção ao esterno [ST], onde pára [S] fazendo contato [c]. Em termos segmentais, como mostra a representação abaixo, nesse sinal, a mão realiza uma suspensão inicial, seguida de 
um movimento que, por sua vez, é sucedido por uma suspensão.

Classe Maior:
Contorno:
Plano:

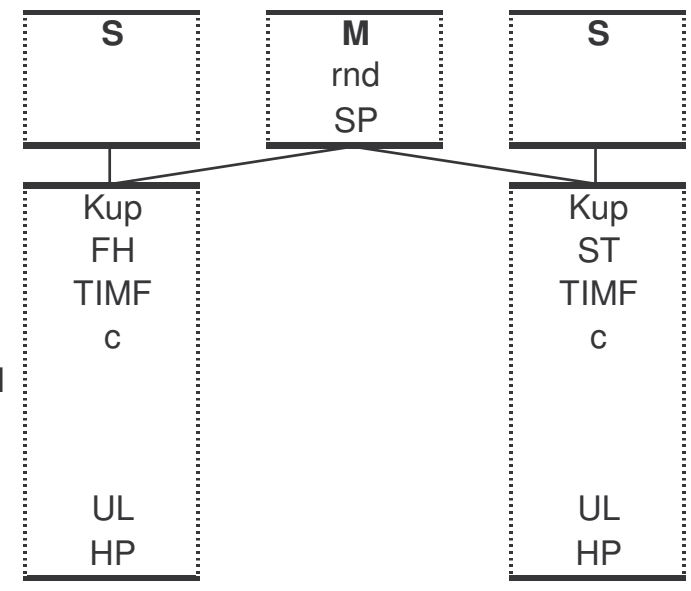

Representação $(23)^{66}$

Cabe dizer que também foi considerado, nessa tentativa de mapeamento dos segmentos dos sinais da libras, o critério [ \pm reduplicação]. Conforme dito no capítulo 3 , com base nesse critério, classifiquei sinais que, de acordo com a descrição de Capovilla \& Raphael (2003), apresentam seu movimento realizado duas vezes. Essa informação é importante para o estabelecimento da estrutura segmental de certos sinais, uma vez que ela determina que qualquer uma das estruturas mencionadas acima (ou outras possíveis) devem aparecer duas vezes na estrutura sublexical destes. Mais especificamente, sinais constituídos de uma estrutura do tipo $\mathrm{S} M, M \mathrm{~S}, \mathrm{~S} \mathrm{M}$ S reduplicada, terão como estrutura subjacente, respectivamente, S M S M, M S M S e S M S S M S ${ }^{67}$.

Um levantamento de todas essas possibilidades entre os sinais da libras incluídos no banco de sinais pode ser visto no quadro a seguir.

\footnotetext{
${ }^{66}$ Como mencionado no capítulo 2, esta representação captura o fato de segmentos de movimento se valerem do feixe de traço da suspensão inicial e da final.

${ }^{67}$ Ver Liddell (1990:50-1).
} 
Quadro (7)

\begin{tabular}{|c|c|c|c|c|}
\hline & $\begin{array}{l}\text { estrutura } \\
\text { segmental }\end{array}$ & 1 mão & 2 mãos & $\begin{array}{l}1 \text { das mãos } \\
\text { parada }\end{array}$ \\
\hline contato inicial & S M & SOM (p.1208) & $\begin{array}{l}\text { ABENÇOAR } \\
\text { (p.136) }\end{array}$ & OUTONO (p.987) \\
\hline $\begin{array}{l}\text { contato inicial } \\
\text { reduplicação }\end{array}$ & S M S M & $\begin{array}{l}\text { OPINAR } \\
\text { (p.982) }\end{array}$ & ASSOAR (p.235) & PULAR (p.1094) \\
\hline contato final & M S & $\begin{array}{l}\text { ABSURDO } \\
\text { (p.142) }\end{array}$ & $\begin{array}{l}\text { TRAUMATIZAR } \\
\text { (p.1269) }\end{array}$ & $\begin{array}{c}\text { PROCESSO- } \\
\text { JUDICIAL } \\
\text { (p.1083) }\end{array}$ \\
\hline $\begin{array}{l}\text { contato final } \\
\text { reduplicação }\end{array}$ & M S M S & $\begin{array}{l}\text { ALEMANHA } \\
\text { (p.169) }\end{array}$ & $\begin{array}{l}\text { SOFRER (2) } \\
\text { (p.1205) }\end{array}$ & PORQUE (p.1064) \\
\hline $\begin{array}{l}\text { contato inicial e } \\
\text { final }\end{array}$ & S M S & $\begin{array}{l}\text { EGOÍSMO } \\
\text { (p.572) }\end{array}$ & $\begin{array}{l}\text { CAMISA (1) } \\
\text { (p.346) }\end{array}$ & FRITAR (p.691) \\
\hline $\begin{array}{l}\text { contato inicial e } \\
\text { final e reduplicação }\end{array}$ & S M S S M S & - & - & $\begin{array}{l}\text { TRADUÇÃO } \\
\text { (p.1264) }\end{array}$ \\
\hline
\end{tabular}

Para finalizar esta seção, é preciso dizer que essa primeira tentativa de mapear a estrutura segmental dos sinais da libras, por se basear no traço contato [c] do subfeixe ponto de contato $[\mathrm{PC}]$, restringiu-se a 533 sinais do banco de sinais, ou seja, apenas àqueles descritos com esse traço. Esse número corresponde a $23 \%$ dos sinais selecionados para este trabalho. Tal fato indica que há ainda muito a ser feito não só em relação aos sinais cuja estrututura segmental não foi explorada aqui, mas também, como apontado anteriormente, em relação aos sinais abrangidos por essa primeira tentativa de mapeamento, dado que, com os recursos de que disponho e com o pouco conhecimento que se tem acerca da fonologia das línguas sinalizadas, não assumi como definitiva nenhuma das estruturas que apresentei.

\subsection{Corolários de uma análise segmental}

Um dos objetivos de um estudo como o proposto por Liddell \& Johnson (2000 [1989]) e seguido neste trabalho é identificar os segmentos constitutivos do inventário fonológico de uma língua sinalizada, da mesma forma que se faz nos estudos da fonologia das línguas 
faladas. Mais especificamente, a análise segmental dos sinais de uma língua sinalizada objetiva, entre outras coisas, estabelecer quais e quantos segmentos de suspensão e de movimento representam as unidades mínimas (destituídas de significado, mas capazes de distingui-lo) que, recorrentemente, aparecem na formação dos itens lexicais dessas línguas.

Um provável exemplo de um segmento de suspensão da libras seria a suspensão inicial do sinal ACREDITAR (Figura (161)) que aparece também na suspensão inicial do sinal OBRIGADO (1) (Figura (162)).

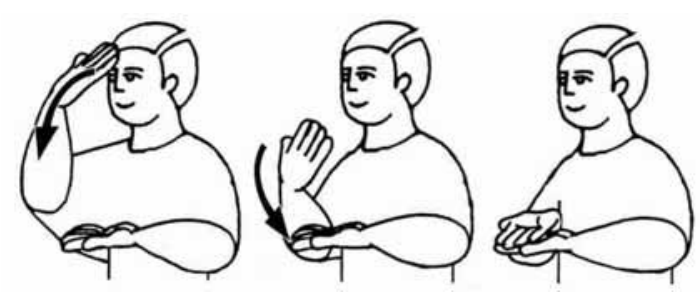

ACREDITAR

Figura (161) Capovilla \& Raphael (2001:152)

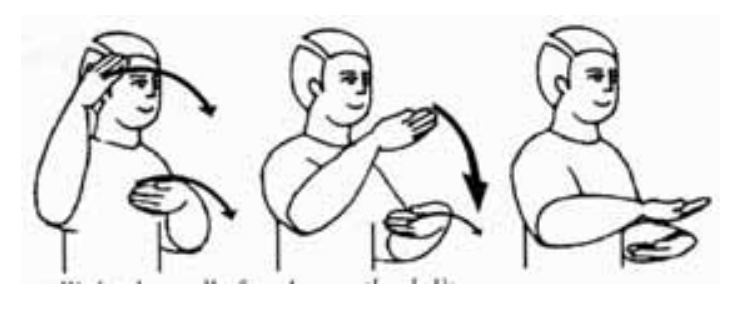

OBRIGADO (1)

Figura (162) Capovilla \& Raphael (2001:968)

Como se pode ver nas representações a seguir ${ }^{68}$, nos dois sinais, a mão dominante, realizando uma suspensão [S], apresenta exatamente os mesmos traços articulatórios. Mais especificamente, apresenta a mesma configuração, [4u], a mesma localização [SF], a mesma especificação para o traço parte da mão, [TIFI] (tip + fingers) e a mesma especificação para o traço de proximidade, [c]. Além disso, ela apresenta a mesma orientação, dado que, nos dois casos, é a base da mão [BA] que está paralela ao plano horizontal [HP].

\footnotetext{
${ }^{68}$ Por não ser relevante para a discussão, não apresento a representação da mão não-dominante.
} 
Mão dominante Classe Maior:

Contorno:

CM:

PC: $\quad$ Localização

Parte da mão

Proximidade

Relação Espacial

FA:

Parte da mão

Localização

OR:

Parte da mão

Plano

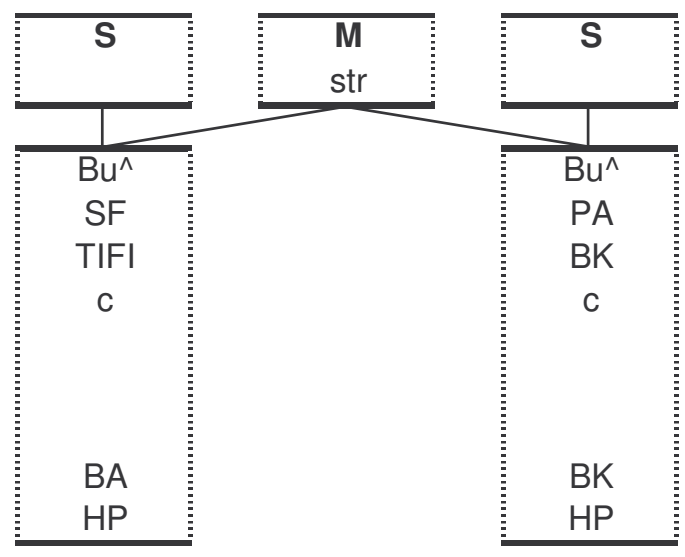

Representação (24) - ACREDITAR

$\begin{array}{ll}\text { Mão dominante Classe Maior: } & \text { Contorno: }\end{array}$

CM:

PC:
Relação Espacial
Parte da mão
Localização
OR:
Parte da mão
Plano

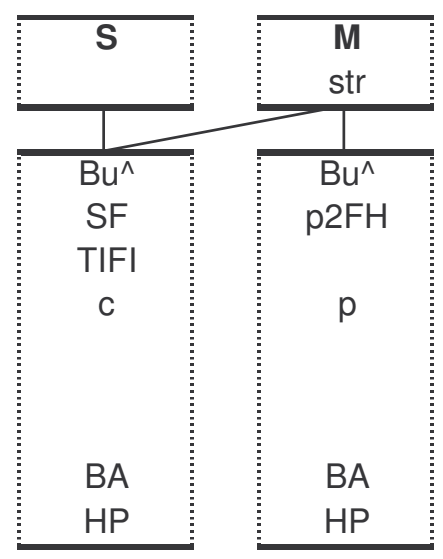

(1)

Pelas razões apontadas anteriormente quanto à determinação dos segmentos dos sinais $\mathrm{e}$ por razões de tempo, neste trabalho, não foi possível fazer um inventário desse tipo. Sendo assim, esse é mais um ponto dos estudos sobre a fonologia da libras que deverá ser mais aprofundado por trabalhos futuros. 


\section{Considerações finais}

Este trabalho, como disse na introdução, objetivou dar um primeiro passo em direção ao estudo das unidades do nível fonético-fonológico da língua de sinais brasileira (libras). Para isso, ele se baseou no modelo de análise sublexical que Liddell \& Johnson (2000 [1989]) propuseram para os itens lexicais das línguas sinalizadas.

Como comecei a apresentar no capítulo 1 e demonstrei com mais detalhes no capítulo 2 , para Liddell \& Johnson os itens lexicais das línguas sinalizadas se assemelham aos itens lexicais das línguas faladas nos seguintes aspectos. Em primeiro lugar, por terem como unidade mínima estruturante o segmento que, por poder se combinar com outros para formar sinais/palavras, é realizado seqüencialmente. Em segundo lugar, por também apresentarem uma organização interna para cada um de seus segmentos.

Dessa forma, os autores capturam, nas línguas de sinais, dois tipos de contrastes exibidos pelas línguas orais. Um deles, decorrente da ordem em que os segmentos são produzidos, ou seja, baseados em sua seqüencialidade, e outro decorrente dos traços que conjuntamente compõem um segmento e que, pode-se dizer, se baseia na simultaneidade.

Além dessa vantagem do modelo de Liddell \& Johnson em relação a outras propostas de análise sublexical dos sinais, esse modelo foi escolhido como quadro teórico para a realização da descrição fonético-fonológica dos sinais da libras por ser, do ponto de vista descritivo, extremamente detalhista.

Diferentemente de propostas anteriores, Liddell \& Johnson apresentam uma descrição mais refinada dos aspectos articulatórios envolvidos na produção dos sinais, a saber, configuração de mão, localização, movimento e orientação. Mais especificamente, eles não tratam cada um deles como todos inanalisáveis, mas sim como aspectos dotados de subaspectos com base nos quais constrastes lexicais podem ser estabelecidos.

Uma outra razão que me levou a assumir essa proposta teórica diz respeito à enorme preocupação dos autores em respeitar o pouco conhecimento que se tem a respeito das línguas sinalizadas em comparação às línguas orais e, conseqüentemente, em não assumir análises apressadas. É nesse sentido que, apesar de ser compatível com a fonologia autosegmental, Liddell \& Johnson ainda não propõem uma geometria para os traços que utilizam na descrição dos segmentos dos sinais. 


\section{Referências Bibliográficas}

AMARAL, M. A., A. COUTINHO \& M. R. DELGADO MARTINS (1994). Para uma gramática da língua gestual portuguesa. Lisboa: Caminho.

American Sign Language Browser

Disponível em: http://commtechlab.msu.edu/Sites/aslweb/browser.htm

Acesso em: 20-08-2007.

BATTISON, R. (1978a). “Analyzing Signs”. In: VALLI, C. \& C. LUCAS (org.). (2000). Linguistics of American Sign Language: an introduction. Washington, D.C.: Clerc Books/Gallaudet University Press.

BATTISON, R. (1978b). "Signs Have Parts: A Simple Idea". In: VALLI, C. \& C. LUCAS (org.). (2000). Linguistics of American Sign Language: an introduction. Washington, D.C.: Clerc Books/Gallaudet University Press.

BENVENISTE, É. (1976). Problemas de Lingüística Geral. São Paulo: Nacional/Edusp.

CAPOVIlla, F. C. \& W. D. RAPHAEL (2001). Dicionário Enciclopédico Ilustrado Trilíngüe da língua de sinais brasileira. São Paulo: Edusp.

CAPOVILlA, F. C. \& V. SUTTON (2001). "Como ler e escrever os sinais da libras: A escrita visual direta de sinais SignWriting. In: CAPOVILLA, F. C. \& W. D. RAPHAEL. (2001). Dicionário Enciclopédico Ilustrado Trilíngüe da língua de sinais brasileira. São Paulo: Edusp.

CAPOVILlA, F. C. \& et al. (2001). "BuscaSigno: sistema computadorizado de busca quirêmica da Libras que recupera sinais por forma de mão e não verbete ou classe semântica. In: CAPOVILlA, F. C. \& W. D. RAPHAEL. (2001). Dicionário Enciclopédico Ilustrado Trilíngüe da língua de sinais brasileira. São Paulo: Edusp.

CHOMSKY, N. \& M. HALLE (1968). The Sound Pattern of English. Harper \& Row.

GOLDSMITH, J. (1976). Autosegmental Phonology. Bloomington: IULS.

HULST, H. \& A. MILLS (1996). "Issues in Sign Linguistes: Phonetics, Phonology and Morph-Syntax". Lingua 98, 3-17.

HULST, H. (1996). “On the other hand”. Lingua 98, 121-143.

KLIMA, E. S. \& U. BELLUGI (1979). The Signs of Language. Cambridge: Harvard University Press. 
LIDDELL, S. K. (1984). "THINK and BELIEVE: Sequentiality in American Sign Language signs". Language 60 vol. 2. 372-399.

LIDDELL, S. K. \& R. E. JOHNSON (1989). “American Sign Language: The Phonological Base”. In: VALLI, C. \& C. LUCAS (org.). (2000). Linguistics of American Sign Language: an introduction. Washington, D.C.: Clerc Books/Gallaudet University Press.

LIDDELL, S. K. (1990). "Structures for Representing Handshape and Local Movement at the Phonemic Level”. In: FISCHER, S. D. \& P. SIPLE (org.). (1990). Theoretical Issues in Sign Lnaguage Research vol. 1. Chicago: The University of Chicago Press.

LIDDELL, S. K. (2003). Grammar, Gesture, and Meaning in American Sign Language. Cambridge: Cambridge University Press.

McCLEARY, L. E. \& E. C. VIOTTI (a sair). Transcrição de Dados de uma Língua Sinalizada: um estudo piloto da transcrição de narrativas da língua de sinais brasileira (LSB). In: SALLES, H. (org.). Bilingüísmo e Surdez. Questões Lingüísticas e Educacionais. Brasília: Editora da UnB.

MOREIRA, R. L. (em preparação). Uma Descrição da Dêixis de Pessoa na Língua de Sinais Brasileira (LSB): Pronomes Pessoais e Verbos Indicadores. Dissertação de Mestrado USP.

PADDEN, C. \& D. PERLMUTTER (1987). “American Sign Language and Architecture of Phonological Theory". Natural Language and Linguistcs Theory 5, 335-376.

PERLMUTTER, D. M. (1990). "On the Segmental Representation of Transitional and Bidirectional Movements in ASL Phonology”. In: FISCHER, S. D. \& P. SIPLE (org.). (1990). Theoretical Issues in Sign Language Research vol. 1. Chicago: The University of Chicago Press.

SANDLER, W. (1990). "Temporal Aspects and ASL Phonology”. In: FISCHER, S. D. \& P. SIPLE (org.). (1990). Theoretical Issues in Sign Lnaguage Research vol. 1. Chicago: The University of Chicago Press.

SANDLER, W. (1996). "Phonological Features in the Feature Classes: The case of movements in sign language". Língua 98, 197-220.

SAUSSURE, F. (1973 [1916]). Curso de Lingüística Geral. São Paulo: Cultrix.

STOKOE, W. C. (1960). Sign Language Structure: An Outline of the Visual 
Comunnication System of the American Deaf. New York: Buffalo University.

STOKOE, W. C. et al. (1965). "Introduction to A Dictionary of American Sign Language. In: VALLI, C. \& C. LUCAS (org.). (2000). Linguistics of American Sign Language: an introduction. Washington, D.C.: Clerc Books/Gallaudet University Press.

VIOTTI, E. C. (2004). A Lingüística das Línguas de Sinais. Notas de curso oferecido pelo Departamento de Lingüística da USP no primeiro semestre de 2004. 
ANEXO

Quadro (1) - Configurações de mão da ASL (Klima \& Bellugi, 1979:44)

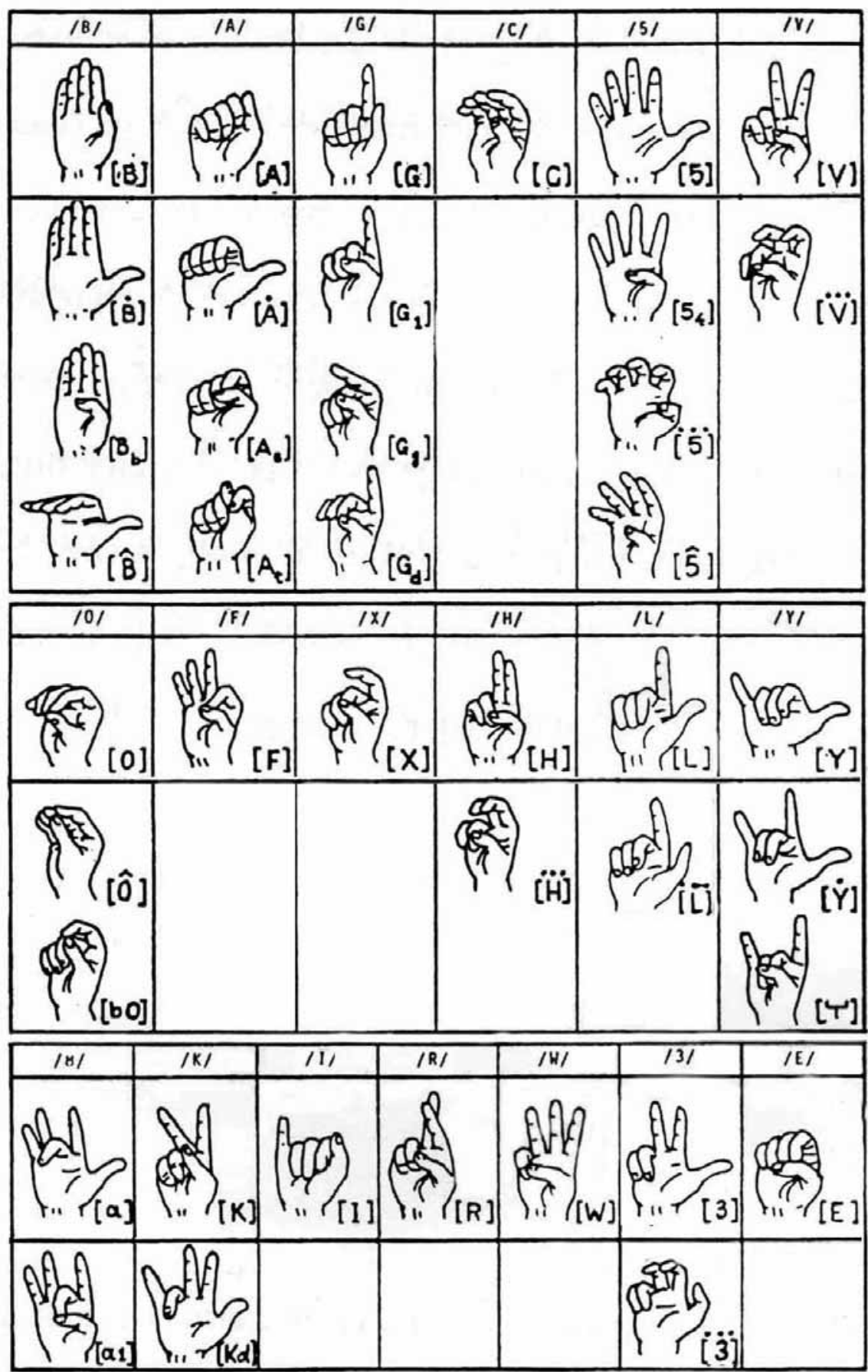


Quadro (2) - Símbolos taxonômicos para da descrição dos dedos indicador, médio, anelar e mínimo ${ }^{69}$

\begin{tabular}{|c|c|}
\hline símbolo & Configuração \\
\hline A & $\begin{array}{l}\text { os quatro dedos fechados e tocando as suas respectivas } \\
\text { almofadas na palma }\end{array}$ \\
\hline $\mathbf{S}$ & os quatro dedos fechados e tocando as pontas na palma \\
\hline 1 & indicador distendido e os demais fechados \\
\hline$!$ & dedo médio distendido e os demais fechados \\
\hline I & dedo mínimo distendido e os demais fechados \\
\hline $\mathbf{Y}$ & dedo mínimo distendido e espalmado e os demais fechados \\
\hline$=$ & dedos indicador e mínimo distendidos e os demais fechados \\
\hline$>$ & $\begin{array}{l}\text { dedos indicador e mínimo distendidos e espalmados e os } \\
\text { demais fechados }\end{array}$ \\
\hline
\end{tabular}
${ }^{69}$ As descrições contidas nesta tabela são traduções minhas das originalmente feitas por Liddell \& Johnson
(1989:284). As fotos foram feitas para tornar mais claras as descrições. 


\begin{tabular}{|c|c|}
\hline $\mathbf{H}$ & $\begin{array}{l}\text { dedos indicador e médio distendidos e unidos e os demais } \\
\text { fechados }\end{array}$ \\
\hline $\mathbf{V}$ & $\begin{array}{l}\text { dedos indicador e médio distendidos e espalmados e os } \\
\text { demais fechados }\end{array}$ \\
\hline $\mathbf{K}$ & $\begin{array}{l}\text { dedos anelar e mínimo fechados, indicador distendido e } \\
\text { médio parcialmente aberto }\end{array}$ \\
\hline $\mathbf{D}$ & dedo indicador distendido e os demais parcialmente abertos \\
\hline $\mathbf{R}$ & dedos indicador e médio cruzados e os demais fechados \\
\hline $\mathbf{r}$ & $\begin{array}{l}\text { dedos anelar e mínimos fechados, dedo médio distendido e } \\
\text { indicador cruzado sob este }\end{array}$ \\
\hline $\mathbf{W}$ & dedo mínimo fechado e todos os outros abertos e unidos \\
\hline 6 & $\begin{array}{l}\text { dedo mínimo fechado e todos os outros abertos e } \\
\text { espalmados }\end{array}$ \\
\hline 7 & dedo anelar fechado e todos os outros abertos e espalmados \\
\hline 8 & dedo médio fechado e todos os outros abertos e espalmados \\
\hline
\end{tabular}




\begin{tabular}{|l|l|l|}
\hline F & dedo indicador fechado e todos os outros abertos e unidos \\
\hline 9 & espalmados \\
\hline $\mathbf{B}$ & & os quatro dedos distendidos e unidos \\
\hline $\mathbf{4}$ & & \\
\hline $\mathbf{T}$ & & \\
\hline $\mathbf{N}$ & & \\
\hline
\end{tabular}




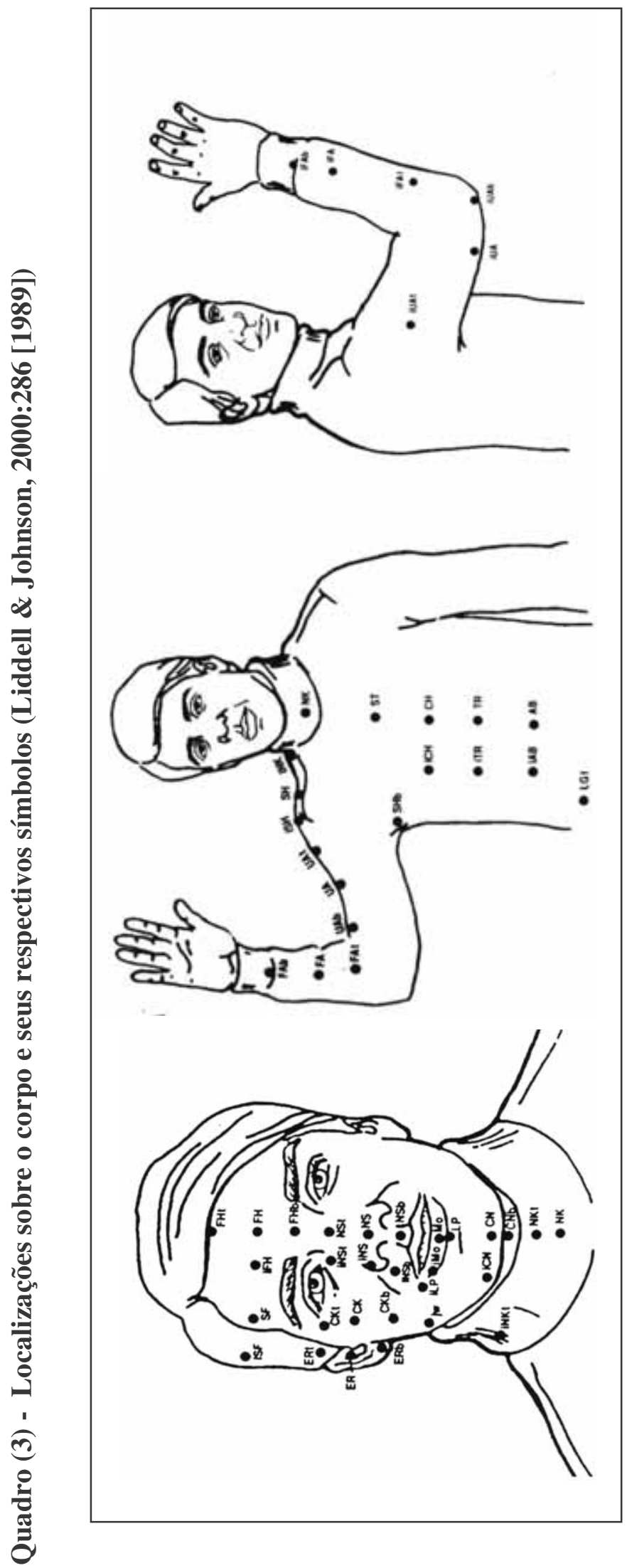


Tabela (1) - Classes mais numerosas de sinais

\begin{tabular}{|c|c|c|c|c|c|c|c|c|c|c|c|}
\hline & {$[ \pm 1 \mathrm{~m}]$} & {$[ \pm$ mov. $]$} & $\begin{array}{c} \pm 1 \mathrm{~m} \\
\text { par. }]\end{array}$ & $\begin{array}{c} \pm \text { mov. } \\
\text { alter.] }\end{array}$ & $\begin{array}{c} \pm \pm \text { mov. } \\
\text { local }]\end{array}$ & {$[ \pm 1 \mathrm{CM}]$} & [士cont.] & [ \pm MNM] & [ \pm red..] & $\mathrm{n}^{0}$ & Exemplos \\
\hline 1 & + & + & & & - & + & - & - & - & 256 & BEBER (p.284) \\
\hline 2 & - & + & + & & - & - & + & - & - & 190 & LEI (p.805) \\
\hline 3 & - & + & - & - & - & + & + & - & - & 140 & LIVRO (1) (p.824) \\
\hline 4 & + & + & & & - & + & + & - & - & 130 & AZAR (1) (p.252) \\
\hline 5 & - & + & - & - & - & + & - & - & - & 115 & FELIZ (p.660) \\
\hline 6 & + & + & & & - & - & - & - & - & 94 & BOM (p.307) \\
\hline 7 & + & + & & & - & + & + & - & + & 79 & PARÁ (p.1004) \\
\hline 8 & - & + & + & & - & + & + & - & - & 76 & TODO (p.1256) \\
\hline 9 & - & + & + & & - & - & + & - & + & 66 & CINZA (p.412) \\
\hline 10 & - & + & - & + & - & + & - & - & - & 63 & QUAL (p.1098) \\
\hline 11 & + & + & 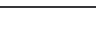 & & - & + & + & + & - & 55 & NOJO (p.950) \\
\hline 12 & - & + & - & - & - & - & + & - & - & 52 & OVO (p.989) \\
\hline 13 & + & - & & & - & + & - & - & & 43 & C (p.327) \\
\hline 14 & + & + & & & - & - & + & - & - & 41 & SOM (p.1208) \\
\hline 15 & + & - & & & - & + & + & - & & 40 & TIA (p.1250) \\
\hline 16 & - & + & - & - & - & - & - & - & - & 39 & FIM (p.670) \\
\hline 17 & + & + & & & - & + & - & + & - & 38 & MAU (p.879) \\
\hline 18 & - & + & + & & - & - & - & - & - & 38 & PAÍS (p.995) \\
\hline 19 & - & + & - & - & - & + & - & + & - & 33 & NADA (2) (p.934) \\
\hline 20 & + & + & & & - & + & - & - & + & 31 & PIPA (p.1048) \\
\hline 21 & - & - & & & - & + & + & - & & 31 & CRUZ (p.483) \\
\hline 22 & + & + & & & + & + & - & - & - & 30 & CORES (p.468) \\
\hline 23 & - & + & - & - & - & + & + & - & + & 27 & REDE (p.1125) \\
\hline 24 & - & + & - & - & - & + & + & + & - & 27 & TOURO (p.1263) \\
\hline 25 & - & + & + & & - & - & + & + & - & 25 & CARTA (p.366) \\
\hline 26 & - & + & + & & - & + & - & - & - & 23 & TREM (p.1271) \\
\hline 27 & + & + & & & - & - & - & - & + & 22 & LEITE (p.806) \\
\hline 28 & - & + & - & - & - & + & - & - & + & 22 & ASA (p.130) \\
\hline 29 & - & - & & & - & - & + & - & & 21 & CAJU (p.340) \\
\hline 30 & - & + & + & & - & + & + & - & + & 21 & FAZER (p.652) \\
\hline 31 & + & + & & & - & + & + & + & + & 20 & BALA (p.265) \\
\hline 32 & + & + & & & - & - & - & + & - & 20 & FORA (p.683) \\
\hline 33 & + & - & & & - & + & + & + & & 17 & TRISTE (p.1274) \\
\hline
\end{tabular}




\begin{tabular}{|c|c|c|c|c|c|c|c|c|c|c|c|}
\hline & [士 $1 \mathrm{~m}]$ & {$[ \pm$ mov. $]$} & $\begin{array}{c}{\left[\begin{array}{l} \pm \mathrm{m} \\
\text { par. }]\end{array}\right.}\end{array}$ & $\begin{array}{c}\text { [ } \pm \text { mov. } \\
\text { alter.] }\end{array}$ & $\begin{array}{c}\text { [ } \pm \text { mov. } \\
\text { local] }\end{array}$ & $\begin{array}{c}{[ \pm 1} \\
\text { CM] }\end{array}$ & [ \pm cont. $]$ & [ \pm MNM] & [tred.] & $n^{0}$ & Exemplos \\
\hline 34 & - & + & - & - & - & - & - & - & + & 16 & GÍRIA (p.709) \\
\hline 35 & + & + & & & - & - & + & - & + & 14 & NORA (p.950) \\
\hline 36 & - & - & & & - & + & - & - & & 14 & CAMA (p.344) \\
\hline 37 & - & + & + & & - & + & + & + & - & 14 & SAPO (p.1169) \\
\hline 38 & - & + & - & + & - & + & - & + & - & 14 & BOXE (p.312) \\
\hline 39 & - & + & + & & - & - & - & - & + & 12 & LEI (p.809) \\
\hline 40 & - & + & - & - & + & + & - & - & - & 12 & TERRA (p.1246) \\
\hline 41 & - & + & + & & + & - & + & - & - & 11 & JIBÓIA (p.779) \\
\hline 42 & - & + & - & - & - & - & - & + & - & 11 & CLARO (p.416) \\
\hline 43 & + & + & & & + & - & - & - & - & 10 & CORTAR (p.473) \\
\hline 44 & + & + & & & - & - & + & + & - & 10 & MEDO (p.882) \\
\hline 45 & - & + & - & + & - & + & + & - & - & 10 & OBA (p.967) \\
\hline 46 & - & + & - & - & + & - & - & - & - & 10 & RICO (p.1146) \\
\hline 47 & - & + & - & - & - & - & + & + & - & 10 & BOMBA (p.308) \\
\hline \multicolumn{10}{|c|}{ TOTAL } & \multicolumn{2}{|r|}{2093} \\
\hline
\end{tabular}


Tabela (2) - Classes menos numerosas de sinais

\begin{tabular}{|c|c|c|c|c|c|c|c|c|c|c|c|}
\hline & [ $1 \mathrm{~m}]$ & [ \pm mov. $]$ & $\begin{array}{c}\text { [ } 1 \mathrm{~m} \\
\text { par.] }\end{array}$ & $\begin{array}{l}\text { [ } \pm \text { mov. } \\
\text { alter.] }\end{array}$ & $\begin{array}{c}{[ \pm \text { mov. }} \\
\text { local }]\end{array}$ & [ $\pm 1 \mathrm{CM}]$ & [tcont.] & [士MNM] & [tred..] & $n^{0}$ & Exemplos \\
\hline 1 & - & + & + & & - & + & - & - & + & 8 & MOLHO (p.118) \\
\hline 2 & - & + & - & - & + & - & + & - & - & 8 & MATO (p.878) \\
\hline 3 & + & - & & & + & + & - & - & & 7 & Ç (p.327) \\
\hline 4 & + & + & & & + & + & - & + & - & 6 & RIR (p.1148) \\
\hline 5 & + & + & & & - & + & - & + & + & 6 & HIENA (p.1328) \\
\hline 6 & - & + & - & + & - & + & - & - & + & 6 & ROBÔ (p.1148) \\
\hline 7 & - & + & - & - & - & - & + & - & + & 6 & COELHO (p.423) \\
\hline 8 & + & - & & & + & + & + & - & & 5 & ÍNDIA (p.752) \\
\hline 9 & + & + & & & + & - & + & - & - & 5 & DIFÍCIL (p.543) \\
\hline 10 & - & - & & & + & - & + & - & & 5 & VELA (p.1303) \\
\hline 11 & - & - & & & + & + & - & + & & 5 & FOGO (p.679) \\
\hline 12 & - & + & - & - & + & + & + & - & - & 5 & FAVELA (p.651) \\
\hline 13 & + & - & & & - & + & - & + & & 4 & TOSSIR (p.1262) \\
\hline 14 & + & + & & & + & + & + & - & - & 4 & OURO (p.986) \\
\hline 15 & - & - & & & + & + & - & - & & 4 & FERVER (p.663) \\
\hline 16 & - & + & + & & + & - & - & - & - & 4 & SALTAR (p.1163) \\
\hline 17 & - & + & + & & + & - & + & + & - & 4 & OBESO (p.967) \\
\hline 18 & - & + & + & & - & + & - & + & - & 4 & CARATÊ (p.360) \\
\hline 19 & - & + & + & & - & + & + & + & + & 4 & IDÊNTICO (p.742) \\
\hline 20 & - & + & - & + & - & - & - & - & + & 4 & ESTRELA (p.630) \\
\hline 21 & - & + & - & + & - & + & + & - & + & 4 & JUNHO (p.790) \\
\hline 22 & - & + & - & - & + & + & - & + & - & 4 & LAMA (p.797) \\
\hline 23 & + & + & & & + & + & + & + & - & 3 & ODOR (p.971) \\
\hline 24 & + & + & & & + & - & - & + & - & 3 & LÁPIS (p.798) \\
\hline 25 & + & + & & & - & - & - & + & + & 3 & SONO (p.1209) \\
\hline 26 & - & - & & & - & - & - & - & & 3 & $\begin{array}{l}\text { MEGA-FONO } \\
\text { (p.883) }\end{array}$ \\
\hline 27 & - & - & & & - & + & - & + & & 3 & GORDO (p.714) \\
\hline 28 & - & - & & & - & + & + & + & & 3 & MOTEL (p.923) \\
\hline 29 & - & + & - & + & - & - & - & - & - & 3 & ALMA (p.180) \\
\hline 30 & - & + & - & + & + & - & - & - & - & 3 & $\begin{array}{l}\text { CARNAVAL } \\
\text { (p.363) }\end{array}$ \\
\hline 31 & - & + & - & + & + & + & - & - & - & 3 & ROLAR (p.1151) \\
\hline 32 & - & + & - & - & + & - & - & + & - & 3 & BARULHO (p.278) \\
\hline 33 & - & + & - & - & - & + & + & + & + & 3 & POBRE (p.1053) \\
\hline
\end{tabular}




\begin{tabular}{|c|c|c|c|c|c|c|c|c|c|c|c|}
\hline & {$[ \pm 1 \mathrm{~m}]$} & [ \pm mov.] & $\begin{array}{c}{[ \pm 1 \mathrm{~m}} \\
\text { par. }]\end{array}$ & $\begin{array}{c}\text { [ } \pm \text { mov. } \\
\text { alter.] }\end{array}$ & $\begin{array}{c}\text { [ } \pm \text { mov. } \\
\text { local }]\end{array}$ & {$[ \pm 1 \mathrm{CM}]$} & [tcont.] & [IMNM] & [ \pm red.. $]$ & $n^{0}$ & Exemplos \\
\hline 34 & + & - & & & + & + & - & + & & 2 & $\begin{array}{l}\text { ADVOGADO } \\
\text { (p.160) }\end{array}$ \\
\hline 35 & + & + & & & + & + & - & - & + & 2 & TEORIA (p.1242) \\
\hline 36 & + & + & & & + & - & + & + & - & 2 & $\begin{array}{l}\text { PERFUMADO } \\
\text { (p.1032) }\end{array}$ \\
\hline 37 & - & - & & & + & + & + & - & & 2 & FOLGAR (p.681) \\
\hline 38 & - & + & + & & - & - & - & + & - & 2 & CAÇAR (p.332) \\
\hline 39 & - & + & + & & + & + & - & - & - & 2 & HARPA (p.730) \\
\hline 40 & - & + & - & + & - & + & + & + & - & 2 & $\begin{array}{l}\text { QUALQUER } \\
\text { (p.1099) }\end{array}$ \\
\hline 41 & - & + & - & - & - & + & - & + & + & 2 & PRECISAR (p.1072) \\
\hline 42 & + & - & & & + & + & + & + & & 1 & RUIM (p.1156) \\
\hline 43 & - & - & & & + & - & - & - & & 1 & $\begin{array}{l}\text { LIQÜIDIFICADOR } \\
\text { (p.822) }\end{array}$ \\
\hline 44 & - & - & & & - & - & - & + & & 1 & $\begin{array}{l}\text { DANÇAR (1) } \\
\text { (p.492) }\end{array}$ \\
\hline 45 & - & - & & & + & + & + & + & & 1 & $\begin{array}{l}\text { COMODISMO } \\
(\mathrm{p} .436)\end{array}$ \\
\hline 46 & - & + & + & & + & - & - & + & - & 1 & $\begin{array}{l}\text { INTERROMPER } \\
\text { (p.765) }\end{array}$ \\
\hline 47 & - & + & + & & - & - & - & + & + & 1 & $\begin{array}{l}\text { BOMBA-DE-AR } \\
\text { (p.308) }\end{array}$ \\
\hline 48 & - & + & + & & - & - & + & + & + & 1 & INSISTIR (p.759) \\
\hline 49 & - & + & + & & + & + & - & - & + & 1 & SANFONA (p.1165) \\
\hline 50 & - & + & + & & + & + & + & - & - & 1 & COMPRIDO (p.440) \\
\hline 51 & - & + & - & + & - & - & - & + & - & 1 & DEVORAR (p.537) \\
\hline 52 & - & + & - & + & + & - & - & + & - & 1 & $\begin{array}{l}\text { FOFOCAR (1) } \\
\text { (p.678) }\end{array}$ \\
\hline 53 & - & + & - & + & + & + & - & + & - & 1 & $\begin{array}{l}\text { INCENDIAR (1) } \\
\text { (p.750) }\end{array}$ \\
\hline 54 & - & + & - & - & - & - & - & + & + & 1 & $\begin{array}{l}\text { FURADEIRA } \\
\text { (p.695) }\end{array}$ \\
\hline 55 & - & + & - & - & + & - & + & - & + & 1 & $\begin{array}{l}\text { PARANÁ (2) } \\
\text { (p.1010) }\end{array}$ \\
\hline 56 & - & + & - & - & + & + & + & + & - & 1 & $\begin{array}{l}\text { CONFLITAR } \\
\text { (p.446) }\end{array}$ \\
\hline \multicolumn{10}{|c|}{ TOTAL } & & 176 \\
\hline
\end{tabular}


Tabela (3) - Buscas que não encontraram sinais

\begin{tabular}{|c|c|c|c|c|c|c|c|c|c|c|}
\hline & {$[ \pm 1 \mathrm{~m}]$} & [ \pm mov.] & $\begin{array}{c}{[ \pm 1 \mathrm{~m}} \\
\text { par. }]\end{array}$ & $\begin{array}{c}\text { [ } \pm \text { mov. } \\
\text { alter.] }\end{array}$ & $\begin{array}{c}\text { [ } \pm \text { mov. } \\
\text { local] }\end{array}$ & {$[ \pm 1 \mathrm{CM}]$} & [ cont.] & {$[ \pm \mathrm{MNM}]$} & [ \pm red.] & $\mathrm{n}^{\circ}$ \\
\hline 1 & + & - & & & - & - & - & - & & 0 \\
\hline 2 & + & - & & & + & - & - & - & & 0 \\
\hline 3 & + & - & & & - & - & - & + & & 0 \\
\hline 4 & + & - & & & + & - & - & + & & 0 \\
\hline 5 & + & - & & & - & - & + & - & & 0 \\
\hline 6 & + & - & & & + & - & + & - & & 0 \\
\hline 7 & + & - & & & - & - & + & + & & 0 \\
\hline 8 & + & - & & & + & - & + & + & & 0 \\
\hline 9 & + & + & & & + & + & - & + & + & 0 \\
\hline 10 & + & + & & & + & + & + & - & + & 0 \\
\hline 11 & + & + & & & + & + & + & + & + & 0 \\
\hline 12 & + & + & & & + & - & - & - & + & 0 \\
\hline 13 & + & + & & & + & - & - & + & + & 0 \\
\hline 14 & + & + & & & + & - & + & - & + & 0 \\
\hline 15 & + & + & & & - & - & + & + & + & 0 \\
\hline 16 & + & + & & & + & - & + & + & + & 0 \\
\hline 17 & - & - & & & + & - & - & + & & 0 \\
\hline 18 & - & - & & & - & - & + & + & & 0 \\
\hline 19 & - & - & & & + & - & + & + & & 0 \\
\hline 20 & - & + & + & & + & - & - & - & + & 0 \\
\hline 21 & - & + & + & & + & - & - & + & + & 0 \\
\hline 22 & - & + & + & & + & - & + & - & + & 0 \\
\hline 23 & - & + & + & & + & - & + & + & + & 0 \\
\hline 24 & - & + & + & & + & + & - & + & - & 0 \\
\hline 25 & - & + & + & & - & + & - & + & + & 0 \\
\hline 26 & - & + & + & & + & + & - & + & + & 0 \\
\hline 27 & - & + & + & & + & + & + & - & + & 0 \\
\hline 28 & - & + & + & & + & + & + & + & - & 0 \\
\hline 29 & - & + & + & & + & + & + & + & + & 0 \\
\hline 30 & - & + & - & + & + & - & - & - & + & 0 \\
\hline 31 & - & + & - & + & - & - & - & + & + & 0 \\
\hline 32 & - & + & - & + & + & - & - & + & + & 0 \\
\hline 33 & - & + & - & + & - & - & + & - & - & 0 \\
\hline
\end{tabular}




\begin{tabular}{|c|c|c|c|c|c|c|c|c|c|c|}
\hline & {$[ \pm 1 \mathrm{~m}]$} & [ \pm mov.] & $\begin{array}{c}{[ \pm 1 \mathrm{~m}} \\
\text { par. }]\end{array}$ & $\begin{array}{c}\text { [ } \pm \text { mov. } \\
\text { alter.] }\end{array}$ & $\begin{array}{c}\text { [ } \pm \text { mov. } \\
\text { local] }\end{array}$ & {$[ \pm 1 \mathrm{CM}]$} & [ \pm cont.] & {$[ \pm \mathrm{MNM}]$} & [ \pm red.] & $n^{0}$ \\
\hline 34 & - & + & - & + & + & - & + & - & - & 0 \\
\hline 35 & - & + & - & + & - & - & + & - & + & 0 \\
\hline 36 & - & + & - & + & + & - & + & - & + & 0 \\
\hline 37 & - & + & - & + & - & - & + & + & - & 0 \\
\hline 38 & - & + & - & + & + & - & + & + & - & 0 \\
\hline 39 & - & + & - & + & - & - & + & + & + & 0 \\
\hline 40 & - & + & - & + & + & - & + & + & + & 0 \\
\hline 41 & - & + & - & + & + & + & - & - & + & 0 \\
\hline 42 & - & + & - & + & - & + & - & + & + & 0 \\
\hline 43 & - & + & - & + & + & + & - & + & + & 0 \\
\hline 44 & - & + & - & + & + & + & + & - & - & 0 \\
\hline 45 & - & + & - & + & + & + & + & - & + & 0 \\
\hline 46 & - & + & - & + & + & + & + & + & - & 0 \\
\hline 47 & - & + & - & + & - & + & + & + & + & 0 \\
\hline 48 & - & + & - & + & + & + & + & + & + & 0 \\
\hline 49 & - & + & - & - & + & - & - & - & + & 0 \\
\hline 50 & - & + & - & - & + & - & - & + & + & 0 \\
\hline 51 & - & + & - & - & + & - & + & + & - & 0 \\
\hline 52 & - & + & - & - & - & - & + & + & + & 0 \\
\hline 53 & - & + & - & - & + & - & + & + & + & 0 \\
\hline 54 & - & + & - & - & + & + & - & - & + & 0 \\
\hline 55 & - & + & - & - & + & + & - & + & + & 0 \\
\hline 56 & - & + & - & - & + & + & + & - & + & 0 \\
\hline 57 & - & + & - & - & + & + & + & + & + & 0 \\
\hline
\end{tabular}


Tabela (4) - Configurações de mão atestadas entre os sinais feitos com uma mão e sem mudança de configuração

\begin{tabular}{|c|c|c|c|c|}
\hline & Configuração & $\begin{array}{l}\text { Exemplo de sinal em que a configuração } \\
\text { ocorre }\end{array}$ & $\begin{array}{l}\mathrm{n}^{\mathbf{0}} \mathrm{de} \\
\text { sinais }\end{array}$ & $\%$ \\
\hline 1 & $\mathrm{Bu}^{\wedge}$ & CRIANÇA $(\mathrm{p} .481)$ & 80 & $10,2 \%$ \\
\hline 2 & $10-$ & CHINA (p.402) & 76 & $9,7 \%$ \\
\hline 3 & $\mathrm{Au}^{\wedge}$ & $\mathrm{A}(\mathrm{p} .129)$ & 43 & $5,5 \%$ \\
\hline 4 & Vo- & LEMBRAR (p. 807) & 43 & $5,5 \%$ \\
\hline 5 & 4" 0" & QUERER (p.1106) & 32 & $4,1 \%$ \\
\hline 6 & $\mathrm{Bu}-$ & B (p.255) & 31 & $4,0 \%$ \\
\hline 7 & Doc & DOMINGO (p.562) & 30 & $3,8 \%$ \\
\hline 8 & So- & VELHO (1) (p.1303) & 30 & $3,8 \%$ \\
\hline 9 & $4 \mathrm{u}$ & CIDADE (1) (p.408) & 26 & $3,3 \%$ \\
\hline 17 & $\mathrm{~B}^{\wedge} \mathrm{op}$ & TENTAR (p.1242) & 23 & $2,9 \%$ \\
\hline 10 & $\mathrm{Ku}^{\wedge}$ & $\mathrm{P}(\mathrm{p} .991)$ & 22 & $2,8 \%$ \\
\hline 11 & $\mathrm{Yu}$ & IDADE & 21 & $2,7 \%$ \\
\hline 12 & B" O" & MAÇÃ (p.849) & 19 & $2,4 \%$ \\
\hline 13 & $1 \mathrm{u}$ & ALEMANHA (p.174) & 18 & $2,3 \%$ \\
\hline 14 & $9 \mathrm{oc}$ & OPINAR (p.982) & 18 & $2,0 \%$ \\
\hline 15 & $\mathrm{Au}$ & NÚMERO-ONZE (p.959) & 18 & $2,0 \%$ \\
\hline 16 & $1 " \sim 0 "$ & INGLATERRA (p.757) & 16 & $2,0 \%$ \\
\hline 18 & Ho- & USAR (p. 1294) & 16 & $2,0 \%$ \\
\hline 19 & V"O- & INTELIGÊNCIA (p.762) & 14 & $1,8 \%$ \\
\hline 20 & $1 " \mathrm{o}-$ & VERDE (2) (p.1310) & 13 & $1,7 \%$ \\
\hline 21 & $1^{\wedge} \mathrm{op}$ & MOSCA (p.922) & 13 & $1,7 \%$ \\
\hline 22 & ro- & RÚSSIA (p.1156) & 13 & $1,7 \%$ \\
\hline 23 & $4 u-$ & QUARTA-FEIRA (2) (p.1101) & 12 & $1,5 \%$ \\
\hline 24 & lo- & MAGRO (p.856) & 12 & $1,5 \%$ \\
\hline 25 & $8 \mathrm{u}$ & DELICIOSO (1) (p.508) & 11 & $1,4 \%$ \\
\hline 26 & $1^{\wedge} \mathrm{O}$ & PEQUENO (1) (p.1028) & 10 & $1,3 \%$ \\
\hline 27 & B" O"c & OUTUBRO (p.988) & 9 & $1,2 \%$ \\
\hline 28 & $60-f$ & TERÇA-FEIRA (1) (p.1243) & 8 & $1,0 \%$ \\
\hline 29 & $\mathrm{~B}^{\wedge} \mathrm{u}^{\wedge}$ & COR-DE-ROSA (p.468) & 8 & $1,0 \%$ \\
\hline 30 & $1 \mathrm{u}^{\wedge}$ & GOIÁS (1) (p.711) & 6 & $0,8 \%$ \\
\hline 31 & 9op & INOCENTE (p.758) & 6 & $0,8 \%$ \\
\hline 32 & Wo-f & $\mathrm{M}(\mathrm{p} .849)$ & 6 & $0,8 \%$ \\
\hline 33 & $1 " \sim 0-$ & CAMPINAS (p.348) & 5 & $0,6 \%$ \\
\hline 34 & $9 \mathrm{u}^{\wedge} \mathrm{p}$ & FLOR (p.676) & 5 & $0,6 \%$ \\
\hline 35 & Ao & NÚMERO-SEIS (p.958) & 5 & $0,6 \%$ \\
\hline 36 & $=\mathrm{O}-$ & ADULTÉRIO (p.158) & 4 & $0,5 \%$ \\
\hline 37 & B"u- & ESTADO (p.622) & 4 & $0,5 \%$ \\
\hline 38 & $1 " \mathrm{u}^{\wedge} \mathrm{c}$ & APITAR (2) (p.212) & 3 & $0,4 \%$ \\
\hline 39 & 90 & ORELHA (p.983) & 3 & $0,4 \%$ \\
\hline 40 & $\mathrm{~B}^{\prime \prime} \sim \mathrm{u}$ & ESCUTAR (p.605) & 3 & $0,4 \%$ \\
\hline
\end{tabular}




\begin{tabular}{|c|c|c|c|c|}
\hline & Configuração & $\begin{array}{c}\text { Exemplo de sinal em que a configuração } \\
\text { ocorre }\end{array}$ & $\begin{array}{l}\mathrm{n}^{\mathbf{0}} \mathrm{de} \\
\text { sinais }\end{array}$ & $\%$ \\
\hline 41 & $\mathrm{~B}^{\wedge} \sim \mathrm{O}^{\prime \prime}$ & QUENTE (p.1106) & 3 & $0,4 \%$ \\
\hline 42 & $\mathrm{~B}^{\wedge} \mathrm{u}$ & SAFADO (p.1159) & 3 & $0,4 \%$ \\
\hline 43 & $\mathrm{Bu}$ & CAMISETA (p.347) & 3 & $0,4 \%$ \\
\hline 44 & $1 " \sim 0 " c$ & CHICLETE (p.400) & 2 & $0,3 \%$ \\
\hline 50 & $4 " \sim u "$ & SOLETRAR-DIGITALMENTE (p. 1206) & 2 & $0,3 \%$ \\
\hline 45 & 40 & CORAGEM (p. 467) & 2 & $0,3 \%$ \\
\hline 46 & $4 \mathrm{u}^{\wedge}$ & MAU (p.879) & 2 & $0,3 \%$ \\
\hline 47 & $\mathrm{~B}^{\wedge} \mathrm{O}$ & ARGENTINA (2) (p.223) & 2 & $0,3 \%$ \\
\hline 48 & $\mathrm{~B} \sim \mathrm{u}^{\wedge}$ & BAIRRO-REPÚBLICA (p.262) & 2 & $0,3 \%$ \\
\hline 49 & $\mathrm{lu}^{\wedge}$ & EXEMPLO (p.636) & 2 & $0,3 \%$ \\
\hline 51 & $/ 1^{\wedge} \mathrm{Oc}$ & ABELHA (p.136) & 1 & $0,1 \%$ \\
\hline 52 & $/ 4^{\wedge} \sim 0^{\prime \prime}$ & BOLICHE (p.305) & 1 & $0,1 \%$ \\
\hline 53 & $/ \mathrm{Bu}^{\wedge} \mathrm{p}$ & TARDE (p.1232) & 1 & $0,1 \%$ \\
\hline 54 & /Doc & DEFICIÊNCIA (p.502) & 1 & $0,1 \%$ \\
\hline 55 & /So-p & MALA (2) (p.860) & 1 & $0,1 \%$ \\
\hline 56 & $>\mathrm{u}$ & AVIÃO (2) (p.251) & 1 & $0,1 \%$ \\
\hline 57 & $1 " \mathrm{o"c}$ & RATO (p.1117) & 1 & $0,1 \%$ \\
\hline 58 & $1 " \mathrm{u}$ & SECADOR-DE-CABELO (p.1172) & 1 & $0,1 \%$ \\
\hline 59 & $1 " \mathrm{u}^{\wedge}$ & PINCEL-DE-BARBEAR (p.1046) & 1 & $0,1 \%$ \\
\hline 60 & $1^{\wedge} \mathrm{u}^{\wedge}$ & NÚMERO-SETE (p.958) & 1 & $0,1 \%$ \\
\hline 61 & 10 & MORENO (p.921) & 1 & $0,1 \%$ \\
\hline 62 & 4"o" & ARREMESSAR (p.227) & 1 & $0,1 \%$ \\
\hline 63 & $4^{\wedge} \sim u$ & DIGITAR (p. 544) & 1 & $0,1 \%$ \\
\hline 64 & $7 \mathrm{o}-\mathrm{f}$ & UNHA (p.1282) & 1 & $0,1 \%$ \\
\hline 65 & 8op & VOCAÇÃO (p.1327) & 1 & $0,1 \%$ \\
\hline 66 & 9of & ÂNUS (1) (p.204) & 1 & $0,1 \%$ \\
\hline 68 & $9 \mathrm{u}$ & DOR (p.563) & 1 & $0,1 \%$ \\
\hline 67 & $9 \mathrm{u}^{\wedge} \mathrm{t}$ & $\mathrm{T}(\mathrm{p} .1229)$ & 1 & $0,1 \%$ \\
\hline 69 & H"o- & NATAL (cidade) (p.940) & 1 & $0,1 \%$ \\
\hline 70 & $\mathrm{Hu}$ & BAIRRO-BELÉM (p.258) & 1 & $0,1 \%$ \\
\hline 71 & loc & CACHIMBAR (p.333) & 1 & $0,1 \%$ \\
\hline 72 & $\mathrm{~T}$ & AVARENTO (1) (p.249) & 1 & $0,1 \%$ \\
\hline 73 & $\mathrm{Vu}$ & PARTICULAR (p.1014) & 1 & $0,1 \%$ \\
\hline 74 & Yo- & LHAMA (p.814) & 1 & $0,1 \%$ \\
\hline \multicolumn{3}{|c|}{ TOTAL } & 782 & $100 \%$ \\
\hline
\end{tabular}


Tabela (5) - Configurações de mão atestadas como iniciais em sinais realizados com mudança de configuração

\begin{tabular}{|c|c|c|c|}
\hline & Configuração inicial & $\begin{array}{l}\text { Exemplo de sinal em que a configuração } \\
\text { ocorre }\end{array}$ & $\mathrm{n}^{\mathbf{0}}$ de sinais \\
\hline 1 & $4 \mathrm{u} *^{70}$ & AMANHÃ (p.183) & 27 \\
\hline 2 & So- $*$ & SUZANO (p.1227) & 17 \\
\hline 3 & $1^{\wedge} \mathrm{O} *$ & PREFERIR (p.1073) & 14 \\
\hline 4 & $\mathrm{Au}^{\wedge} *$ & GALO (p.700) & 11 \\
\hline 5 & B" o"c * & OLINDA (p.977) & 11 \\
\hline 6 & $\mathrm{Bu}^{\wedge} *$ & ESQUECER (p.618) & 11 \\
\hline 7 & $10-*$ & ÚNICO (p.1283) & 10 \\
\hline 8 & Vo- $*$ & CORTAR (p.473) & 9 \\
\hline 9 & $1^{\wedge} \mathrm{op} *$ & GATO (p.704) & 8 \\
\hline 10 & $\mathrm{~B}^{\prime \prime} \sim \mathrm{O}^{\prime \prime} *$ & CLASSIFICADOR (p.416) & 8 \\
\hline 11 & $\mathrm{~B}^{\wedge} \mathrm{op} *$ & BOM (p.307) & 7 \\
\hline 12 & Doc * & DEFICIENTE-MENTAL (2) (p.504) & 6 \\
\hline 13 & $\mathrm{Au} *$ & MAIS (3) (p.858) & 5 \\
\hline 14 & B"o" & APRENDER (p.215) & 5 \\
\hline 15 & $\mathrm{~B}^{\wedge} \mathrm{O}^{*}$ & HOMEM (p.736) & 5 \\
\hline 16 & $10 *$ & ALIVIAR (1) (p.179) & 4 \\
\hline 17 & 8 of & MEDO (p.882) & 4 \\
\hline 18 & $\mathrm{Su}^{\wedge} \mathrm{t}$ & QUASE (p.1102) & 4 \\
\hline 19 & $1 \mathrm{u} *$ & ÁGUA (p.167) & 3 \\
\hline 20 & $14^{\wedge} \sim 0$ & ESPIRITISMO (p.614) & 2 \\
\hline 21 & $1 u^{\wedge} *$ & BAIRRO-ACLIMAÇÃ̃O (p. 258) & 2 \\
\hline 22 & $4 \sim \mathrm{u}$ & LULA (p.830) & 2 \\
\hline 23 & $40 *$ & CONVENCER (1) (p.459) & 2 \\
\hline 24 & Ao * & OFENDER (2) (p.972) & 2 \\
\hline 25 & $\mathrm{Bu}-*$ & BOLETIM-DE-OCORRÊNCIA (p.304) & 2 \\
\hline 26 & $\mathrm{H}^{\wedge} \mathrm{O}$ & PATO (p.1018) & 2 \\
\hline 27 & Ho- $*$ & NUNCA (2) (p.964) & 2 \\
\hline 28 & ro- * & DIFERENTE (2) (p.543) & 2 \\
\hline 29 & $\mathrm{~V}^{\wedge} \mathrm{O}$ & ENGANAR (2) (p.587) & 2 \\
\hline 30 & $1 " \sim 0^{-} *$ & REVÓLVER (p.1145) & 1 \\
\hline 31 & $1 " \mathrm{on} *$ & PERIQUITO (p.1034) & 1 \\
\hline 32 & $1 " \mathrm{o"c} *$ & PÍLULA (p.1044) & 1 \\
\hline 33 & $1 " \mathrm{u}$ & ALICATE-DE-UNHA (p.178) & 1 \\
\hline 34 & $4 " \sim 0 " *$ & MORDER (1) (p.921) & 1 \\
\hline 35 & $4 \mathrm{u}-*$ & TEIMOSO (3) (p.1235) & 1 \\
\hline 36 & 80 & COLA (p.426) & 1 \\
\hline 37 & $8 \mathrm{u} *$ & FÁCIL (1) (p.642) & 1 \\
\hline 38 & $90 *$ & CRACHÁ (p.479) & 1 \\
\hline
\end{tabular}
${ }^{70}$ (*) indica que a configuração de mão ocorre em sinais realizados com uma mão e só com uma configuração
de mão. 


\begin{tabular}{|c|c|c|c|}
\hline & Configuração inicial & $\begin{array}{l}\text { Exemplo de sinal em que a configuração } \\
\text { ocorre }\end{array}$ & $\mathrm{n}^{\mathbf{0}}$ de sinais \\
\hline 39 & $9 \mathrm{u} *$ & ATENÇÃO (1) (p.240) & 1 \\
\hline 40 & $\mathrm{~B} " \mathrm{u}-*$ & HORAS-EXTRAS (p.739) & 1 \\
\hline 41 & $\mathrm{Hu} *$ & CAVALO (p.379) & 1 \\
\hline 42 & Io- * & JULHO (p.789) & 1 \\
\hline 43 & Kop & ANTIGO (p. 203) & 1 \\
\hline 44 & V"o" & INJETAR (p.757) & 1 \\
\hline 45 & V"o" & CASTOR (1) (p.374) & 1 \\
\hline \multicolumn{3}{|c|}{ TOTAL } & 205 \\
\hline
\end{tabular}

Tabela (6) - Configurações de mão atestadas como finais em sinais realizados com mudança de configuração

\begin{tabular}{|c|c|c|c|}
\hline & Configuração final & $\begin{array}{l}\text { Exemplo de sinal em que a configuração } \\
\text { ocorre }\end{array}$ & $n^{0}$ de sinais \\
\hline 1 & So-* & APRECIAR (p.215) & 26 \\
\hline 2 & $4 u *$ & FÁCIL (1) (p.642) & 25 \\
\hline 3 & $1^{\wedge} \mathrm{op} *$ & PREFERIR (p.1073) & 20 \\
\hline 4 & $\mathrm{Au}^{\wedge} *$ & BONITO (p.310) & 15 \\
\hline 5 & $1 " \mathrm{O}-*$ & REVÓLVER (p.1145) & 12 \\
\hline 6 & $\mathrm{~B}^{\wedge} \mathrm{op} *$ & LOBO (p.825) & 12 \\
\hline 7 & $1 \mathrm{u} *$ & GATO (p.704) & 11 \\
\hline 8 & Ho- * & OU (p.986) & 9 \\
\hline 9 & Vo- * & ADEFAV (p.154) & 6 \\
\hline 10 & $1^{\wedge} \mathrm{u}$ & ÁGUA (p.167) & 4 \\
\hline 11 & $10 *$ & SOL (p.1206) & 4 \\
\hline 12 & $10-*$ & ESTRANHO (2) (p.629) & 4 \\
\hline 13 & $\mathrm{Au} *$ & MATO-GROSSO & 4 \\
\hline 14 & $\mathrm{~B}^{\prime \prime} \sim \mathrm{O}^{\prime} *$ & VIAJAR (2) (p.1315) & 4 \\
\hline 15 & $\mathrm{H}^{\wedge} \mathrm{op}$ & PATO (p.1018) & 4 \\
\hline 16 & 10- * & OI (p.974) & 4 \\
\hline 17 & $\mathrm{Su} *$ & QUASE (p.1102) & 4 \\
\hline 18 & $\mathrm{Ku}^{\wedge} *$ & APOSENTAR (2) (p.214) & 3 \\
\hline 19 & Wo-f * & CENTÍMETRO (p.385) & 3 \\
\hline 20 & $/ \mathrm{B}^{\wedge} \mathrm{op}$ & ESPIRITISMO (p.614) & 2 \\
\hline 21 & $1 u^{\wedge} *$ & BAIRRO-ACLIMAÇÃO (p. 258) & 2 \\
\hline 22 & 9 oc $*$ & ATENÇÃO (1) (p.240) & 2 \\
\hline 23 & B" O"c * & PORCENTAGEM (p.1063) & 2 \\
\hline 24 & $\mathrm{~B}^{\wedge} \mathrm{u}^{\wedge} *$ & FAMOSO (p.647) & 2 \\
\hline 25 & $\mathrm{H}^{\wedge} \mathrm{O}-$ & NUNCA (2) (p.964) & 2 \\
\hline 26 & $\mathrm{Vu} *$ & ESPERTO (p.612) & 2 \\
\hline 27 & $1 " \mathrm{o"c} *$ & PERIQUITO (p.1034) & 1 \\
\hline 28 & $1 " \mathrm{u}^{\wedge}$ & ALICATE-DE-UNHA (p.178) & 1 \\
\hline 29 & $40 *$ & MEDO (p.882) & 1 \\
\hline 30 & 8 op * & COLA (p.426) & 1 \\
\hline
\end{tabular}




\begin{tabular}{|c|c|c|c|}
\hline & Configuração inicial & $\begin{array}{l}\text { Exemplo de sinal em que a configuração } \\
\text { ocorre }\end{array}$ & $\mathrm{n}^{0}$ de sinais \\
\hline 31 & 80 & SÓ (2) (p.1201) & 1 \\
\hline 32 & $8 \mathrm{u} *$ & AMANHÃ (p.183) & 1 \\
\hline 33 & 9 op * & CRACHÁ (p.479) & 1 \\
\hline 34 & $9 \mathrm{u}-$ & TEIMOSO (3) (p.1235) & 1 \\
\hline 35 & $9 \mathrm{u}^{\wedge} *$ & SAN-FRANCISCO (EUA) (p. 1164) & 1 \\
\hline 36 & $\mathrm{~B}^{\wedge} \mathrm{op}$ & CONVENCER (1) (p.459) & 1 \\
\hline 37 & Bo & GARGANTA (p.702) & 1 \\
\hline 38 & $\mathrm{Bu} *$ & FODA-SE (p.678) & 1 \\
\hline 39 & D"oc & CAVALO-MARINHO (p.379) & 1 \\
\hline 40 & Doc * & ÓBVIO (p.969) & 1 \\
\hline 41 & ro-* & DOUTOR (p.565) & 1 \\
\hline 42 & V"o- * & CEGO (1) (p.383) & 1 \\
\hline 43 & V"o"c & CASTOR (1) (p.374) & 1 \\
\hline \multicolumn{3}{|c|}{ TOTAL } & 205 \\
\hline
\end{tabular}

Tabela (7) - Outros sinais realizados com uma mão e com mudança de configuração de mão

\begin{tabular}{|c|c|c|c|c|}
\hline & $\begin{array}{c}\text { Configuração } \\
\text { inicial }\end{array}$ & $\begin{array}{l}\text { Configuração } \\
\text { final }\end{array}$ & $\begin{array}{l}\text { Exemplo em que tais } \\
\text { configurações ocorrem }\end{array}$ & $n^{0}$ de sinais \\
\hline 1 & $1^{\wedge} \mathrm{op}$ & $\mathrm{Au}^{\wedge}$ & DINHEIRO (p.545) & 2 \\
\hline \multirow{3}{*}{2} & \multirow{3}{*}{$\mathrm{Au}$} & $1 \mathrm{u}$ & MAIS (3) (p.858) & 1 \\
\hline & & $\mathrm{Vu}$ & ANTEOTEM (p.203) & 1 \\
\hline & & $\mathrm{Bu}$ & FODA-SE (p.678) & 1 \\
\hline \multirow[t]{4}{*}{3} & \multirow[t]{4}{*}{$\mathrm{Au}^{\wedge}$} & Vo- & ADEFAV (p.154) & 2 \\
\hline & & $\mathrm{Ku}^{\wedge}$ & APOSENTAR (2) (p.214) & 1 \\
\hline & & $1 \mathrm{u}$ & AZUL (p.254) & 2 \\
\hline & & $\mathrm{Vu}$ & ESPERTO (p.612) & 1 \\
\hline 4 & $\mathrm{Bu}^{\wedge}$ & $\mathrm{Au}^{\wedge}$ & ESQUECER (p.618) & 7 \\
\hline \multirow[t]{2}{*}{5} & \multirow[t]{2}{*}{$\mathrm{Bu}-$} & $\mathrm{B}^{\wedge} \sim \mathrm{Oc}^{\prime \prime}$ & $\begin{array}{c}\text { BOLETIM-DE- } \\
\text { OCORRÊNCIA (p.304) }\end{array}$ & 1 \\
\hline & & lo- & BILHÃO (p.292) & 1 \\
\hline 6 & B"u- & 1 "o- & HORAS-EXTRAS (p.739) & 1 \\
\hline \multirow[t]{4}{*}{7} & \multirow[t]{4}{*}{ B" O" } & $1 \mathrm{u}$ & CLASSIFICADOR (p.416) & 1 \\
\hline & & Vo- & CURRÍCULO (p.488) & 1 \\
\hline & & Wof & CENTÍMETRO (p.385) & 1 \\
\hline & & $1 u^{\wedge}$ & CAMPO-GRANDE (p.349) & 1 \\
\hline \multirow[t]{5}{*}{8} & \multirow[t]{5}{*}{$\mathrm{B} " \sim \mathrm{O} " \mathrm{c}$} & $1 \mathrm{u}$ & OLINDA (p.977) & 1 \\
\hline & & Ho- & OU (p.986) & 1 \\
\hline & & $\mathrm{Ku}^{\wedge}$ & OK (p. 975) & 1 \\
\hline & & lo- & OI (p.974) & 1 \\
\hline & & Vo- & VENENOSO (p.1306) & 1 \\
\hline
\end{tabular}




\begin{tabular}{|c|c|c|c|c|}
\hline & $\begin{array}{c}\text { Configuração } \\
\text { inicial }\end{array}$ & $\begin{array}{l}\text { Configuração } \\
\text { final }\end{array}$ & $\begin{array}{l}\text { Exemplo em que tais } \\
\text { configurações ocorrem }\end{array}$ & $\mathrm{n}^{0}$ de sinais \\
\hline \multirow[t]{5}{*}{9} & \multirow[t]{5}{*}{ Doc } & Wof & $\begin{array}{l}\text { DEFICIENTE-MENTAL (2) } \\
\text { (p.504) }\end{array}$ & 1 \\
\hline & & $\mathrm{Au}^{\wedge}$ & $\begin{array}{l}\text { DEFICIENTE-AUDITIVA (2) } \\
(\mathrm{p} .503)\end{array}$ & 1 \\
\hline & & $\mathrm{B}^{\wedge} \sim \mathrm{O}^{\wedge}$ & DERDIC (p.516) & 1 \\
\hline & & ro- & DOUTOR (p.565) & 1 \\
\hline & & Vo- & $\begin{array}{l}\text { DEFICIENTE-VISUAL (2) } \\
\text { (p. 505) }\end{array}$ & 1 \\
\hline 10 & 10- & $1 \mathrm{u}$ & JULHO (p.789) & 1 \\
\hline 11 & Kop & $1 u^{\wedge}$ & ANTIGO (p. 203) & 1 \\
\hline 12 & ro- & Vo- & DIFERENTE (2) (p.543) & 2 \\
\hline 13 & $\mathrm{Su}^{\wedge} \mathrm{t}$ & $\mathrm{Su}$ & QUASE (p.1102) & 5 \\
\hline \multirow[t]{3}{*}{14} & \multirow[t]{3}{*}{ So- } & Ho- & SUZANO (p.1227) & 1 \\
\hline & & $9 u^{\wedge} p$ & $\begin{array}{l}\text { SAN-FRANCISCO (EUA) } \\
\text { (p. 1164) }\end{array}$ & 1 \\
\hline & & B" $\sim 0 "$ & SANTA-CATARINA (p.1166) & 1 \\
\hline 15 & Vo- & Ho- & CORTAR (p.473) & 7 \\
\hline 16 & Vo- & Wof & $\begin{array}{l}\text { BAIRRO-VILA-MATILDE } \\
\text { (p. 264) }\end{array}$ & 1 \\
\hline \multicolumn{4}{|c|}{ TOTAL } & 55 \\
\hline
\end{tabular}


Quadro (4) ${ }^{71}$

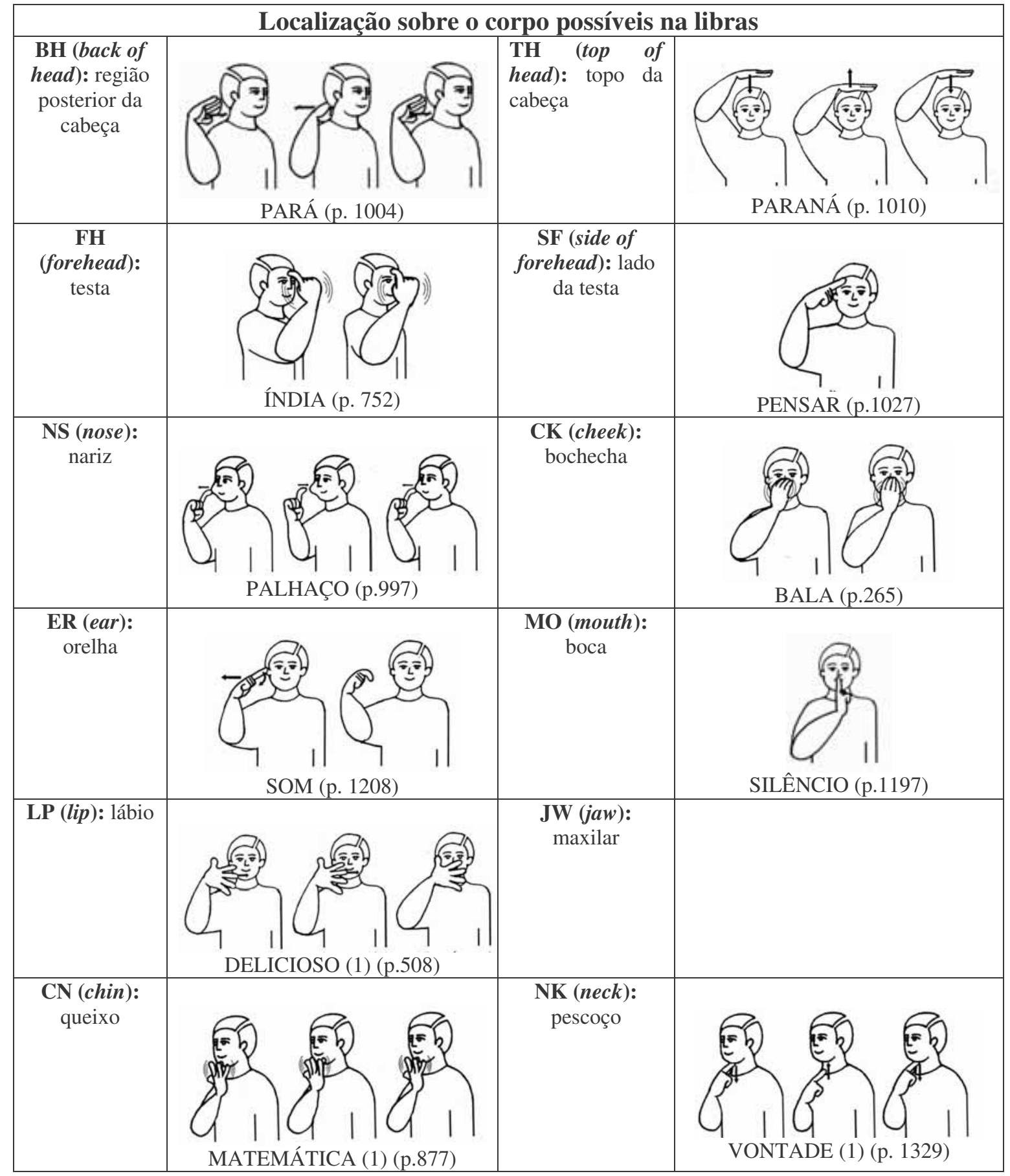

\footnotetext{
${ }^{71}$ Todas as figuras contidas neste quadro foram extraídas de Capovilla \& Raphael (2003).
} 


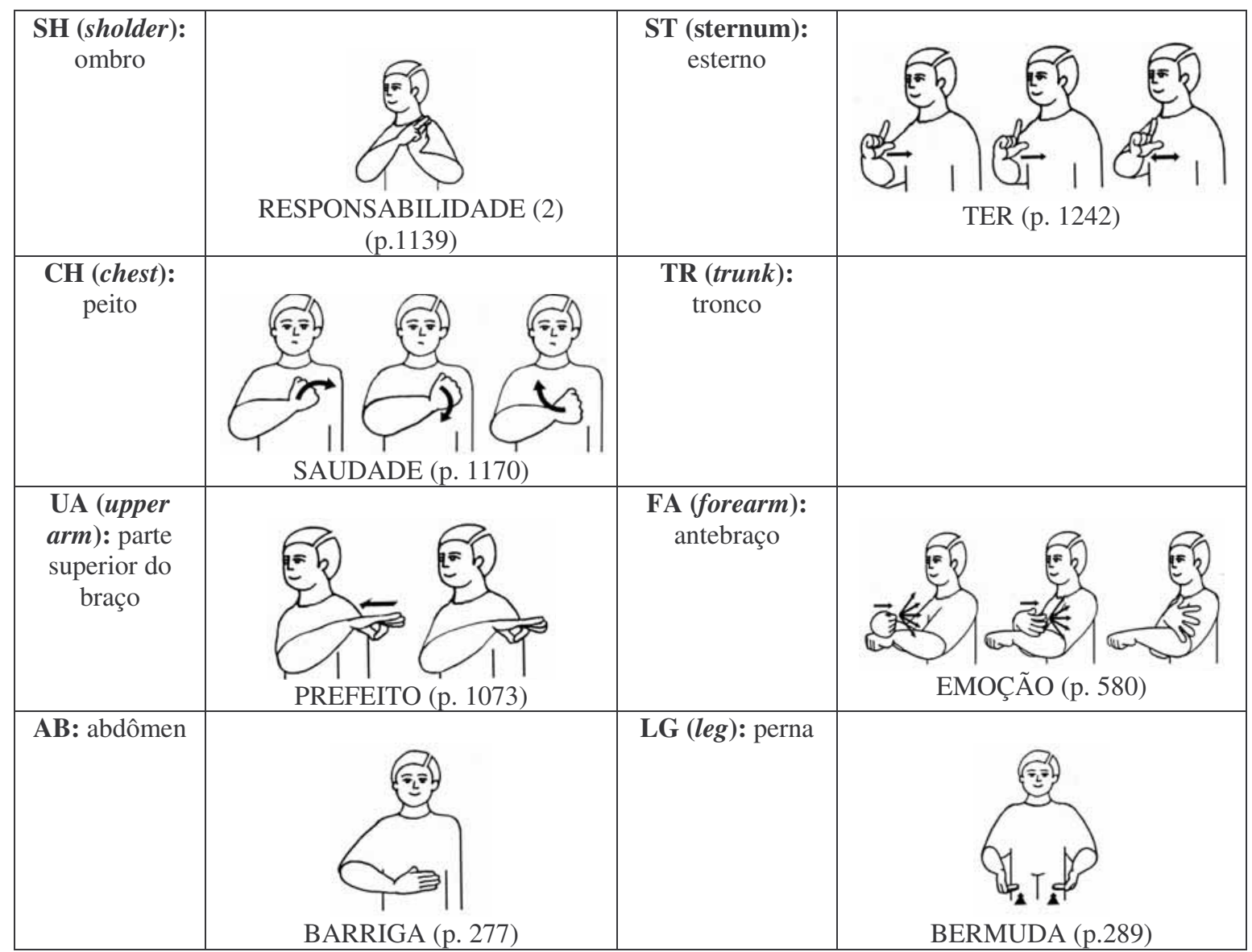




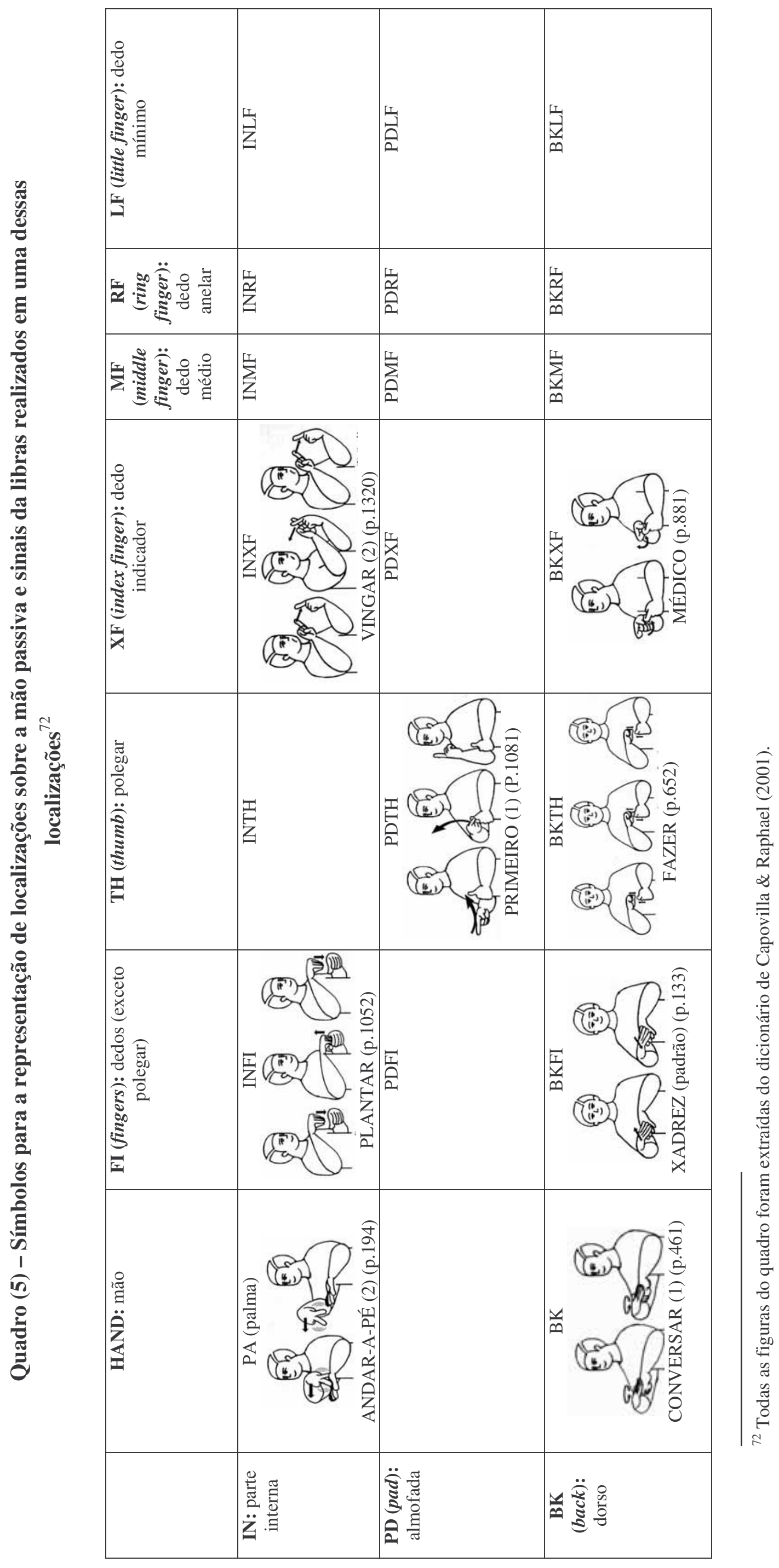




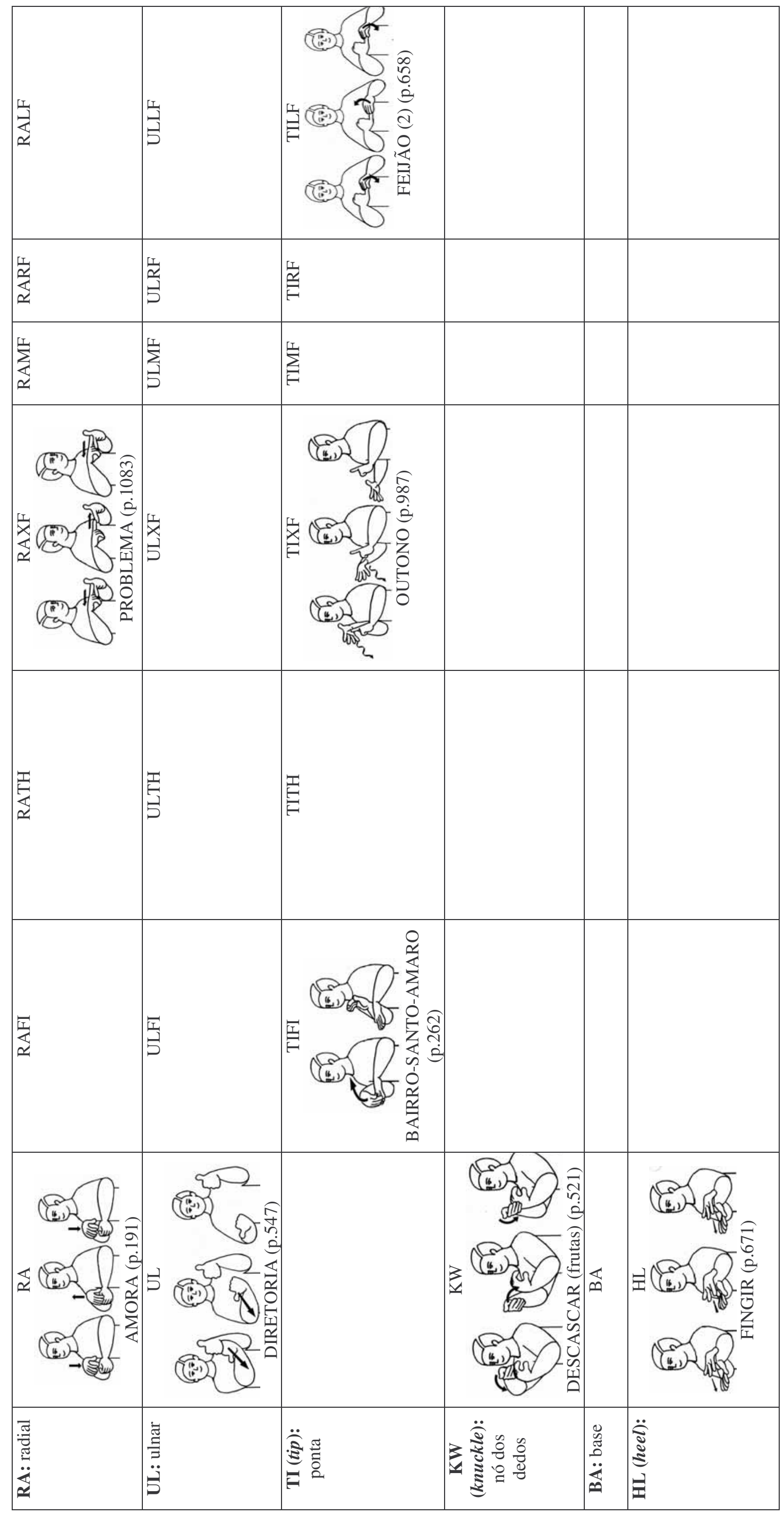




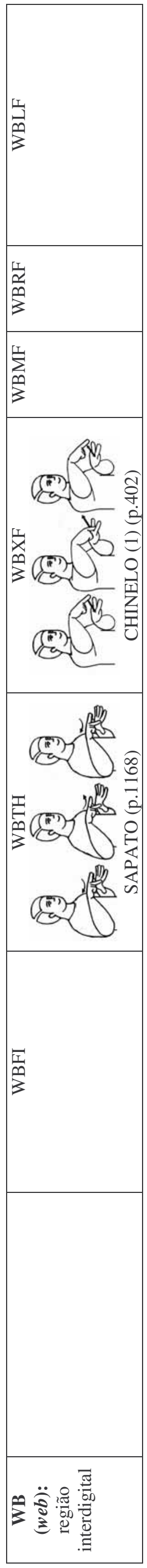

$:=$ 
